Universidade de São Paulo

Instituto de Astronomia, Geofísica e Ciências Atmosféricas

Departamento de Ciências Atmosféricas

Ángel Liduvino Vara Vela

\title{
Avaliação do impacto da mudança dos fatores de emissão veicular na formação de ozônio troposférico na Região Metropolitana de São Paulo (RMSP)
}

São Paulo 
Ángel Liduvino Vara Vela

\section{Avaliação do impacto da mudança dos fatores de emissão veicular na formação de ozônio troposférico na Região Metropolitana de São Paulo (RMSP)}

Dissertação apresentada ao Departamento de Ciências Atmosféricas do Instituto de Astronomia, Geofísica e Ciências Atmosféricas da Universidade de São Paulo como requisito parcial para obtenção do título de Mestre em Ciências.

Área de Concentração: Meteorologia Orientadora: Profa. Dra. Maria de Fátima Andrade

Versão Corrigida. O original encontra-se disponível na Unidade.

São Paulo 
Aos meus pais e irmãos 


\section{Agradecimentos}

À professora Maria de Fátima Andrade, pela excelente orientação, paciência, confiança e amizade ao longo de todo o mestrado. À Simone Garcia de Ávila, grande amiga e responsável por esta conquista. À professora Rita Yuri Ynoue, pelas discussões e sugestões, principalmente com relação ao cálculo das emissões veiculares. Aos membros da banca do Exame de Qualificação, Profs. Rita Yuri Ynoue e Fábio Gonçalves pelas críticas construtivas e valiosas sugestões, imprescindíveis para o desenvolvimento do trabalho. Aos colegas do Laboratório de Análise dos Processos Atmosféricos (LAPAt), especialmente ao Márcio Gledson, pelas dicas quanto ao uso do modelo WRF-Chem. A todos os professores do departamento de Ciências Atmosféricas do IAG-USP que contribuíram para minha formação. A todos os funcionários do IAGUSP, sempre muito amáveis e prestativos. Ao Ángel Muñoz, por permitir-me realizar um estágio acadêmico no centro de Modelado Científico de La Universidad Del Zulia. Ao IAG-USP pela oportunidade de realização do curso de mestrado. À Coordenação de Aperfeiçoamento de Pessoal de Nível Superior (CAPES) pela concessão da bolsa de Mestrado e à Fundação de Amparo à Pesquisa do Estado de São Paulo (FAPESP) pelo apoio financeiro. Finalmente gostaria de agradecer a todos aqueles que de alguma forma me incentivaram e contribuíram para o desenvolvimento deste trabalho de pesquisa. 
"A ciência é a progressiva aproximação do homem ao mundo real" Max Planck 
Resumo

Vela, A. L. V. Avaliação do impacto da mudança dos fatores de emissão veicular na formação de ozônio troposférico na Região Metropolitana de São Paulo. 2013.

Dissertação de Mestrado. Instituto de Astronomia, Geofísica e Ciências Atmosféricas, Universidade de São Paulo, São Paulo.

Este trabalho teve como objetivo avaliar o impacto da mudança dos fatores de emissão veicular na formação de ozônio troposférico na Região Metropolitana de São Paulo (RMSP), Brasil, comparando os anos de 2004 e 2011. Essa avaliação foi realizada por meio de modelagem numérica com o modelo de qualidade do ar Weather Research and Forecasting with Chemistry (WRF-Chem), configurado sobre um domínio com 4 grades aninhadas: 27, 9, 3 e $1 \mathrm{~km}$; e com o mecanismo químico considerado, o RADM2, acionado apenas nas grades de 3 e $1 \mathrm{~km}$. Os inventários de emissão foram baseados em informações estimadas de número de veículos, fatores de emissão de compostos químicos e número médio de quilômetros percorridos por dia pelos distintos tipos de veículos considerados. Os períodos de estudo 06 a 09 de setembro de 2004 e 12 a 15 de novembro de 2011 foram selecionados, principalmente, por apresentarem episódios de altas concentrações de ozônio e pela existência de dados experimentais de determinação de fatores de emissão. Para avaliar a 'performance' das simulações foram utilizados dados observados de temperatura, umidade relativa, vento, concentração de ozônio, óxidos de nitrogênio e monóxido de carbono das estações de qualidade do ar da rede de monitoramento da Companhia de Tecnologia de Saneamento Ambiental (CETESB). Os resultados mostraram que as configurações físicas e químicas estabelecidas no modelo conseguiram representar adequadamente os ciclos de formação do ozônio, no entanto, com defasagens e intensidades máximas menores, características relacionadas com o cálculo das distribuições espaço/temporal das emissões como também pelo transporte não só do ozônio, mas também de seus precursores desde regiões externas à RMSP. Por outro lado, dadas as características de emissão em 2004 e 2011, encontrou-se que a atmosfera da RMSP estava caracterizada por um regime COV-limitante naqueles anos, principalmente no ano 2004. Finalmente, o cenário de emissão para 2011 considerando os mesmos fatores de emissão de 2004 mostrou um grande impacto na formação do ozônio troposférico, considerando a grade de $1 \mathrm{~km}$ de espaçamento. Esse resultado foi 
produto do estabelecimento de uma razão média COV/NOx mais eficiente em termos de formação de ozônio, apesar das emissões dos seus precursores ter diminuído em relação a 2004.

Palavras-chave: Ozônio troposférico, fatores de emissão veicular, modelo numérico WRF-Chem. 


\begin{abstract}
Vela, A. L. V. Evaluating the impact of vehicular emission factors change on tropospheric ozone formation in the Metropolitan Area of São Paulo (MASP). 2013. Master Dissertation. Institute of Astronomy, Geophysics and Atmospheric Sciences, University of São Paulo, São Paulo.
\end{abstract}

The objective of this work was to evaluate the impact of vehicular emission factors change on tropospheric ozone formation in the Metropolitan Area of São Paulo (MASP), Brazil for 2004 and 2011. Weather Research and Forecasting with Chemistry (WRF-Chem) model was used as the photochemical modeling tool. WRF-Chem was set up to run with four nested grid cells: 27, 9, 3 and $1 \mathrm{~km}$. The Regional Acid Deposition Model $(R A D M)$ version 2 was the chemical mechanism considered, turned it on barely in 3 and $1 \mathrm{~km}$ grid cells. The emission inventories were based on the estimated information of number of vehicles, emission factors and average driving kilometers for vehicle per day. The study periods September 06-09, 2004 and November 12-15, 2011 were chosen due to the high ozone concentrations observed, and the experimental data available for these periods. Observation of temperature, relative humidity, winds, and $\mathrm{O}_{3}, \mathrm{CO}$ and $\mathrm{NOx}$ concentrations from the air quality monitoring network of Companhia de Tecnologia de Saneamento Ambiental do Estado de São Paulo (CETESB) were used to evaluate WRF-Chem simulations performance. The results showed that the chemical and physics configurations in WRF-Chem represented adequately the ozone formation cycles; however, with mismatches and maximum concentrations lower than observations, characteristics related with the estimative of the spatial and temporal distributions of the emissions as well as by the transportation of ozone and its precursors from external regions to MASP. On the other hand, given the characteristics of emission in 2004 and 2011, we found that MASP was under a strong COV-limited regime, principally in 2004. Finally, the scenario considering the emission factor of 2004 valid for 2011 in MASP showed a great impact in tropospheric ozone formation with high concentrations calculated for 2011 considering $1 \mathrm{~km}$ grid cell (with the most realistic vehicular activity), as result of a more efficient COV/NOx ratio calculation in terms of ozone formation.

Keywords: tropospheric ozone, vehicular emission factors, WRF-Chem model. 
Fig. 1.1. Ciclo foto-estacionário do ozônio 23

Fig. 1.2. Isopleta de ozônio. Representação bidimensional gerada pelo modelo EKMA (Empirical Kinetic Modeling Approach) (Fonte: Finlayson-Pitts e Pitts, 2000)..... 25

Fig. 1.3. Evolução do número de dias de ultrapassagens do $P Q A$ para o ozônio na RMSP (dados extraídos de CETESB, 2012a)................................................................ 26

Fig. 1.4. Número de ultrapassagens do $P Q A\left(160 \mu \mathrm{g} / \mathrm{m}^{3}\right)$ e do nível de atenção (200 $\mu \mathrm{g} / \mathrm{m}^{3}$ ) para o ozônio durante o período 2006-2010 na RMSP (Fonte: CETESB, 2011)27 Fig. 1.5. Contribuição relativa por tipo de fonte para os principais poluentes emitidos na RMSP durante os anos 2004 (esquerda) e 2010 (direita) (Fonte: CETESB, 2005 e CETESB, 2011). 28

Fig. 2.1. Coordenada vertical $\eta$ utilizada nas simulações (Fonte: Wang et al., 2009)... 39 Fig. 2.2. Esquema simplificado das componentes do sistema WRF (Fonte: Skamarock et al., 2008). 41

Fig. 2.3. Imagem de satélite de Intensidade de Luzes Noturnas (ILN) para América do Sul no ano 2009, mostrando uma ampliação da área de estudo. 49

Fig. 2.4. Mapa de emissão diária do $C O$ na $R M S P$ compilado a partir do International Environmental Database (IED) para o ano base 2009. 50

Fig. 2.5. Perfis horários de emissão considerados para distribuir as emissões totais ao longo do dia, para os poluentes primários. 51

Fig. 2.6. Domínio da simulação com a indicação das quatro grades utilizadas.... 53 Fig. 2.7. Topografias consideradas para as grades de 3 (esquerda) e $1 \mathrm{~km}$ (direita), respectivamente. 53

Fig. 2.8. Taxas de emissão do $N O x$ às 18 h, hora local, para as grades de 3 (lado esquerdo) e $1 \mathrm{~km}$ (lado direito) para o ano 2011 54

Fig. 2.9. Diagrama de Taylor. A distância radial desde a origem é proporcional ao desvio padrão de um determinado campo "test". A diferença do RMSE entre o "test" e o campo de referência é proporcional a sua distância de separação. O coeficiente de correlação entre os dois campos é dado pela posição azimutal do "test" (Fonte: Taylor, 2001) 58

Fig. 3.1. Localização da área de estudo (Fonte: Silva Junior, 2009). 61 
Fig. 3.2. Séries temporais de nebulosidade (décimos) e intensidade do vento $(\mathrm{m} / \mathrm{s})$ na estação IAG-USP para o período de 06 a 09 de setembro de 2004. 62

Fig. 3.3. Imagens GOES no canal do infravermelho para América do Sul correspondentes ao período de 06 a 09 de setembro de 2004. Os círculos vermelhos ilustram a localização da área de estudo.

Fig. 3.4. Séries temporais de nebulosidade (décimos) e precipitação (mm) na estação climatológica do IAG-USP para o período de 12 a 15 de novembro de 2011 64

Fig. 3.5. Imagens GOES no canal do infravermelho para América do Sul correspondentes ao período de 12 a 15 de setembro de 2004. Os círculos vermelhos ilustram a localização da área de estudo.

Fig. 3.6. Cartas sinóticas para os dias 12 e 13 de novembro de 2011 (Fonte: Diretoria de Hidrografia e Navegação). 66

Fig. 3.7. Cartas sinóticas para os dias 14 e 15 de novembro de 2011 (Fonte: Diretoria de Hidrografia e Navegação). 67

Fig. 4.1. Temperatura observada (pontos pretos) e simulada para $3 \mathrm{~km}$ (pontos azuis) e 1 $\mathrm{km}$ (pontos vermelhos) de resolução, em ' ${ }^{\circ} C$ ' para sete estações na $R M S P$ para o período de 06 a 09 de setembro de 2004 69

Fig. 4.2. Umidade relativa observada (pontos pretos) e simulada a $3 \mathrm{~km}$ (pontos azuis) e $1 \mathrm{~km}$ (pontos vermelhos) em '\%’ para sete estações na $R M S P$ para o período de 06 a 09 de setembro de 2004 70

Fig. 4. 3. Intensidade do vento observada (pontos pretos) e simulada a $3 \mathrm{~km}$ (pontos azuis) e $1 \mathrm{~km}$ (pontos vermelhos) em ' $\mathrm{m} / \mathrm{s}$ ' para quatro estações na $R M S P$ para o período de 06 a 09 de setembro de 2004 ...... 71

Fig. 4.4. Rosa dos ventos observada (esquerda) e simulada a $3 \mathrm{~km}$ (centro) e $1 \mathrm{~km}$ (direita) para as estações Osasco (superior), Santo Amaro (centro) e Santo Andre Capuava (inferior) na RMSP para o período de 06 a 09 de setembro de 2004 72 Fig. 4.5. Rosa dos ventos observadas (esquerda) e simulada a $3 \mathrm{~km}$ (centro) e $1 \mathrm{~km}$ (direita) para a estação AF-IAG na RMSP para o período de 06 a 09 de setembro de 2004 73

Fig. 4.6. Concentração de ozônio observada (pontos pretos) e simulada a $3 \mathrm{~km}$ (pontos azuis) e $1 \mathrm{~km}$ (pontos vermelhos) em ' $\mu \mathrm{g} / \mathrm{m}^{3}$, para onze estações na $R M S P$ para o período de 06 a 09 de setembro de 2004. 75 
Fig. 4.7. Diagrama de Taylor para a concentração do ozônio em onze estações na RMSP para o período de 06 a 09 de setembro de 2004, para a grade de 1 (pontos vermelhos) e $3 \mathrm{~km}$ (pontos azuis).

Fig. 4.8. Cálculo superficial da concentração de ozônio às $14 \mathrm{~h}$, hora local, na grade de 3 km para o período de 06 a 09 de setembro de 2004. 77

Fig. 4.9. Cálculo superficial da concentração de ozônio às $14 \mathrm{~h}$, hora local, na grade de 1 km para o período de 06 a 09 de setembro de 2004. 78

Fig. 4.10. Concentrações médias observadas e simuladas pelos modelos CIT (acima) (Martins, 2006) e WRF-Chem (abaixo) para os grupos de estações: Pinheiros; Mooca; Ibirapuera e São Caetano do Sul. 79

Fig. 4.11. Concentrações médias observadas e simuladas pelos modelos CIT (acima) (Martins, 2006) e WRF-Chem (abaixo) para os grupos de estações: Diadema e Santo Amaro. 80

Fig. 4.12. Concentração de $C O$ observada (pontos pretos) e simulada a $3 \mathrm{~km}$ (pontos azuis) e $1 \mathrm{~km}$ (pontos vermelhos) em 'ppmv' para sete estações na $R M S P$ para o período de 06 a 09 de setembro de 2004 82

Fig. 4.13. Concentração de $N O x$ observada (pontos pretos) e simulada a $3 \mathrm{~km}$ (pontos azuis) e $1 \mathrm{~km}$ (pontos vermelhos) em ' $p p b v$ ' para seis estações na $R M S P$ para o período de 06 a 09 de setembro de 2004 82

Fig. 4.14. Razão CO/NOx observada (pontos pretos) e simulada a $3 \mathrm{~km}$ (pontos azuis) e $1 \mathrm{~km}$ (pontos vermelhos) em 'ppmv/ppbv' para duas estações na $R M S P$ para o período de 06 a 09 de setembro de 2004 . 84

Fig. 4.15. Cálculo da razão $\mathrm{CH}_{2} \mathrm{O} / \mathrm{NOy}$ para a grade de $1 \mathrm{~km}$ às $14 \mathrm{~h}$, hora local. 85 Fig. 4.16. Temperatura observada (pontos pretos) e simulada com resolução de $3 \mathrm{~km}$ (pontos azuis) e $1 \mathrm{~km}$ (pontos vermelhos) em ' ${ }^{\circ} \mathrm{C}$ ' para seis estações na $R M S P$ para o período de 12 a 15 de novembro de 2011 86 Fig. 4.17. Umidade relativa observada (pontos pretos) e simulada para resoluções de 3 $\mathrm{km}$ (pontos azuis) e $1 \mathrm{~km}$ (pontos vermelhos) em '\%' para seis estações na RMSP para o período de 12 a 15 de novembro de 2011

Fig. 4.18. Intensidade do vento observada (pontos pretos) e simulada para grades com resoluções de $3 \mathrm{~km}$ (pontos azuis) e $1 \mathrm{~km}$ (pontos vermelhos) em ' $\mathrm{m} / \mathrm{s}$ ' para seis estações na RMSP para o período de 12 a 15 de novembro de 2011. 88 
Fig. 4.19. Rosa dos ventos observada (esquerda) e simulada a $3 \mathrm{~km}$ (centro) e $1 \mathrm{~km}$ (direita) para as estações Ibirapuera (superior), Mooca (centro) e Pinheiros (inferior) na RMSP para o período de 12 a 15 de novembro de 2011

Fig. 4.20. Rosa dos ventos observada (esquerda) e simulada a $3 \mathrm{~km}$ (centro) e $1 \mathrm{~km}$ (direita) para as estações Santana (superior), MS-INMET (centro) e AF-IAG (inferior) na RMSP para o período de 12 a 15 de novembro de 2011. 90

Fig. 4.21. Concentração de ozônio observada (pontos pretos) e simulada a $3 \mathrm{~km}$ (pontos azuis) e $1 \mathrm{~km}$ (pontos vermelhos) em ' $\mu \mathrm{g} / \mathrm{m}^{3}$ ' para dez estações na $R M S P$ para o período de 12 a 15 de novembro de 2011.

Fig. 4.22. Diagrama de Taylor para a concentração do ozônio em onze estações na RMSP para o período de 12 a 15 de novembro de 2011

Fig. 4.23. Cálculo superficial de precipitação acumulada horária em ' $m m$ ' às $14 \mathrm{~h}$, hora local, para a grade de $3 \mathrm{~km}$ para o período de 12 a 15 de novembro de 2011 93

Fig. 4.24. Cálculo superficial de ozônio às $14 \mathrm{~h}$, hora local, na grade de $3 \mathrm{~km}$ para o período de 12 a 15 de novembro de 2011 94 Fig. 4.25. Cálculo superficial de ozônio às $14 \mathrm{~h}$, hora local, na grade de $1 \mathrm{~km}$ para o período de 12 a 15 de novembro de 2011 95

Fig. 4.26. Concentração de $C O$ observada (pontos pretos) e simulada a $3 \mathrm{~km}$ (pontos azuis) e $1 \mathrm{~km}$ (pontos vermelhos) em ' $p p m v$ ' para dez estações na $R M S P$ para o período de 12 a 15 de novembro de 2011 97

Fig. 4.27. Concentração de NOx observada (pontos pretos) e simulada a de $3 \mathrm{~km}$ (pontos azuis) e $1 \mathrm{~km}$ (pontos vermelhos) em ' $p p b v$ ' para nove estações na $R M S P$ para o período de 12 a 15 de novembro de 2011

Fig. 4.28. Razão CO/NOx observada (pontos pretos) e simulada para resolução de $3 \mathrm{~km}$ (pontos azuis) e $1 \mathrm{~km}$ (pontos vermelhos) em 'ppmv/ppbv' para sete estações na RMSP para o período de 12 a 15 de novembro de 2011 99

Fig. 4.29. Cálculo da razão $\mathrm{CH}_{2} \mathrm{O} / \mathrm{NO}$ y para a grade de $1 \mathrm{~km}$ às $14 \mathrm{~h}$, hora local 100

Fig. 4.30. Diferença de concentração de ozônio, em ' $\mu \mathrm{g} / \mathrm{m}^{3}$ ', entre o cenário com os $F E$ referentes ao ano de 2004 atuando em 2011, e a simulação correspondente para o período de 12 a 15 de novembro de 2011 para a grade de $3 \mathrm{~km}$. A linha azul representa o valor médio do período 101 
Fig. 4.31. Diferença de concentração do $N O x$, em ' $p p b v$ ', entre o cenário com os $F E$ referentes ao ano de 2004 atuando em 2011, e a simulação correspondente para o período de 12 a 15 de novembro de 2011 para a grade de $3 \mathrm{~km}$. A linha azul representa o valor médio do período

Fig. 4.32. Diferença da concentração de ozônio, em ' $\mu \mathrm{g} / \mathrm{m}^{3}$ ', entre o cenário com os $F E$ referentes ao ano de 2004 atuando em 2011, e a simulação correspondente para o período de 12 a 15 de novembro de 2011 para a grade de $1 \mathrm{~km}$. A linha azul representa o valor médio do período 103

Fig. 4.33. Diferença de concentração do $N O x$, em ' $p p b v$ ', entre o cenário com os $F E$ referentes ao ano de 2004 atuando em 2011, e a simulação correspondente para o período de 12 a 15 de novembro de 2011 para a grade de $1 \mathrm{~km}$. A linha azul representa o valor médio do período

Fig. 8.1. Diferença de ozônio no período de 12 a 15 de novembro de 2011 com as emissões estimadas para os anos 2004 e 2011 na grade de $3 \mathrm{~km}$. 130

Fig. 8.2. Continuação da figura 8.1 131

Fig. 8.3. Continuação da figura 8.2. 132

Fig. 8.4. Continuação da figura 8.3. 133

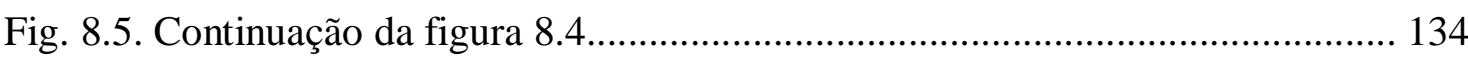

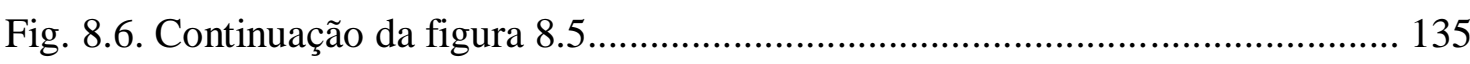

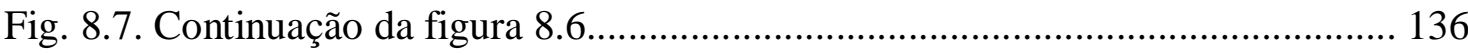

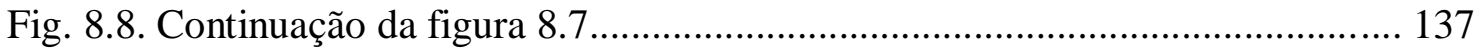

Fig. 8.9. Diferença de ozônio no período de 12 a 15 de novembro de $2011 \mathrm{com}$ as emissões estimadas para os anos 2004 e 2011 na grade de 1 km................................. 138

Fig. 8.10. Continuação da figura 8.9......................................................................... 139

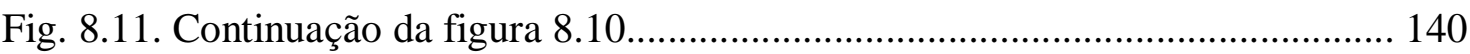

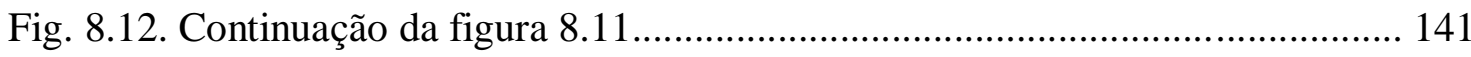

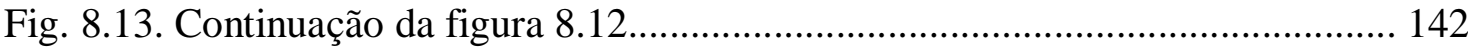

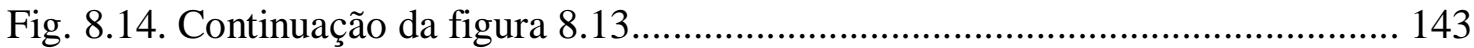

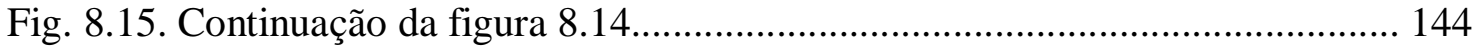

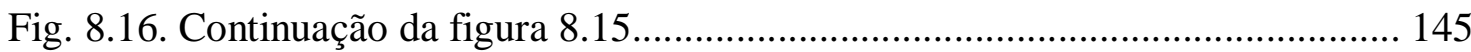


Lista de tabelas

Tabela 2.1. Configuração das principais parametrizações físicas e químicas utilizadas nas simulações com o modelo WRF-Chem.

Tabela 2.2. Fração por tipo de veiculo 2004 (CETESB, 2005) e 2011 (CETESB, 2012a), e suas respectivas intensidades de uso, consideradas do ano de 2007 (Fonte: SPTrans)46

Tabela 2.3. FE dos veículos em uso na $R M S P$ considerados nas simulações. ${ }^{(1)} F E$ para CO e NOx obtidos de medidas experimentais em túneis nos anos 2004 (Martins et al., 2006) e 2011 (Nogueira et al., 2013), ${ }^{(2)} F E$ estimados a partir da contribuição relativa dos processos de transferência de combustível na emissão total e os demais $F E$ obtidos por meio de protocolos em dinamômetro (CETESB, 2005; CETESB, 2010). 48 Tabela 2.4. Emissões totais consideradas nas simulações para resoluções de 1 e $3 \mathrm{~km}$, emissões totais extraídas do inventário de fontes da CETESB e razão molar entre $C O V$ e NOx. 51

Tabela 2.5. Configurações iniciais e de contorno utilizadas nas simulações numéricas.52 Tabela 4.1. Testes estatísticos para as concentrações médias de ozônio para os agrupamentos 1 e 2 referentes às estações de qualidade do ar 81

Tabela 8.1. Padrões nacionais de qualidade do ar (Resolução CONAMA n 03/90). ${ }^{(1)}$ Não deve ser excedido mais que uma vez ao ano, ${ }^{(2)}$ Média Geométrica Anual, ${ }^{(3)}$ Média Aritmética Anual (Fonte: CETESB, 2010). Em verde ressalta-se o padrão correspondente para o ozônio 118

Tabela 8.2. Espécies químicas consideradas no mecanismo químico RAMD2. Esta tabela mostra a quantidade de massa emitida dos COV considerados no mecanismo químico $R A D M 2$ (espécies 1 a 15) por cada $100 \mathrm{~g}$ de $C O V$ total emitido por um veículo, considerando três tipos de combustíveis: Gasolina, Álcool e Diesel............................119

Tabela 8.3. Estações utilizadas para avaliação do primeiro período de estudo............. 122

Tabela 8.4. Estações utilizadas para avaliação do segundo período de estudo............. 123

Tabela 8.5. Testes estatísticos para a temperatura no primeiro período....................... 124

Tabela 8.6. Testes estatísticos para a umidade relativa no primeiro período................ 124

Tabela 8.7. Testes estatísticos para a magnitude do vento no primeiro período........... 125

Tabela 8.8. Testes estatísticos para o ozônio no primeiro período................................ 125

Tabela 8.9. Continuação da tabela 8.8 ....................................................................... 125

Tabela 8.10. Testes estatísticos para o NOx no primeiro período................................ 126 
Tabela 8.11. Testes estatísticos para o $C O$ no primeiro período. 126

Tabela 8.12. Testes estatísticos para a temperatura no segundo período. 126

Tabela 8.13. Testes estatísticos para a umidade relativa no segundo período. 127

Tabela 8.14. Testes estatísticos para a magnitude do vento no segundo período. 127

Tabela 8.15. Testes estatísticos para o ozônio no segundo período. 127

Tabela 8.16. Continuação da tabela 8.15 . 128

Tabela 8.17. Testes estatísticos para o NOx no segundo período. 128

Tabela 8.18. Continuação da tabela 8.17. 128

Tabela 8.19. Testes estatísticos para o $C O$ no segundo período. 129

Tabela 8.20. Continuação da tabela 8.19 129 
Lista de abreviaturas e siglas

$A R W$

BOULAC

BRAMS

$C B M Z$

CETESB

CFSR

CIT

CLP

CMAQ

$\mathrm{CO}$

$\mathrm{CO}_{2}$

CONOMA

$\mathrm{COV}$

DETRAN

$D H N$

DMSP

EDGAR

EKMA

EMME/2

FE

GDAS

GOES

GTOPO30

$\mathrm{HCs}$

$\mathrm{HO}_{2}$

HOx

$I A G-U S P$

$I B G E$
Advanced Research $W R F$

Esquema de CLP BOUgeault e LACarrère

Brazilian Regional Atmospheric Modeling System

Carbon Bond Mechanism version Z

Companhia de Tecnologia de Saneamento Ambiental do

Estado de São Paulo

Climate Forecast System Reanalysis

California/Carnegie Institute of Technology model

Camada Limite Planetária

Comunity Multi-Scale Air Quality

Monóxido de Carbono

Dióxido de Carbono

Conselho Nacional do Meio Ambiente

Compostos Orgânicos Voláteis

Departamento Estadual de Trânsito de São Paulo

Diretoria de Hidrografia e Navegação

Defense Meteorological Satellite Program

Emission Database for Global Atmospheric Research

Empirical Kinetic Modeling Approach

Equilibre Multi-Modal/Multi-Modal Equilibrium vehicular traffic model

Fator de Emissão

Global Data Assimilation System

Geostationary Operational Environmental Satellite

Global TOPOgraphy 30 Arc Second Elevation Data

Hidrocarbonetos totais

Radical hidroperoxila

Radicais de óxido de hidrogênio

Instituto de Astronomia, Geofísica e Ciências Atmosféricas

- Universidade de São Paulo

Instituto Brasileiro de Geografia e Estadística 
IED

ILN

INMET

LAPAt

MEGAN

MM5

MOZART

MP

$M P Q$

MP2.5

$N A S A$

NCAR

NCAR MM

NCEP

$N C L$

NO

Noah LSM

$\mathrm{NO}_{2}$

NOx

$\mathrm{OH}$

$O L E^{2}$

$O L S$

$\mathrm{O}_{3}$

$P Q A$

PROCONVE

RADM2

RETRO

RHCs

RMSE

$R M S P$
International Environmental Database

Intensidade de Luzes Noturnas

Instituto Nacional de Meteorologia

Laboratório de Análise dos Processos Atmosféricos

Model of Emissions of Gases and Aerosols from Nature

Fifth-Generation PSU/NCAR Mesoscale Modeling

System

Model for Ozone And Related chemical Tracers

Material Particulado

Modelos de Previsão Química

Material particulado inalável com diâmetro aerodinâmico menor que $10 \mu \mathrm{m}$

National Aeronautics and Space Administration

National Center for Atmospheric Research

NCAR Master Mechanism

National Center for Environmental Prediction

NCAR Command Language

Óxido de nitrogênio

Noah Land Surface Model

Dióxido de nitrogênio

Óxidos de nitrogênio

Radical hidroxila

Observatorio Latinoamericano de Eventos Extraordinarios

Operational Linescan System

Ozônio

Padrão de Qualidade do Ar

Programa Nacional de Controle de Poluição por Veículos

Automotores

Regional Acid Deposition Model version 2

REanalysis of the TROpospheric global emissions

Hidrocarbonetos reativos

Raiz do Erro Médio Quadrático

Região Metropolitana de São Paulo 
$\mathrm{RO}_{2}$

RRTM

SAPRC

SOx

$S P M$

SRTM

$U C M$

USGS

$Y S U$

WRF

WRF-Chem

WRF/Chem-MADRID

ZCAS
Radical peroxi orgânico

Rapid Radiative Transfer Model

Statewide Air Pollution Research Center

Óxidos de Enxofre

Simple Photochemical Model

Shuttle Radar Topography Mission

Urban Canopy Model

United States Geological Survey

Esquema de $C L P$ Yonsei University

Weather Research and Forecasting

Weather Research and Forecasting with Chemistry

WRF-Chem - Model of Aerosol Dynamics, Reaction,

Ionization and Dissolution

Zona de Convergência do Atlântico Sul 
Sumário

1. INTRODUÇÃO

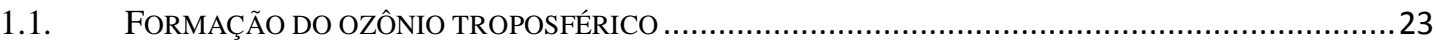

1.1.1. Papel dos COV e NOx na formação do ozônio troposférico...............................................24

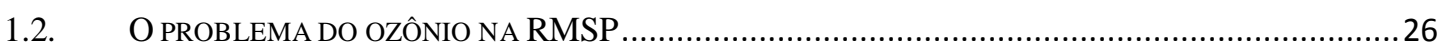

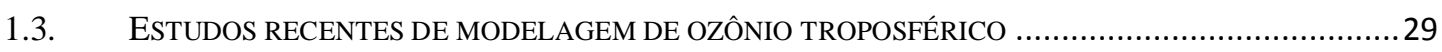

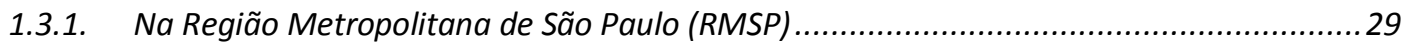

1.3.2. Estudos em outras regiões .......................................................................................

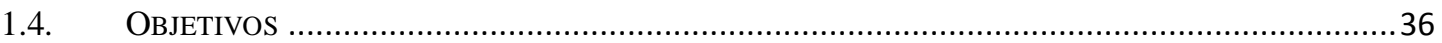

2. METODOLOGIA

2.1. DESCRIÇÃO SUCINTA DA FERRAMENTA DE MODELAGEM ........................................................ 38

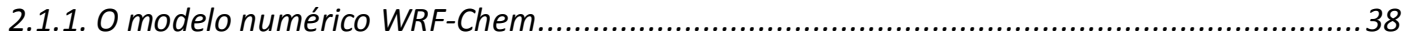

2.1.2. Principais parametrizações utilizadas ................................................................... 41

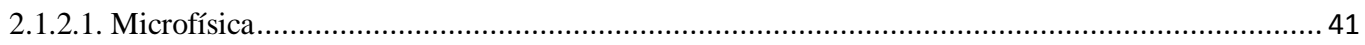

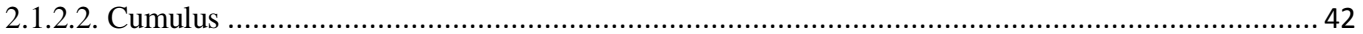

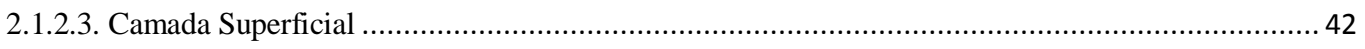

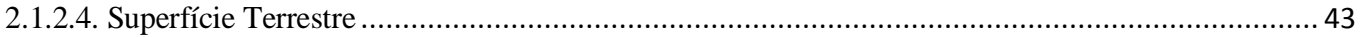

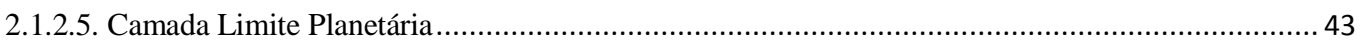

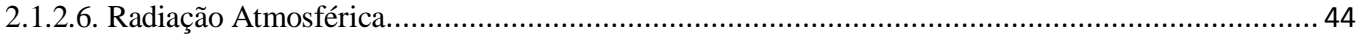

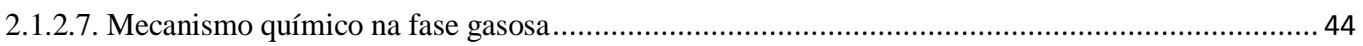

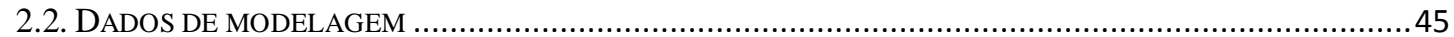

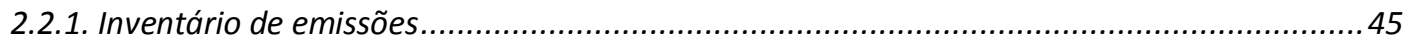

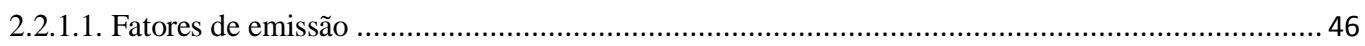

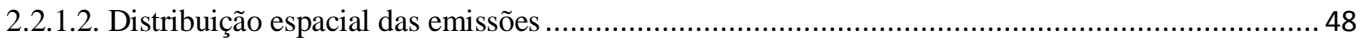

2.2.1.3. Distribuição temporal de emissão de poluentes ........................................................................ 50

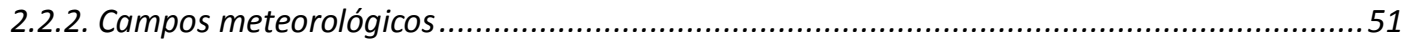

2.2.3. Configuração e características das simulações............................................................52

2.2.4. Testes estatísticos utilizados para avaliação das simulações...........................................55

2.2.4.1. Coeficiente de correlação de Pearson $(r)$........................................................................ 55

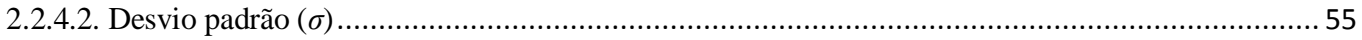

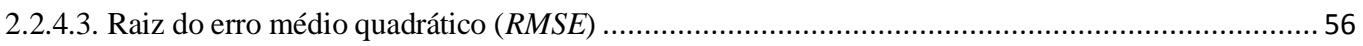

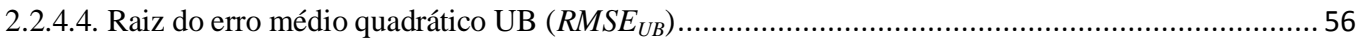

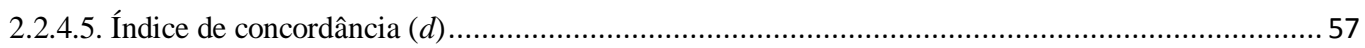

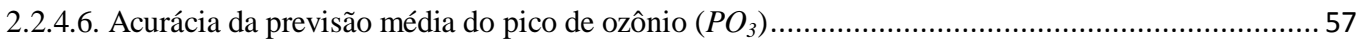

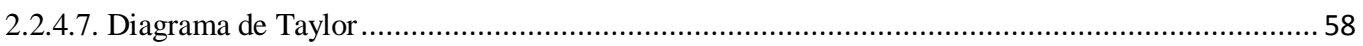

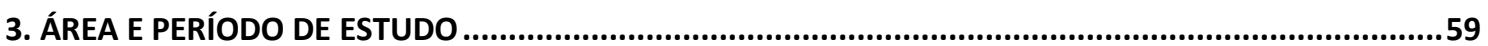




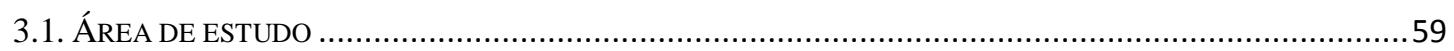

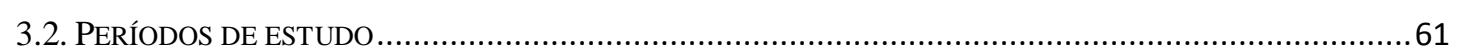

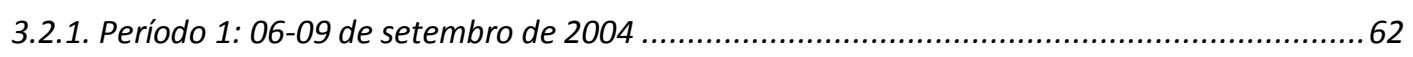

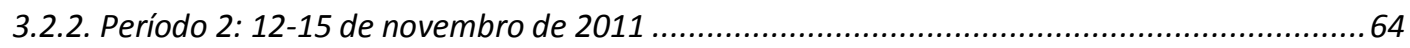

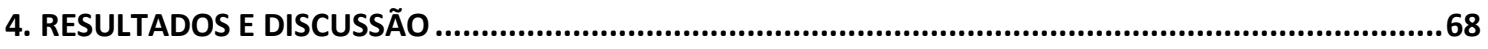

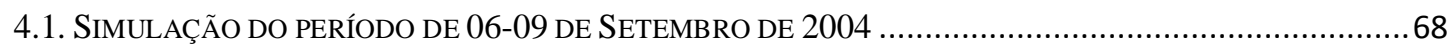

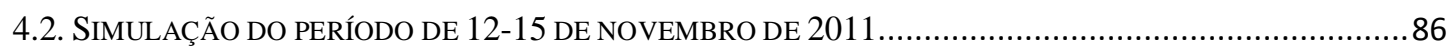

4.3. CENÁRIO DE EMISSÃo COM OS FE 2004 ATUANDO NO PERÍODO ESTABELECIDO PARA O ANO 2011101

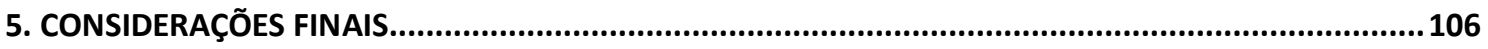

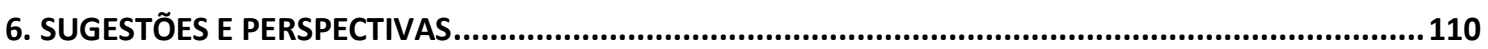

6.1. SUGESTÕES PARA TRABALHOS FUTUROS .................................................................... 110

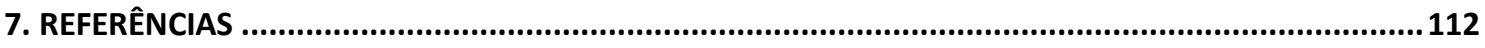

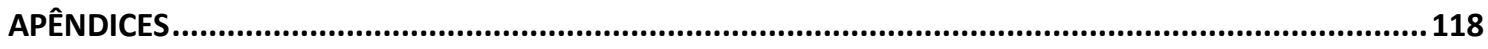

A. PADRÕES NACIONAIS DE QUALIDADE DO AR .............................................................. 118

B. AGRUPAMENTO DE ESPÉCIES QUÍMICAS NO MECANISMO QUÍMICO RADM2 .............................. 119

C. DESCRIÇÃo do CÁLCULO DAS TAXAS DE EMISSÃO DE POLUENTES ............................................ 120

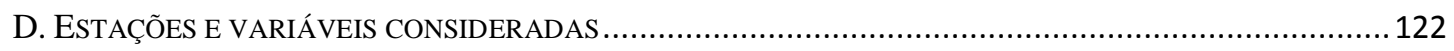

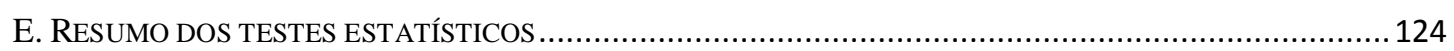

F. DIFERENÇA ESPAÇO-TEMPORAL DE OZÔNIO NO PERÍODO DE 12-15 NOVEMBRO DE 2011 COM AS

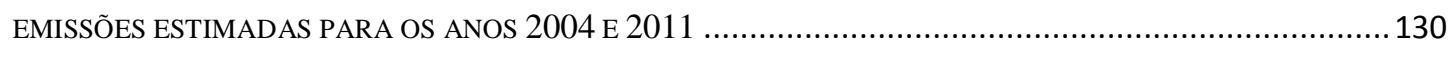




\section{INTRODUÇÃO}

A maioria das grandes megacidades do mundo sofre sérios problemas de qualidade do ar, os quais têm recebido mais atenção desde o final do século XX. Uma das principais razões destes problemas é o crescimento populacional e a necessidade de consumo de energia, combinado com a mudança no uso do solo devido ao incremento de áreas urbanas, provocando consequentemente altas emissões de poluentes para o ar (Mayer, 1999). Os principais poluentes emitidos para a atmosfera destas megacidades compreendem os óxidos de enxofre $(S O x)$, óxidos de nitrogênio ( $N O x)$, monóxido de carbono $(\mathrm{CO})$, compostos orgânicos voláteis $(\mathrm{COV})$, óxidos metálicos e material particulado $(M P)$. Este último é composto principalmente de carbono elementar, sulfatos, nitratos e material orgânico (Tie et al., 2009a). Outro poluente que frequentemente apresenta altas concentrações atmosféricas em áreas urbanas é o ozônio troposférico, que tem seus precursores ( $C O, C O V$ e $N O x)$ emitidos principalmente como produto de atividades antropogênicas, isto é, queima de combustíveis fósseis, geração de energia e atividades industriais (Tie et al., 2010). A aplicação de modelos atmosféricos tem se expandido em diferentes áreas da meteorologia, e com a chegada dos computadores de grande desempenho criou-se mais uma possibilidade de utilização na previsão da qualidade do ar com os chamados Modelos de Previsão Química $(M P Q)$. No Brasil e mais especificamente na Região Metropolitana de São Paulo (RMSP) os modelos de qualidade do ar que têm sido mais utilizados são o California/Carnegie Institute of Technology model (CIT) (Silva Junior, 2009) e o Brazilian Regional Atmospheric Modeling System (BRAMS) acoplado ao Simple Photochemical Model (SPM) (SPM-BRAMS) (Freitas et al., 2005). Para poder realizar previsões da qualidade do ar, os $M P Q$ requerem um conhecimento prévio do inventário de emissões que consiste na distribuição espaço/temporal média de algumas espécies primárias. Os inventários envolvem a descrição da emissão de gases e partículas para a atmosfera a partir de atividades como transporte (atividade veicular, aviação, navegação), queima de biomassa, atividade industrial, geração de energia, aterros sanitários, entre outros (Martins et al., 2010). Os inventários atuais são caracterizados por duas grandes incertezas: a quantidade total de cada poluente emitido e suas distribuições temporal e espacial (horizontal e vertical) (Wang et al., 2010). Dado que o objetivo deste trabalho foi estudar o impacto das emissões veiculares na formação do ozônio troposférico na 
RMSP comparativamente para os anos de 2004 e 2011, foi considerada apenas uma estimativa da emissão de seus principais precursores: $C O, N O x$ e $C O V$ e a caracterização das classes de Compostos Orgânicos Voláteis.

\subsection{Formação do ozônio troposférico}

Quando moléculas de $\mathrm{NO}$ e $\mathrm{NO}_{2}$ estão sob a ação da radiação solar, a formação de ozônio ocorre como um resultado da fotólise do $\mathrm{NO}_{2}$ para comprimentos de onda menores do que $424 \mathrm{~nm}$.

$$
\begin{aligned}
& \mathrm{NO}_{2}+h v \rightarrow \mathrm{NO}+\mathrm{O} \\
& \mathrm{O}+\mathrm{O}_{2}+\mathrm{M} \rightarrow \mathrm{O}_{3}+\mathrm{M}
\end{aligned}
$$

Não existem outras fontes significativas de ozônio na atmosfera que não seja a reação (1.2). Uma vez formado, o ozônio reage com o $\mathrm{NO}$ para regenerar o $\mathrm{NO}_{2}$ consumido (Seinfeld e Pandis., 2006).

$$
\mathrm{O}_{3}+\mathrm{NO} \rightarrow \mathrm{NO}_{2}+\mathrm{O}_{2}
$$

As reações (1.1) a (1.3) representam o que na literatura se conhece como o ciclo foto-estacionário do ozônio, e consiste no equilíbrio entre a produção (reações (1) e (2)) e o consumo (reação (3)) do ozônio troposférico numa atmosfera rica em $N O x$ $\left(\mathrm{NO}+\mathrm{NO}_{2}\right)$ quando na ausência de $\mathrm{COV}$. A figura 1.1 mostra uma representação gráfica deste ciclo, onde a molécula de ozônio gerada pela fotólise do $\mathrm{NO}_{2}$ é consumida pela molécula de $\mathrm{NO}$ também gerada pela fotólise do $\mathrm{NO}_{2}$, resultando em um equilíbrio entre o $\mathrm{NO}, \mathrm{NO}_{2}$ e $\mathrm{O}_{3}$.

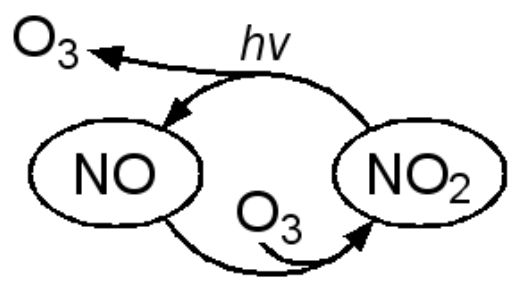

Figura 1.1. Ciclo foto-estacionário do ozônio. 


\subsubsection{Papel dos COV e NOx na formação do ozônio troposférico}

Um mecanismo químico COV/NOx generalizado, como o mostrado pelas reações (1.4) a (1.10) (Tie et al., 2007), compreenderia a oxidação do $C O$ e dos Hidrocarbonetos $(H C s)$ pelo radical hidroxila $(O H)$ (reações (1.4) e (1.5)) para formar radicais intermediários hidroperoxila $\left(\mathrm{HO}_{2}\right)$ e peróxi orgânicos $\left(\mathrm{RO}_{2}\right)$, com algumas espécies de HCs realizando este processo diretamente através da sua fotólise como, por exemplo, o formaldeído (Carbone, 2008). Uma vez formados os radicais intermediários $\mathrm{HO}_{2}$ e $\mathrm{RO}_{2}$, estes podem reagir por sua vez com o $\mathrm{NO}$ para formar $\mathrm{NO}_{2}$ (reações (1.6) e (1.7)), sendo este último capaz de realizar fotólise segundo a reação (1.10) e formando moléculas de ozônio. Dependendo da disponibilidade e proporção dos $C O V$ e $N O x$ na atmosfera, dado que a formação do ozônio troposférico é um fenômeno não linear relacionado à presença do CO, NOx e COV (Tie et al., 2010), o processo pode-se tornar eficiente ou não eficiente, em termos de produção de ozônio. Assim, por exemplo, quando os caminhos seguidos pelas reações (1.4) e (1.5) ocorrem com maior frequência que os caminhos seguidos pelas reações (1.6) e (1.7) devido a uma disponibilidade maior de $C O V$ do que $N O x$, diz-se se que a produção de ozônio é sensível às concentrações de NOx ou que está em um regime de NOx-limitante, situação que vai mudando em sentido oposto a medida que as emissões de NOx forem se incrementando.

$$
\begin{aligned}
& \mathrm{OH}+\mathrm{CO}+\mathrm{O}_{2} \rightarrow \mathrm{HO}_{2}+\mathrm{CO}_{2} \\
& \mathrm{OH}+\mathrm{HC}+\mathrm{O}_{2} \rightarrow \mathrm{RO}_{2}+\mathrm{H}_{2} \mathrm{O} \\
& \mathrm{RO}_{2}+\mathrm{NO} \rightarrow \mathrm{NO}_{2}+\mathrm{RO} \\
& \mathrm{HO}_{2}+\mathrm{NO} \rightarrow \mathrm{OH}+\mathrm{NO}_{2} \\
& \mathrm{HO}_{2}+\mathrm{HO}_{2} \rightarrow \mathrm{H}_{2} \mathrm{O}_{2}+\mathrm{O}_{2} \\
& \mathrm{NO}_{2}+\mathrm{OH} \rightarrow \mathrm{HNO}_{3} \\
& \mathrm{NO}_{2}+h \mathrm{~N}+\mathrm{O}_{2} \rightarrow \mathrm{NO}+\mathrm{O}_{3} \\
& \mathrm{O}_{3}+\mathrm{NO} \rightarrow \mathrm{NO}_{2}+\mathrm{O}_{2}
\end{aligned}
$$

Por outro lado, se a produção de ozônio é sensível às concentrações de $C O V$ se diz que o sistema está em um regime COV-limitante. Por exemplo, Ying et al., 2009 e Tie et al., 2007 encontraram que a formação do ozônio na Cidade do México, no 
México, responde a um regime de COV-limitante. No caso da RMSP, Orlando et al., 2010 sugere, após encontrar uma razão COV/NOx de aproximadamente 11, que a formação de ozônio troposférico é um processo controlado pelos $C O V$. Uma ferramenta que ajuda no entendimento da dependência $\mathrm{O}_{3}$ - COV/NOx são as isopletas de ozônio, diagramas utilizados para examinar sistematicamente estas relações.

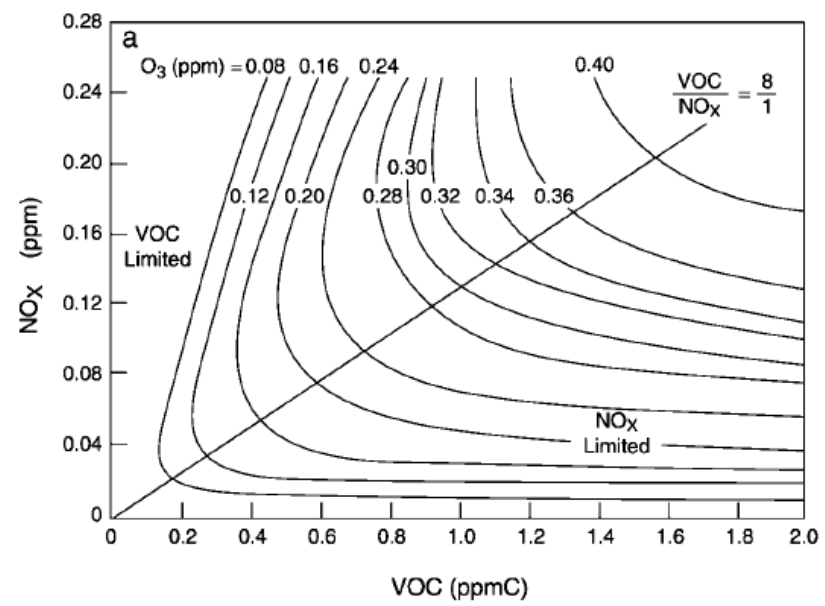

Figura 1.2. Isopleta de ozônio. Representação bidimensional gerada pelo modelo EKMA (Empirical Kinetic Modeling Approach) (Fonte: Finlayson-Pitts e Pitts, 2000).

A figura 1.2, por exemplo, mostra uma típica representação bidimensional de isopletas de máximos de ozônio geradas pelo modelo tipo caixa EKMA (Empirical Kinetic Modeling Approach) a partir da mistura de concentrações iniciais de COV e NOx no ar. Nesta figura pode-se observar uma linha reta cujas interseções às isopletas determinam pontos com razões COV/NOx 8 (as mesmas que seriam responsáveis por produzir picos de concentração), além de dividir as isopletas em duas regiões: uma região COV-limitante (razões COV/NOx baixas) onde o ozônio tipicamente irá decrescer por consumo do $N O$ (reação (3)) seguida da reação (9) (Tie et al., 2007); e uma região NOx-limitante (razões $\mathrm{COV} / \mathrm{NOx}$ altas) com altas concentrações de $\mathrm{HO}_{2} \mathrm{e}$ $\mathrm{RO}_{2}$ ainda que com pouca disponibilidade de $\mathrm{NOx}$, sendo que uma redução deste último seria mais efetiva no controle do ozônio, porém até um certo limiar, pois caso contrário um decréscimo nas emissões de NOx pode causar um aumento do ozônio devido à redução do consumo de ozônio pelo $N O$ e/ou redução da formação do acido nítrico. É importante apontar que na literatura atual há uma divergência em relação à definição dos limites e de forma geral, razões de 8 a 15 caracterizam locais intermediários onde tanto o controle de $C O V$ quanto $N O x$ são efetivos na diminuição do $O_{3}$ (Martins, 2006). 


\subsection{O problema do ozônio na RMSP}

A má qualidade do ar por ozônio troposférico na RMSP é um problema observado ao longo das últimas décadas. Martins et al., 2004 mostraram a evolução da qualidade do ar em São Paulo desde a década de 80 até 2000. O estudo mostra, por exemplo, que só no ano de 2002, o Padrão de Qualidade do Ar ( $P Q A$ ) para este poluente no Brasil (concentração máxima de $160 \mu \mathrm{g} / \mathrm{m}^{3}$ durante uma hora de amostragem), considerando os dados de onze estações de monitoramento espalhadas por toda a RMSP, foi excedido em 88 dias, o que representa um quarto do total de dias do ano, aproximadamente (ver figura 1.3). Além disso, o estudo indica que as concentrações de ozônio não mudaram significativamente desde 1997, sendo as variações ano a ano possivelmente causadas por fatores meteorológicos. Gallardo et al., 2012 mostraram que para todos os poluentes regulamentados, houve um decréscimo ao longo dos anos de 2000 a 2009, com exceção do ozônio, que para algumas estações de qualidade do ar tem apresentado um aumento no número de ultrapassagens do padrão ao longo dos anos. Os $P Q A$ no Brasil seguem a norma estabelecida pela Resolução CONAMA n ${ }^{\circ} 3$ de 28/06/90 (ver tabela 8.1 no apêndice A). A figura 1.3 mostra que na última década a evolução do número de dias de ultrapassagens do $P Q A$ para o ozônio não apresenta uma clara tendência de diminuição devido ao aumento do número de ultrapassagens do $P Q A$. Deve-se considerar que houve um aumento no número de estações de qualidade do ar na Região Metropolitana de São Paulo e assim o número total de ultrapassagens do padrão também aumentou (CETESB, 2012a).

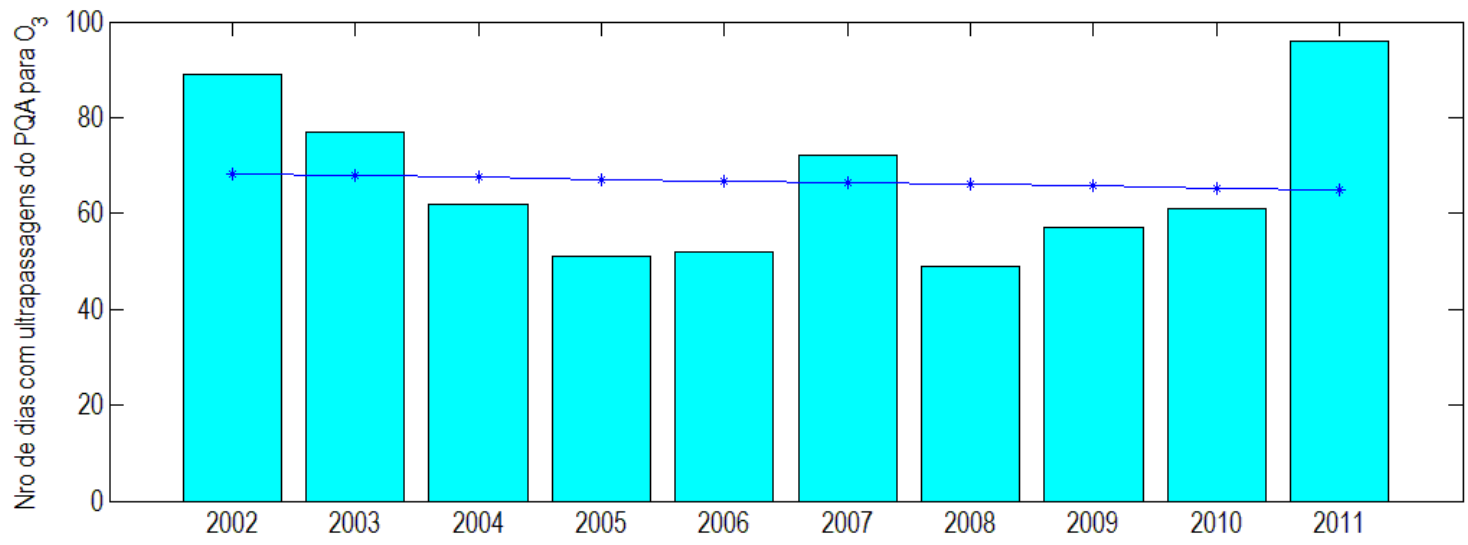

Figura 1.3. Evolução do número de dias de ultrapassagens do $P Q A$ para o ozônio na RMSP (dados extraídos de CETESB, 2012a). 
Para entender essa tendência há um aspecto que precisa ser melhor avaliado: o impacto dos diversos programas de controle de emissões veiculares implementados na RMSP. Sanchez-Ccoyllo et al., 2007, por exemplo, mostram, após realizar um estudo numérico com o modelo fotoquímico (CIT) para cenários sem e com implementação do Programa Nacional de Controle de Poluição por Veículos Automotores (PROCONVE) para o ano 2000 que, no geral, as concentrações do ozônio não foram correspondentes com a redução dos seus precursores; devido à dependência do ozônio com as razões COV/NOx. Os autores recomendam estudar esta razão na área de interesse para estabelecer melhores estratégias de controle de ozônio. É importante ressaltar que a variabilidade ano a ano do número de dias de ultrapassagens do $P Q A$ está diretamente relacionada com as condições meteorológicas favoráveis para sua formação, principalmente de intensa radiação ultravioleta e ventos fracos; podendo o número de dias de ocorrência de ultrapassagem do $P Q A$ em um determinado ano estar modulado em grande parte pelo número de dias de condições favoráveis à formação do ozônio. Na $R M S P$ a formação do ozônio ocorre com maior frequência nos meses de verão e mais significativamente na entrada da primavera, quando tem ocorrido a maioria das ultrapassagens do valor do $P Q A$ para ozônio na RMSP (Carbone, 2008). A figura 1.4 mostra o número de ultrapassagens por mês do $P Q A\left(160 \mu \mathrm{g} / \mathrm{m}^{3}\right)$ e do nível de atenção $\left(200 \mu \mathrm{g} / \mathrm{m}^{3}\right.$ ) para ozônio (estabelecidos pela Companhia de Tecnologia de Saneamento Ambiental do Estado de São Paulo (CETESB)) durante o período 2006-2010 na RMSP.

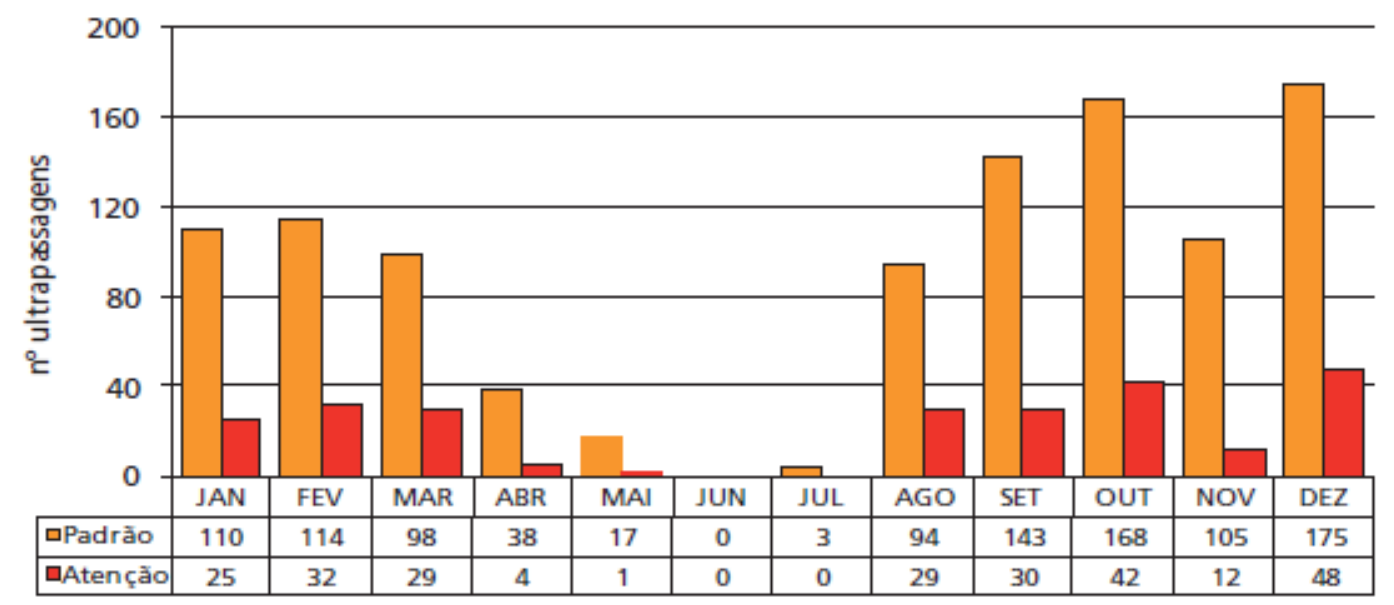

Base: Todas as estações fixas, mais as móveis Horto-Florestal e Itaquera-EM.

Figura 1.4. Número de ultrapassagens do $P Q A\left(160 \mu \mathrm{g} / \mathrm{m}^{3}\right)$ e do nível de atenção (200 $\mu \mathrm{g} / \mathrm{m}^{3}$ ) para o ozônio durante o período 2006-2010 na RMSP (Fonte: CETESB, 2011). 
Em relação aos precursores do ozônio: $C O V$ e $N O x$, estes provêm dos veículos, principal fonte de poluição do ar nesta região (Sánchez-Ccoyllo et al., 2009). Segundo a CETESB, no ano 2004, os veículos foram responsáveis por $98 \%$ das emissões de $C O$, $97 \%$ de $H C$ e $96 \%$ de NOx (CETESB, 2005), comparativamente aos $97 \%$ de CO, 77 $\%$ de $H C$ e $82 \%$ de NOx reportados no ano 2010 (CETESB, 2011). A figura 1.5 mostra a contribuição relativa por tipo de fonte para os principais poluentes emitidos na RMSP para os anos 2004 e 2010.
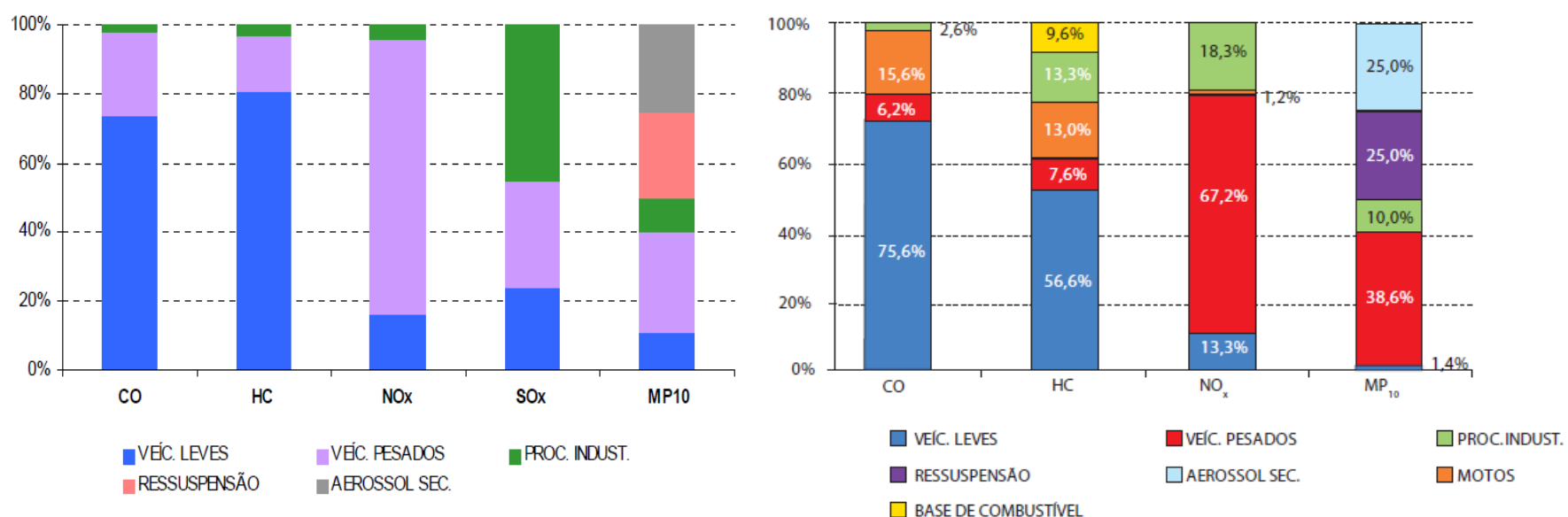

Figura 1.5. Contribuição relativa por tipo de fonte para os principais poluentes emitidos na RMSP durante os anos 2004 (esquerda) e 2010 (direita) (Fonte: CETESB, 2005 e CETESB, 2011).

Um aspecto importante que vem acontecendo ao longo dos últimos anos é a mudança no uso do tipo de combustível. Assim, por exemplo, os veículos 'flex-fuel' (capazes de queimar tanto gasolina quanto etanol em quaisquer proporções) e cujas vendas começaram aproximadamente no ano 2003 passaram de representar $1 \%$ no ano 2004 (CETESB, 2005) para $32 \%$ da frota total no ano 2011 (CETESB, 2012), impactando a formação de ozônio troposférico como será mostrado e discutido no capítulo dos resultados.

Muitos estudos têm avaliado a formação do ozônio troposférico na $R M S P$. Nos últimos anos essa avaliação foi realizada por meio de modelagem numérica devido ao grande avanço no conhecimento tanto físico quanto químico no entendimento da variabilidade espaço-temporal das concentrações do ozônio troposférico, fato acompanhado dos constantes desenvolvimentos computacionais na área de modelagem 
fotoquímica. Do grupo de pesquisadores que utilizaram modelos numéricos, podemos classificá-los ainda de acordo à natureza do tratamento dinâmico/químico em dois grupos: aqueles que utilizaram modelos fotoquímicos 'off-line' ou de física e química desacoplada e aqueles que utilizaram modelos fotoquímicos 'on-line' ou de física e química totalmente acoplada. Entre os que usaram modelos fotoquímicos desacoplados podemos citar: Sánchez-Ccoyllo et al., 2006a; Sánchez-Ccoyllo et al., 2006b; Martins, 2006; Sánchez-Ccoyllo et al., 2007; Martins e Andrade, 2008a; Martins e Andrade, 2008b e Carbone, 2008, todos eles baseados no uso do modelo CIT. Por outro lado, entre aqueles que usaram modelos fotoquímicos acoplados podemos citar: Silva Junior, 2009; Galichio, 2011 (ambos baseados no uso do modelo WRF-Chem); Itimura, 2010 e Carvalho, 2010 (modelo SPM-BRAMS). Na seção 1.3.1 será feita uma descrição sucinta de alguns destes trabalhos. Além dos trabalhos realizados por meio de modelagem numérica podemos citar outros trabalhos baseados nas análises de dados observacionais como os realizados por Silva Junior et al., 2009 e Orlando et al., 2010.

\subsection{Estudos recentes de modelagem de ozônio troposférico}

Muitos estudos de modelagem da qualidade do ar, especificamente por ozônio troposférico, foram realizados nos últimos anos, sejam envolvendo modelos 'off-line' como o CIT e CMAQ e/ou 'on-line' como o WRF-Chem (ferramenta utilizada neste estudo) e SPM-BRAMS.

\subsubsection{Na Região Metropolitana de São Paulo (RMSP)}

Sánchez-Ccoyllo et al., 2006b estudaram a resposta das concentrações de ozônio às variações individuais de três variáveis meteorológicas: altura da camada de mistura, velocidade do vento e temperatura do ar, além de avaliar a formação do ozônio por reduções hipotéticas dos seus precursores, com o modelo fotoquímico CIT durante um dia de inverno no ano 2000. Os resultados mostraram que os aumentos da altura da camada de mistura e velocidade do vento assim como a diminuição da temperatura, levam para uma diminuição do ozônio. Por outro lado mediante a aplicação da metodologia proposta por Baertsch-Ritter et al., 2004, em que uma diferença do ozônio entre cenários com reduções de Hidrocarbonetos reativos (RHCs) e NOx determinaria 
um limiar para a formação do ozônio por regimes RHCs e NOx limitantes, encontraram que a produção de ozônio era regida por um ambiente $R H C$-limitante forte na região central da RMSP enquanto que nos arredores a formação de ozônio esteve sob um regime $N O x$-limitante pouco acentuado.

Martins, 2006 avaliou a sensibilidade da formação de ozônio troposférico às mudanças nas emissões veiculares com os modelos fotoquímicos CIT e NCAR Master Mechanism (NCAR MM) (modelo tipo caixa) para três períodos com características meteorológicas diferentes. A distribuição espacial das emissões considerada no modelo CIT foi baseada nos resultados obtidos com o simulador de tráfego EMME/2 (Landmann, 2004), em que a estimativa das emissões é relacionada com o número de veículos e a velocidade média em cada tramo. Por outro lado, a distribuição das emissões ao longo do dia foi baseada em perfis de concentração de $C O$ (veículos leves) e NOx (veículos pesados) observados nos túneis de tráfego Jânio Quadros e Maria Maluf (Martins et al., 2006). Os resultados mostraram que a sensibilidade do ozônio às emissões veiculares é altamente sensível às emissões de $C O V$ nos períodos estudados, concluindo que o controle da emissão de $C O V$ é o mais efetivo para o controle do ozônio na RMSP, e que dentre os $C O V$ analisados o ozônio apresentou maior sensibilidade para as espécies aromáticas, olefinas, eteno e formaldeído.

Carbone, 2008 explicitou alguns $C O V$ como xilenos, 1-buteno e trimetilbenzenos dentro do módulo químico (SAPRC99) no modelo fotoquímico CIT além de atualizar dados cinéticos e estequiométricos das reações envolvidas na formação do ozônio troposférico, com o objetivo de melhorar a descrição dos processos da sua formação e consumo na RMSP. O período de estudo avaliado correspondeu a um episódio de altas concentrações de ozônio durante a primavera do ano 2006, período em que também foram realizados lançamentos de ozoniossondas no terraço do prédio principal do IAGUSP. As emissões foram distribuídas espacialmente de acordo com Martins, 2006, no entanto, com perfis diários diferentes por espécies. As simulações com o módulo químico modificado mostraram uma ligeira melhora na representação do ozônio com um aumento de aproximadamente $10 \%$ no centro da pluma. O perfil vertical simulado do ozônio representou de forma estatisticamente significativa os dados observados das ozoniossondas lançadas durante o período estudado.

Silva Junior, 2009 realizou um estudo de sensibilidade no cálculo de concentrações de poluentes fotoquímicos, principalmente o ozônio troposférico, em 
função da aplicação de diferentes esquemas de parametrização de Camada Limite Planetária (CLP) por meio do acoplamento do modelo WRF-Chem com o modelo urbano Urban Canopy Model $(U C M)$. Foi selecionado um período de 6 dias, que abrange o caso estudado por Carbone, 2008. Como no estudo realizado por Martins, 2006, a distribuição espacial das emissões foi também baseada nos resultados obtidos por Landmann, 2004. A distribuição temporal das emissões foi considerada a partir dos resultados obtidos por Lents et al., 2007. Os resultados mostraram que o modelo conseguiu representar adequadamente a variabilidade temporal e espacial do ozônio troposférico na superfície, melhorando significativamente com o esquema de CLP BOULAC (BOUgeault e LACarrére) quando comparado com o esquema YSU (Yonsei University), em função do primeiro ser um esquema de tipo local; no entanto ambos forneceram resultados semelhantes na representação do perfil vertical.

Galichio, 2011 avaliou o desempenho do modelo WRF-Chem para representar altas concentrações de ozônio troposférico durante um episódio observado em outubro do ano 2002. O esquema utilizado para distribuir as emissões espacialmente foi baseado no uso de dados de satélite de Intensidade de Luzes Noturnas (ILN), similar ao utilizado neste estudo para a grade de $3 \mathrm{~km}$, e de acordo com o estudo realizado por Martins et al., 2008. Para distribuir temporalmente as emissões foram considerados perfis horários obtidos a partir do monitoramento das emissões em vias de tráfego e atividade veicular realizado por Lents et al., 2004. Os resultados das simulações apresentaram boa representação dos ciclos diurnos, com máximos de concentração coincidentes com as observações, no entanto, com certa deficiência para representar os picos de emissão que ultrapassaram os $140 \mathrm{ppbv}$.

Carvalho, 2010 avaliou a distribuição das concentrações de ozônio troposférico e o impacto das mesmas sobre a qualidade do ar nas regiões metropolitanas de São Paulo e Rio de Janeiro. O estudo foi realizado por meio de modelagem numérica com o modelo SPM-BRAMS baseado no mecanismo químico SPRAC99. No caso da RMSP foram selecionados quatro períodos entre 2003 e 2006 caracterizados pelo grande número de violações do Padrão de Qualidade do $\operatorname{Ar}(P Q A)$ registrados durante diversos dias consecutivos. A distribuição espacial das emissões foi realizada com base no tipo de ocupação urbana de acordo com Freitas et al., 2005, considerando duas áreas principais: a primeira, localizada no centro da $R M S P$, responsável por $70 \%$ das emissões veiculares; e a segunda, uma área menos urbanizada responsável pelos $30 \%$ 
restantes. Os ciclos diurnos das emissões veiculares foram ajustados por uma função gaussiana dupla, de forma a representar os horários com maior fluxo de veículos (de manhã à tarde) de acordo com a hora do dia e com o dia da semana. As simulações representaram, em geral, o ciclo diurno do ozônio de forma coerente, com as concentrações máximas ligeiramente subestimadas na maioria das estações e períodos considerados. No período da tarde, predominantemente, foi identificada a intensificação dos ventos associados com a entrada da brisa marítima que atuou no transporte da pluma com maiores concentrações de ozônio, principalmente, para noroeste do domínio.

Itimura, 2010 estudou as condições atmosféricas associadas à ocorrência de concentrações máximas e mínimas de ozônio selecionando alguns eventos, principalmente de altas concentrações. A ferramenta de modelagem utilizada foi o modelo SPM-BRAMS. As simulações apresentaram os melhores resultados para as concentrações de ozônio, com representatividade estatística maior quando comparada com a representatividade de seus gases precursores. Os casos de altas concentrações de ozônio estiveram associados à presença de total de irradiância de onda curta superior a $1000 \mathrm{~W} / \mathrm{m}^{2}$, altas temperaturas e com menor umidade quando comparadas com os casos de baixas concentrações, as quais foram associadas com irradiância total que não ultrapassou $800 \mathrm{~W} / \mathrm{m}^{2}$, com cobertura de nuvens relativamente alta, tendo, as simulações destes últimos casos menor representatividade estatística do que no caso do cálculo das altas concentrações. Todas as simulações apresentaram o pico de concentração de ozônio atrasado quando comparado com a ocorrência da concentração máxima medida pela CETESB.

Em resumo, os estudos acima descritos indicam, de forma geral, uma boa representação dos ciclos de formação do ozônio, no entanto, com dificuldade para representar as máximas concentrações diárias (Carbone, 2008; Galichio, 2011; Carvalho, 2010). Por outro lado, indicam também uma deficiência na representação das concentrações dos seus precursores, principalmente as do $N O x$ e $C O V$ dado que a dependência com o grau de detalhamento na descrição das emissões é mais significativa do que os processos meteorológicos e de fotoquímica. Alguns desses estudos indicam ainda que a formação do ozônio troposférico na RMSP é um processo controlado pelas emissões dos COV (Sánchez-Ccoyllo et al., 2006; Martins, 2006). 


\subsubsection{Estudos em outras regiões}

Tie et al., 2007, Ying et al., 2009 e Tie et al., 2010 realizaram estudos numéricos com o modelo WRF-Chem para avaliar o comportamento de oxidantes químicos, principalmente o ozônio troposférico na Cidade do México, no México. Tie et al., 2007, por exemplo, estudaram a caracterização físico-química de oxidantes químicos como $C O, N O x$ e particularmente o ozônio troposférico através da comparação de valores simulados (com as emissões "caso base") para observações na superfície, além do estabelecimento de cinco cenários hipotéticos variando as emissões totais como segue: (1) triplicando apenas as emissões de $C O V$, (2) reduzindo as emissões de $C O V$ a terceira parte, (3) triplicando as emissões de $N O x$, (4) reduzindo as emissões de NOx a terceira parte e (5) triplicando as emissões de ambos precursores. Os resultados mostraram que as intensidades e variações dos ciclos diurnos calculados para o $C O$, $N O x$ e principalmente do $\mathrm{O}_{3}$ estiveram de acordo com as observações nos pontos analisados e que um cenário triplicando as emissões de $C O V$ e $N O x$ produziria concentrações máximas de ozônio maiores que no caso de triplicar somente as emissões de $C O V$.

Ying et al., 2009, por outro lado, realizaram um estudo para avaliar a sensibilidade do ozônio troposférico às variações diurnas das emissões superficiais dos seus precursores mediante o estabelecimento de quatro cenários baseados apenas nas mudanças dos perfis de emissão dos COV, NOx e CO: (1) perfil diário constante, resultado de se utilizar a média das taxas de emissão ao longo do dia; (2) as taxas de emissão das 00 às $11 \mathrm{~h}$ e das 12 às $23 \mathrm{~h}$ como sendo constantes e maiores durante o período das 00 às 11 ; (3) parecido ao caso (2) com a diferença de que as emissões são maiores no período das 12 às 23 e; (4) um perfil diário atrasado duas horas em relação ao perfil normal, sugerindo que sem redução das emissões totais, as concentrações do $\mathrm{CO}, \mathrm{NOx}$ e $\mathrm{O}_{3}$ assim como seus máximos diários podem ser reduzidas significativamente por mudanças nas variações das emissões dos precursores do ozônio. Diferentemente aos estudos anteriores que consideraram cenários variando os totais e os perfis de emissão dos precursores do ozônio, o estudo realizado por Tie et al., 2010 avaliou o impacto da resolução do modelo na formação do ozônio. Concluindo, após cinco experimentos variando as resoluções espaciais dos campos meteorológicos e de emissão para 3, 6, 12 e $24 \mathrm{~km}$, além de um caso misto com $6 \mathrm{~km}$ para os campos meteorológicos e $24 \mathrm{~km}$ para as emissões, que uma resolução de $6 \mathrm{~km}$ é adequada para 
o cálculo do ozônio e seus precursores na Cidade do México. O estudo sugere também que uma razão de 6 para 1 entre o comprimento médio de uma determinada área urbana e uma resolução horizontal do modelo, denominada "resolução limite" (12 km para Cidade do México), é apropriada para se ter um equilíbrio entre a performance do modelo e a carga computacional associada, no entanto campos meteorológicos com maiores resoluções podem melhorar as simulações. Além dos estudos acima descritos, existem outros estudos envolvendo modelagem de ozônio troposférico na Cidade do México como os realizados por Zhang e Dubey, 2009 e Tie et al., 2009 b.

Geng et al., 2007 e Tie et al., 2009a estudaram períodos de alta variabilidade de ozônio troposférico através da análise de dados observacionais e simulações numéricas na cidade de Shanghai, na China. Geng et al., 2007 utilizaram o modelo WRF-Chem para estudar o ozônio troposférico em um período caracterizado pela atuação de um sistema de alta pressão, contribuindo negativamente à formação de ozônio durante os primeiros dias do período estudado, e, no entanto, enfraquecendo e se dissipando nos últimos dias, favorecendo a formação fotoquímica do ozônio. Nesse trabalho os autores utilizaram também o modelo tipo caixa NCAR Master Mechanism (NCAR MM) para estudar a contribuição dos diferentes $C O V$ para as concentrações de ozônio. Os resultados mostraram que o modelo WRF-Chem representou bem as variações dia-a-dia, além da diferença nos ciclos diurnos produto da influencia do sistema anteriormente mencionado no período de estudo. Por outro lado, as variações diurnas de ozônio calculadas pelo modelo NCAR MM para quatro cenários sem concentrações variáveis dos seguintes $\operatorname{COV}$ (1) alcanos; (2) alcenos; (3) etenos e (4) aromáticos, mostram que os COV aromáticos contribuem com $79 \%$ da concentração total do ozônio, sugerindo que um aumento nas emissões de aromáticos nesta região, especialmente pelos veículos, poderia resultar em um aumento do ozônio.

Tie et al., 2009a por sua vez analisaram um período caracterizado por condições sinóticas opostas àquele estudado por Geng et al., 2007, ou seja, pela atuação pouca influente de um sistema de alta pressão durante os primeiros dias e que somado com o efeito local da brisa marítima resultou em ventos calmos mantendo em Shanghai as altas concentrações de ozônio produzidas nesta região. Com o decorrer dos dias o sistema de alta pressão foi se aproximando produzindo ventos intensos na região, os quais transportaram as altas concentrações de ozônio formadas quimicamente na cidade para regiões mais afastadas na direção do vento. O estudo começou com algumas possíveis 
explicações para a progressiva diminuição das concentrações do ozônio nas estações analisadas durante o período de estudo como, por exemplo, o aumento da nebulosidade, a redução da radiação $U V$ por aumento de aerossóis, as mudanças dos precursores de ozônio e das condições meteorológicas, especialmente dos ventos; sendo esta última, após verificação, a principal razão da diminuição das concentrações do ozônio ao longo do período estudado, concluindo que o modelo WRF-Chem é uma ferramenta muito útil para estudar a alta variabilidade das concentrações do ozônio em Shanghai.

Wang et al., 2010 avaliaram a sensibilidade do WRF-Chem na representação da qualidade do ar no leste asiático. O estudo compreende um conjunto de seis simulações para avaliar o impacto individual e combinado das variações temporal e vertical das emissões antropogênicas durante episódios de altas concentrações de ozônio no verão na região leste do continente asiático, principalmente sobre China e Japão. As emissões antropogênicas foram separadas em quatro categorias: energéticas, industriais, residenciais e veiculares; consideradas de inventários regionais e atribuindo-lhes perfis do tipo estacionário, com variação por dia-de-semana e diário, dependendo da espécie química. No caso das emissões energéticas, estas foram redistribuídas em várias camadas do modelo, mas, conservando a massa total em toda a coluna. No caso das outras categorias, as emissões foram consideradas apenas na primeira camada do modelo. As seis simulações foram: E_WDV (incluiu todos os perfis, com modificação total das emissões); E_DV (não incluiu o perfil dia-de-semana); E_V (incluiu apenas a o perfil vertical); E_WD (não incluiu o perfil vertical); E_D (incluiu apenas o perfil diurno) e E_N (simulação caso base, sem modificação das emissões). As características temporal e espacial das concentrações superficiais no Japão (dados horários e com maior numero de estações) foram simuladas realisticamente, com pequenas diferenças em resposta à redistribuição das emissões. Tendo os melhores resultados quando todos os perfis são considerados. Os resultados mostram também que a formação do ozônio é mais sensível ao perfil diário do que aos outros perfis.

Chuang et al., 2011 realizaram testes de sensibilidade com o modelo acoplado 'online' Weather Research and Forecasting with Chemistry model (WRF-Chem) Model of Aerosol Dynamics, Reaction, Ionization and Dissolution (MADRID) (WRF/Chem-MADRID) (Zhang et al., 2004) modificando o esquema de emissões biogênicas de Guenther (Guenther et al., 1993 e Simpson et al., 1995) e as condições de fronteira laterais com o objetivo de avaliar a 'performance' do modelo para sua 
aplicação como um sistema de previsão da qualidade do ar em tempo real, especificamente para avaliação de ozônio e material particulado fino $M P 2.5$ na região sudeste dos Estados Unidos. Os resultados correspondentes para o ozônio durante o período de simulação (maio-setembro de 2009) mostraram que a modificação do esquema de Guenther, através da explicitação do monoterpeno, resulta em baixas emissões de isopreno fazendo com que se tenha uma maior disponibilidade de radicais $\mathrm{HOx}$ para conversão do $\mathrm{NO}$ para $\mathrm{NO}_{2}$, favorecendo a formação de ozônio em grandes áreas do domínio, melhorando a previsão em algumas regiões. Por outro lado, com as condições de fronteira laterais reduzidas para o ozônio, observou-se uma diminuição da formação do $\mathrm{NO}_{2}$, resultando em uma melhor previsão do ozônio.

Dessa revisão pode-se concluir que a modelagem de qualidade do ar é uma importante ferramenta na descrição dos processos de formação e transporte dos poluentes. Para a Região Metropolitana de São Paulo várias questões ainda precisam ser respondidas com relação à formação do ozônio e de aerossóis secundários, em especial como resultado do uso de diferentes combustíveis. Este trabalho concentra-se no estudo da formação do ozônio, com a avaliação do impacto dos fatores de emissão dos veículos sobre a fotoquímica atmosférica.

\subsection{Objetivos}

Este trabalho teve como objetivo avaliar o impacto da emissão de precursores de ozônio pela frota veicular na formação de ozônio troposférico na atmosfera da $R M S P$, a partir da avaliação da mudança dos Fatores de Emissão $(F E)$ de 2004 para 2011. Esses períodos foram definidos com base nas medidas realizadas em túneis de tráfego para os cálculos dos $F E$. Os $F E$ para o ano 2004 foram calculados em estudos anteriores nos túneis de tráfego (Túnel Jânio Quadros e Túnel Maria Maluf), e assim para atender ao nosso objetivo atualizaram-se esses fatores para o ano 2011, quando se realizou novo experimento de medida de $F E$ em túneis (Túnel Jânio Quadros e Túnel 1 do Rodoanel Oeste). A ferramenta de modelagem utilizada foi o modelo Weather Research and Forecasting with Chemistry (WRF-Chem).

Como objetivos secundários pode-se citar:

- Estudar a variação dos $F E$ de 2004 para 2011; 
- Avaliar a evolução da relação de $C O V$ e $N O x$ nos dois inventários e seu impacto na formação de ozônio;

- Avaliar o impacto sobre a formação do ozônio de dois esquemas de distribuição espacial das emissões com espaçamentos de grade de 3 e $1 \mathrm{~km}$.

Esta dissertação se organiza da seguinte forma: no capítulo 2 são apresentadas as metodologias e dados utilizados, no capítulo 3 a área e os períodos de estudo, no capítulo 4 os resultados e discussões, no capítulo 5 as considerações finais, no capítulo 6 as sugestões e perspectivas; finalmente são mostradas as referências e os apêndices. 


\section{METODOLOGIA}

\subsection{Descrição sucinta da ferramenta de modelagem}

\subsubsection{O modelo numérico WRF-Chem}

O modelo numérico Weather Research and Forecasting with Chemistry (WRFChem), descrito em Grell et al., 2005, é um modelo meteorológico de mesoescala 'online' suportado pelo National Center for Atmospheric Research (NCAR) dos Estados Unidos. O WRF-Chem é composto de uma componente meteorológica e uma componente química. A componente meteorológica do WRF-Chem, o Weather Research and Forecasting $(W R F)$ é um sistema desenhado com fins de previsão operacional e atividades relacionadas à investigação dos processos atmosféricos. $\mathrm{O}$ núcleo dinâmico do WRF utilizado neste trabalho corresponde ao Advanced Research WRF $(A R W)$ versão 3. O $A R W$ é um sistema de simulação atmosférica estado da arte, portátil, computacionalmente eficiente e adequado para ser usado em uma vasta gama de aplicações com escalas que vão de metros até milhares de quilômetros (Wang et al., 2009). Neste núcleo, as equações do modelo são resolvidas para condições não hidrostáticas e para uma atmosfera totalmente compressível. As equações são formuladas usando uma coordenada vertical do tipo sigma, denotada por $\eta$ (ver figura 2.1), caracterizada por seguir o terreno e definida como:

$$
\begin{aligned}
& \eta=\frac{p_{h}-p_{h t}}{\mu} \\
& \mu=p_{h s}-p_{h t}
\end{aligned}
$$

Onde $p_{h}$ é a componente hidrostática da pressão, enquanto $p_{h s}$ e $p_{h t}$ referem-se a valores na superfície e no topo, respectivamente. $\eta$ varia de um valor de 1 na superfície para 0 no limite superior. Outras características presentes no sistema $A R W$ utilizado incluem a grade $C$ de Arakawa para a grade horizontal, o esquema Runge-Kutta para a integração 
no tempo, todos os termos de Coriolis, quatro projeções geográficas, opções de aninhamento 'one-way' e 'two-way' (Skamarock et al., 2008).

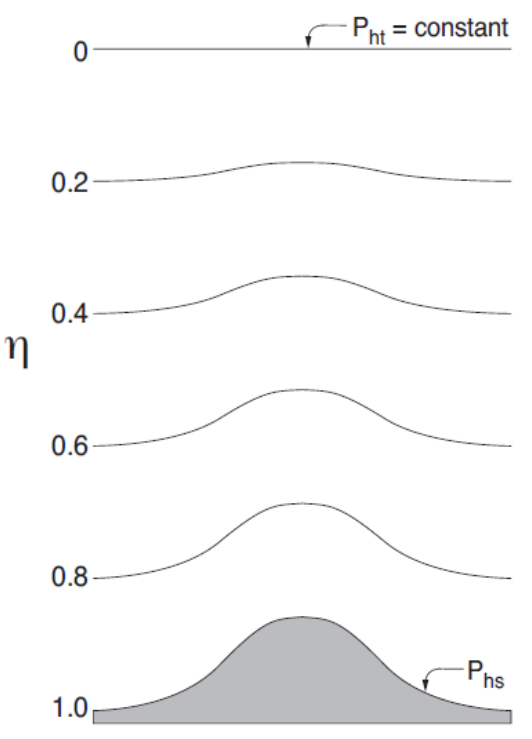

Figura 2.1. Coordenada vertical $\eta$ utilizada nas simulações (Fonte: Wang et al., 2009).

A componente química do modelo trata uma variedade de processos físicos e químicos acoplados tais como transporte, deposição seca, química da fase gasosa, emissões, distribuição, parametrização e química de aerossóis e frequência de fotólise.

O transporte de todas as espécies químicas é 'on-line'. A integração das equações prognósticas no sistema $A R W$ é feita na forma conservativa para variáveis conservativas. As variáveis não conservativas como a pressão e a temperatura são diagnosticadas a partir de variáveis conservativas prognosticadas. Na aproximação de variável conservativa, o sistema $A R W$ integra uma equação de conservação de massa e uma equação de conservação de massa escalar, segundo:

$$
\begin{aligned}
& \mu_{t}+\nabla \cdot(V \mu)=0, \\
& (\mu \phi)_{t}+\nabla \cdot(V \mu \phi)=0
\end{aligned}
$$

Nestas equações $\mu$ é a coluna de ar seco, $V$ é a velocidade $(u, v$,$) e \phi$ é uma razão de mistura escalar. Estas equações são discretizadas em uma formulação de volume finito, e como resultado o modelo conserva exatamente a massa e massa escalar. 
O fluxo dos gases traços e partículas da atmosfera para a superfície é calculado por multiplicação das concentrações no nível mais baixo do modelo pela variação espaço/temporal da velocidade de deposição, sendo esta proporcional à soma de três resistências características: resistência aerodinâmica, de subcamada e superficial (Grell et al., 2005).

Quanto às emissões antropogênicas, o WRF-Chem dispõe de um pré-processador químico desenvolvido exclusivamente para assimilar dados do National Emissions Inventory (NEI, 2005) como forçantes químicas dentro do modelo. No entanto, dado que o nosso objetivo é avaliar a formação do ozônio por veículos automotores em uma escala urbana, foi considerado um inventário de emissões de fontes móveis, de acordo com procedimentos descritos na seção 2.3.1. No caso das emissões biogênicas o WRFChem usa um módulo baseado na descrição de Guenther et al. (1993, 1994), Simpson et al. 1995 e Schoenemeyer et al. 1997. O módulo trata as emissões do isopreno, monoterpenos e outros $C O V$ biogênicos assim como as emissões de nitrogênio pelo solo. Assim, por exemplo, as emissões de isopreno pelas florestas são calculadas a partir da temperatura e radiação fotossinteticamente ativa (Grell et al., 2005). O modelo possui também módulos que permitem a inclusão de emissões globais antropogênicas como RETRO e EDGAR, além de um cálculo 'online' de emissões biogênicas através do MEGAN (Wang et al., 2009).

As frequências de fotólise para as 21 reações fotoquímicas consideradas no mecanismo químico para a fase gasosa utilizado neste estudo, o $R A D M 2$ e descrito na próxima seção, são calculados em cada ponto de grade de acordo com Madronich, 1987. A frequência de fotólise do gás ' $i$ ', $J_{i}$, é dada pela integral do produto do fluxo actínico $I_{A}(\lambda)$, as seções transversais de absorção $\sigma(\lambda)$, e os rendimentos quânticos $\phi(\lambda)$ no comprimento de onda $\lambda$ (Grell et al., 2005):

$$
J_{i}=\int^{\lambda} I_{A}(\tau, \lambda) \sigma_{i}(\lambda) \phi_{i}(\lambda) d \lambda
$$

Além das componentes já apresentadas, o WRF-Chem inclui também módulos de descrição de aerossóis tratando aspectos como as suas distribuições de tamanho e processos de formação (química e crescimento). 


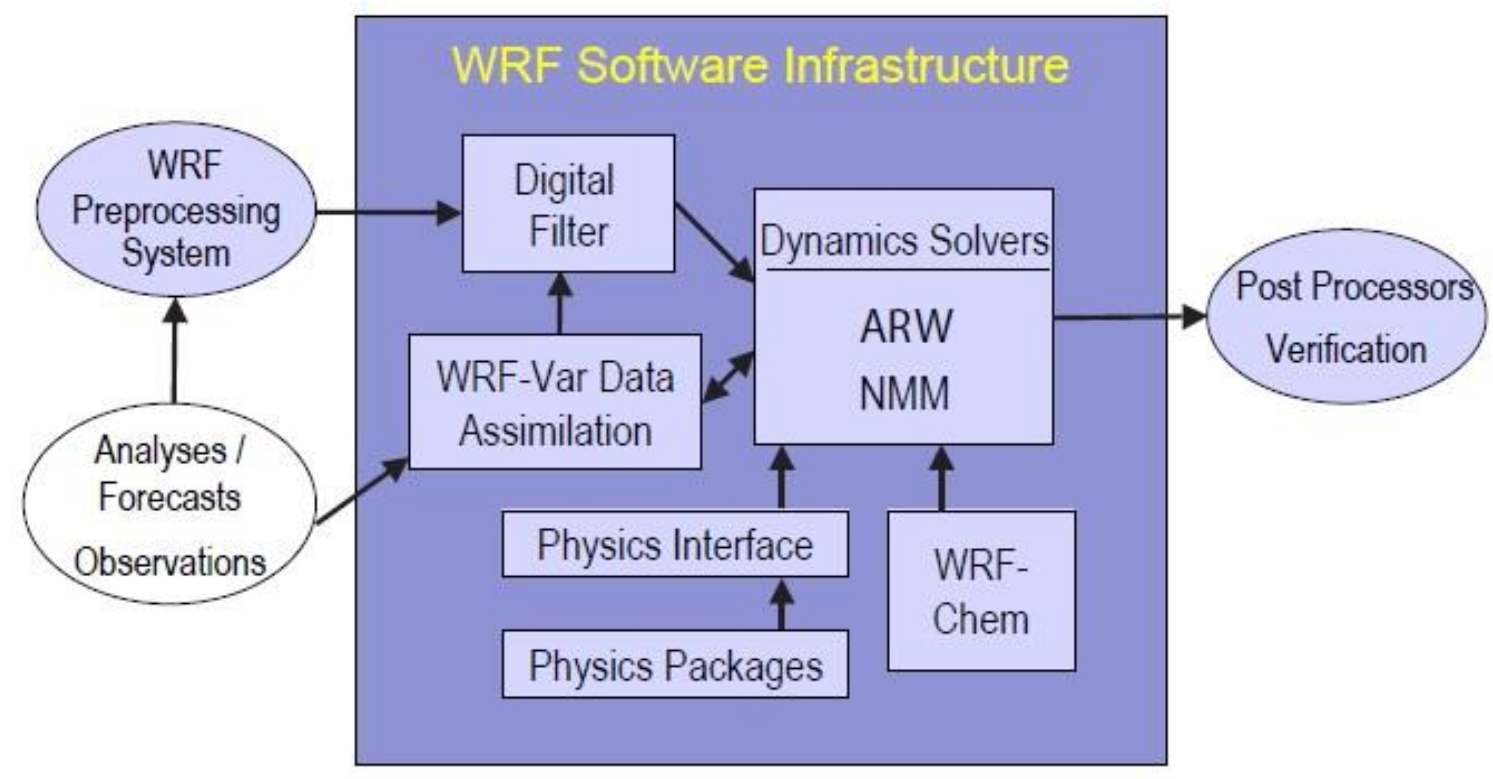

Figura 2.2. Esquema simplificado das componentes do sistema WRF (Fonte: Skamarock et al., 2008).

\subsubsection{Principais parametrizações utilizadas}

Segue uma breve descrição das principais parametrizações físicas e químicas utilizadas pelo WRF-Chem.

\subsubsection{Microfísica}

A microfísica resolve a fase em que a água se encontra na atmosfera, quantitativamente, qualitativamente e a distribuição dos hidrometeoros. Existem três camadas na atmosfera que são bem definidas pelos modelos em termos de fase da água: camada abaixo do nível de $0^{\circ} \mathrm{C}$ (presença de vapor de água e gotículas de água), a camada no nível entre 0 e $-40^{\circ} \mathrm{C}$ (presença de cristais de gelo e gotículas de água superresfriadas), e acima do nível de $-40^{\circ} \mathrm{C}$ (só há presença de cristais de gelo e neve) (Silva Junior, 2009). O esquema de microfísica considerado neste estudo é o esquema Purdue Lin. O esquema Purdue Lin, baseado nos estudos de Lin et al., 1983 e Rutledge e Hobbs, 1984, inclui 6 classes de hidrometeoros: vapor de água, água de nuvem, chuva, gelo na nuvem, neve e 'graupel'; e representa um esquema de microfísica relativamente sofisticado no sistema $W R F$, sendo o mais adequado para fins de pesquisa (Skamarock et al., 2008). 


\subsubsection{Cumulus}

Os esquemas de cumulus são responsáveis pelos efeitos de escala subgrade de convecção e/ou nuvens rasas. Estes esquemas são construídos para representar fluxos verticais devido às correntes ascendentes e descendentes não resolvidas e movimentos de compensação fora das nuvens. Operam apenas em colunas individuais, onde o esquema é ativado para fornecer aquecimento e umedecimento vertical. Alguns esquemas fornecem adicionalmente nuvens e tendências de precipitação na coluna. Todos os esquemas fornecem a componente convectiva da precipitação superficial. Os esquemas de cumulus são teoricamente válidos só para espaçamentos de grade com menores resoluções, por exemplo, maiores do que $10 \mathrm{~km}$. A parametrização de cumulus considerada neste estudo corresponde ao esquema Grell-3D, introduzido pela primeira vez na versão 3.0 do modelo. Este esquema se distingue de outros esquemas de cumulus por permitir que efeitos de subsidência sejam transmitidos entre colunas de grades vizinhas (Skamarock et al., 2008).

\subsubsection{Camada Superficial}

Os esquemas de Camada Superficial calculam as velocidades de fricção e a mudança dos coeficientes que permitem os cálculos dos fluxos de calor e umidade pelos modelos de Superfície Terrestre e cisalhamento superficial na Camada Limite Planetária $(C L P)$. Sobre superfícies de água, os fluxos e campos diagnósticos superficiais são calculados no próprio esquema de Camada Superficial. Estes esquemas não fornecem curvas de tendências, apenas informações da dependência com a estabilidade sobre a camada superficial para os esquemas de Superfície Terrestre e CLP. Atualmente, cada opção de Camada Superficial esta vinculada com um determinado esquema de CLP, mas no futuro mais opções de intercâmbio podem estar disponíveis. O esquema de Camada Superficial considerado neste estudo é a Teoria da Similaridade (MM5). Este esquema usa as funções de estabilidade de Paulson, 1970, Dyer e Hicks, 1970 e Webb, 1970 para calcular os coeficientes de trocas superficiais para o calor, umidade e impulso (Skamarock et al., 2008). 


\subsubsection{Superfície Terrestre}

Os modelos de Superfície Terrestre usam informação atmosférica do esquema de Camada Superficial, forçamento radiativo do esquema de radiação, e precipitação dos esquemas de microfísica e convecção, para juntamente com informação interna das variáveis de estado do solo e propriedades na superfície terrestre fornecer fluxos de calor e umidade sobre pontos terrestres e pontos de gelo no mar. Estes fluxos fornecem uma condição de limite inferior para o transporte vertical calculado nos esquemas de CLP. O modelo de Superfície Terrestre considerado neste estudo é o Noah LSM. O Noah LSM, desenvolvido pelo NCAR juntamente com o NCEP, é um modelo de quatro camadas de temperatura e umidade do solo com previsão de cobertura de neve. Inclui zona com raízes, evapotranspiração, drenagem do solo e escoamento superficial, além de considerar várias categorias de vegetação, fração mensal de vegetação e textura do solo (Skamarock et al., 2008).

\subsubsection{Camada Limite Planetária}

A Camada Limite Planetária $(C L P)$ é responsável pelos fluxos verticais de escala subgrade devido ao transporte turbulento em toda a coluna atmosférica, e não somente na camada limite. Portanto, quando um esquema de CLP é ativado, a difusão vertical explícita é desativada assumindo que o esquema de CLP realizará este processo. Os fluxos de superfície são fornecidos pelos esquemas de Camada Superficial e Superfície Terrestre. Os esquemas de CLP determinam os perfis do fluxo dentro da camada de mistura e da camada estável, e assim fornecem tendências atmosféricas de temperatura, umidade (incluindo nuvens) e impulso horizontal em toda a coluna atmosférica. Os esquemas de CLP considerados neste estudo são: Yonsei University (YSU) para as grades de 27, 9 e $3 \mathrm{~km}$ e BOUgeault-LACarrère (BOULAC) para a grade de $1 \mathrm{~km}$. O esquema YSU (Hong et al., 2006) usa termos contra-gradiente para representar fluxos devido a gradientes não locais, além de tratar explicitamente a camada de entranhamento no topo da CLP (Skamarock et al., 2008). O esquema BOULAC (Bougeault e Lacarrère, 1989) é um modelo de fechamento de primeira ordem que usa a equação da energia cinética turbulenta, e baseia-se na analogia entre a turbulência e transporte molecular das propriedades. Uma importante consideração feita em BOULAC que o diferencia do esquema $Y S U$ é a inclusão do efeito orográfico que é introduzido na 
escala de comprimento e por sua vez é passado para os coeficientes de difusões turbulentas verticais e horizontais (Silva Junior, 2009).

\subsubsection{Radiação Atmosférica}

Os esquemas de radiação fornecem os perfis de aquecimento atmosférico devido ao fluxo radiativo de onda curta e longa para manter o balanço energético do planeta. A radiação de onda longa considera radiação infravermelha ou termal absorvida e emitida por gases e superfícies. A radiação de onda curta considera comprimentos de onda no espectro visível e próximos que compõem o espectro solar. Assim, a única fonte é o Sol, mas os processos incluem absorção, reflexão e dispersão na atmosfera e em superfícies. Para resolver o balanço de onda longa é considerado o esquema Rapid Radiative Transfer Model (RRTM) Longwave descrito em Mlawer et al., 1997. Este esquema usa tabelas pré-estabelecidas para representar processos de radiação de onda longa devidos ao vapor de água, $\mathrm{CO}_{2}, \mathrm{O}_{3}$, e gases traços (se presentes), assim como uma estimativa para a profundidade ótica das nuvens. Para o caso da radiação de onda curta, o esquema considerado é o Goddard Shortwave. O esquema de Goddard, baseado em Chou e Suarez, 1994, considera um total de 11 bandas espectrais além das componentes de radiação solar direta e difusa em uma aproximação 'two-stream' que dão conta das componentes espalhada e refletida (Skamarock et al., 2008).

\subsubsection{Mecanismo químico na fase gasosa}

O mecanismo químico na fase gasosa considerado neste estudo é o Regional Acid Deposition Model version 2 (RADM2) (Stockwell et al., 1990). Desenvolvido originalmente por Stockwell et al., 1986, o mecanismo RADM2 é um compromisso entre o detalhamento químico, a acurácia nas previsões químicas e os recursos computacionais disponíveis. Amplamente usado em modelos atmosféricos para a previsão de concentrações de oxidantes fotoquímicos e outros poluentes, o mecanismo considera uma série de espécies inorgânicas, das quais 14 são estáveis, 4 reativas intermediárias, e 3 estáveis abundantes (oxigênio, nitrogênio e vapor de água). A química orgânica está representada por 26 espécies estáveis e 16 radicais peroxi através de agregados moleculares reativos descritos em Middleton et al., 1990 (Grell et al., 2005). As emissões são agrupadas em espécies com reatividade química, funções 
orgânicas e reatividade de compostos orgânicos com o radical $O H$ similares (Gross e Stockwell, 2003).

A tabela 2.1 mostra um resumo das principais parametrizações físicas e químicas utilizadas nas simulações numéricas.

\begin{tabular}{|l|l|l|}
\hline \multicolumn{1}{|c|}{$\begin{array}{c}\text { Processos Físicos e } \\
\text { Químicos }\end{array}$} & \multicolumn{2}{c|}{ Esquema usado pelo WRF-Chem } \\
\cline { 2 - 3 } \multicolumn{1}{c|}{$1 \mathrm{~km}$} \\
\hline Radiação de onda longa $3 \mathrm{~km}$ & RRTM & RRTM \\
\hline Radiação de onda curta & Goddard & Goddard \\
\hline Camada Superficial & Monin-Obukhov & Monin-Obukhov \\
\hline Superficie Terrestre & Unified Noah land-surface & Unified Noah land-surface \\
\hline Camada Limite Planetária & YSU & BOULAC \\
\hline Microfísica & Purdue Lin & Purdue Lin \\
\hline Cumulus & Grell-3 ensemble & Desativado \\
\hline Fotólise & Fast-J & Fast-J \\
\hline Química da fase gasosa & RADM2 (grade de $3 \mathrm{~km})$ & RADM2 \\
\hline
\end{tabular}

Tabela 2.1. Configuração das principais parametrizações físicas e químicas utilizadas nas simulações com o modelo WRF-Chem.

\subsection{Dados de modelagem}

Como dados de modelagem foram considerados os campos meteorológicos calculados pelo NCEP dos Estados Unidos e parâmetros envolvidos no cálculo das emissões veiculares como, por exemplo, os Fatores de Emissão.

\subsubsection{Inventário de emissões}

As emissões totais dos poluentes foram calculadas basicamente com informações estimadas de número e tipo de veículos, fatores de emissão e número médio de quilômetros percorridos pelos veículos segundo a metodologia adotada pela CETESB para emissões por escapamento (CETESB, 2012b) de acordo com a equação abaixo:

$$
\mathrm{E}_{P}=\sum_{\text {veic }=1}^{5} \mathrm{~N}_{\text {veic }} \times \mathrm{FE}_{\mathrm{P}, \mathrm{veic}} \times \mathrm{I}_{\text {veic }}
$$


Onde

- $\mathrm{E}_{P}$ : Emissão total, em gramas por dia, do poluente " $P$ ”;

- $\mathrm{N}_{\text {veic }}$ : Número de veículos do tipo "veic”;

- $\mathrm{FE}_{P, v e i c}$ Fator de emissão do poluente "P", em gramas por quilometro, para o veículo tipo "veic";

- $\mathrm{I}_{\text {veíc }}$ : Intensidade de uso, em quilômetros por dia, para o veiculo tipo "veic”;

- veic: Índice que indica o tipo de veículo considerado (ver Tabela 2.2);

Segundo o Departamento Estadual de Trânsito de São Paulo (DETRAN) a frota veicular foi aproximadamente de 5,8 milhões para o ano 2004 e de 7,2 milhões para o ano 2011. A tabela 2.2 mostra o fracionamento veicular e tipos de veículos, assim como as intensidades de uso consideradas no esquema de emissão utilizado e baseado na equação 2.4 .

\begin{tabular}{|c|c|c|c|}
\hline Tipo de combustível & 2004 & 2011 & Intensidade de uso \\
\hline Gasolina & $69,50 \%$ & $46,53 \%$ & $41,09 \mathrm{~km} / \mathrm{dia}$ \\
\hline Álcool & $14,50 \%$ & $3,20 \%$ & $41,09 \mathrm{~km} / \mathrm{dia}$ \\
\hline Flex & $1,00 \%$ & $32,02 \%$ & $41,09 \mathrm{~km} / \mathrm{dia}$ \\
\hline Diesel & $5,80 \%$ & $5,58 \%$ & $109,58 \mathrm{~km} / \mathrm{dia}$ \\
\hline Motocicletas & $9,30 \%$ & $12,67 \%$ & $136,98 \mathrm{~km} / \mathrm{dia}$ \\
\hline
\end{tabular}

Tabela 2.2. Fração por tipo de veiculo 2004 (CETESB, 2005) e 2011 (CETESB, 2012a), e suas respectivas intensidades de uso, consideradas do ano de 2007 (Fonte: SPTrans).

\subsubsection{Fatores de emissão}

Os Fatores de Emissão $(F E)$ são definidos como sendo a quantidade de massa emitida de um certo poluente atmosférico em função da distância percorrida ou volume de combustível consumido por um veículo (Kristensson et al., 2004). Os FE baseados em tipos de combustível, e que são expressos em massa emitida por unidade de volume de combustível queimado, são representativos de uma situação típica com diferentes tipos de veículos e sobre diferentes condições de operação do veículo: velocidade, aceleração, tipo de motor, etc. (Martins et al., 2006). Os $F E$ foram calculados a partir de campanhas experimentais realizadas nos túneis de tráfego Jânio Quadros (22 a 26 de março) e Maria Maluf (04 a 07 de maio) para o ano de 2004 (Martins et al., 2006) e 
Jânio Quadros (02 a 15 de maio) e Rodoanel (04 a 18 de julho) para o ano de 2011 (campanha experimental liderada pelo grupo LAPAt/IAG-USP e com participação de outros grupos de pesquisa), assim como os obtidos por meio de dinamômetros (CETESB, 2005 e CETESB, 2010). A tabela 2.3 mostra os FE considerados para os anos 2004 e 2011 respectivamente, e utilizados na equação 2.4 para calcular as emissões totais consideradas nas simulações numéricas. Para o ano 2011 os FE foram calculados de acordo com a metodologia proposta por Marr et al., 1999, a mesma que foi utilizada por Martins et al., 2006 para obter os FE no ano 2004. Apresenta-se uma descrição sucinta das expressões utilizadas para o cálculo dos FE (Marr et al., 1999; Martins, 2006; Martins et al., 2006):

$$
F E_{P}=10^{3} \times\left(\frac{\Delta[p]}{\Delta\left[C O_{2}\right]+\Delta[C O]}\right) \omega_{c}
$$

Onde $F E_{P}$ é o fator de emissão ( $\mu g$ de poluente emitido por $k g$ de combustível queimado); $\Delta[p]$ é a concentração do poluente subtraído do seu valor de fundo (isto é da medida de concentração fora do túnel) em $\mu \mathrm{g} / \mathrm{m}^{3} ; \Delta\left[\mathrm{CO}_{2}\right]$ e $\Delta[\mathrm{CO}]$ são as concentrações de $\mathrm{CO}_{2}$ e $\mathrm{CO}$ subtraídas do valor da concentração fora do túnel, em $\mu g \mathrm{C} / \mathrm{m}^{3}$; e $\omega_{c}$ é a fração em massa de carbono no combustível, sendo 0,85 para a gasolina e 0,87 para o diesel. Para o cálculo da contribuição do diesel nas emissões do $\mathrm{CO}_{2}$ foi utilizada a equação abaixo:

$$
\frac{\Delta\left[\mathrm{CO}_{2}\right]_{\mathrm{D}}}{\Delta\left[\mathrm{CO}_{2}\right]}=\frac{\mathrm{f}_{\mathrm{D}} \mathrm{U}_{\mathrm{D}} \rho_{\mathrm{D}} \omega_{\mathrm{D}}}{\left(\mathrm{f}_{\mathrm{D}} \mathrm{U}_{\mathrm{D}} \rho_{\mathrm{D}} \omega_{\mathrm{D}}\right)+\left(1-\mathrm{f}_{\mathrm{D}}\right) \cdot \mathrm{U}_{\mathrm{G}} \rho_{\mathrm{G}} \omega_{\mathrm{G}}}
$$

Onde $\Delta\left[\mathrm{CO}_{2}\right]_{D}$ é a fração de $\mathrm{CO}_{2}$ atribuída ao diesel; $\triangle\left[\mathrm{CO}_{2}\right]$ é a concentração interna subtraída da externa $\left(\mu \mathrm{gC} / \mathrm{m}^{3}\right)$ para o $\mathrm{CO}_{2} ; f_{D}$ é a fração média de veículos a diesel que passaram por hora pelo túnel Rodoanel; $U_{D}$ e $U_{G}$ são as taxas de consumo dos motores à diesel (47 litros por 100 quilômetros) e gasolina (12 litros por 100 quilômetros) respectivamente; $\rho_{D}$ e $\rho_{G}$ são as densidades para o diesel $(840 \mathrm{~g} / \mathrm{l})$ e gasolina $(740 \mathrm{~g} / \mathrm{l})$ respectivamente; $\omega_{D}$ e $\omega_{G}$ são as frações do carbono (em massa) no diesel $(0,87)$ e gasolina $(0,85)$ respectivamente. 


\begin{tabular}{|c|c|c|c|c|c|c|c|}
\hline \multirow{2}{*}{$\begin{array}{c}\text { Fontes de } \\
\text { emissão }\end{array}$} & \multirow{2}{*}{$\begin{array}{c}\text { Tipo de } \\
\text { combustível }\end{array}$} & \multicolumn{6}{|c|}{ Fator de emissão $(\mathrm{g} / \mathrm{km})$} \\
\cline { 3 - 8 } & & \multicolumn{2}{|c|}{$C O$} & \multicolumn{2}{c|}{$H C$} & \multicolumn{2}{c|}{ NOx } \\
\cline { 2 - 8 } & Gasolina & $14,60^{(1)}$ & $6,50^{(1)}$ & 1,24 & 1,17 & $1,60^{(1)}$ & $0,50^{(1)}$ \\
\cline { 2 - 8 } & Álcool & $14,60^{(1)}$ & $6,50^{(1)}$ & 2,12 & 2,17 & $1,60^{(1)}$ & $0,50^{(1)}$ \\
\cline { 2 - 8 } $\begin{array}{c}\text { Tubo de } \\
\text { escapamento }\end{array}$ & Flex & $14,60^{(1)}$ & $6,50^{(1)}$ & 0,15 & 0,10 & $1,60^{(1)}$ & $0,50^{(1)}$ \\
\cline { 2 - 8 } & Diesel & $20,60^{(1)}$ & $4,95^{(1)}$ & 2,48 & 2,05 & 11,17 & 9,81 \\
\cline { 2 - 8 } & Motocicletas & 18,00 & 10,40 & 2,37 & 1,41 & 0,11 & 0,12 \\
\hline \multirow{2}{*}{$\begin{array}{c}\text { Emissão de } \\
\text { cárter e } \\
\text { evaporativa }\end{array}$} & Gasolina & -- & -- & 2,00 & 2,00 & -- & -- \\
\cline { 2 - 8 } & Álcool & -- & -- & 1,50 & 1,50 & -- & -- \\
\cline { 2 - 8 } $\begin{array}{c}\text { Operações de } \\
\text { transferência }\end{array}$ & Gasocicletas & -- & -- & 1,40 & 1,20 & -- & -- \\
\cline { 2 - 8 } & Álcool & -- & -- & $0,17^{(2)}$ & $0,23^{(2)}$ & -- & -- \\
\hline
\end{tabular}

Tabela 2.3. FE dos veículos em uso na RMSP considerados nas simulações. ${ }^{(1)} F E$ para CO e NOx obtidos de medidas experimentais em túneis nos anos 2004 (Martins et al., 2006) e 2011 (Nogueira et al., 2013), ${ }^{(2)} F E$ estimados a partir da contribuição relativa dos processos de transferência de combustível na emissão total e os demais $F E$ obtidos por meio de protocolos em dinamômetro (CETESB, 2005; CETESB, 2010).

A contribuição do diesel na emissão do $C O$ foi obtida através da ponderação pelo número de veículos. Para os outros poluentes no túnel Rodoanel, a contribuição do diesel na emissão total foi estimada pela subtração da contribuição dos veículos leves, através da seguinte equação:

$$
\Delta[\mathrm{P}]_{\mathrm{D}}=\Delta[\mathrm{P}]-\Delta[\mathrm{CO}]\left(1-\mathrm{f}_{\mathrm{D}}\right)\left(\frac{\Delta[\mathrm{P}]_{\mathrm{JQ}}}{\Delta[\mathrm{CO}]_{\mathrm{JQ}}}\right)
$$

Onde $\Delta[P]_{D}$ é a componente do poluente atribuída ao diesel; $\Delta[C O]\left(1-f_{D}\right)$ é a fração do $\Delta[C O]$ no túnel Rodoanel atribuída aos veículos leves; finalmente $\Delta[P]_{J Q} / \Delta[C O]_{J Q}$ é a razão da emissão para os veículos leves, medida no túnel Jânio Quadros.

\subsubsection{Distribuição espacial das emissões}

Com o objetivo de distribuir espacialmente as emissões na grade de $3 \mathrm{~km}$ foi aplicada uma metodologia que faz uma relação entre ocupação urbana e densidade de 
veículos. Para a caracterização da ocupação urbana, utilizaram-se dados de satélite de Intensidade de Luzes Noturnas $(I L N)$ fornecidas pelo sensor Operational Linescan System $(O L S)$ do Defense Meteorological Satellite Program (DMSP) (http://www.ngdc.noaa.gov/dmsp/downloadV4composites.html\#AXP) em uma escala de intensidade variando de 0 (sem luzes) a 63 (luzes saturadas), com resolução espacial de 30 segundos de arco, para regiões compreendidas entre $-180^{\circ}$ e $180^{\circ}$ de longitude e entre $-65^{\circ}$ e $75^{\circ}$ de latitude. É importante ressaltar que a ILN está associada, em geral, à ocupação urbana. Estudos anteriores mostram uma boa correlação entre o número de veículos e a ILN (ainda que com uma grande dispersão, reflexo das diferenças de uma localidade para outra em termos de fatores socioeconômicos e ambientais) para os maiores conglomerados urbanos do Brasil (Martins et al., 2008). Considerando essas aproximações utilizaram-se as ILN para estimar o número de veículos em cada ponto de grade, sendo esse cálculo a base da distribuição espacial das emissões na grade de $3 \mathrm{~km}$.

Por outro lado, para a grade de $1 \mathrm{~km}$ foi utilizado um mapa de emissão diária de $C O$ na $R M S P$ compilado pelo International Environmental Database (IED) para o ano base 2009 (Lents et al., 2012). Este produto, de $1 \mathrm{~km}$ de resolução espacial, é a construção de um inventário georreferenciado para os poluentes emitidos em uma determinada área, neste caso a RMSP. A distribuição da emissão de poluentes foi normalizada pela de $C O$, calculada com o IED. Diferentemente ao caso da grade de 3 $\mathrm{km}$ em que o número de veículos é estimado como sendo proporcional à ILN (imagem de satélite correspondente ao ano 2009), no caso da grade de $1 \mathrm{~km}$ esta informação corresponde aos dados oficiais fornecidos pela DETRAN. Uma representação visual das matrizes numéricas utilizadas para distribuir espacialmente as emissões nas grades de 3 e $1 \mathrm{~km}$ são mostradas nas figuras 2.3 e 2.4 , respectivamente.
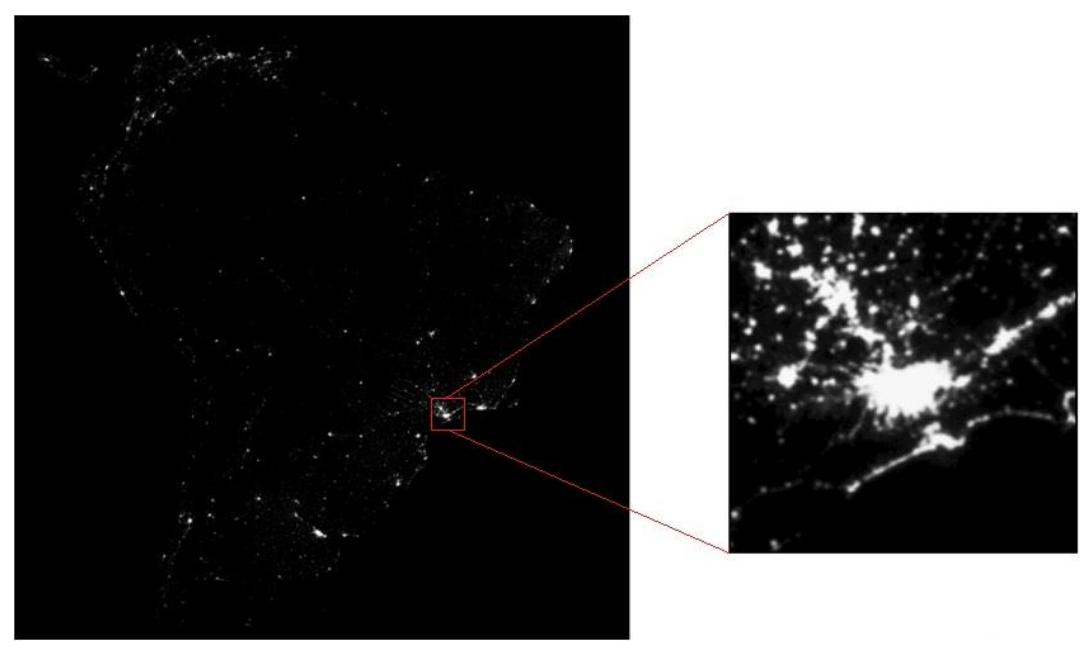

Figura 2.3. Imagem de satélite de Intensidade de Luzes Noturnas (ILN) para América do Sul no ano 2009, mostrando uma ampliação da área de estudo. 


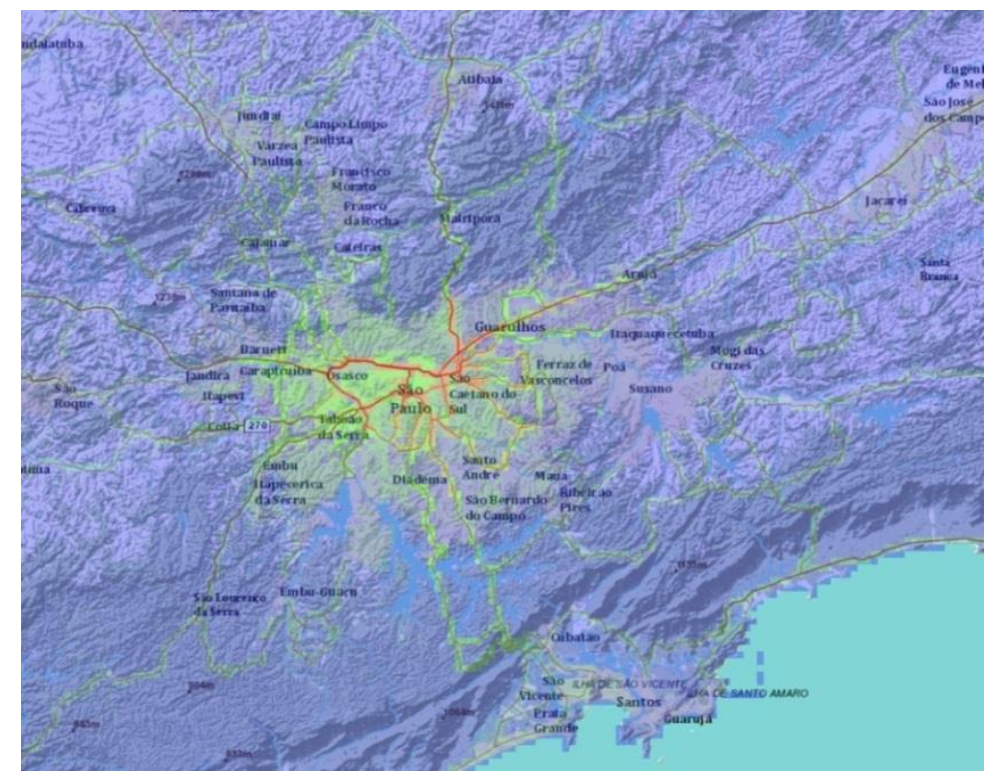

Figura 2.4. Mapa de emissão diária do $C O$ na $R M S P$ compilado a partir do International Environmental Database (IED) para o ano base 2009.

\subsubsection{Distribuição temporal de emissão de poluentes}

Devido à complexidade que significaria conhecer a variação temporal das emissões em cada ponto de grade, foram considerados neste estudo os perfis temporais de emissão veicular obtidos no interior dos túneis de tráfego Jânio Quadros e Rodoanel (campanha experimental 2011) através de medições experimentais de contagens de tráfego (tipos de veículos), como sendo os perfis diários das emissões para todos os pontos $(x, y)$ da grade a se tratar, por exemplo, como os perfis considerados no estudo realizado por Tie et al., 2007 (perfil médio entre dias 'weekday' e 'weekend'). No caso dos $C O V$, os perfis de emissão para os 15 agrupamentos (ver tabela 8.2 no apêndice B) no mecanismo químico da fase gasosa utilizado, o RADM2, foram considerados como sendo iguais ao perfil diário do $\mathrm{CO}$, por serem estes poluentes $(\mathrm{CO}$ e $\mathrm{COV})$ traçadores característicos dos veículos leves, enquanto que o $N O x$ é emitido majoritariamente pelos veículos pesados à diesel. A figura 2.5 mostra os perfis de emissão utilizados para distribuir as emissões totais nos pontos de grade ao longo do dia. Uma descrição mais detalhada do esquema considerado para calcular as taxas de emissão nas grades de 3 e 1 $\mathrm{km}$ pode ser consultada no apêndice C. As massas totais diárias dos poluentes considerados $(\mathrm{CO}, \mathrm{NOx}$ e $\mathrm{COV})$ foram emitidas persistentemente de hora em hora para a atmosfera desde a superfície durante os 6 dias de simulação (2 dias de 'spin-up') considerados para cada um dos períodos estudados. 


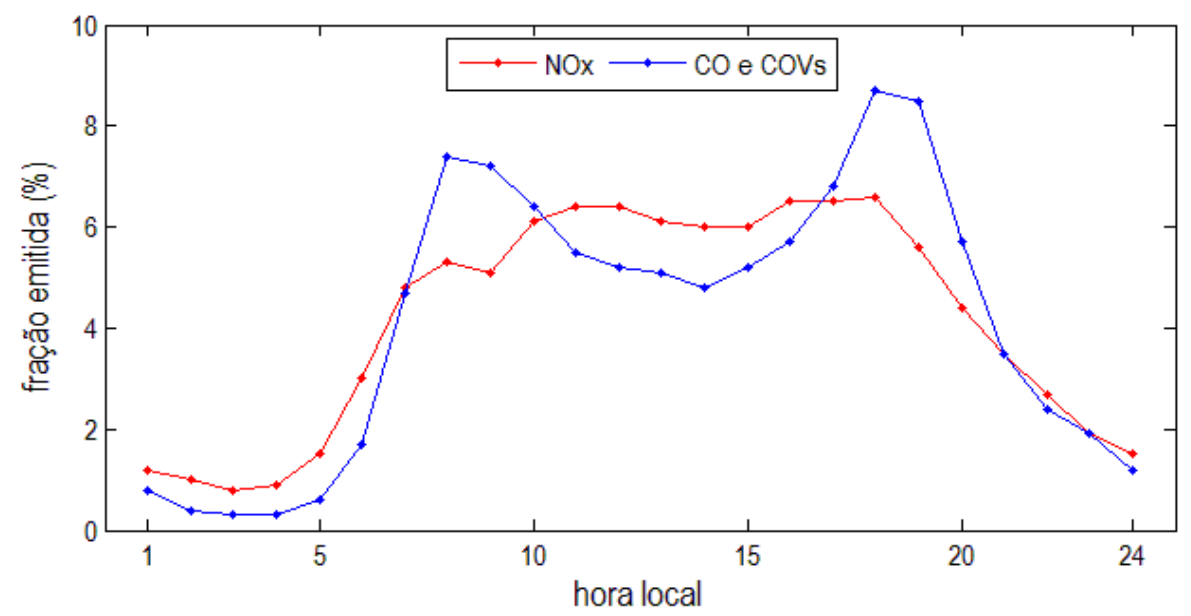

Figura 2.5. Perfis horários de emissão considerados para distribuir as emissões totais ao longo do dia, para os poluentes primários.

A tabela 2.4 apresenta as emissões totais estimadas de $C O, N O x$ e $C O V$ para os anos 2004 e 2011 nas grades de 3 e 1 km, respectivamente, e os valores extraídos do inventário de emissões da CETESB. A tabela 2.4 mostra também um cálculo estimado da razão molar $C O V / N O x$ considerando um $C O V$ médio da forma $C_{n} H_{2 n+2} \operatorname{com} 5,32$ átomos de carbono unidos a dois átomos de hidrogênio cada um.

\begin{tabular}{|l|c|c|c|c|c|}
\cline { 2 - 6 } \multicolumn{1}{c|}{} & \multicolumn{4}{c|}{ Emissões estimadas RMSP $(* 1000$ ton/ano) } \\
\cline { 2 - 6 } \multicolumn{1}{c|}{} & Grade $1 \mathrm{~km}$ & Grade $3 \mathrm{~km}$ & CETESB & Grade $1 \mathrm{~km}$ & Grade 3 km \\
\hline CO & 1842,6 & 1710,2 & 1706,1 & 1086,2 & 849,2 \\
\hline NOx & 271,6 & 254,0 & 356,5 & 123,2 & 155,8 \\
\hline COV & 327,0 & 325,0 & 392,5 & 257,0 & 213,8 \\
\hline COV/NOx & 3,9 & 4,1 & 3,5 & 6,7 & 4,4 \\
\hline
\end{tabular}

Tabela 2.4. Emissões totais consideradas nas simulações para resoluções de 1 e 3 km, emissões totais extraídas do inventário de fontes da CETESB e razão molar entre $C O V$ e NOx.

\subsubsection{Campos meteorológicos}

Os campos meteorológicos usados nas simulações foram as análises NCEP FNL Operational Model Global Tropospheric Analyses (http://rda.ucar.edu/datasets/ds083.2/) do Global Data Assimilation System (GDAS). Estas informações contam com uma resolução horizontal de $1^{\circ} \times 1^{\circ}, 26$ níveis verticais e estão disponíveis a cada 6 horas. 


\subsubsection{Configuração e características das simulações}

Foram feitas três simulações. A primeira correspondente ao período do ano 2004 (06-09 setembro), a segunda correspondente ao período do ano 2011 (12-15 novembro) e a terceira correspondente a um cenário idealizado, com os $F E$ referentes ao ano de 2004 atuando no período estabelecido para o ano 2011, configurando assim um cenário em que não houve melhorias nas emissões de 2011 com relação ao ano de 2004. Numericamente, o modelo foi configurado para ser executado em um domínio com quatro grades aninhadas: grade 1 com $70 \times 70$ pontos e $27 \mathrm{~km}$ de espaçamento de grade; grade 2 com 100x100 pontos e $9 \mathrm{~km}$ de espaçamento de grade; grade 3 com 118x118 pontos e $3 \mathrm{~km}$ de espaçamento de grade e grade 4 com 100x100 pontos e $1 \mathrm{~km}$ de espaçamento de grade. Todas elas centradas na $R M S P: 23.550^{\circ} \mathrm{S}$ e $46.633^{\circ} \mathrm{O}$ (ver figura 2.6) com o módulo de descrição dos processos químicos, o $R A D M 2$, acionado apenas nas grades de 3 e $1 \mathrm{~km}$. O 'downscaling' dinâmico foi feito nas duas formas existentes no WRF, ou seja, no modo 'two-way-nesting' para as grades de 27 e $9 \mathrm{~km}$ e no modo 'one-way-nesting' para as grades de 3 e 1 km. Foram utilizadas essas opções em função dos limitados recursos computacionais disponíveis. As simulações correspondentes às grades de 3 e $1 \mathrm{~km}$ foram inicializadas com a química 'default' do modelo, sendo de dois dias o tempo considerado para estabilidade numérica ou 'spin-up'. A tabela 2.5 mostra um resumo das principais configurações de grade, condições de contorno e inicialização usadas nas simulações de ambos os períodos de estudo.

\begin{tabular}{|c|c|c|c|c|}
\hline \multicolumn{5}{|c|}{ Características do domínio } \\
\hline Grade & $27 \mathrm{~km}$ & $9 \mathrm{~km}$ & $3 \mathrm{~km}$ & $1 \mathrm{~km}$ \\
\hline$(\mathrm{nx}, \mathrm{ny}, \mathrm{nz})$ & $(70,70,35)$ & $(100,100,35)$ & $(118,118,35)$ & $(100,100,35)$ \\
\hline Dados geográficos & $10^{\prime}$ & 2 & $30 \mathrm{~s}$ & $30 s+3 s$ \\
\hline \multicolumn{5}{|c|}{ Condições iniciais e de contorno } \\
\hline \multicolumn{2}{|c|}{ Meteorologia } & \multicolumn{3}{|c|}{ Química (limite inferior) } \\
\hline Campos meteorológicos & NCEP FNL & Emissões veicl & res & LAPAt/IAG \\
\hline Resolução horizontal & $1^{\circ} \mathrm{x} 1^{\circ}$ & Resolução hor & ntal & 3 e $1 \mathrm{~km}$ \\
\hline Resolução temporal & $6 \mathrm{~h}$ & Resolução tem & & $1 \mathrm{~h}$ \\
\hline Número níveis verticais & 26 & Número de nív & s verticais & 1 (superfície) \\
\hline Espessura 1ra camada & $57 \mathrm{~m}$ (default) & Espessura da $p$ & meira camada & $0 \mathrm{~m}$ \\
\hline \multicolumn{5}{|c|}{ Inicialização } \\
\hline Período 1 & \multicolumn{4}{|c|}{$0409200400 Z$} \\
\hline Período 2 & \multicolumn{4}{|c|}{$1011201100 Z$} \\
\hline Tempo de simulação & \multicolumn{4}{|c|}{6 dias (48h spin-up) } \\
\hline Frequência das saídas & \multicolumn{4}{|c|}{$1 \mathrm{~h}$} \\
\hline
\end{tabular}

Tabela 2.5. Configurações iniciais e de contorno utilizadas nas simulações numéricas. 


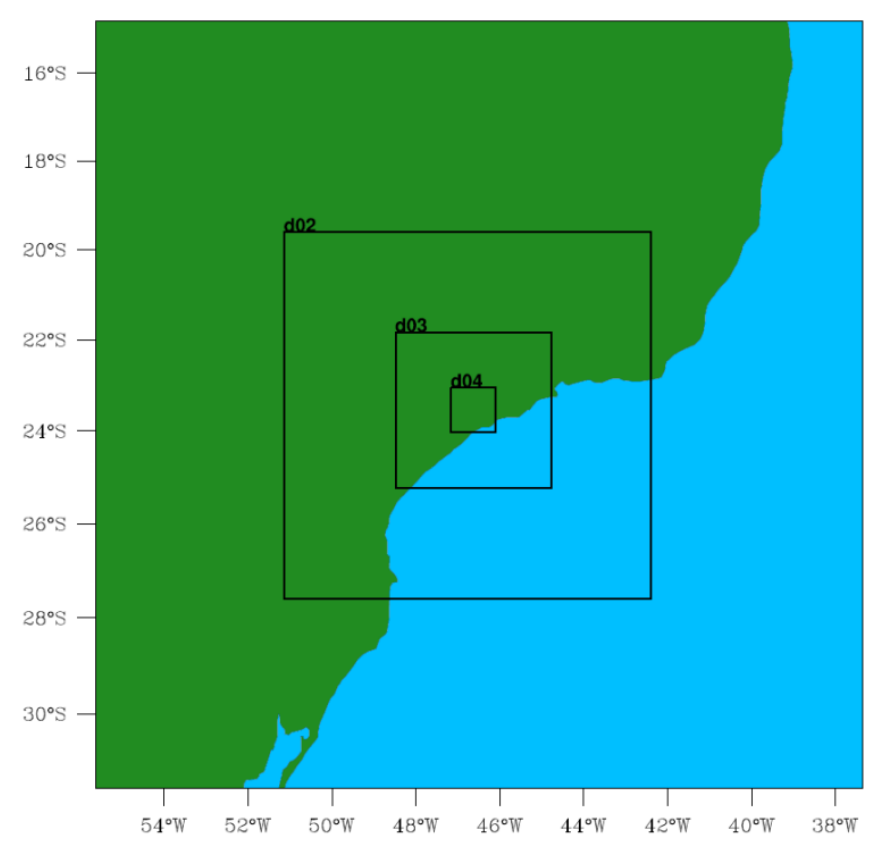

Figura 2.6. Domínio da simulação com a indicação das quatro grades utilizadas.

A topografia considerada para a grade de $1 \mathrm{~km}$ foi construída com dados topográficos de três segundos de arco fornecidos pelo sensor Shuttle Radar Topography Mission (SRTM) da NASA, enquanto que a topografia considerada para a grade de $3 \mathrm{~km}$ foi calculada a partir dos dados topográficos de 30 segundos de arco fornecidos pelo modelo de elevação digital GTOPO30 desenvolvido pelo USGS. A figura 2.7 mostra as topografias consideradas para as grades de 3 e $1 \mathrm{~km}$, respectivamente.
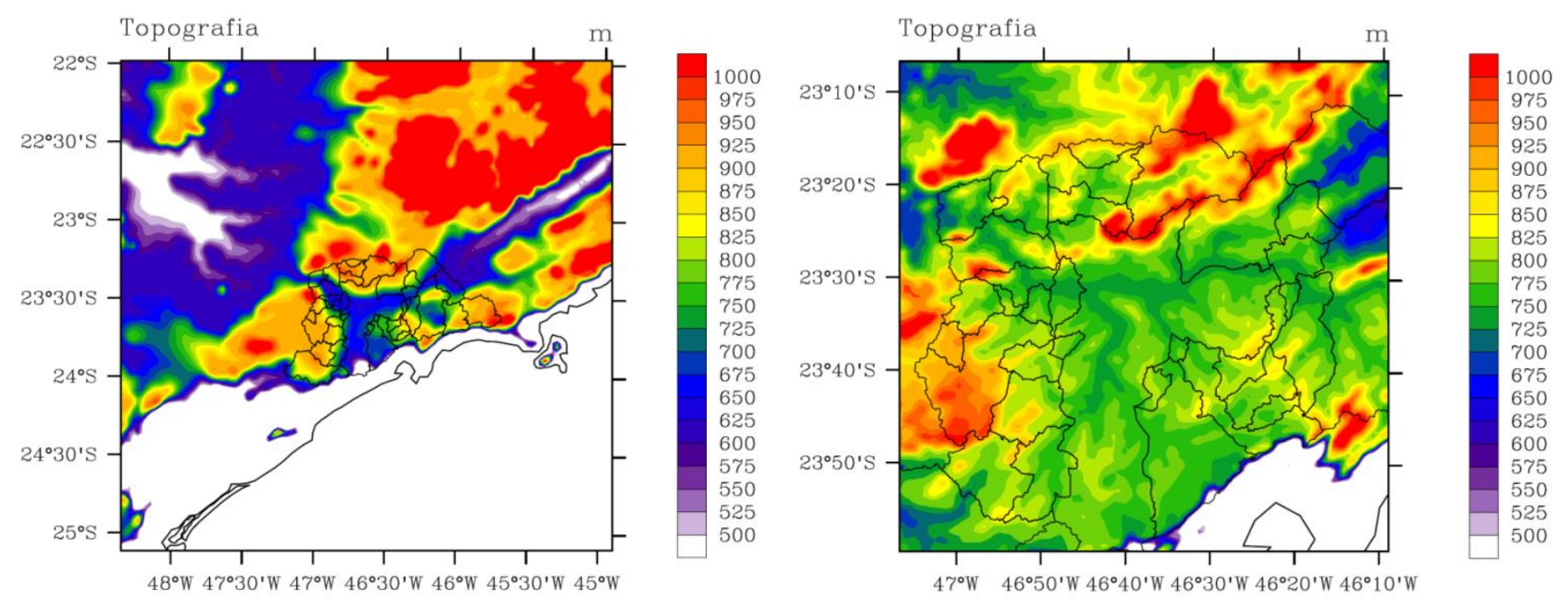

Figura 2.7. Topografias consideradas para as grades de 3 (esquerda) e $1 \mathrm{~km}$ (direita), respectivamente. 
A figura 2.8 mostra as taxas de emissão de $N O x$ para as grades de 3 e $1 \mathrm{~km}$ às 18h, hora local, resultados dos cálculo descritos anteriormente e correspondentes para um dia qualquer do ano 2011.

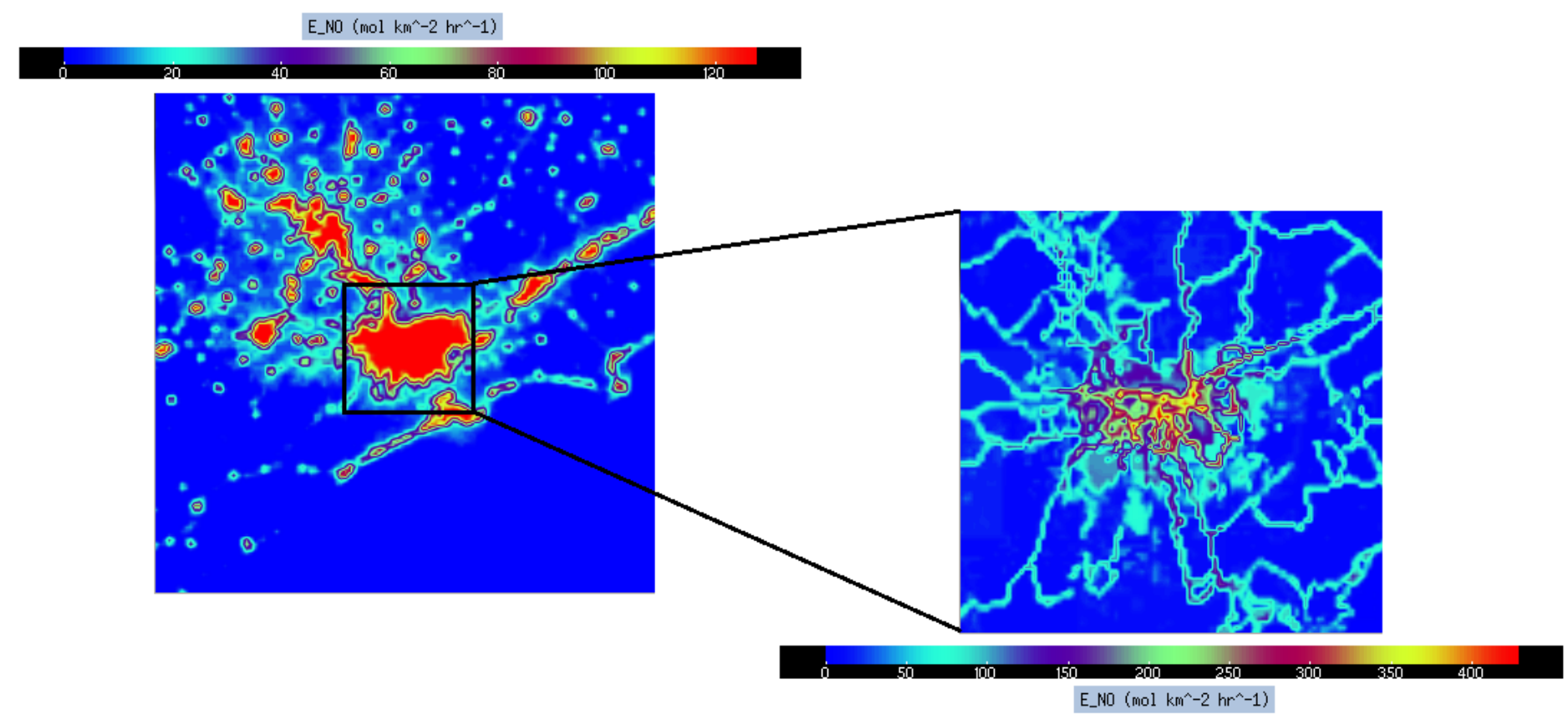

Figura 2.8. Taxas de emissão do NOx às $18 \mathrm{~h}$, hora local, para as grades de 3 (lado esquerdo) e $1 \mathrm{~km}$ (lado direito) para o ano 2011.

Finalmente, para avaliar o impacto que as características da frota veicular circulante na $R M S P$ no ano 2004 teriam na formação do ozônio troposférico para um período de observação deste poluente em 2011, simulou-se um cenário de emissão em 2011 (período de 12-15 novembro) com os fatores de emissão referentes ao ano de 2004. Com os resultados deste experimento hipotético e os previamente obtidos da segunda simulação (período de 12-15 novembro de 2011 com as emissões referentes para esse ano), conseguiu-se avaliar em uma perspectiva espaço/temporal a formação de ozônio troposférico que resultaria se no ano 2011 os veículos tivessem apresentado as mesmas características de uso que eles tinham no ano 2004. Os resultados mostraram, como será visto no capítulo 4, que não só a quantidade dos precursores do ozônio é importante para sua formação, mas também a proporção em que eles se encontram na atmosfera. 


\subsubsection{Testes estatísticos utilizados para avaliação das simulações}

Para avaliar o desempenho do modelo na representação das variáveis meteorológicas e de concentração observadas, foi aplicada uma série de testes estatísticos utilizados em inúmeros trabalhos de investigação relacionados com a caracterização físico-química do ozônio troposférico.

\subsubsection{Coeficiente de correlação de Pearson $(r)$}

Este parâmetro quantifica o grau de linearidade entre duas variáveis, sendo neste estudo as variáveis observadas e simuladas. É definido como a razão da covariância das duas variáveis e o produto dos seus correspondentes desvios padrões.

$$
r_{x y}=\frac{\operatorname{Cov}(x, y)}{s_{x} s_{y}}=\frac{\sum_{i=1}^{N}\left(x_{i}^{\prime} y_{i}^{\prime}\right)}{\left[\sum_{i=1}^{N}\left(x_{i}^{\prime}\right)^{2}\right]^{1 / 2}\left[\sum_{i=1}^{N}\left(y_{i}^{\prime}\right)^{2}\right]^{1 / 2}}
$$

Onde $x_{i}^{\prime}=x_{i}-x$ e $y_{i}^{\prime}=y_{i}-y$ e $N$ o número de dados. A correlação de Pearson tem duas propriedades importantes. A primeira delas é que está limitado por -1 e 1 , ou $-1 \leq r \leq 1$. Se $r=-1$, existe uma perfeita relação linear negativa entre as variáveis. Similarmente se $r=1$ existe uma perfeita relação linear positiva. A segunda propriedade é que o seu quadrado, $r^{2}$, especifica a proporção da variabilidade de uma das duas variáveis que é linearmente representada ou descrita pela outra (Wilks, 2006).

\subsubsection{Desvio padrão $(\sigma)$}

O desvio padrão, $\sigma$, é um parâmetro estatístico muito útil para avaliar a variabilidade ou dispersão média de uma série de dados. É definido pela raiz quadrada da média da diferença quadrática entre cada valor da série de dados com a média da mesma. 


$$
\sigma=\left[\frac{\sum_{i=1}^{N}\left(\phi_{i}-\phi_{o}\right)^{2}}{N}\right]^{1 / 2}
$$

Onde $\phi_{i}$ e $\phi_{o}$ representam os valores individuais e a média do conjunto de dados.

\subsubsection{Raiz do erro médio quadrático (RMSE)}

Sua formulação matemática é parecida com a do desvio padrão, com a diferença de que a diferença é feita entre as variáveis que se quer comparar. Dado que apresenta a mesma unidade física que as observações, este parâmetro é interpretado como uma magnitude típica para representar os erros das simulações.

$$
R M S E=\left[\frac{\sum_{i=1}^{N}\left(\phi_{i}-\phi_{o b s}\right)^{2}}{N}\right]^{1 / 2}
$$

Onde $\phi_{i}$ e $\phi_{o b s}$ são os pares simulados e observados, respectivamente.

\subsubsection{Raiz do erro médio quadrático UB $\left(R M S E_{U B}\right)$}

O $R M S E_{U B}$ é o RMSE da diferença entre os desvios simulados e observados, ou seja, após remover as médias dos valores simulados e observados.

$$
\operatorname{RMSE}_{U B}=\left[\frac{\sum_{i=1}^{N}\left[\left(\phi_{i}-\phi_{o}\right)-\left(\phi_{o b s}-\phi_{i o b s}\right)\right]^{2}}{N}\right]^{1 / 2}
$$


Onde $\phi_{o}$ e $\phi_{i o b s}$ são os valores médios dos valores simulados, $\phi_{i}$, e observados, $\phi_{\text {obs }}$, respectivamente. As expressões matemáticas usadas para o cálculo do $\sigma, R M S E \mathrm{e}$ $R M S E_{U B}$ foram consideradas de Pielke, 2002, que sugere ainda uma boa representação estatística dos valores observados quando:

- $\sigma \sim \sigma_{o b s}$

- $R M S E<\sigma_{o b s}$

- $R M S E_{U B}<\sigma_{o b s}$

\subsubsection{5. Índice de concordância $(d)$}

O índice de concordância não é uma medida de correlação ou associação no sentido formal e sim uma medida do grau na qual os valores simulados estão "livres". Este índice varia entre 0 e 1 , onde um valor de 1 indica prefeita concordância entre os valores observados e simulados e um valor de 0 implica uma discordância absoluta (Willmott, 1981).

$$
d=1-\frac{\sum_{i=1}^{N}\left(P_{i}-O_{i}\right)^{2}}{\sum_{i=1}^{N}\left(\left|P_{i}\right|+\left|O_{i}\right|\right)^{2}}
$$

Onde $O_{i}$ e $P_{i}$ são os valores observado e simulado, respectivamente.

\subsubsection{Acurácia da previsão média do pico de ozônio $\left(\mathrm{PO}_{3}\right)$}

É obtida calculando-se a média da diferença entre os picos diários simulados e observados de ozônio, normalizado pelo pico observado. Um valor 0 indica que os valores preditos acima e os preditos abaixo do valor observado se cancelam (Martins, 2006). A expressão matemática utilizada para o cálculo deste índice foi considerada de Seinfeld e Pandis, 2006, sendo simplificada para o caso temporal.

$$
P O_{3}=\frac{1}{N} \sum_{i=1}^{N}\left(\frac{P_{i}-O_{i}}{O_{i}}\right)
$$


Onde $P_{i}$ e $O_{i}$ são os valores simulados e observados, respectivamente.

\subsubsection{Diagrama de Taylor}

Este diagrama proporciona uma representação visual bidimensional de três parâmetros estatísticos: coeficiente de correlação $(r)$, variância $\left(\sigma^{2}\right)$ e raiz do erro médio quadrático (RMSE); indicando quão próximo um padrão simulado se aproxima do observado. Na figura 2.9 é apresentado um exemplo do diagrama.

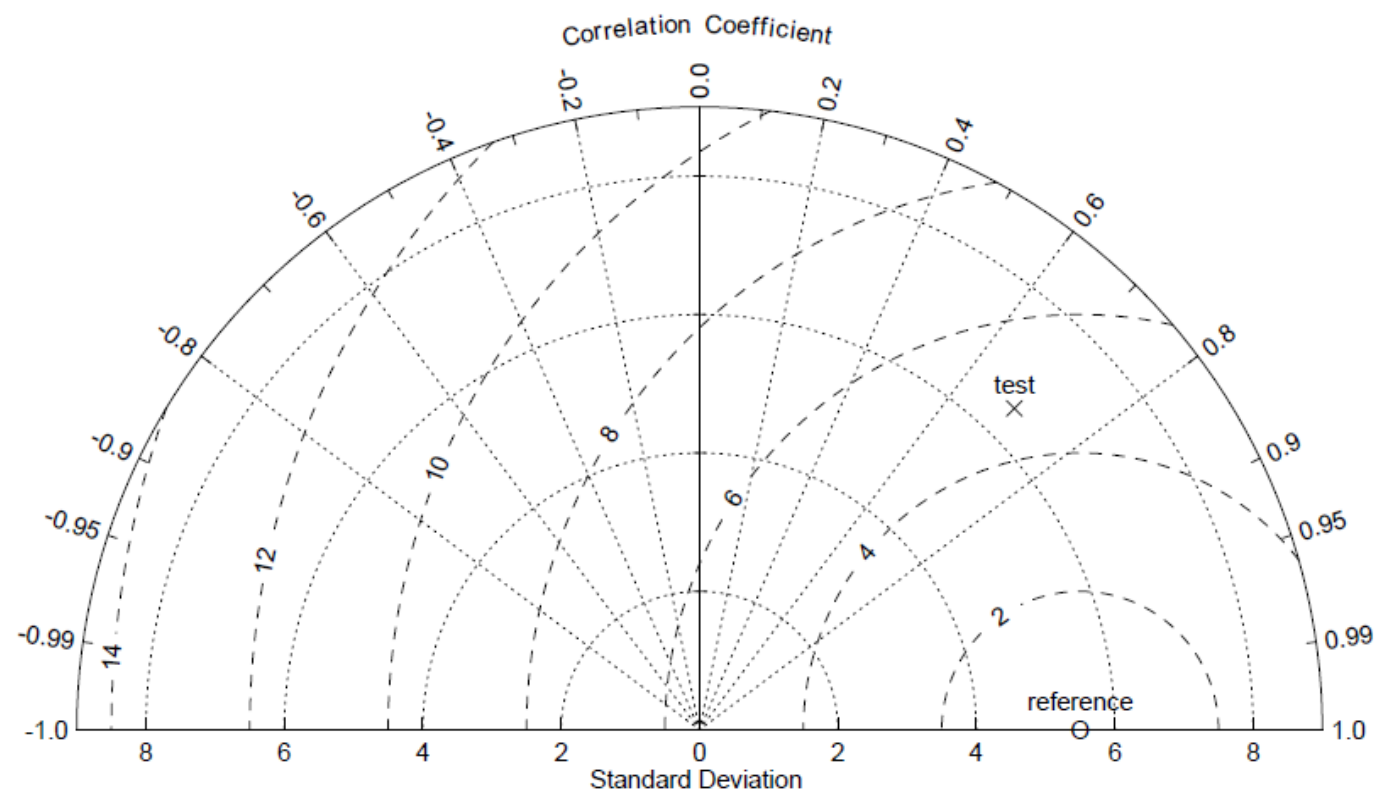

Figura 2.9. Diagrama de Taylor. A distância radial desde a origem é proporcional ao desvio padrão de um determinado campo "test". A diferença do RMSE entre o "test" e o campo de referência é proporcional a sua distância de separação. O coeficiente de correlação entre os dois campos é dado pela posição azimutal do "test” (Fonte: Taylor, 2001). 


\section{3. ÁREA E PERÍODO DE ESTUDO}

\section{1. Área de estudo}

A Região Metropolitana de São Paulo (RMSP), localizada a $23^{\circ} \mathrm{S}$ e $46^{\circ} \mathrm{W}$ na porção sudeste Brasil (ver figura 3.1), é um dos maiores conglomerados urbanos do mundo com uma população superior a 19 milhões de habitantes segundo o Instituto Brasileiro de Geografia e Estatística $(I B G E)$ com base no último censo demográfico realizado em 2010. O sítio urbano situa-se na Bacia Sedimentar de São Paulo, cujo principal vale é o do Rio Tietê, orientado no sentido Leste-Oeste, com uma altitude média de 720 m e uma extensa planície de inundação. Essa bacia é cercada ao norte pela Serra da Cantareira, também orientada no sentido Leste-Oeste e com altitudes que atingem até $1200 \mathrm{~m}$, e a Leste-Sul pelo reverso da Serra do Mar, com altitudes que, em geral, ultrapassam 800 m. Está distante 45 km do Oceano Atlântico (CETESB, 2010).

O clima da região é caracterizado por um inverno seco entre junho-agosto e um verão úmido entre dezembro-março. As médias mensais mínimas e máximas acumuladas de precipitação ocorrem durante agosto $(35 \mathrm{~mm})$ e fevereiro $(255 \mathrm{~mm})$, respectivamente (Oliveira et al., 2002). Durante o período úmido, grandes áreas de instabilidade alimentadas pela umidade proveniente do interior do continente se formam na região Sul e Sudeste do Estado de São Paulo, iniciando-se mais cedo no sul da região, em decorrência da atuação das frentes frias (Cavalcanti et al., 2009), organizando, dessa forma, intensa atividade convectiva e aumentando sobremaneira a precipitação na faixa leste do Estado onde se encontra a RMSP (CETESB, 2010), características associadas com a permanência da Zona de Convergência do Atlântico Sul $(Z C A S)$ por períodos prolongados sobre a região Sudeste. A ZCAS tem um papel fundamental na modulação da precipitação sobre a região mais populosa do Brasil, a qual possui centros urbanos com densidade de habitantes entre as maiores do mundo, como é o caso da cidade de São Paulo. A influência dos controles de grande e de mesoescala, como latitude, maritimidade e circulação induzida por topografia, é maior, refletindo-se em uma distribuição espacial em sentido mais latitudinal, com diminuição dos volumes na direção SE-NW, em sentido do interior do continente. Em anos de maior aquecimento do oceano, as chuvas começam mais cedo, ou ocorre um atraso quando as temperaturas da superfície do mar são mais frias (Cavalcanti et al., 2009). 
Cavalcanti et al., 2009 cita ainda estudos anteriores que encontraram que dez dos municípios do sudeste que registram mais raios estão na $R M S P$, com descargas atmosféricas que estariam associadas as condições atmosféricas inerentes dessa região e ao crescimento urbano, e que propiciariam maiores instabilidades. No período seco a região encontra-se sob o domínio dos anticiclones subtropical e polar. Os anticiclones que atuam nesse período são de dois tipos: os anticiclones polares que podem ser continentais ou marítimos e o anticiclone subtropical marítimo. Os sistemas frontais, provenientes do extremo sul do continente, atuam de maneira rápida na região, causando normalmente pouca precipitação (CETESB, 2010). Além disso, alguns estudos mostram que o desenvolvimento urbano acelerado da região ocasionou o processo de formação de ilha de calor urbana provocando algumas mudanças no clima da região. Pereira et al., 2007 indicam um aumento da temperatura e diminuição da umidade relativa na RMSP após analisar eventos de enchente relacionados com a ilha de calor urbana e brisa marítima. O estudo também sugere que tais mudanças sejam em parte devido a fatores locais, tais como o aumento da área urbana horizontal (modificando o balanço energético superficial) e vertical (modificando a rugosidade superficial e dinâmica da camada limite). Freitas et al., 2007 realizaram experimentos numéricos para estudar a interação entre a ilha de calor urbano e as circulações de brisa marítima durante o inverno na $R M S P$, encontrando que a presença da região urbana intensifica a magnitude da frente da brisa marítima aproximadamente em $0.32 \mathrm{~m} / \mathrm{s}$ quando comparada com a situação hipotética desta (a cidade) não existir, além de frear o avanço da brisa no centro da cidade durante um tempo aproximado de duas horas, levando, por convergência de grande quantidade de umidade desde a superfície para níveis superiores na atmosfera urbana. Associadas a esse fenômeno estão as alterações na composição das precipitações, cada vez mais acidificadas, e o padrão das distribuições espacial menos uniforme e temporal mais concentrada (Cavalcanti et al., 2009). Vemado, 2012 encontrou que a interação entre as circulações locais de brisa marítima e ilha de calor urbano geraram tempestades, inundações e enxurradas na RMSP.

Entre outros sistemas meteorológicos que atuam sobre a RMSP estão os bloqueios atmosféricos. O bloqueio atmosférico, numa descrição sinótica, corresponde a uma anomalia persistente de alta pressão, com deslocamento meridional característico em relação às trajetórias normais médias das perturbações atmosféricas nos subtrópicos e 
latitudes médias. Seu impacto sinótico mais relevante é o de agir como uma barreira para a migração dos sistemas meteorológicos transientes provenientes de latitudes mais altas (Cavalcanti et al., 2009).

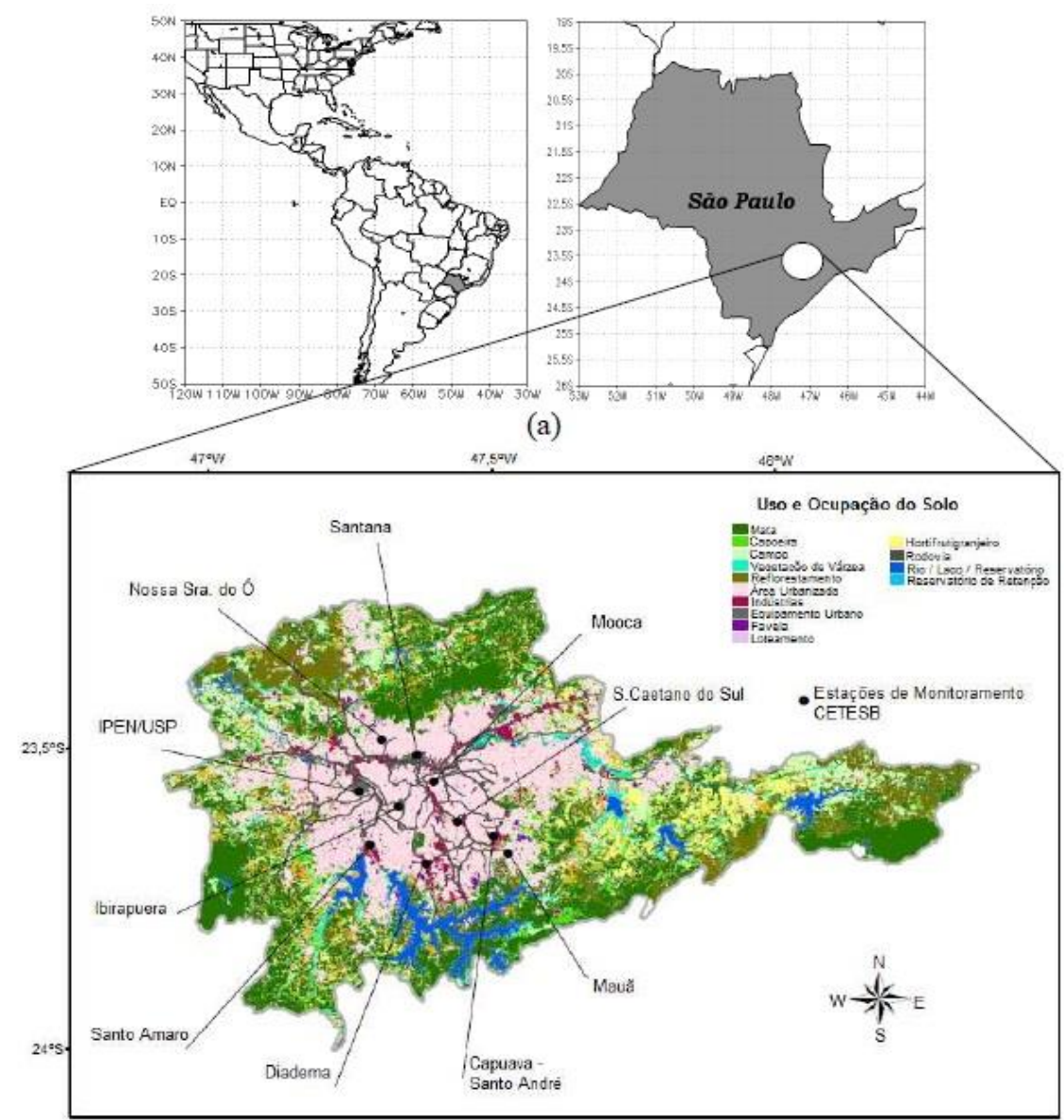

Figura 3.1. Localização da área de estudo (Fonte: Silva Junior, 2009).

\subsection{Períodos de estudo}

Foram definidos dois períodos de estudo, em 2004 e 2011. Esses períodos foram escolhidos em função da existência de dados de fatores de emissão veiculares calculados a partir de experimentos em túneis. Martins et al., 2006 e Sánchez-Ccoyllo et al., 2009, descrevem o experimento de 2004 apresentando os fatores de emissão para gases e partículas, respectivamente. Para 2011, os resultados estão sendo apresentados por Nogueira et al., 2013. As escolhas dos dias nesses períodos de estudo estiveram de acordo com características como: maior número de estações com mais do que o $75 \%$ dos dados válidos e ocorrências de ultrapassagens do $P Q A$ para o ozônio. 


\subsubsection{Período 1: 06-09 de setembro de 2004}

Este período representa um episódio típico de condições meteorológicas favoráveis à formação do ozônio observado durante o final do inverno. Registrou-se um total de 24 ultrapassagens do PQA $\left(160 \mu \mathrm{g} / \mathrm{m}^{3}\right)$ em 21 estações de monitoramento da CETESB localizadas na RMSP (Martins, 2006). Das onze estações da rede de monitoramento da CETESB analisadas para o ozônio (ver tabela 8.3 no apêndice D), apenas a estação Pinheiros não apresenta ultrapassagens do $P Q A$ no período estudado. A máxima concentração de ozônio registrada foi de $234 \mu \mathrm{g} / \mathrm{m}^{3}$ na estação Santo Amaro às $16 \mathrm{~h}$, hora local.

A análise sinótica para o mês de setembro mostra que os sistemas frontais atuaram com fraca intensidade ocasionando poucas chuvas sobre a Região Sudeste. Houve predomínio de desvios negativos de precipitação em toda a região. Apenas no litoral do Estado de São Paulo, os totais acumulados de precipitação excederam os 50 mm, devido principalmente à passagem do segundo sistema frontal entre os dias 11 e 12 de setembro (Climanálise, 2004). As estações meteorológicas do IAG-USP na Água Funda e do INMET em Santana não registraram de precipitação durante este período. A figura 3.3 mostra uma sequencia de oito imagens do satélite GOES no canal do infravermelho para América do Sul, podendo-se destacar a atuação persistente de uma massa de ar seco com ausência de nuvens e alta radiação solar durante todo o período de estudo, fatores que contribuíram para o estabelecimento de condições meteorológicas favoráveis à formação do ozônio. Séries temporais de nebulosidade e vento correspondentes à estação meteorológica do IAG-USP para o período de estudo são mostradas na figura 3.2.

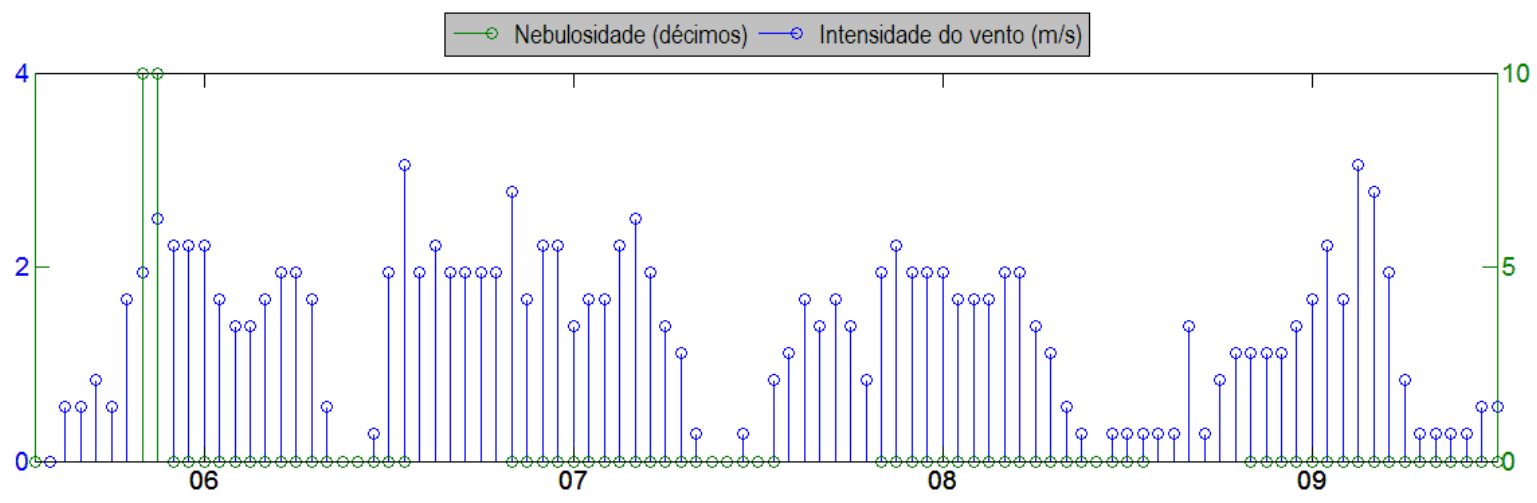

Figura 3.2. Séries temporais de nebulosidade (décimos) e intensidade do vento $(\mathrm{m} / \mathrm{s})$ na estação IAG-USP para o período de 06 a 09 de setembro de 2004. 
2004-09-06-12097

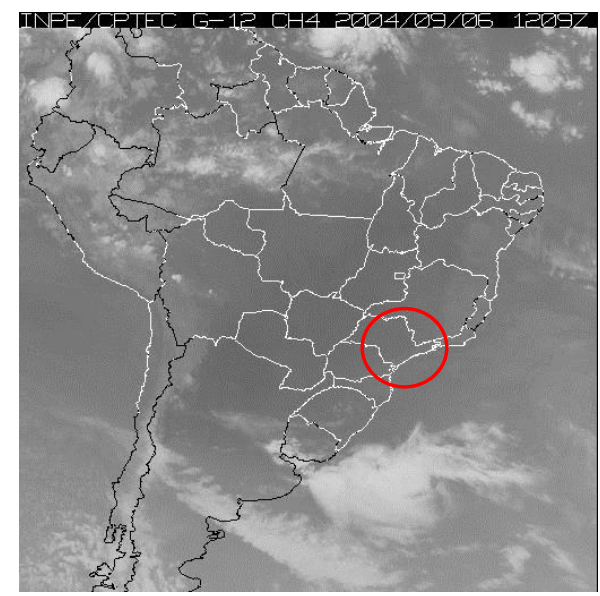

2004-09-08-1209Z

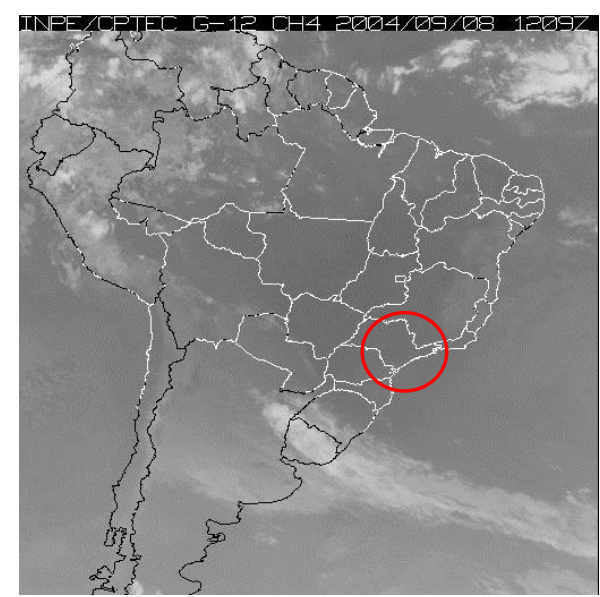

2004-09-06-18097

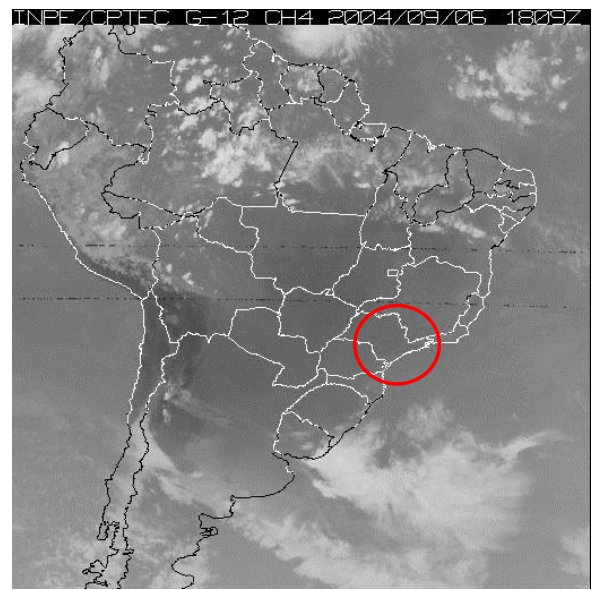

2004-09-08-1809Z

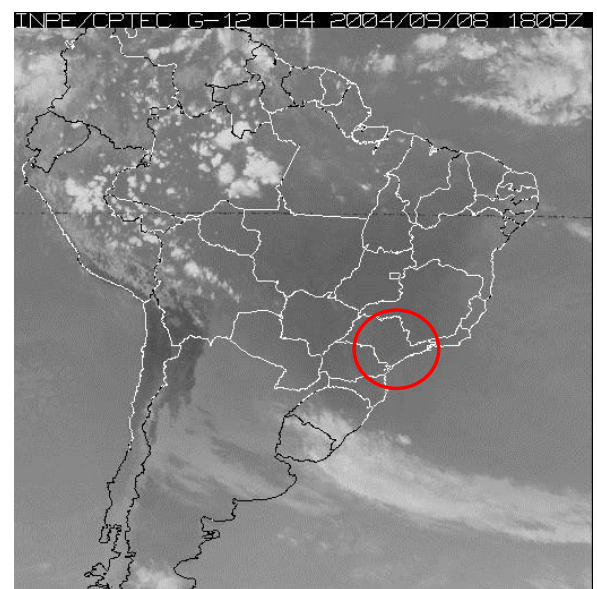

2004-09-07-1209Z

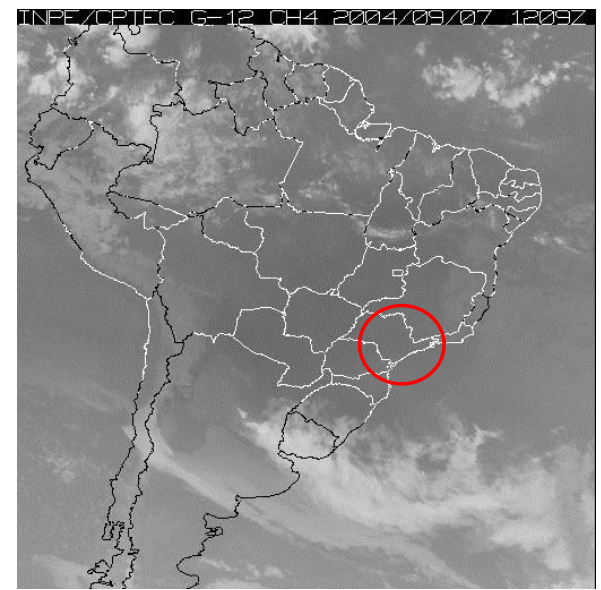

2004-09-09-1209Z

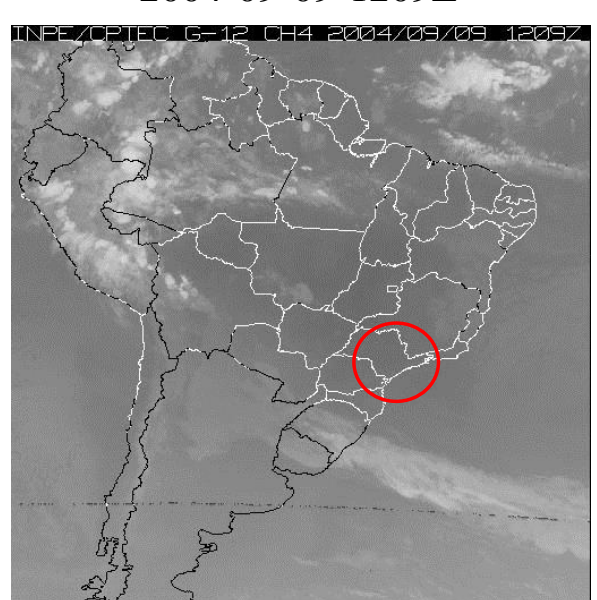

2004-09-07-1809Z

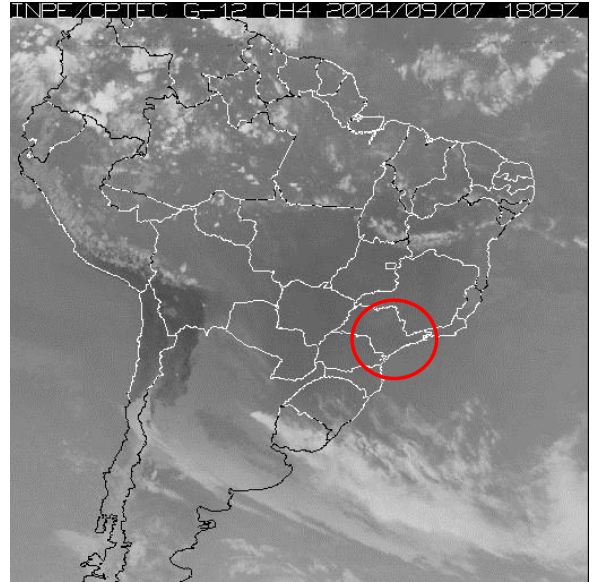

2004-09-09-1739Z

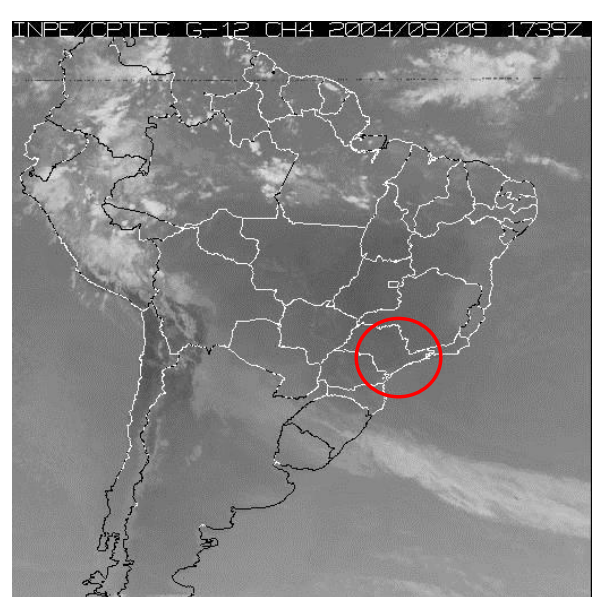

Figura 3.3. Imagens GOES no canal do infravermelho para América do Sul correspondentes ao período de 06 a 09 de setembro de 2004 . Os círculos vermelhos ilustram a localização da área de estudo. 


\subsubsection{Período 2: 12-15 de novembro de 2011}

O período selecionado para o ano de 2011 (12-15 de novembro) apresentou um número menor de ultrapassagens do $P Q A$ nas 10 estações analisadas (ver tabela 8.4 no apêndice D) quando comparado ao número de ultrapassagens no período analisado em 2004. É importante destacar que ao longo do ano 2011 não houve um episódio de altas concentrações de ozônio tão prolongado como aquele observado em setembro do ano 2004. O mês de novembro foi o mês que apresentou o maior número de ultrapassagens do PQA na RMSP com 12 de acordo com as medições realizadas em todas as estações fixas, além das móveis Horto-Florestal e Itaquera (CETESB, 2012a), sendo apenas 4 as observadas no período estudado.

Em termos sinóticos, apenas uma das quatro frentes atuantes no território brasileiro durante o mês de novembro foi observada no período de estudo, originando-se de um centro de baixa pressão que se formou próximo ao litoral do estado de São Paulo entre os dias 14 e 15. No entanto, no dia 12, a presença de um cavado na média e alta troposfera, associado a elevados valores de temperatura e umidade do ar na baixa troposfera formaram áreas de instabilidade no centro-sul do Brasil, em particular no Mato Grosso do Sul e São Paulo, com ocorrência de temporais e granizo (Climanálise, 2011). Similarmente ao primeiro período, a figura 3.5 mostra uma sequencia de oito imagens do satélite GOES para América do Sul, e onde se pode observar a constante nebulosidade associada com as áreas de instabilidade formadas no centro-sul e com a passagem de um sistema frontal nos últimos dias do período analisado. A estação meteorológica do $I A G$ registrou céu praticamente encoberto durante todo o período de observação com precipitação principalmente nos dias 14 e 15 (ver figura 3.4).

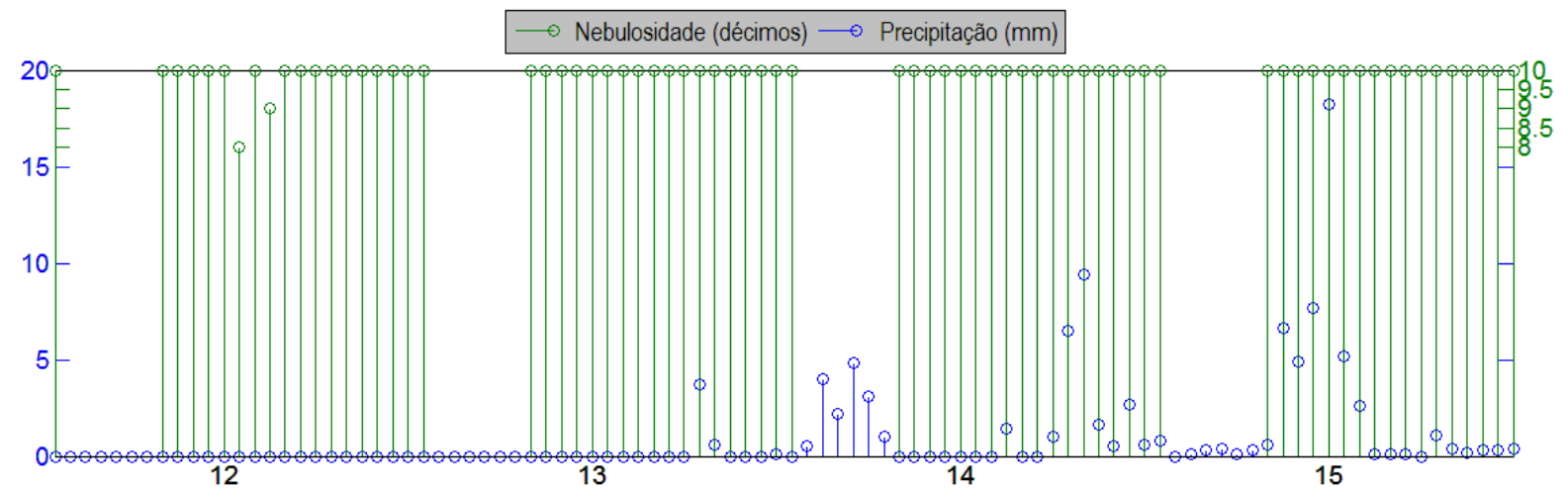

Figura 3.4. Séries temporais de nebulosidade (décimos) e precipitação (mm) na estação climatológica do IAG-USP para o período de 12 a 15 de novembro de 2011. 
2011-11-12-1215Z

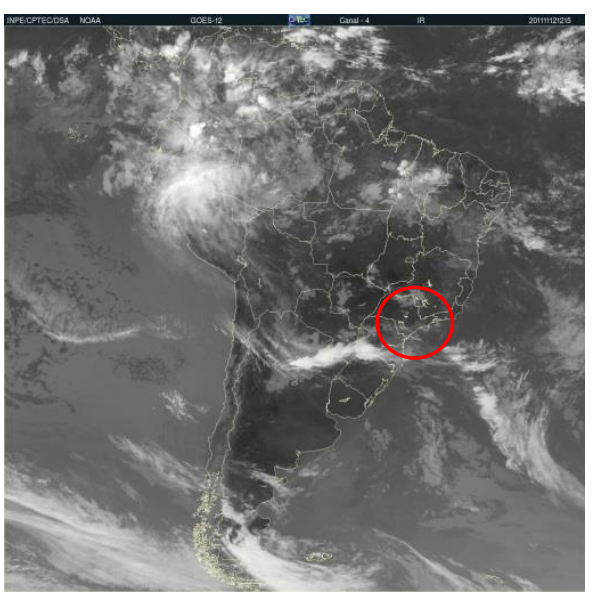

2011-11-14-1215Z

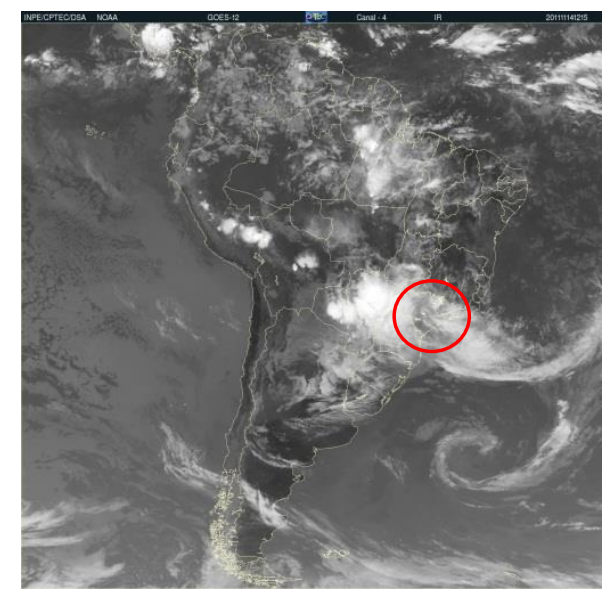

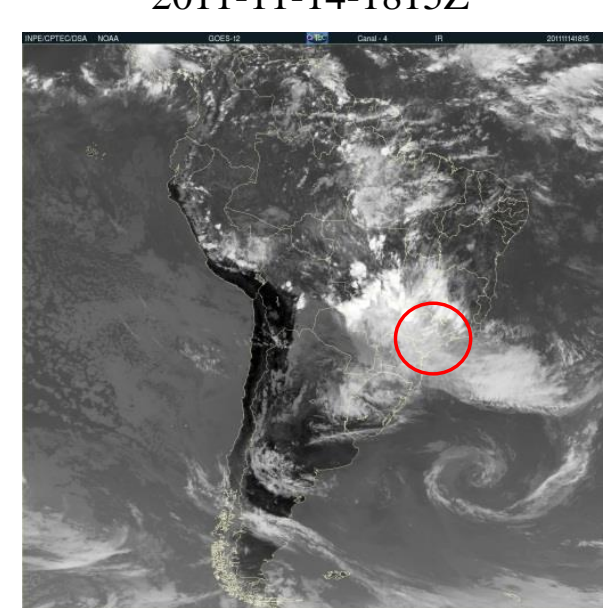

2011-11-13-1215Z
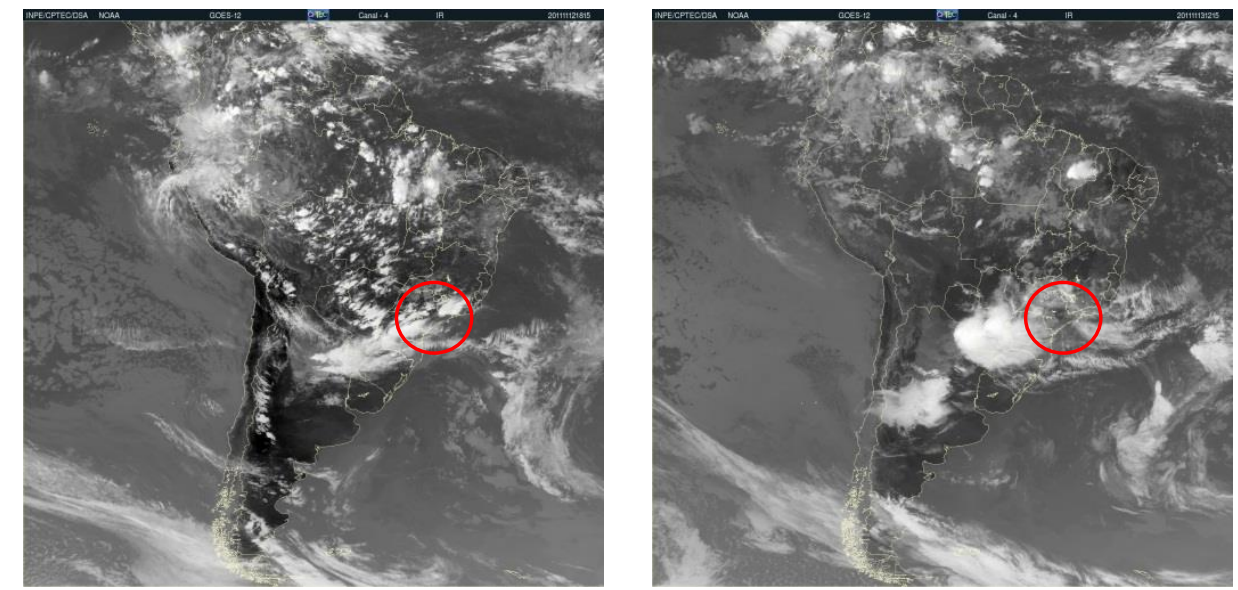

2011-11-15-1215Z

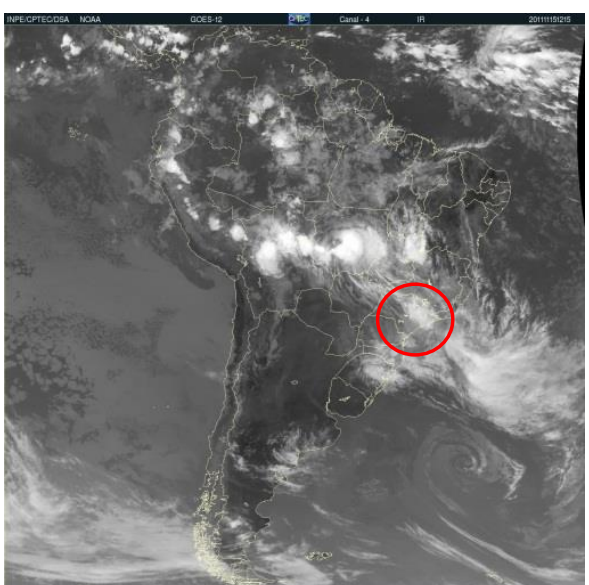

2011-11-13-1815Z

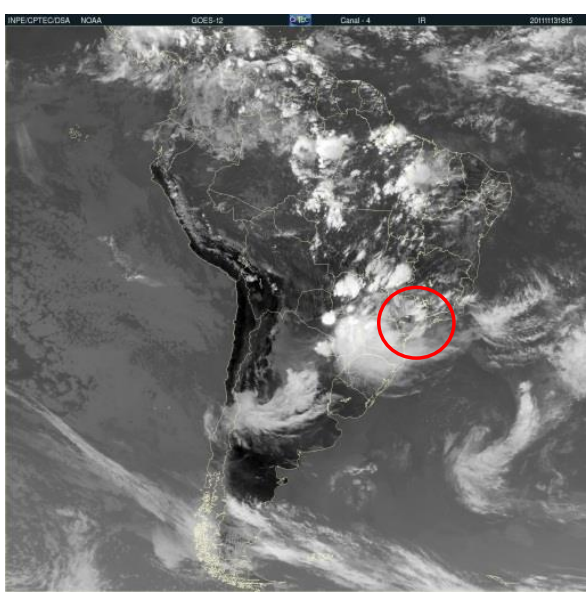

2011-11-15-1815Z

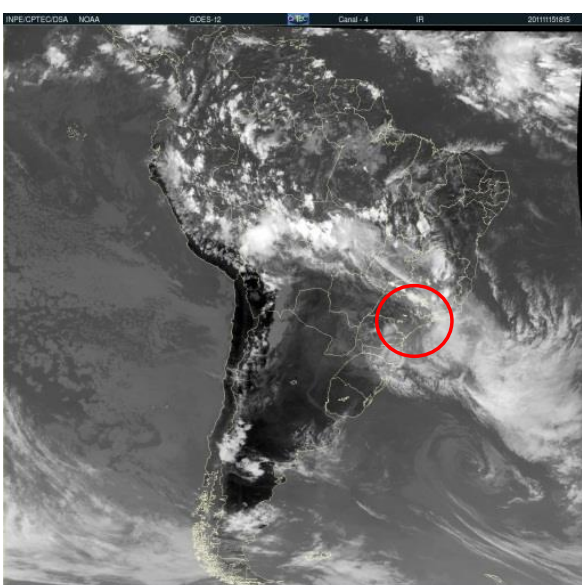

Figura 3.5. Imagens GOES no canal do infravermelho para América do Sul correspondentes ao período de 12 a 15 de setembro de 2004 . Os círculos vermelhos ilustram a localização da área de estudo. 
2011-11-12-0000Z

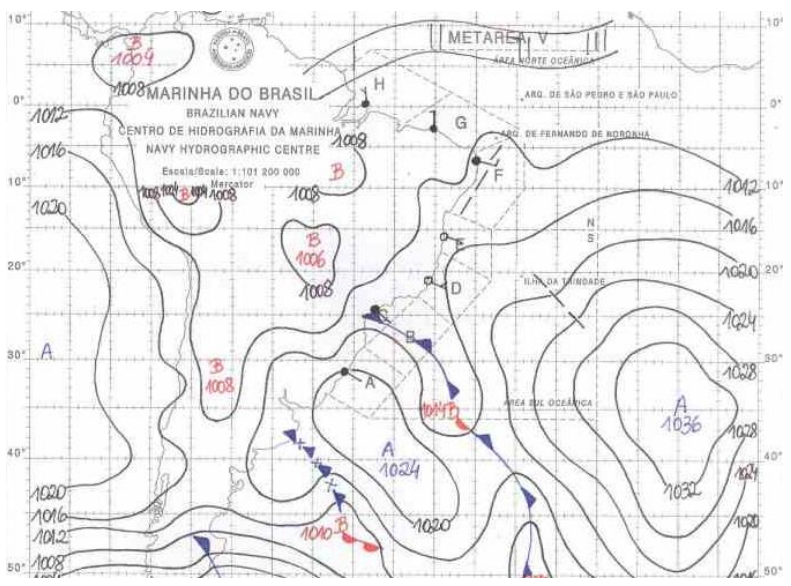

2011-11-13-0000Z

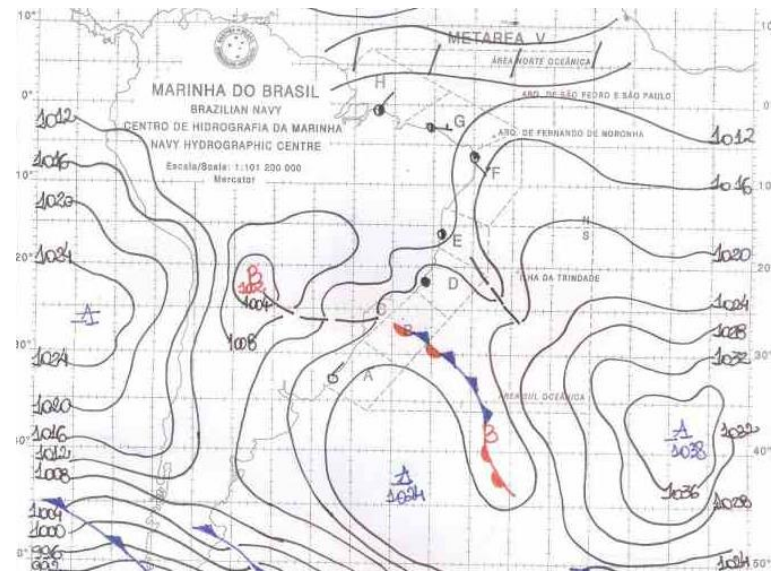

2011-11-12-1200Z

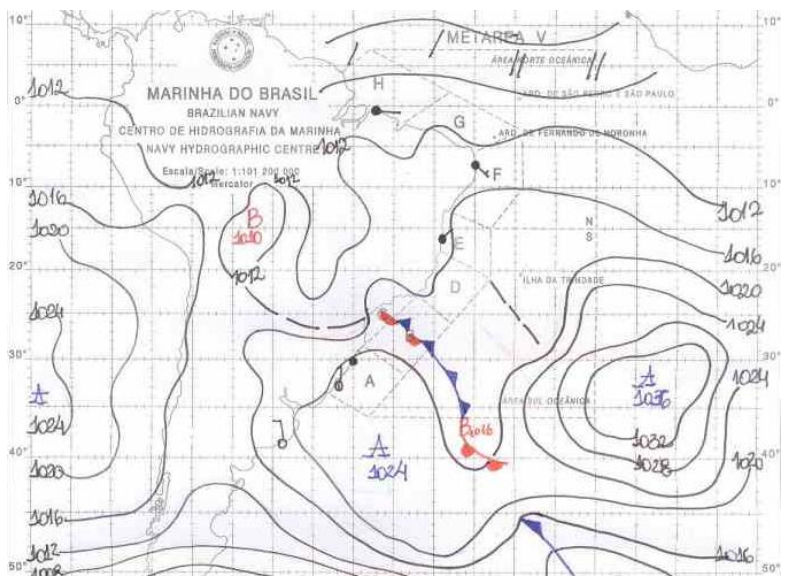

2011-11-13-1200Z

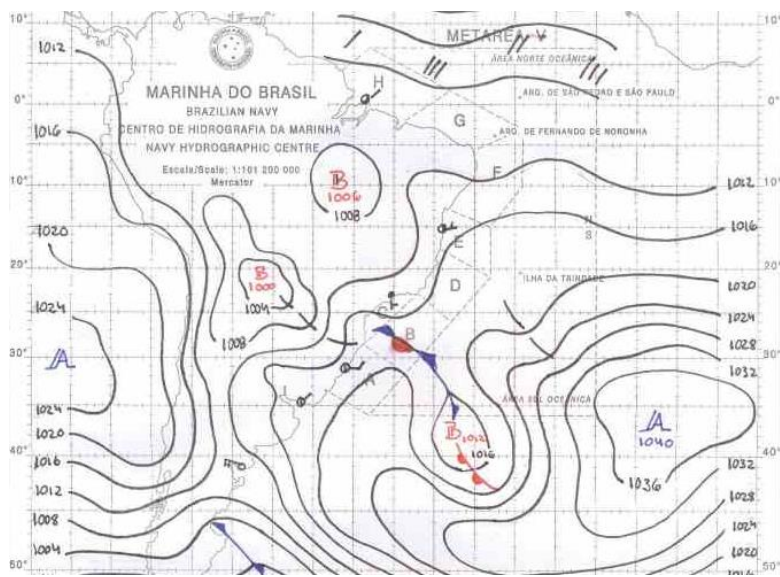

Figura 3.6. Cartas sinóticas para os dias 12 e 13 de novembro de 2011 (Fonte: Diretoria de Hidrografia e Navegação).

As cartas sinóticas elaboradas pela Diretoria de Hidrografia e Navegação ( $D H N)$ da Marinha do Brasil (http://www.mar.mil.br/dhn/chm/meteo/prev/cartas/cartas.htm) para o período de estudo (figuras 3.6 e 3.7) concordam, de forma geral, com o que foi descrito anteriormente. Durante os dias 12 e 13 (figura 3.6) estas cartas indicam um posicionamento máximo norte no litoral sul do estado de São Paulo alcançada pela frente fria que vinha se deslocando desde a faixa litorânea da Argentina nos dias anteriores, assim como uma transição posterior desta para estacionária ou quaseestacionária no seu extremo mais próximo do continente. Observa-se também um cavado (representado pelos traços pretos) atuando na região centro-sul do Brasil ocasionando um desenvolvimento vertical de nuvens convectivas nessa região, e 
relacionadas com as áreas de instabilidade no Mato Grosso do Sul e São Paulo descritas na Climanálise, 2011 para este período.

Por outro lado, durante os dias 14 e 15 (figura 3.7) as cartas mostram outro cavado próximo da região litorânea sul do Estado de São Paulo, gerando um centro de baixa pressão e posteriormente formando uma região de frontogênese com o ramo frio atingindo o continente, ocasionando temporais com acumulados significativos de chuva. Na estação meteorológica do $I A G$, por exemplo, a precipitação acumulada só para o dia 15 foi de $50,8 \mathrm{~mm}$.

2011-11-14-0000Z

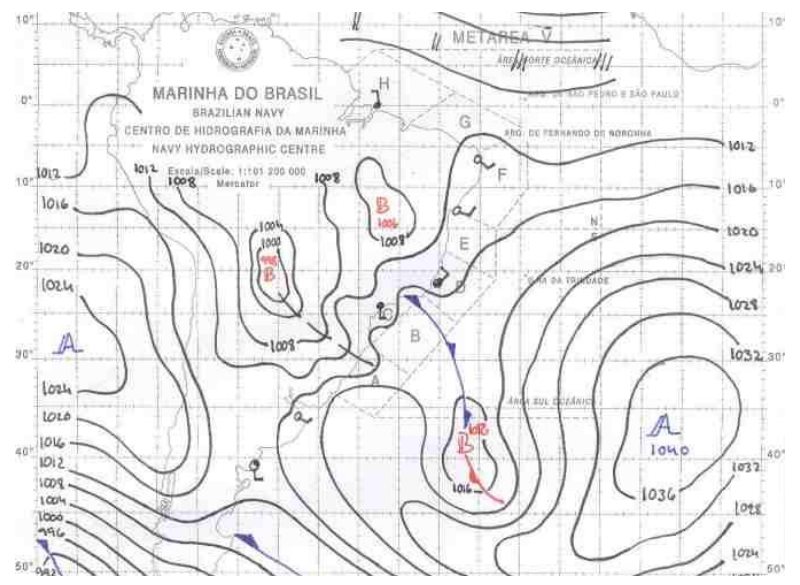

2011-11-15-0000Z

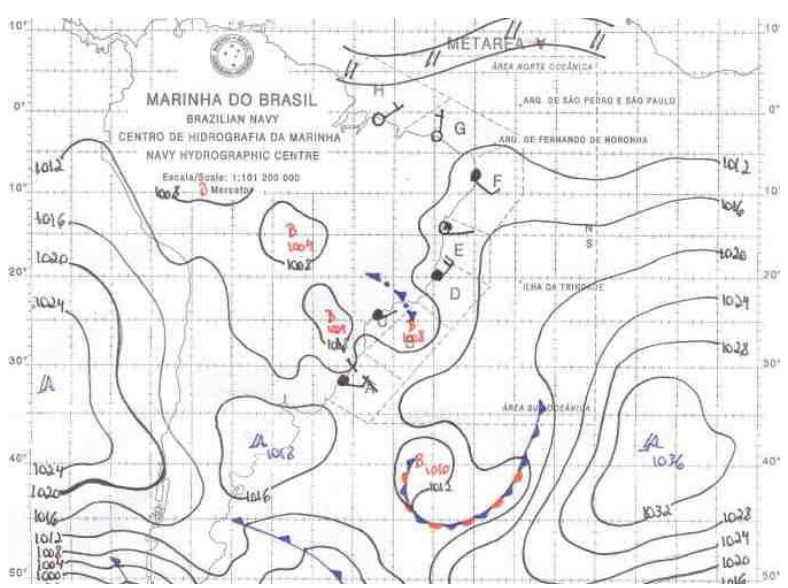

2011-11-14-1200Z

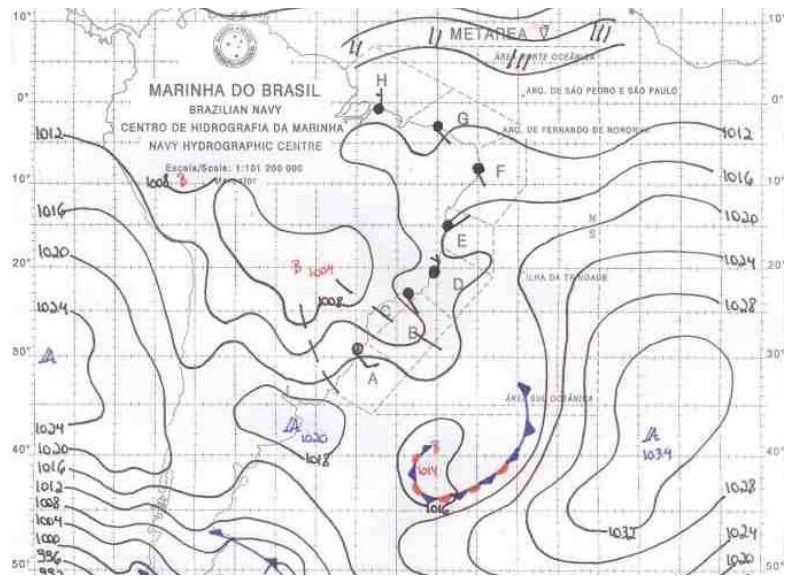

2011-11-15-1200Z

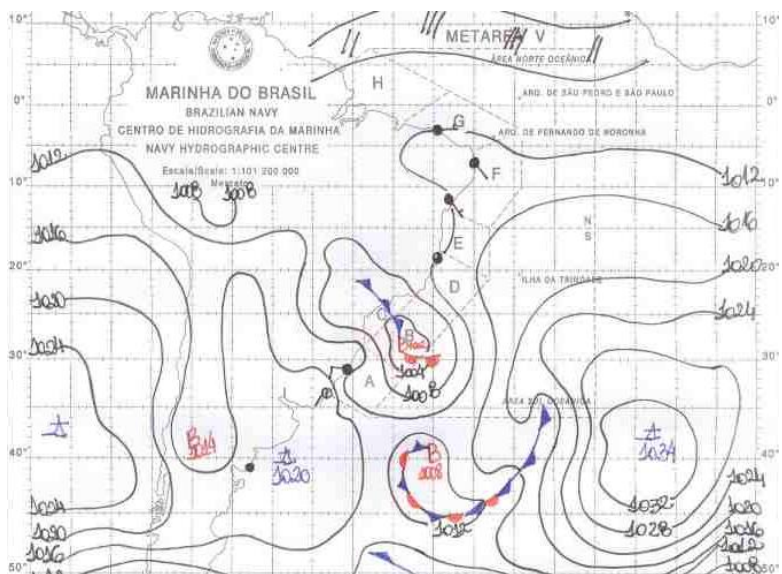

Figura 3.7. Cartas sinóticas para os dias 14 e 15 de novembro de 2011 (Fonte: Diretoria de Hidrografia e Navegação). 


\section{RESULTADOS E DISCUSSÃO}

Neste capitulo serão apresentados os resultados obtidos referentes às simulações de concentração de poluentes com o modelo WRF-Chem. Primeiramente, serão apresentados e discutidos os resultados das simulações correspondentes aos dois períodos estudados (cenário 2004 e cenário 2011) para avaliar o desempenho do modelo na representação do ozônio troposférico. Em seguida serão apresentados os resultados das simulações considerando para o período de 2011 os FE referentes ao ano de 2004. As concentrações obtidas com esse cenário serão comparadas com aquelas obtidas com o caso 2011. Para avaliar o grau de incerteza das simulações em relação às observações foram aplicados quatro índices estatísticos: coeficiente de correlação linear de Pearson $(r)$, desvio padrão $(\sigma)$, raiz quadrada do erro médio quadrático $(R M S E)$ e índice de concordância $(d)$. Além desses quatro índices, para o caso do ozônio foi aplicado o viés médio normalizado para representação das concentrações máximas diárias $\left(\mathrm{PO}_{3}\right)$. A seção 2.2.4 descreve suscintamente os testes estatísticos utilizados para avaliar a o desempenho do modelo na simulação das variáveis estudadas. Todas as variáveis observadas analisadas foram comparadas com suas correspondentes simuladas no primeiro nível vertical do modelo: a superfície.

\subsection{Simulação do período de 06-09 de Setembro de 2004}

As comparações entre os valores horários observados e preditos pelo WRF-Chem para as variáveis meteorológicas: temperatura, umidade relativa e vento mostraram que a configuração estabelecida para a grade de $1 \mathrm{~km}$ representou melhor a evolução temporal das observações do que a configuração estabelecida para a grade de $3 \mathrm{~km}$. Em termos de parametrizações físicas há apenas uma diferença: a Camada Limite Planetária. O esquema de $C L P$ utilizado para a grade de $3 \mathrm{~km}$ foi o $Y S U$, entanto que para a grade de $1 \mathrm{~km}$ foi o BOULAC. O critério da escolha deste parâmetro para a grade de $1 \mathrm{~km}$ responde ao fato de ser um esquema de tipo local já testado anteriormente por Silva Junior, 2009 para a RMSP por meio do acoplamento do WRF-Chem com o modelo urbano Urban Canopy Model (UCM). Para a grade de $3 \mathrm{~km}$, foram obtidos resultados estatisticamente melhores para a concentração de ozônio superficial quando comparados 
com o esquema $Y S U$, no entanto, os resultados foram semelhantes nos níveis superiores. Durante os experimentos de sensibilidade para a grade de $1 \mathrm{~km}$ foram testados apenas dois esquemas para a CLP (YSU e BOULAC) e dois esquemas para a radiação de onda curta (MM5 e Goddard). Os outros esquemas como, por exemplo, para a Camada Superficial e Superfície Terrestre foram considerados de acordo com Silva Junior, 2009, resultando nos melhores resultados de simulação com a configuração mostrada na tabela 2.1. A figura 4.1 mostra as séries temporais de temperaturas observadas (pontos pretos) e simuladas para $3 \mathrm{~km}$ (pontos azuis) e $1 \mathrm{~km}$ (pontos vermelhos) em ' ${ }^{\circ} \mathrm{C}$ ' para as estações consideradas neste período (ver tabela 8.3 no apêndice D). Em geral, observase uma representação adequada da evolução temporal observada (ciclo diurno, máximos e mínimos) para ambas grades, embora com uma acurácia maior para a grade de $1 \mathrm{~km}$.
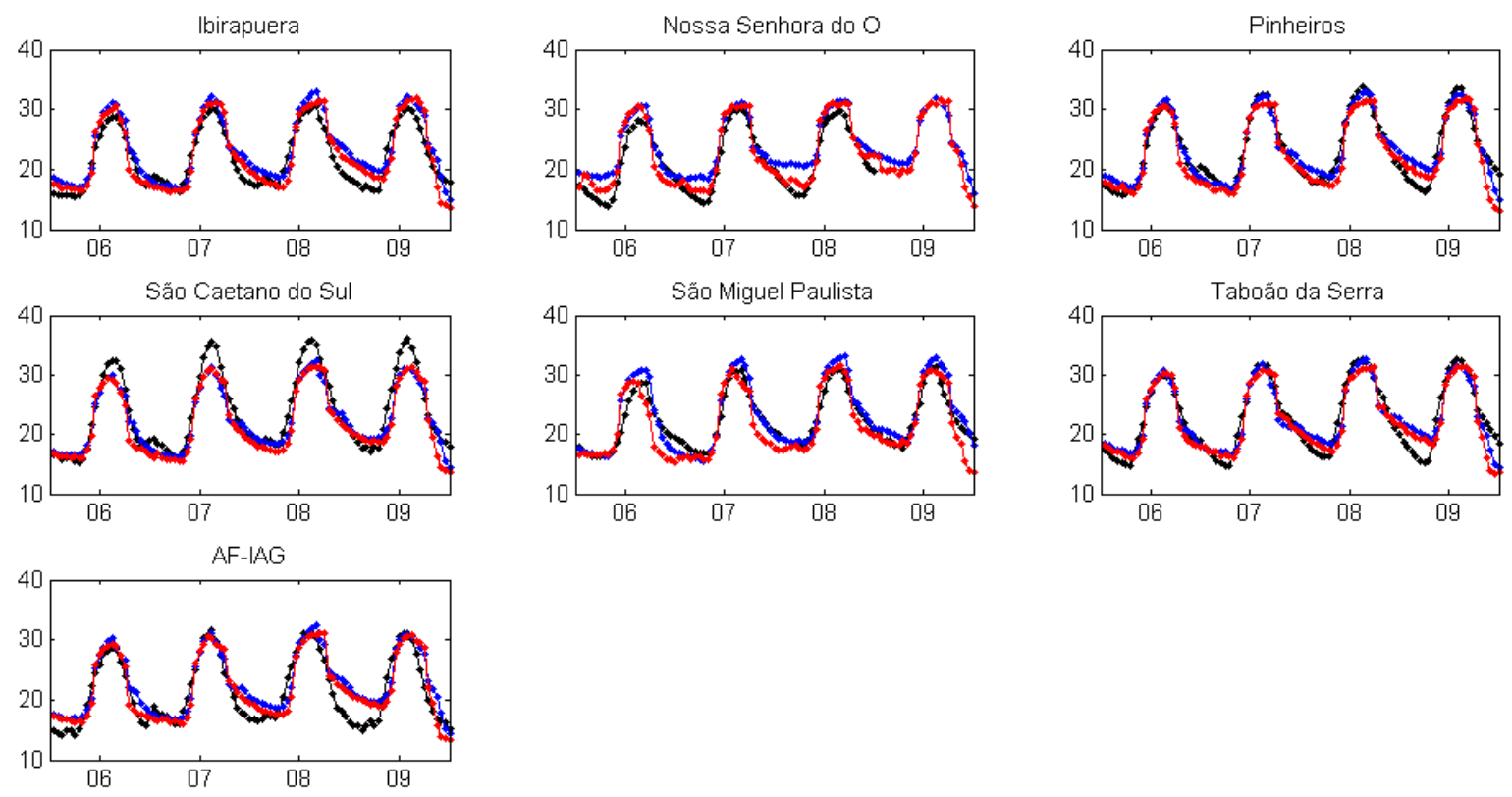

Figura 4.1. Temperatura observada (pontos pretos) e simulada para $3 \mathrm{~km}$ (pontos azuis) e $1 \mathrm{~km}$ (pontos vermelhos) de resolução, em ' ${ }^{\circ} C$ ' para sete estações na $R M S P$ para o período de 06 a 09 de setembro de 2004.

Na tabela 8.5 (ver apêndice E) são apresentados os resultados dos testes estatísticos aplicados para verificação da acurácia da simulação numérica para a temperatura do ar nas estações analisadas. Pode-se notar que para ambas as grades o coeficiente de correlação linear e o índice de concordância são superiores a 0,9 em todas as estações, no entanto, com erros $R M S E$ médios de 2,20 e 2,33 ${ }^{\circ} \mathrm{C}$ para as grades de 3 e 
$1 \mathrm{~km}$ respectivamente. Em termos dos desvios padrões, a grade de $1 \mathrm{~km}$ foi quem representou melhor a dispersão dos valores observados.

Similarmente à temperatura, a umidade relativa para a grade de $1 \mathrm{~km}$, representou melhor, estatisticamente falando, as variações temporais observadas do que para a grade de $3 \mathrm{~km}$, no entanto, com maiores divergências entre os valores máximos observados e simulados. A figura 4.2 mostra as séries temporais de umidade relativa observada (pontos pretos) e simulada a $3 \mathrm{~km}$ (pontos azuis) e $1 \mathrm{~km}$ (pontos vermelhos) em '\%' para sete estações na $R M S P$, as mesmas consideradas no caso da temperatura.
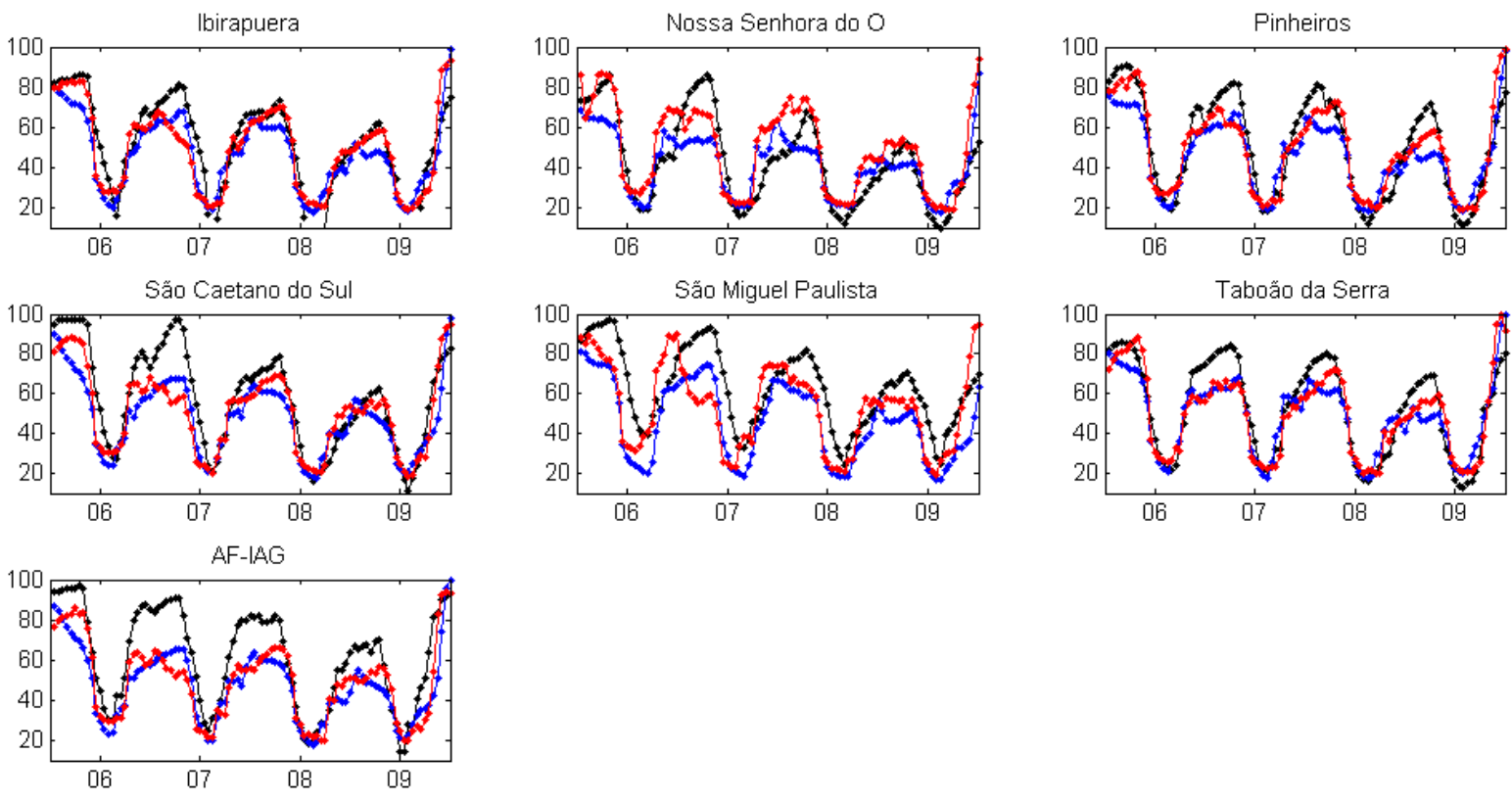

Figura 4.2. Umidade relativa observada (pontos pretos) e simulada a $3 \mathrm{~km}$ (pontos azuis) e $1 \mathrm{~km}$ (pontos vermelhos) em '\%’ para sete estações na RMSP para o período de 06 a 09 de setembro de 2004.

Os resultados dos testes estatísticos para esta variável são apresentados na tabela 8.6 (ver apêndice E). Neste caso os coeficientes de correlação linear e índices de concordância foram superiores a 0,8 na maioria dos casos para ambas as grades, salvo na estação São Miguel Paulista onde se observa uma ligeira defasagem com os valores calculados antecipando as horas de ocorrência dos máximos e mínimos. Os erros RMSE médios foram de 14,0 e 13,2 \% para as grades de 3 e $1 \mathrm{~km}$ respectivamente. Em termos dos desvios padrões, novamente a grade de $1 \mathrm{~km}$ foi, em geral, quem melhor representou a dispersão dos dados. Uma característica observada no final do período para as variáveis simuladas temperatura e umidade relativa é que ambas respondem a 
uma situação pré-frontal evidenciada pela queda na temperatura e o aumento da umidade relativa, no entanto, estas condições (pré-frontais) foram observadas mais acentuadamente após algumas horas de simulação já durante o dia 10 e prévias a passagem do segundo sistema frontal no mês, entre os dias 11 e 12 .

A terceira e última variável meteorológica avaliada foi o vento. Em termos de intensidade (ver figura 4.3), observa-se que os valores calculados pelo modelo, na média, são maiores que as observações, fato claramente observado nas estações Santo Amaro e AF-IAG e menos evidente nas estações Osasco e Santo Andre Capuava.
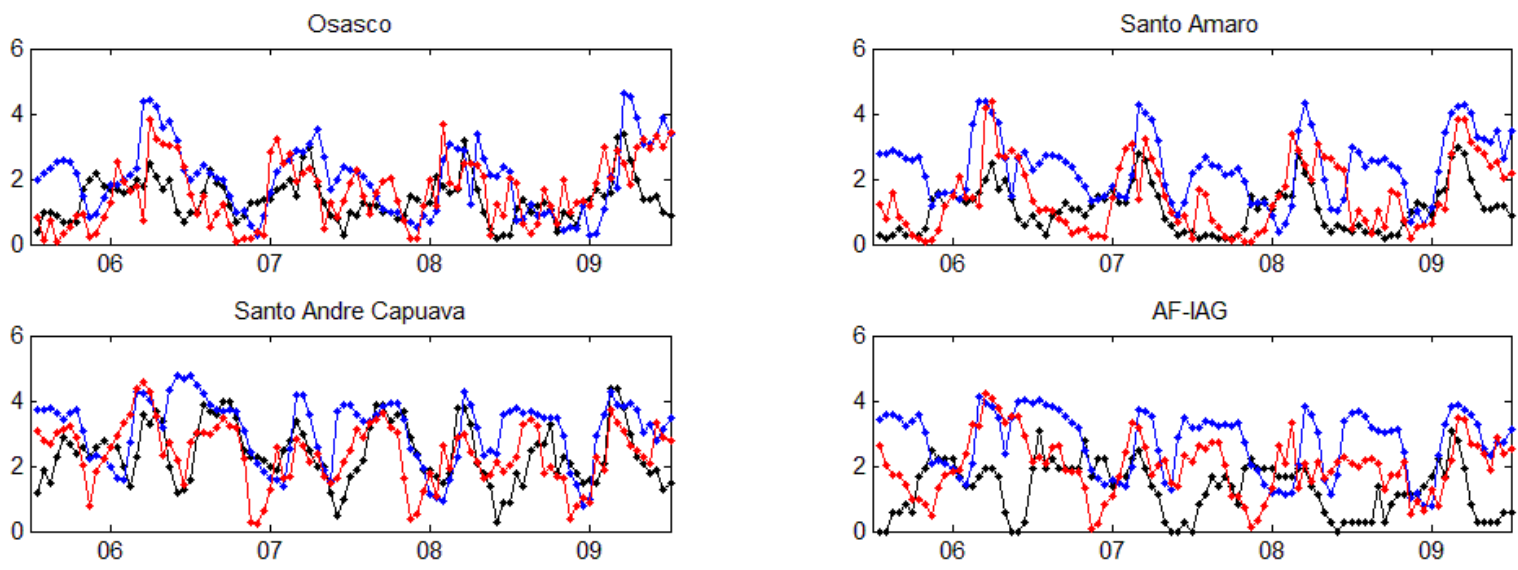

Figura 4.3. Intensidade do vento observada (pontos pretos) e simulada a $3 \mathrm{~km}$ (pontos azuis) e $1 \mathrm{~km}$ (pontos vermelhos) em ' $\mathrm{m} / \mathrm{s}$ ' para quatro estações na $R M S P$ para o período de 06 a 09 de setembro de 2004.

Quanto à direção, pode-se observar, das figuras 4.4 e 4.5, uma componente vindo da direção entre SE-S comum a todas as estações e outra componente vindo entre NNENEE comum às estações Santo Amaro, Santo Andre Capuava e AF-IAG; todas elas representadas coerentemente pelo modelo. Similarmente aos casos da temperatura e umidade relativa foi a configuração da grade de $1 \mathrm{~km}$ quem melhor representou as variações temporais do vento ao longo do período estudado, sugerindo uma melhora nos resultados a partir da implementação de dados geográficos de alta resolução. Mas, sabese que não só a inclusão de dados topográficos de alta resolução é necessária para melhorar a sensibilidade dos modelos no cálculo das variáveis de superfície, mas também de outras características da superfície terrestre como, por exemplo, o tipo e uso do solo, ainda mais para regiões metropolitanas como a RMSP onde um levantamento adequado destas variáveis deve ser feito para poder utilizá-las no pacote geográfico do 
WRF. Chin et al., 2005 conclui que a consideração dos aspectos térmicos e mecânicos devido aos efeitos das construções em escala subgrade no modelo de mesoescala utilizado é importante para melhorar a previsão do vento em áreas urbanas.
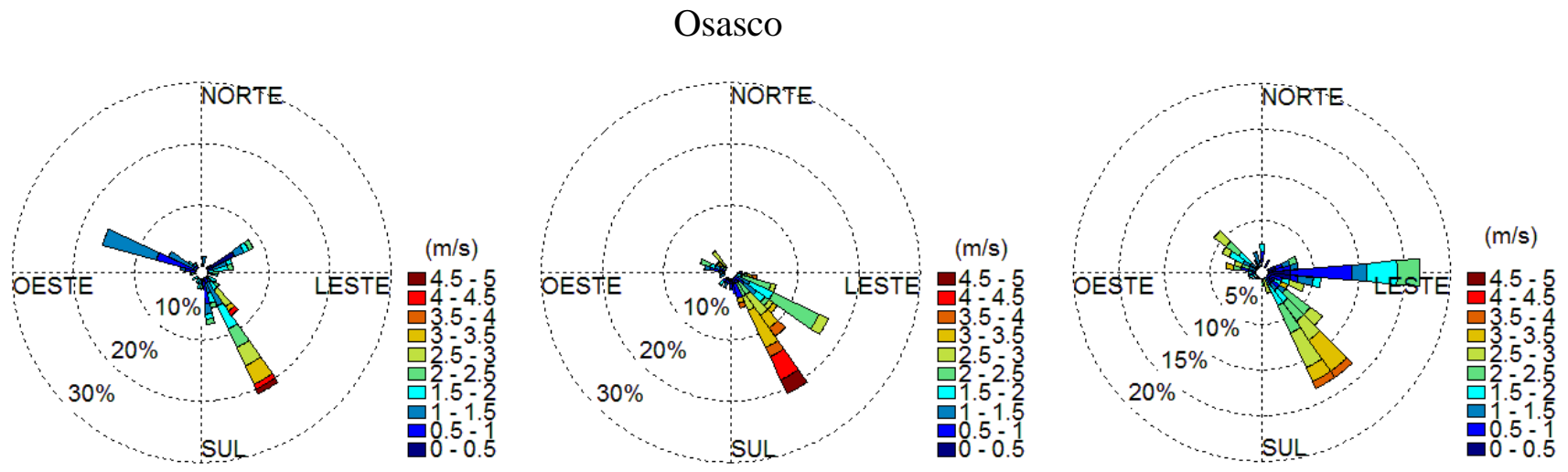

\section{Santo Amaro}
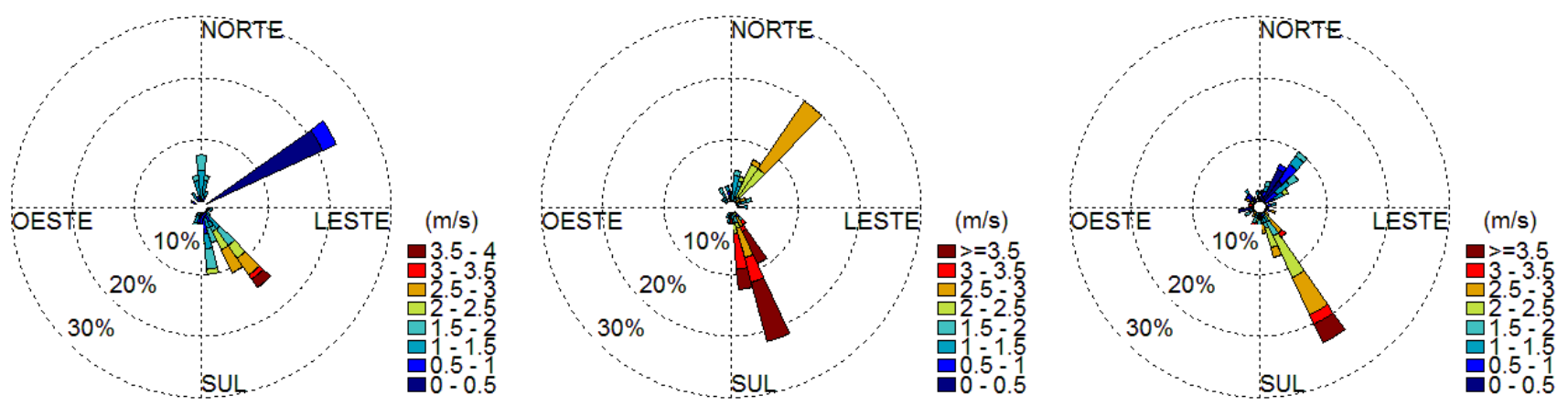

Santo Andre Capuava
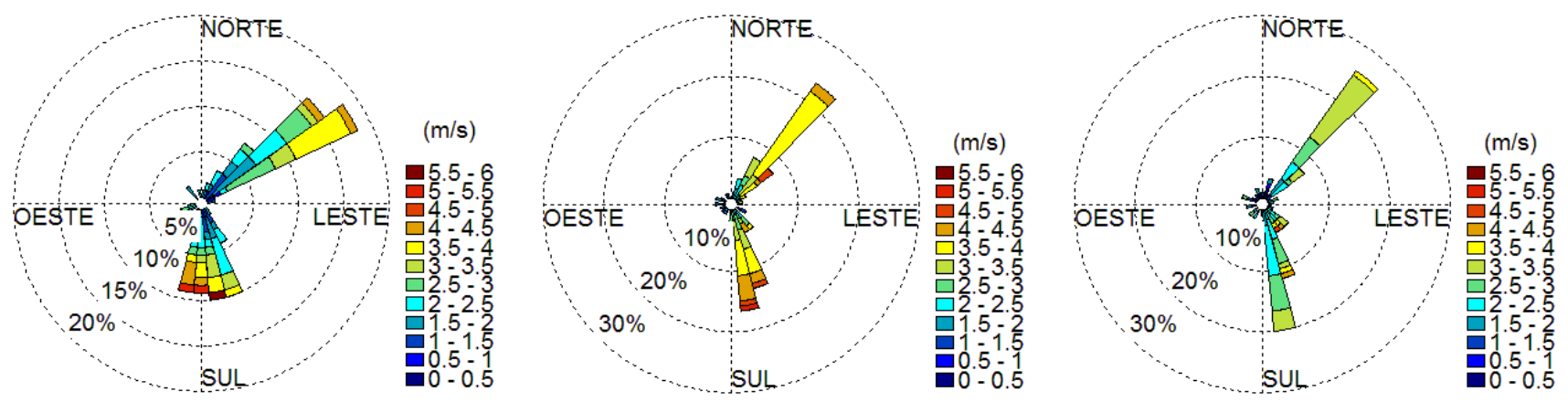

Figura 4.4. Rosa dos ventos observada (esquerda) e simulada a $3 \mathrm{~km}$ (centro) e $1 \mathrm{~km}$

(direita) para as estações Osasco (superior), Santo Amaro (centro) e Santo Andre

Capuava (inferior) na RMSP para o período de 06 a 09 de setembro de 2004. 


\section{AF-IAG}
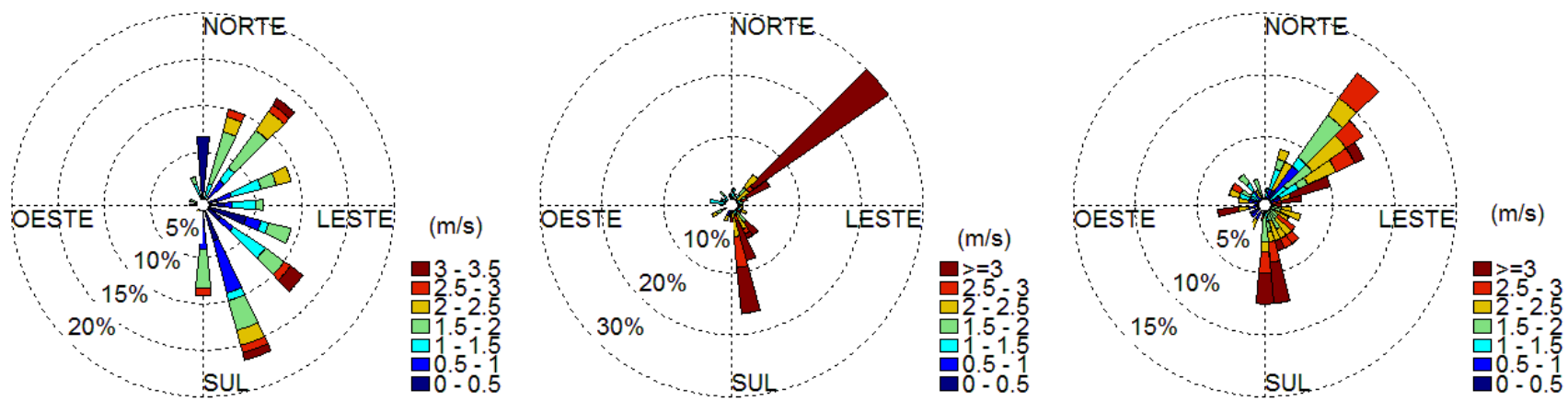

Figura 4.5. Rosa dos ventos observadas (esquerda) e simulada a $3 \mathrm{~km}$ (centro) e $1 \mathrm{~km}$ (direita) para a estação AF-IAG na RMSP para o período de 06 a 09 de setembro de 2004.

Os índices estatísticos (ver tabela 8.7 no apêndice E) mostram o que de alguma forma já era esperado para simulação do vento em uma região metropolitana como a $R M S P$, com coeficientes de correlação linear no máximo de 0,57 para a estação Santo Amaro com a grade de $1 \mathrm{~km}$ e ainda valores negativos para a estação AF-IAG. Os erros RMSE médios foram de 1,51 e $1,10 \mathrm{~m} / \mathrm{s}$ para as grades de 3 e $1 \mathrm{~km}$ respectivamente. $\mathrm{O}$ modelo considerando a resolução da grade de $1 \mathrm{~km}$ representou melhor a intensidade do vento do que considerando a configuração estabelecida para a grade de $3 \mathrm{~km}$. É importante mencionar que as análises meteorológicas utilizadas para este período e para todo o ano de 2004 contaram com informação apenas para duas camadas de temperatura e umidade do solo. Em 2005 foram incluídas mais duas camadas (quatro camadas no total), sendo disponibilizadas desta forma até o dia de hoje.

No caso do ozônio troposférico, as comparações entre os valores horários observados e calculados pelo WRF-Chem mostraram que os esquemas de emissão utilizados e diferenciados principalmente pelas suas distribuições espaciais, representaram adequadamente o ciclo de formação, no entanto, com algumas defasagens nos horários de ocorrência dos picos (ver figura 4.6); resultado de se ter considerado dois perfis de emissão constantes em todos os pontos no primeiro nível do modelo onde foram designadas as emissões (um perfil para o $C O$ e os $C O V$ e o outro para o $N O x$ ), além de serem únicos para todos os tipos de veículos considerados. Uma distribuição temporal mais adequada compreenderia perfis diários para cada ponto ou trecho emissor, como no inventário de fontes móveis considerado por Carvalho, 2010 para a 
cidade do Rio de Janeiro. No entanto, dada esta complexidade na representação do tráfego e falta de dados, uma alternativa mais viável seria considerar dois tipos de perfil: um perfil que representasse a atividade veicular durante os dias de semana 'weekday' e um outro perfil que representasse a menor atividade veicular observada durante o fim de semana 'weekend', como os considerados por Wang et al., 2010 e Zhang e Dubey, 2009. Observa-se também que as concentrações mínimas foram superestimadas em algumas estações para ambas grades, fato muito provavelmente relacionado com uma subestimativa das emissões de $N O x$ durante as horas de mínima concentração de ozônio. Ying et al., 2009 e Wang et al., 2010 sugerem que a variação diária do NOx tem um papel fundamental na formação do ozônio à noite e madrugada. Este comportamento foi também observado por Tie et al., 2007 em algumas regiões simuladas. Quanto às intensidades, observa-se que o modelo com a grade de $3 \mathrm{~km}$ foi quem melhor representou as concentrações máximas de ozônio, característica que pode estar relacionada ao fato desta grade incluir emissões de outras regiões metropolitanas próximas como, por exemplo, a Baixada Santista e onde as emissões veiculares foram incluídas de acordo com Martins et al., 2008. Todas as fontes móveis consideradas no esquema de representação das fontes, tiveram como base as mesmas características de uso dos veículos em circulação na RMSP; contribuindo remotamente através do transporte não só do ozonio, mas também de seus precursores. Já na grade de $1 \mathrm{~km}$ não foram consideradas as emissões provenientes desde outras regiões metropolitanas contiguas à $R M S P$. Outras características que podem ter contribuído para estimativas de concentrações máximas de ozonio mais elevadas na grade de $3 \mathrm{~km}$ estão relacionadas às distribuições espaciais consideradas nos esquemas de emissão utilizados, além de uma subestimativa maior de $N O x$ na grade de $3 \mathrm{~km}$, levando para uma razão COV/NOx média ligeiramente maior nesta grade (ver tabela 2.4). Devido ao fato da ILN ter um limiar superior igual a 63, surge um problema nas regiões onde a ocupação urbana é muito densa: a ILN resulta subestimada ao valor daquele limiar superior, subestimando assim as emissões nestas regiões, situação que é observada com maior frequência nas regiões centrais das grandes cidades. Por outro lado, a grande maioria dos pontos de grade representando a região urbanizada da $R M S P$ foi considerada como sendo constituída por fontes emissoras, aumentando assim a emissão e contrapondo o efeito ocasionado pelo limiar do sensor nas áreas centrais da região metropolitana. No caso da grade de $1 \mathrm{~km}$, a matriz numérica considerada para distribuir espacialmente as emissões 
veiculares, em princípio, representaria melhor a localização dos pontos ou trechos com maior atividade veicular dado que foi construída com informações sobre tipos de vias. A figura 4.6 mostra as séries temporais observadas (pontos pretos) e simuladas para 3 $\mathrm{km}$ (pontos azuis) e $1 \mathrm{~km}$ (pontos vermelhos) em ' $\mu \mathrm{g} / \mathrm{m}^{3}$ ' para onze estações da rede de monitoramento da CETESB (ver tabela 8.3 no apêndice D). A linha verde representa o $P Q A$ para este poluente (concentração máxima de $160 \mu \mathrm{g} / \mathrm{m}^{3}$ durante uma hora de amostragem ). Dado que as observações estão expressas em ' $\mu \mathrm{g} / \mathrm{m}^{3}$ ' e o modelo fornece as concentrações em razão de mistura em ' $p p m v=0.001 p p b v$ ', utilizou-se um fator de conversão de 1:2 para converter as concentrações de ' $p p b v$ ' para ' $u g / m^{3}$ ' como considerado por Wang et al., 2010.
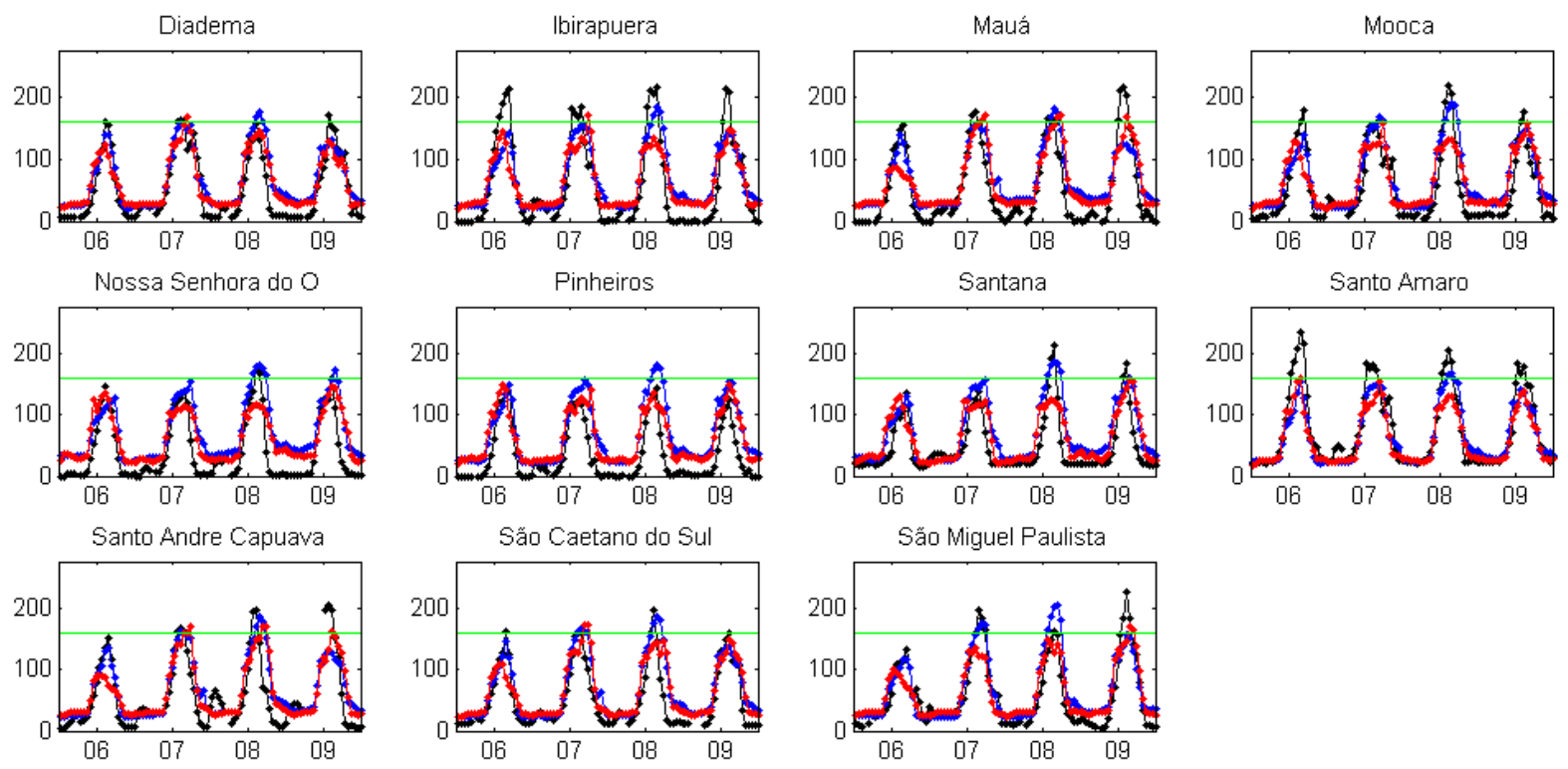

Figura 4.6. Concentração de ozônio observada (pontos pretos) e simulada a $3 \mathrm{~km}$ (pontos azuis) e $1 \mathrm{~km}$ (pontos vermelhos) em ' $\mu \mathrm{g} / \mathrm{m}^{3}$ ' para onze estações na $R M S P$ para o período de 06 a 09 de setembro de 2004. 
Apesar das variáveis meteorológicas terem sido ligeiramente melhor representadas com a configuração da grade de $1 \mathrm{~km}$, as concentrações máximas do ozônio foram melhor representadas com a configuração da grade de $3 \mathrm{~km}$. Os testes estatísticos (ver tabelas 8.8 e 8.9 no apêndice E) mostraram que a concentração de ozônio troposférico foi melhor representada pelos esquemas da grade de $3 \mathrm{~km}$. Os coeficientes de correlação linear e índices de concordância foram, em geral, superiores a 0,8. Os erros RMSE médios foram de 31,9 e 32,2 $\mu \mathrm{g} / \mathrm{m}^{3}$ para as grades de 3 e $1 \mathrm{~km}$, respectivamente. $\mathrm{O}$ viés médio normalizado para representação da previsão média do pico de ozônio $\left(\mathrm{PO}_{3}\right)$ foi de $-8,12$ e $-17,13 \%$ para as grades de 3 e $1 \mathrm{~km}$, respectivamente, no caso pareado. A figura 4.7 mostra o Diagrama de Taylor para a concentração do ozônio em ambas as grades.

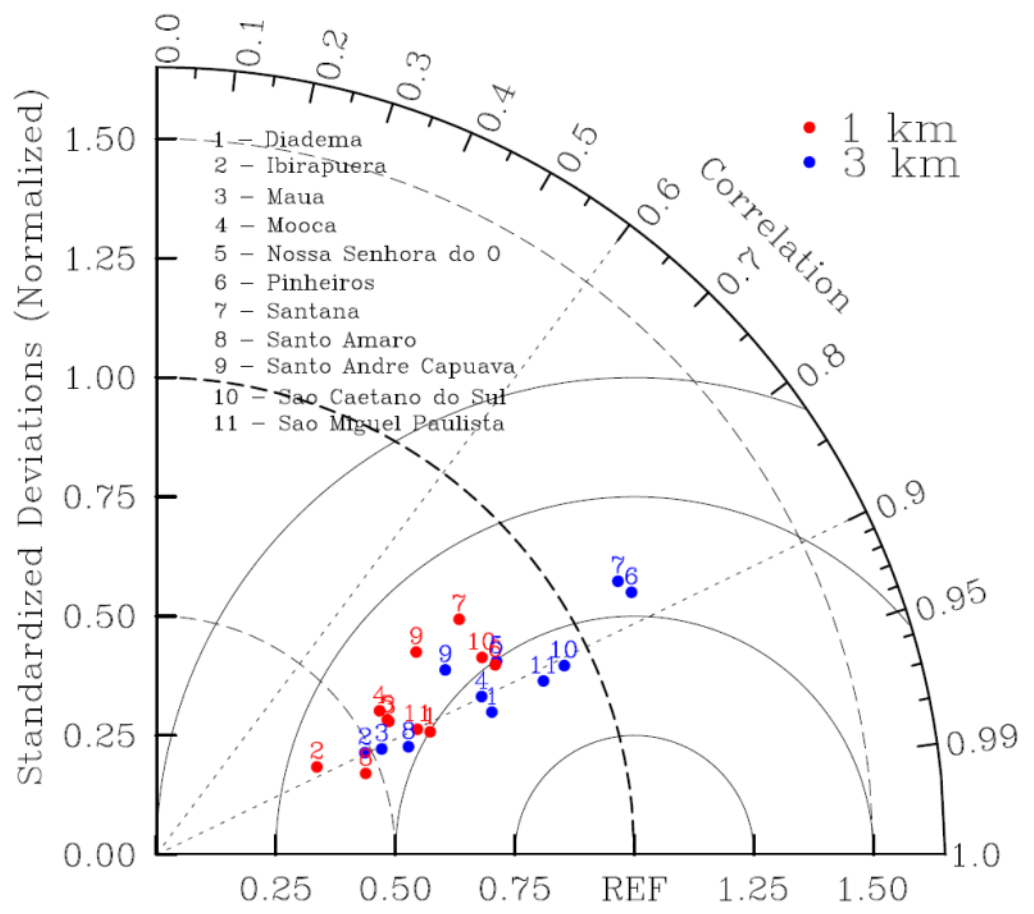

Figura 4.7. Diagrama de Taylor para a concentração do ozônio em onze estações na RMSP para o período de 06 a 09 de setembro de 2004, para a grade de 1 (pontos vermelhos) e $3 \mathrm{~km}$ (pontos azuis).

A distribuição espacial do cálculo das concentrações do ozônio para às $14 \mathrm{~h}$, hora local, para as grades de 3 e $1 \mathrm{~km}$ é mostrada nas figuras 4.8 e 4.9, respectivamente. Pode-se observar destas figuras (como discutido anteriormente na comparação com os valores observados) que a configuração da grade de $3 \mathrm{~km}$ estima um valor maior para as 
concentrações do ozônio na $R M S P$. Observa-se também um transporte de ozônio para a $R M S P$ proveniente do interior do Estado, mais notoriamente durante o dia 8 em que se produziram as maiores diferenças de ozônio entre ambas as grades (ver figura 4.6). No caso da grade de $1 \mathrm{~km}$ (que abrange apenas a $R M S P$ ) não foi considerado o 'downscaling' para a química calculada a partir da grade de $3 \mathrm{~km}$, fato que resultou em um cálculo menor das concentrações de ozônio.
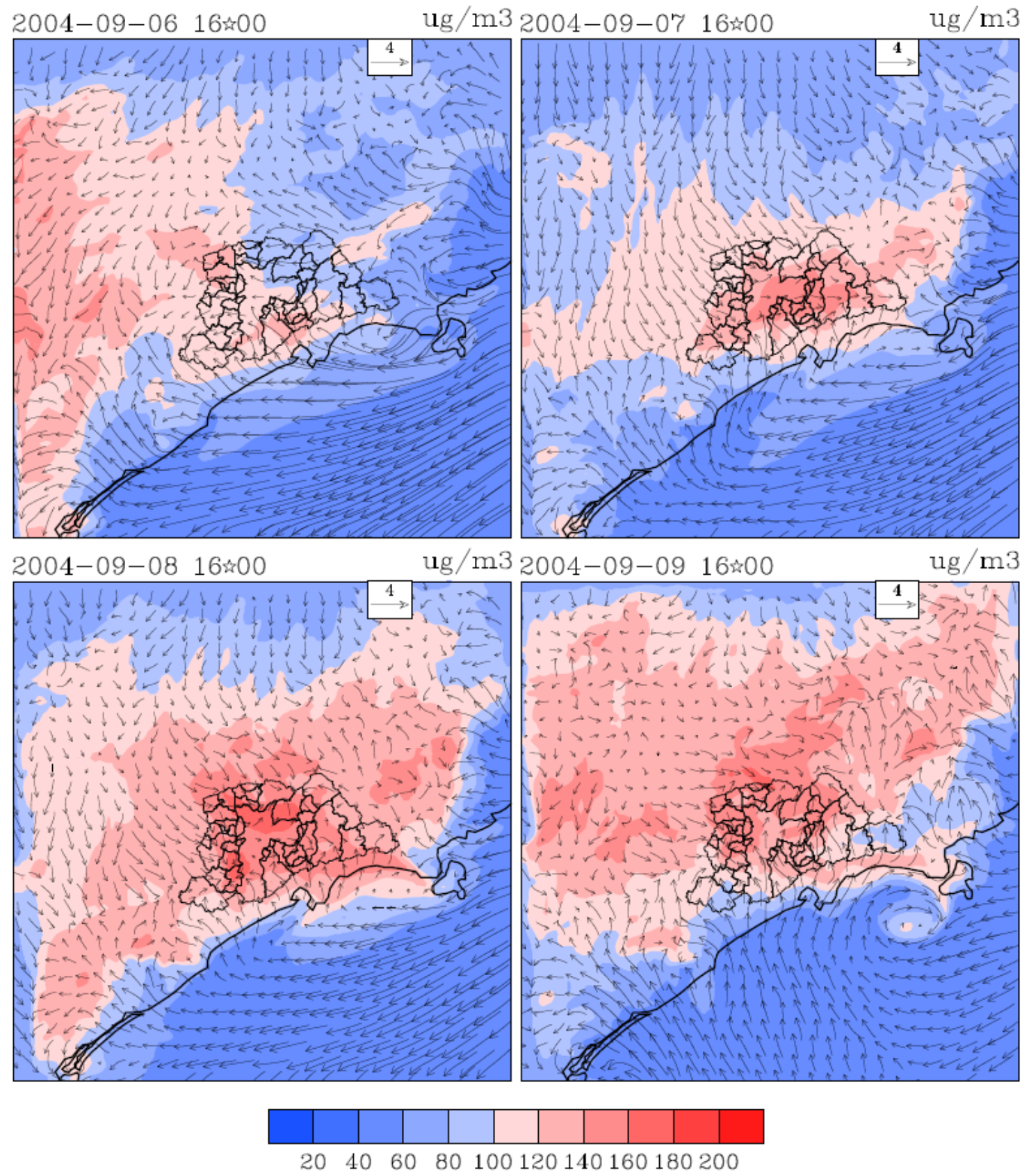

Figura 4.8. Cálculo superficial da concentração de ozônio às $14 \mathrm{~h}$, hora local, na grade de $3 \mathrm{~km}$ para o período de 06 a 09 de setembro de 2004. 

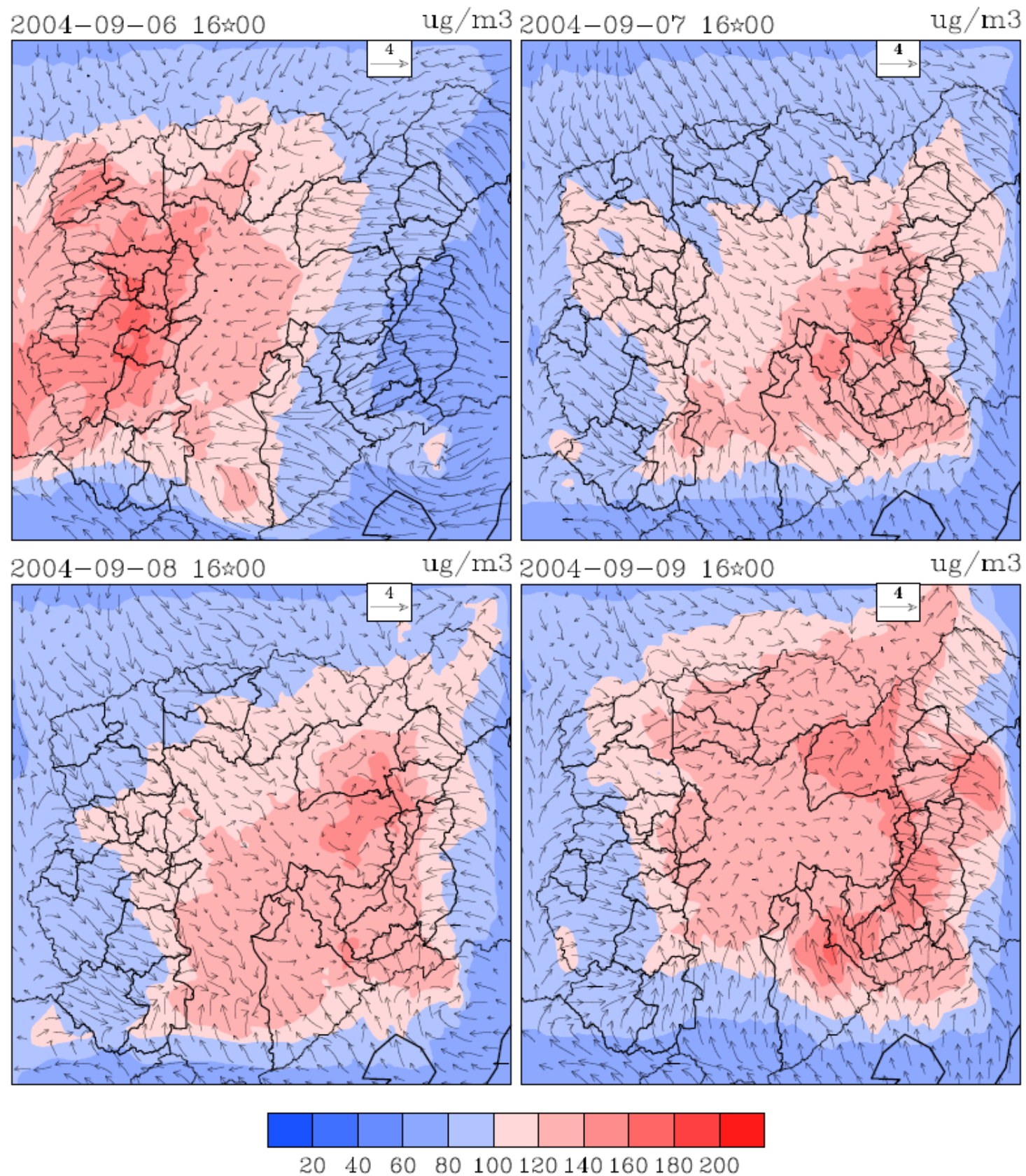

Figura 4.9. Cálculo superficial da concentração de ozônio às 14h, hora local, na grade de $1 \mathrm{~km}$ para o período de 06 a 09 de setembro de 2004.

Algumas estações de Qualidade do Ar apresentam características muito semelhantes em termos de concentrações de poluentes. Martins, 2006 realizou um estudo de Análise Cluster para agrupar as estações com perfis semelhantes. Abaixo se apresenta uma análise comparativa por grupos de estações, considerando esse critério de agrupamento para o mês de setembro de 2004 utilizando dados horários de CO, NOx e ozônio observados em todas as estações da rede de monitoramento automático da CETESB. Os grupos considerados foram grupo 1: Pinheiros; Mooca; Ibirapuera e São 
Caetano do Sul e grupo 2: Diadema e Santo Amaro. As concentrações médias desses dois grupos foram comparadas com as suas correspondentes concentrações médias simuladas pelo WRF-Chem. Martins, 2006, realizou uma simulação com o modelo CIT para o mesmo período e os resultados são apresentados para comparação. As figuras 4.10 e 4.11 mostram uma comparação entre os valores médios observados de ozônio e os valores médios calculados por meio de modelagem numérica com os modelos CIT (acima e para o período de 06 a 10 de setembro) e WRF-Chem (abaixo e para o período de 06 a 09 de setembro) para os grupos 1 e 2, respectivamente. Neste caso as concentrações observadas foram convertidas de unidades em ' $\mu \mathrm{g} / \mathrm{m}^{3}$ ' para ' $p p b v$ '.
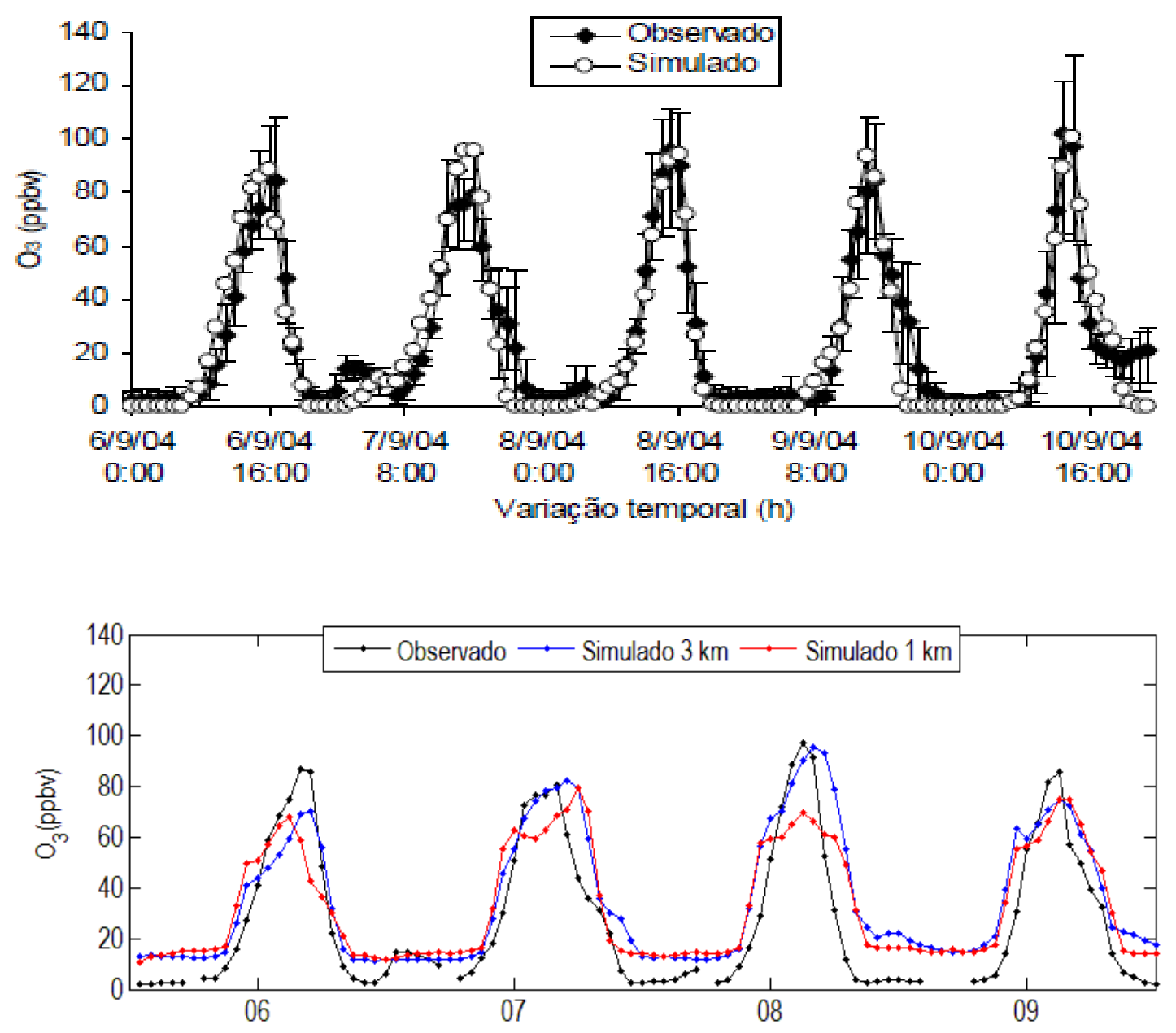

Figura 4.10. Concentrações médias observadas e simuladas pelos modelos CIT (acima) (Martins, 2006) e WRF-Chem (abaixo) para os grupos de estações: Pinheiros; Mooca; Ibirapuera e São Caetano do Sul. 

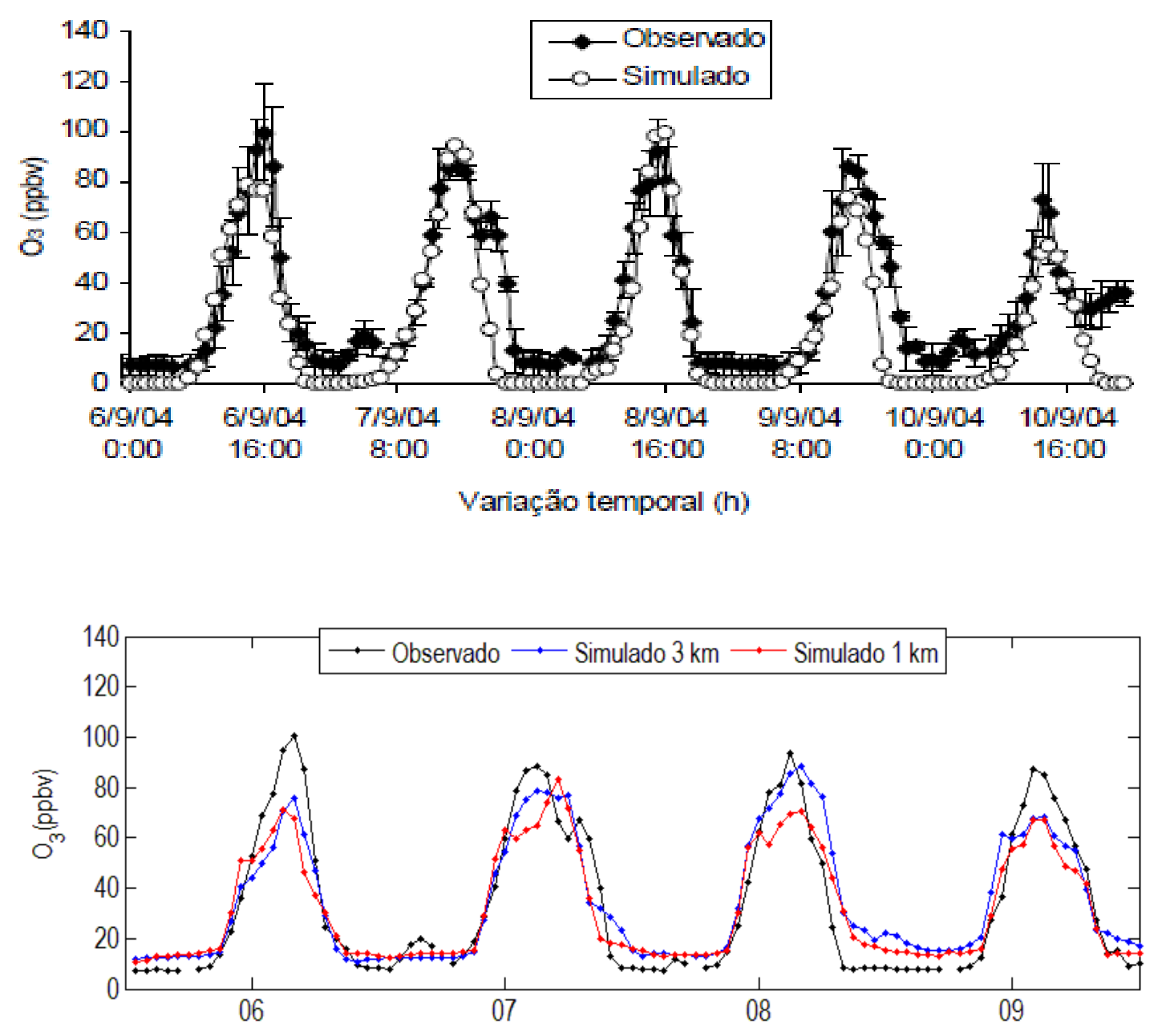

Figura 4.11. Concentrações médias observadas e simuladas pelos modelos CIT (acima)

(Martins, 2006) e WRF-Chem (abaixo) para os grupos de estações: Diadema e Santo Amaro.

Como na análise individual por estação, a análise por agrupamento mostra novamente que a simulação com a grade de $3 \mathrm{~km}$ representou melhor, estatisticamente falando (ver tabela 4.1), as observações do que a grade de $1 \mathrm{~km}$, embora não seja possível comparar diretamente os testes estatísticos obtidos dos resultados das modelagens com os modelos CIT e WRF-Chem dada a diferença dos períodos de simulação. A tabela 4.1 mostra os testes estatísticos para as concentrações médias de ozônio para os agrupamentos 1 e 2, além daqueles obtidos por Martins, 2006 com o modelo CIT embora para o período de 06-10 de Setembro. 


\begin{tabular}{|c|c|c|c|c|c|c|}
\cline { 2 - 7 } \multicolumn{1}{c|}{} & \multicolumn{3}{c|}{ Grupo 1 } & \multicolumn{3}{c|}{ Grupo 2 } \\
\cline { 2 - 7 } \multicolumn{1}{c|}{} & $3 \mathrm{~km}$ & $1 \mathrm{~km}$ & CIT & $3 \mathrm{~km}$ & $1 \mathrm{~km}$ & CIT \\
\hline$\sigma_{\text {obs }}\left(\mu \mathrm{g} / \mathrm{m}^{3}\right)$ & 29,1 & 29,1 & 28,6 & 29,8 & 29,8 & 27,4 \\
\hline$\sigma_{\text {sim }}\left(\mu \mathrm{g} / \mathrm{m}^{3}\right)$ & 25,9 & 22,6 & 31,5 & 24,5 & 22,0 & 28,8 \\
\hline $\mathrm{r}$ & 0,91 & 0,88 & 0,95 & 0,93 & 0,93 & 0,9 \\
\hline $\mathrm{RMSE}\left(\mu \mathrm{g} / \mathrm{m}^{3}\right)$ & 15,4 & 15,6 & 12,5 & 11,5 & 12,1 & 16,3 \\
\hline $\mathrm{D}$ & 0,91 & 0,90 & 0,97 & 0,95 & 0,94 & 0,9 \\
\hline $\mathrm{PO}_{3}(\%)$ & $-7,60$ & $-16,00$ & 2,00 & $-15,70$ & $-20,60$ & $-10,30$ \\
\hline
\end{tabular}

Tabela 4.1. Testes estatísticos para as concentrações médias de ozônio para os agrupamentos 1 e 2 referentes às estações de qualidade do ar.

Quanto aos precursores de ozônio analisados: $C O$ e $N O x$, os resultados mostram como a inadequada localização de algumas estações da rede de monitoramento automático da CETESB como Congonhas, localizada na intersecção de duas vias de tráfego veicular, podem não ser boas referências para avaliar resultados de modelagem numérica com o grau de aproximação considerado neste estudo, até porque na realidade o tráfego veicular e consequentemente as emissões veiculares respondem a comportamentos sociais muitas vezes imprevisíveis. No entanto, em estações como Ibirapuera, localizadas em áreas com menor influência direta de fontes veiculares, os processos de mistura são melhor representados devido ao tempo de mistura ser maior que a vida média dos compostos. Carbone, 2008 e Galichio, 2011 indicaram problemas com o inventário de emissão utilizado associado com os resultados pouco convergentes para as concentrações de $C O$ e $N O x$. As figuras 4.12 e 4.13 mostram as séries temporais observadas (pontos pretos) e simuladas a $3 \mathrm{~km}$ (pontos azuis) e $1 \mathrm{~km}$ (pontos vermelhos) do $C O$ em ' $p p m v$ ' e $N O x$ em ' $p p b v$ ', respectivamente, nas estações consideradas para estas variáveis (ver tabela 8.3 no apêndice D). Destas figuras pode-se observar que o modelo conseguiu representar, em geral, a variabilidade temporal diária, no entanto, teve deficiência em representar os picos máximos, principalmente em estações com características de localização inadequadas para avaliação de simulações numéricas como será discutido posteriormente. 

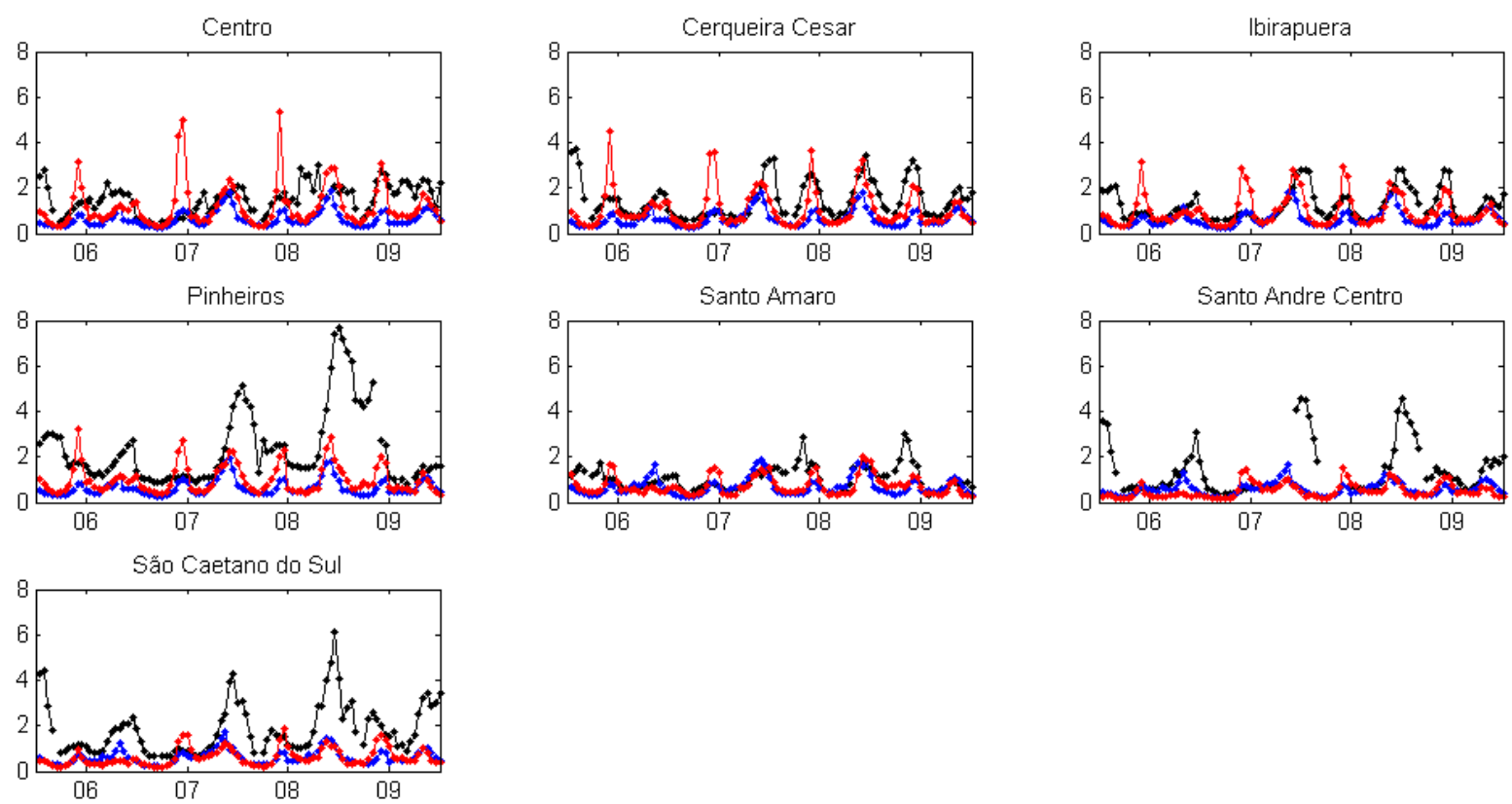

Figura 4.12. Concentração de $C O$ observada (pontos pretos) e simulada a $3 \mathrm{~km}$ (pontos azuis) e $1 \mathrm{~km}$ (pontos vermelhos) em 'ppmv' para sete estações na RMSP para o período de 06 a 09 de setembro de 2004.
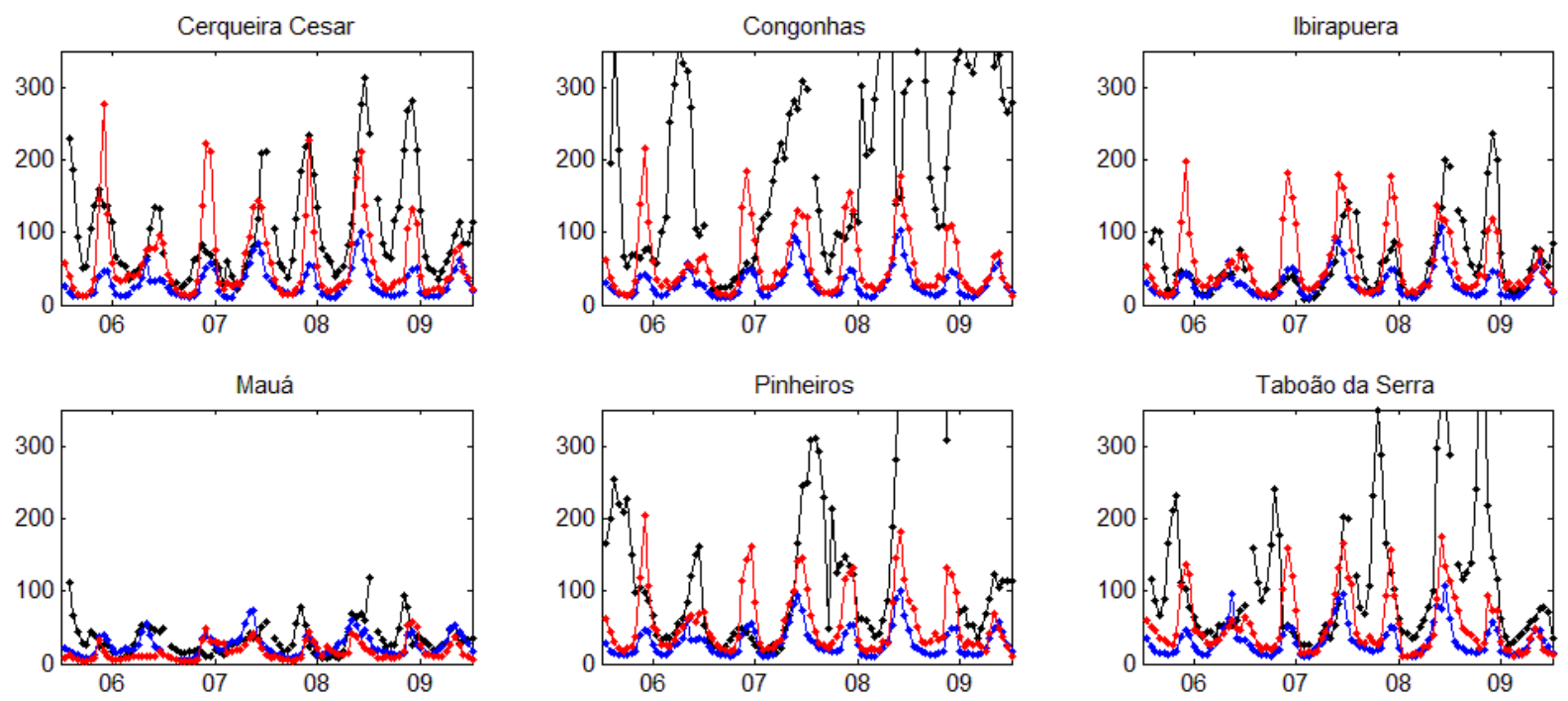

Figura 4.13. Concentração de $N O x$ observada (pontos pretos) e simulada a $3 \mathrm{~km}$ (pontos azuis) e $1 \mathrm{~km}$ (pontos vermelhos) em ' $p p b v$ ' para seis estações na $R M S P$ para o período de 06 a 09 de setembro de 2004. 
Não é possível entender o comportamento do ozônio analisando somente o $C O$ e $N O x$, já que os $C O V$ são os principais responsáveis pelas altas concentrações de ozônio, considerando que a atmosfera da RMSP pode ser descrita como COV-dependente, resultado encontrado por Martins, 2006; Sánchez-Ccoyllo et al., 2006b, Martins e Andrade, 2008a e Orlando et al., 2010. Na ausência de dados destes últimos, a razão CO/NOx poderia nos ajudar a entender o comportamento do ozônio calculado em ambas grades, já que tanto o $C O$ quanto os $C O V$ são emitidos principalmente por veículos leves. É importante destacar que no esquema de emissão utilizado, as emissões de $C O$ e COV por veículos leves, foram calculadas de forma proporcional aos seus fatores de emissão $(14,60 \mathrm{~g} / \mathrm{km}$ para o $C O$ e 1,17 $\mathrm{g} / \mathrm{km}$, aproximadamente, para os $C O \mathrm{~V})$. A figura 4.14 mostra as séries temporais da razão CO/NOx observadas (pontos pretos) e simuladas a $3 \mathrm{~km}$ (pontos azuis) e $1 \mathrm{~km}$ (pontos vermelhos) em 'ppmv/ppbv' para as estações Ibirapuera e Pinheiros. Apesar das concentrações de $C O$ e $N O x$, em geral, não terem sido bem representadas em intensidade (ver, por exemplo, nas figuras 4.12 e 4.13 as séries temporais correspondentes à estação Pinheiros) devido às incertezas no cálculo das taxas de emissão como também às características de localização das estações de monitoramento, as razões $C O / N O x$ mostram que os ciclos diários pelo menos nestas duas estações foram representados coerentemente pelo modelo, principalmente na estação Ibirapuera. Na figura 4.14 observa-se também uma razão CO/NOx maior com a grade de $3 \mathrm{~km}$, consequência das maiores diferenças nas concentrações do NOx quando comparadas com as diferenças nas concentrações do $C O$ na grade de $1 \mathrm{~km}$ em relação à grade de $3 \mathrm{~km}$. Esta característica pode ter contribuído para o cálculo de concentrações mais elevadas de ozônio com a grade de $3 \mathrm{~km}$ em relação à grade de $1 \mathrm{~km}$, dado que as diferenças nas emissões de $C O V$ seriam, em princípio, aproximadamente proporcionais e menores às diferenças nas emissões ou concentrações de $C O$, permitindo uma razão COV/NOx mais favorável (em termos de produção de ozônio) na grade de $3 \mathrm{~km}$. Podese observar da tabela 2.4 que a razão molar COV/NOx calculada a partir das emissões totais estimadas é maior para a grade de $3 \mathrm{~km}(4,09)$ quando comparada com a grade de $1 \mathrm{~km}(3,85)$, no entanto, é muito provável que as razões observadas e calculadas nos diferentes pontos de grade na primeira camada do modelo sejam maiores que as razões estimadas pelo modelo de emissões veiculares considerado neste estudo, dada as altas concentrações de ozônio observadas no período estudado. 

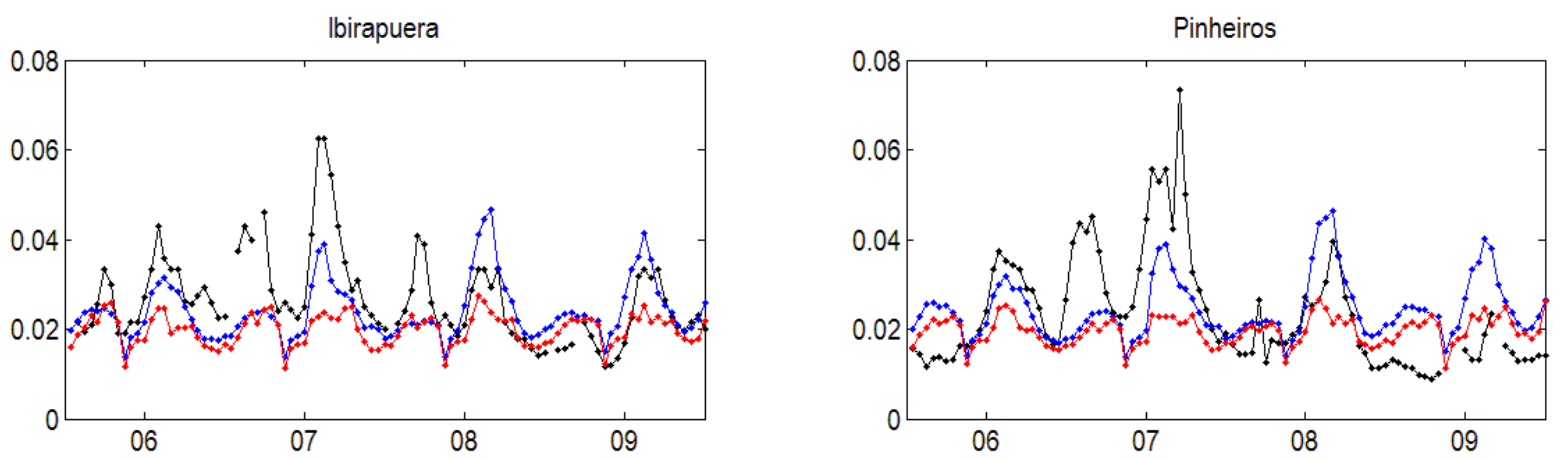

Figura 4.14. Razão CO/NOx observada (pontos pretos) e simulada a $3 \mathrm{~km}$ (pontos azuis) e $1 \mathrm{~km}$ (pontos vermelhos) em ' $p p m v / p p b v$ ' para duas estações na $R M S P$ para o período de 06 a 09 de setembro de 2004.

Atualmente, estimar as emissões veiculares de $C O V$ e $N O x$ em uma região com as características de frota veicular como as observadas na RMSP representa um desafio devido à grande incerteza dos parâmetros envolvidos na construção do inventário da fonte móvel (em especial da estimativa da frota e fatores de emissão), resultando na maioria das vezes em uma subestimativa das mesmas. Finlayson-Pitts e Pitts, 2000 mostram uma comparação entre a razão COV/NOx observada e calculada a partir de inventários de emissão para várias regiões metropolitanas dos Estados Unidos, e onde se obtém que a razão observada é mais do que duas vezes a razão calculada, atribuindo o fato a uma subestimativa dos $C O V$, principalmente os provenientes de emissões veiculares. As tabelas 8.10 e 8.11 no apêndice E mostram os testes estatísticos para o $N O x$ e $C O$, respectivamente. Em geral, a grade de $1 \mathrm{~km}$ foi quem melhor representou a variabilidade destes poluentes, com Ibirapuera e Congonhas como sendo as estações melhor e pior representadas respectivamente, reforçando o argumento exposto anteriormente. Os coeficientes de correlação linear e índices de concordância foram menores a 0,5 e 0,7, respectivamente para o caso do $C O$ e menores a 0,6 e 0,7, respectivamente, para o caso do NOx. Os erros RMSE médios foram de 1,30 e 1,24 ppmv para as grade de 3 e $1 \mathrm{~km}$, respectivamente, para o caso do $C O$, e 116,70 e 107,41 ppbv para as grades de 3 e $1 \mathrm{~km}$, respectivamente, para o caso do $N O x$. A dispersão dos dados foi melhor representada com a grade de $1 \mathrm{~km}$.

Finalmente aplicando o critério sugerido por Sillman, 1995, onde um valor de 0.28 para a razão $\mathrm{CH}_{2} \mathrm{O} / \mathrm{NOy}\left(\mathrm{NO} y=\mathrm{NO}+\mathrm{NO}_{2}+\mathrm{HNO}_{3}+\mathrm{PAN}+\mathrm{NO}_{3}+2 \mathrm{~N}_{2} \mathrm{O}_{5}\right)$ à tarde pode 
definir um limite entre regimes $N O x$ e $C O V$ limitantes, concluímos que a $R M S P$ está sobre um forte regime COV-limitante (ver figura 4.15).

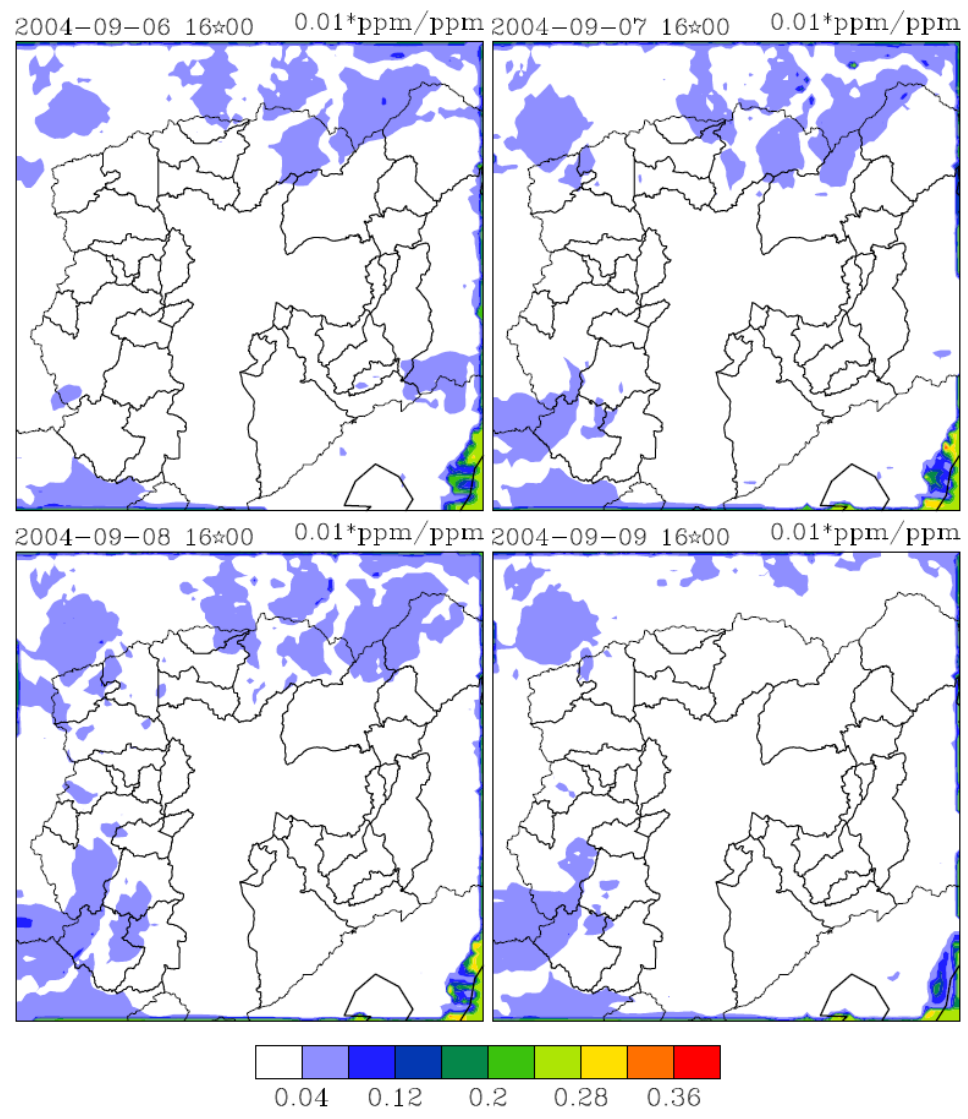

Figura 4.15. Cálculo da razão $\mathrm{CH}_{2} \mathrm{O} / \mathrm{NO} \mathrm{y}$ para a grade de $1 \mathrm{~km}$ às $14 \mathrm{~h}$, hora local. 


\subsection{Simulação do período de 12-15 de novembro de 2011}

Diferentemente do período anterior, as variáveis meteorológicas analisadas neste período foram melhor representadas pela configuração da grade de $3 \mathrm{~km}$, embora com índices estatísticos menores quando comparados ao período anterior. Este fato está relacionado diretamente às condições meteorológicas de ambos os períodos o que mostra a necessidade de realizar-se um estudo mais exaustivo sobre a sensibilidade dos valores preditos pelo modelo WRF-Chem em função de parâmetros físicos que descrevem a CLP, Superfície Terrestre e Camada Superficial (responsáveis pelo cálculo dos fluxos horizontais e verticais de calor e umidade) em função do espaçamento de grade. O estudo realizado por Misenis e Zhang, 2010, por exemplo, mostra que os campos meteorológicos e químicos calculados pelo modelo WRF-Chem são mais sensíveis aos esquemas de Superfície Terrestre do que aos esquemas de CLP. O estudo mostra ainda uma maior sensibilidade dos campos preditos ao espaçamento de grade usando a opção de aninhamento 'one-way-nesting' (opção usada para as grades de 3 e 1 km) do que a opção 'two-way-nesting' (opção usada para as grades de 27 e 9 km).
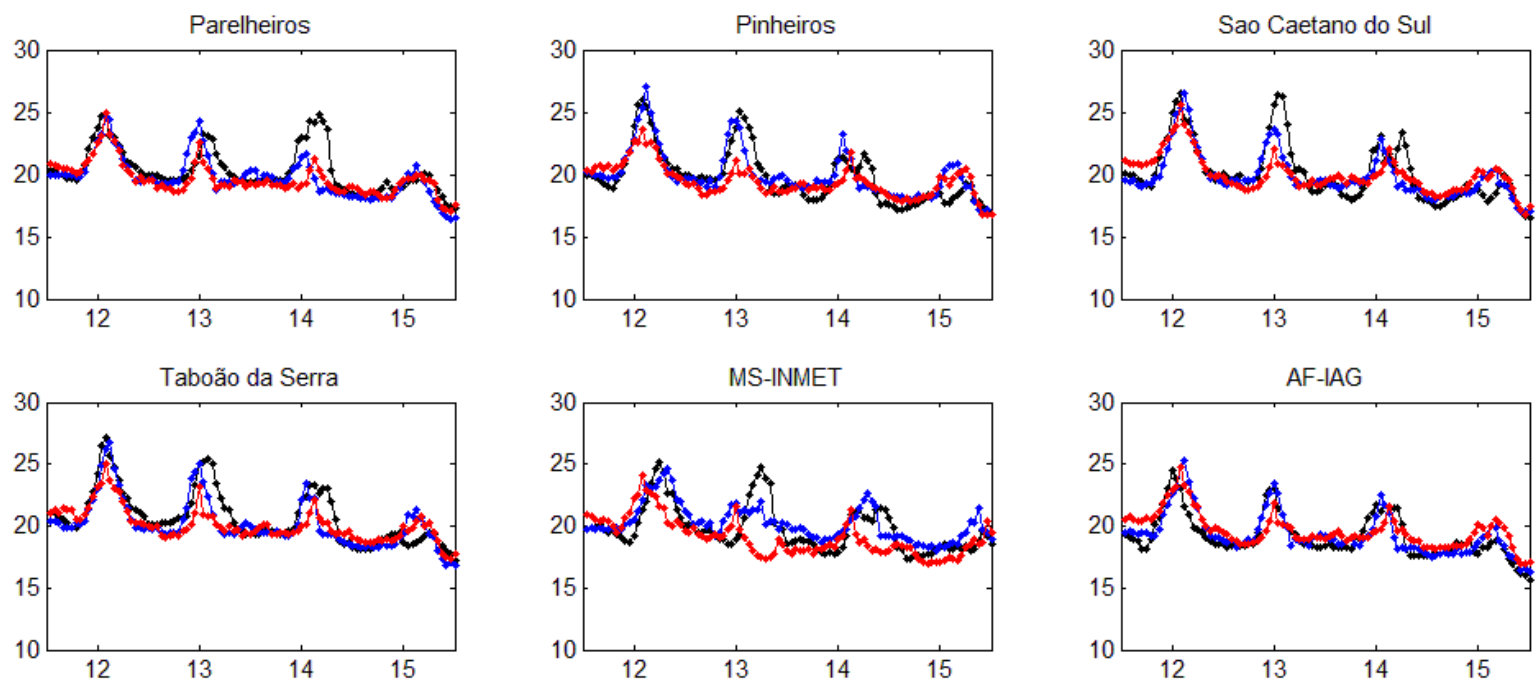

Figura 4.16. Temperatura observada (pontos pretos) e simulada com resolução de $3 \mathrm{~km}$ (pontos azuis) e $1 \mathrm{~km}$ (pontos vermelhos) em ' ${ }^{\circ} \mathrm{C}$ ' para seis estações na $R M S P$ para o período de 12 a 15 de novembro de 2011.

A figura 4.16 mostra as séries temporais de temperaturas observadas (pontos pretos) e simuladas a $3 \mathrm{~km}$ (pontos azuis) e $1 \mathrm{~km}$ (pontos vermelhos) em ' ${ }^{\circ} \mathrm{C}$ ' para as 
seis estações consideradas neste período (ver tabela 8.4 no apêndice D). Desta figura, pode-se observar que, em geral, o modelo representou coerentemente a variabilidade, amplitude e queda progressiva da temperatura, produzida pelos sistemas que atuaram na RMSP: áreas de instabilidade no dia 12 e a passagem de uma frente fria entre os dias 14 e 15. Os testes estatísticos (ver tabela 8.12 no apêndice E) mostram que a simulação com a grade de $3 \mathrm{~km}$ foi quem melhor representou as observações na maioria das estações analisadas. Os coeficientes de correlação linear e índices de concordância foram, em geral, superiores a 0,7. Os erros $R M S E$ médios foram de 1,25 e $1,51{ }^{\circ} C$ para as grades de 3 e $1 \mathrm{~km}$, respectivamente. A dispersão dos dados observados foi melhor representada com a configuração da grade de $3 \mathrm{~km}$.

No caso da umidade relativa, os testes estatísticos mostram que a simulação com a grade de $3 \mathrm{~km}$ representou melhor a sua variabilidade temporal, no entanto, com coeficientes de correlação linear e índices de concordância muito baixos em Parelheiros e São Caetano do Sul, estações em que a umidade relativa atingiu valores próximos de $100 \%$ em grande parte do período, principalmente na estação Parelheiros (erros RMSE menores, não superando $5 \%$ para ambas as grades). Os erros RMSE médios foram de
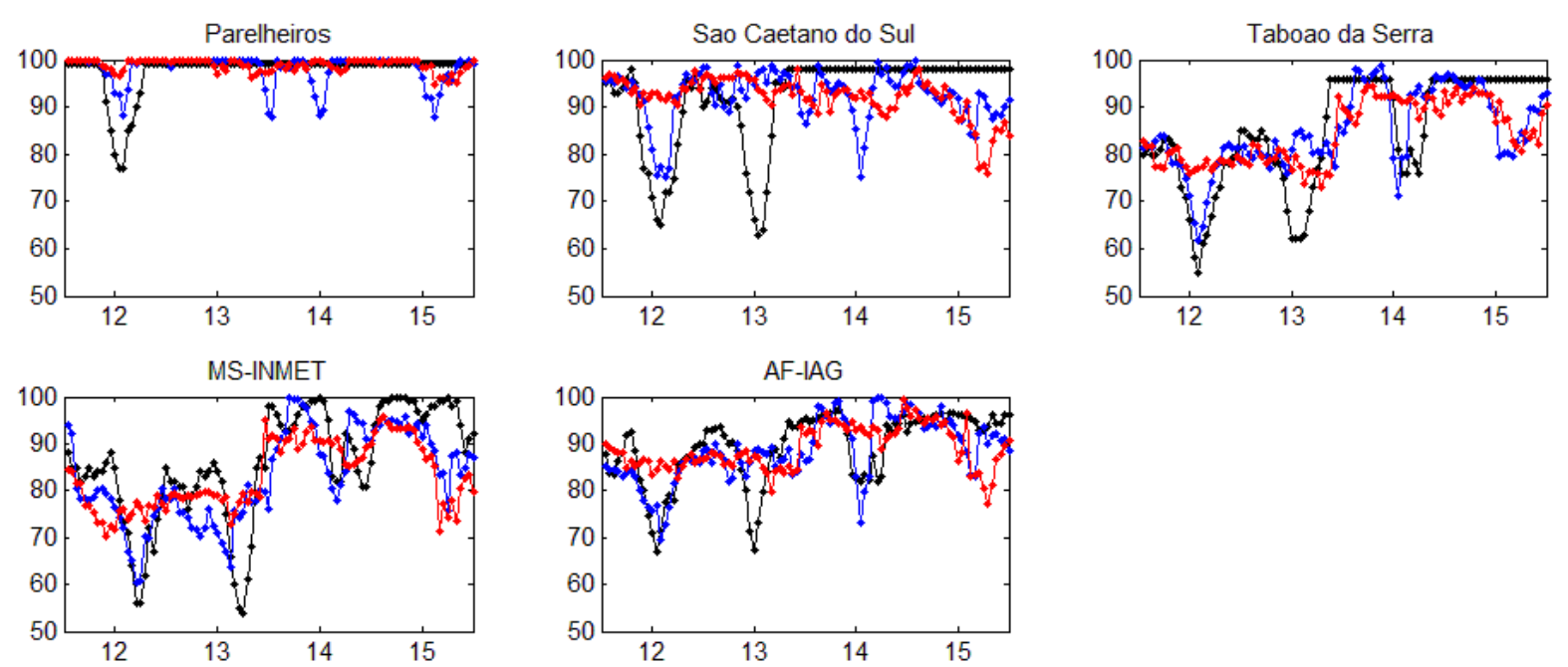

Figura 4.17. Umidade relativa observada (pontos pretos) e simulada para resoluções de $3 \mathrm{~km}$ (pontos azuis) e $1 \mathrm{~km}$ (pontos vermelhos) em '\%’ para seis estações na $R M S P$ para o período de 12 a 15 de novembro de 2011.

7,54 e 8,40\% para as grades de 3 e $1 \mathrm{~km}$, respectivamente. A figura 4.17 mostra as séries temporais de umidade relativa observada (pontos pretos) e simuladas a $3 \mathrm{~km}$ 
(pontos azuis) e $1 \mathrm{~km}$ (pontos vermelhos) em '\%' para as cinco estações consideradas (ver tabela 8.4 no apêndice D). É possível observar nesta figura que o aumento progressivo da umidade relativa é correspondente com a queda consequente da temperatura ao longo do período (ver figura 4.16).

No caso do vento, observa-se na figura 4.18 que a sua intensidade foi notavelmente superestimada pelas configurações de ambas as grades, principalmente pela grade de $1 \mathrm{~km}$, com máximos que atingiram valores de até $8 \mathrm{~m} / \mathrm{s}$, fato que certamente influiu no cálculo da distribuição espacial do ozônio.
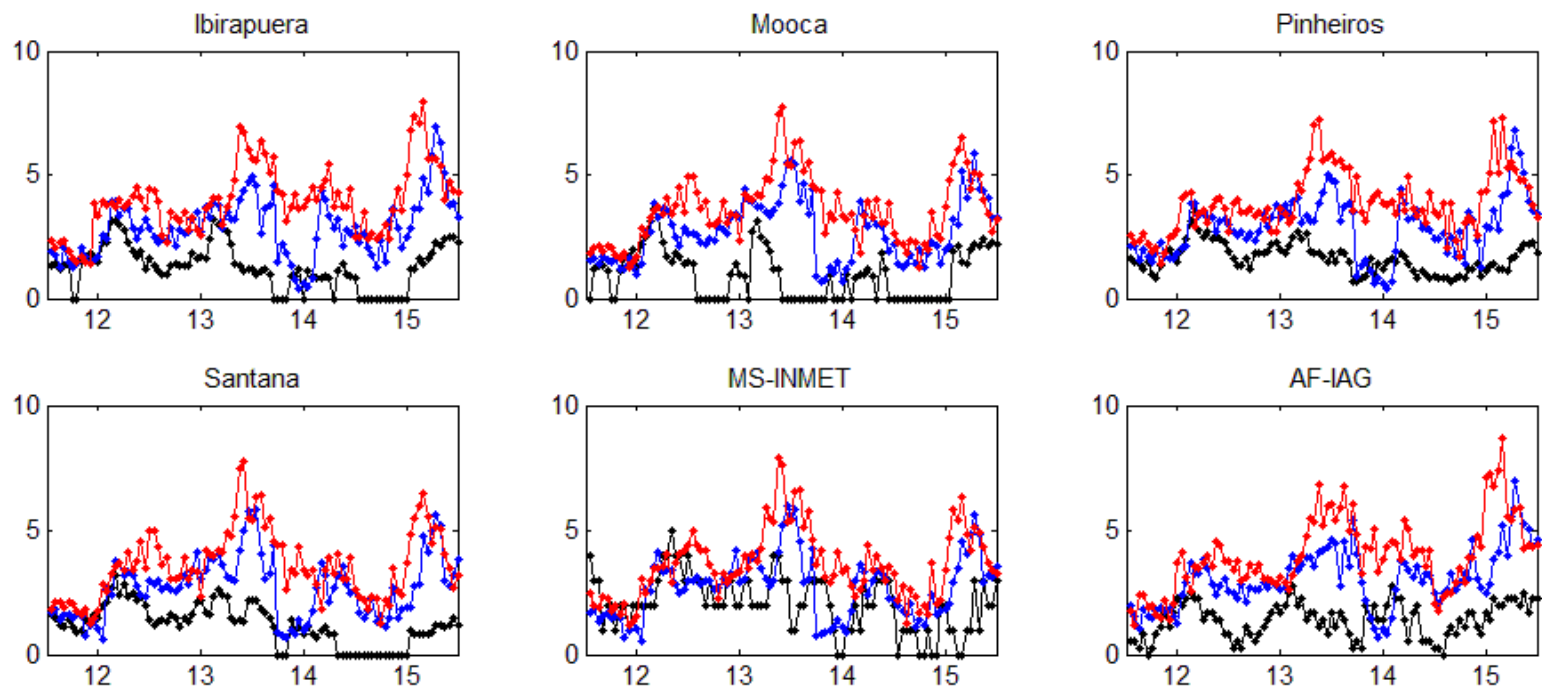

Figura 4.18. Intensidade do vento observada (pontos pretos) e simulada para grades com resoluções de $3 \mathrm{~km}$ (pontos azuis) e $1 \mathrm{~km}$ (pontos vermelhos) em ' $\mathrm{m} / \mathrm{s}$ ' para seis estações na RMSP para o período de 12 a 15 de novembro de 2011.

Quanto à direção, pode-se observar nas figuras 4.19 e 4.20 que o modelo representou coerentemente a distribuição dos ventos nas estações Pinheiros, MSINMET e AF-IAG, com componentes vindo predominantemente de direções entre S-E, no entanto, apresentou deficiência na representação dos ventos calmos provenientes de direções entre NE-E comuns às estações Ibirapuera, Mooca e Santana. Contudo, quando a velocidade do vento está abaixo de $0,5 \mathrm{~m} / \mathrm{s}$ o instrumento de medição não consegue medir a direção e velocidade com precisão. Ao todo, sabe-se através da literatura que os modelos numéricos de uma forma geral não possuem sensibilidade suficiente para simular velocidade do vento muito baixa (Albuquerque, 2010). Como já observado na 
figura 4.18, as rosas dos ventos mostram que a intensidade do vento foi superestimada pelas configurações das duas grades, principalmente, a de $1 \mathrm{~km}$.

Ibirapuera
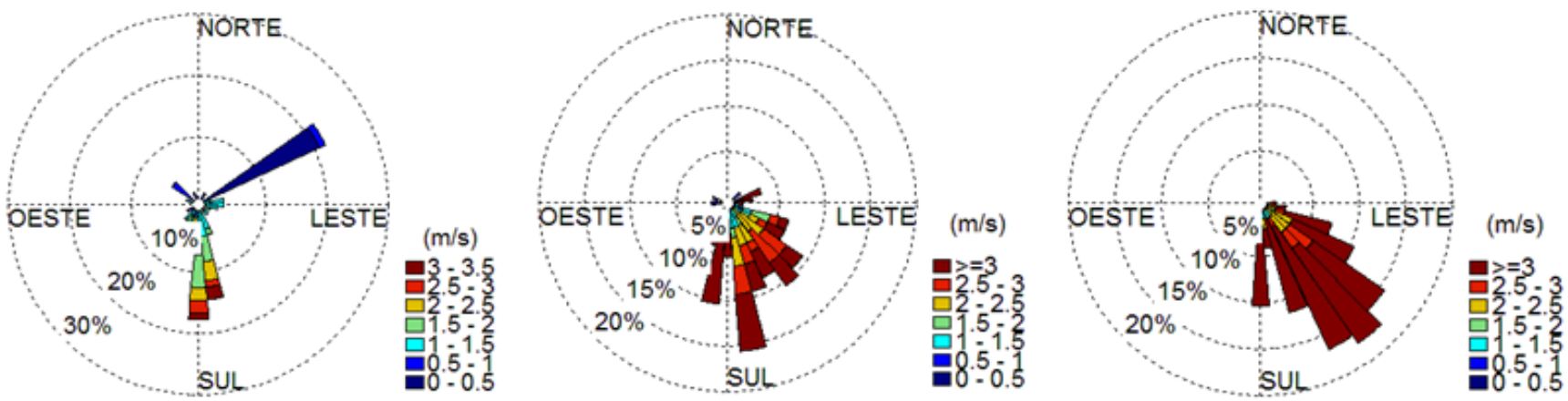

Mooca
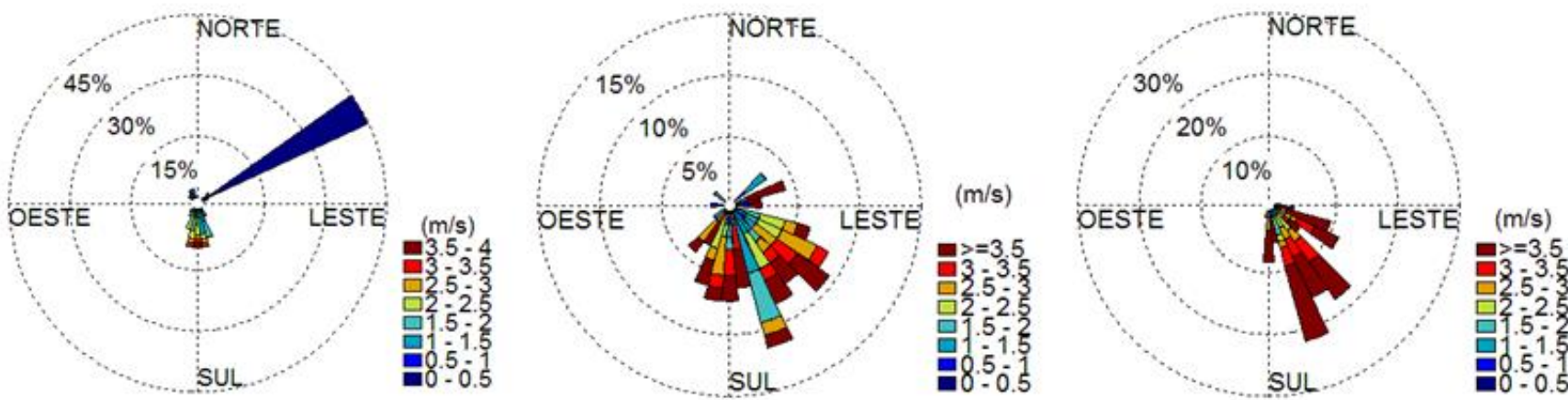

Pinheiros
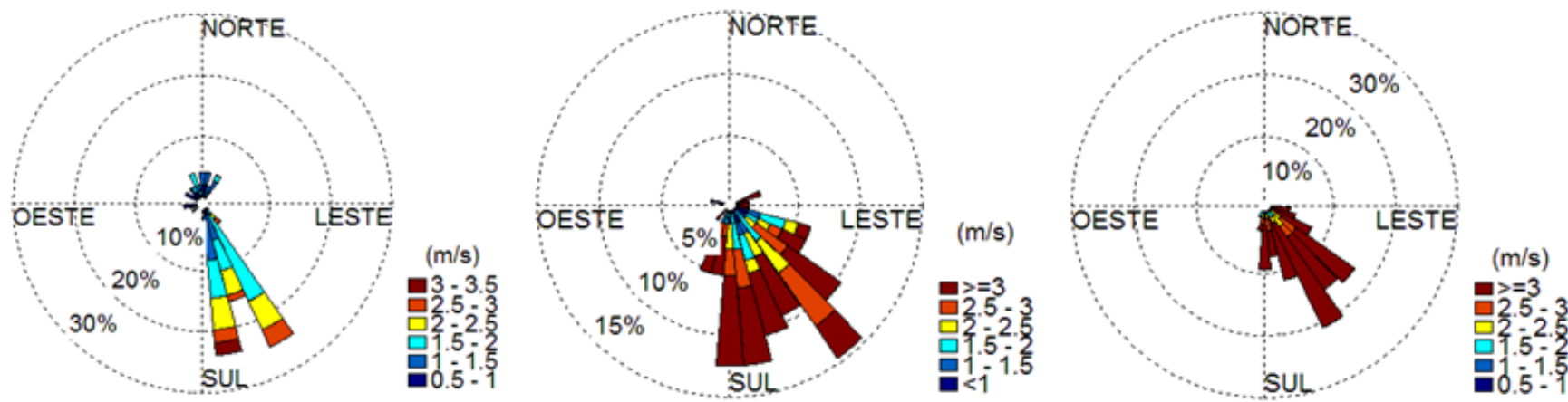

Figura 4.19. Rosa dos ventos observada (esquerda) e simulada a $3 \mathrm{~km}$ (centro) e $1 \mathrm{~km}$ (direita) para as estações Ibirapuera (superior), Mooca (centro) e Pinheiros (inferior) na RMSP para o período de 12 a 15 de novembro de 2011. 


\section{Santana}
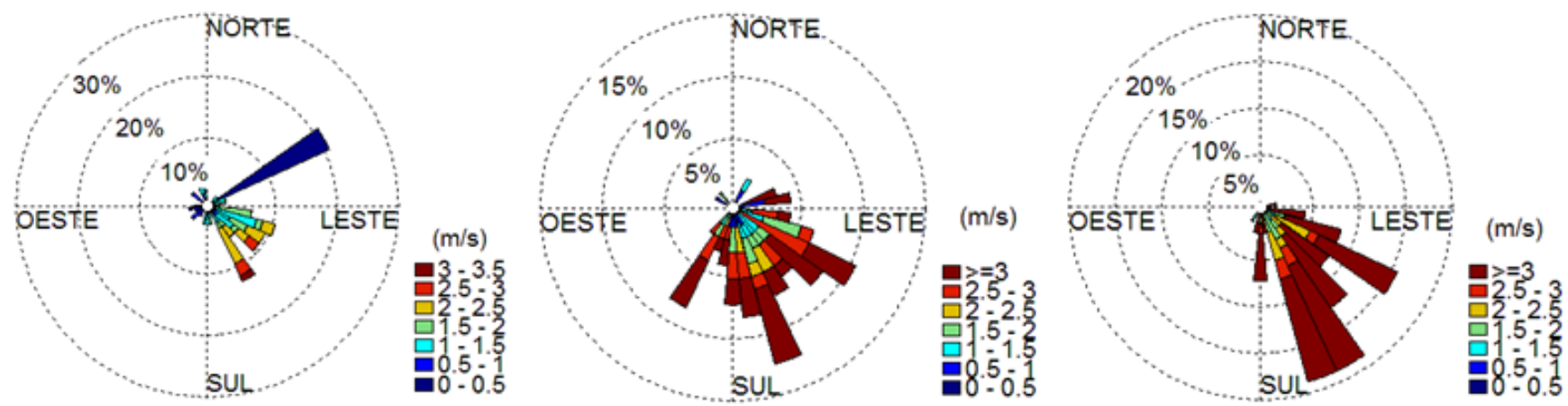

\section{MS-INMET}
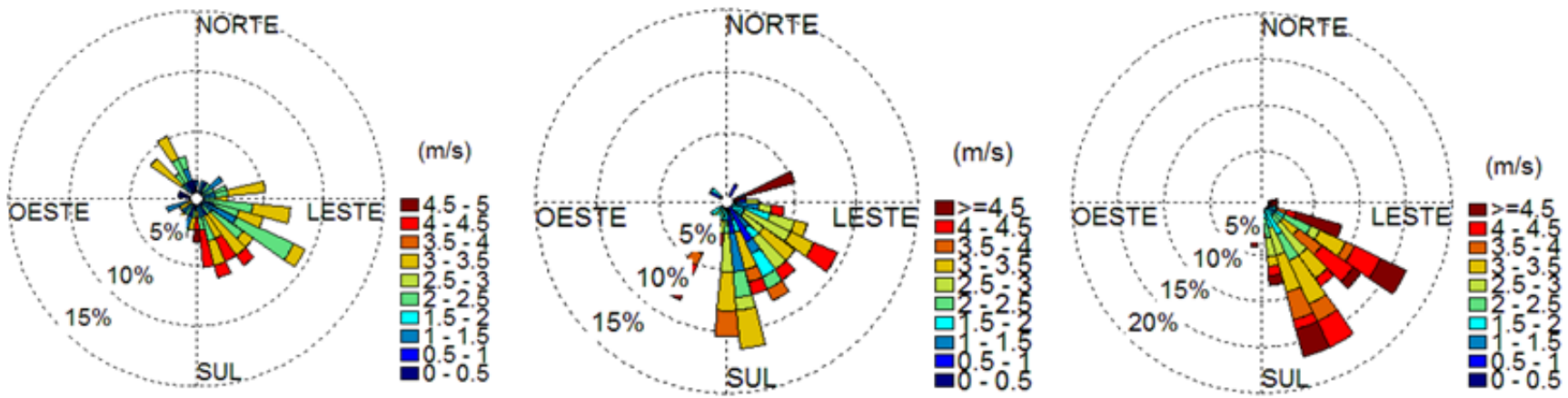

AF-IAG
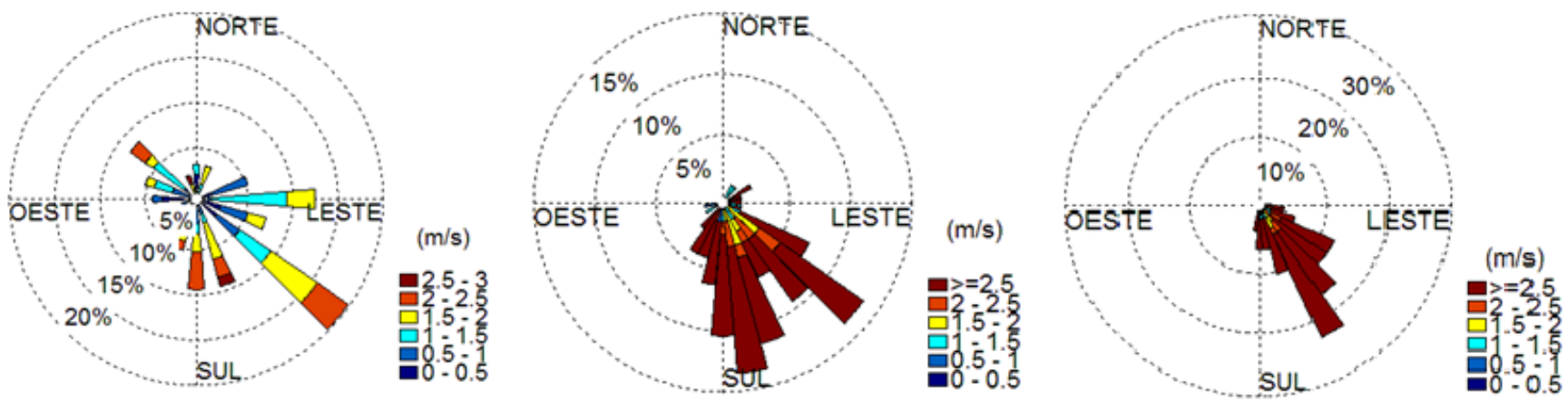

Figura 4.20. Rosa dos ventos observada (esquerda) e simulada a $3 \mathrm{~km}$ (centro) e $1 \mathrm{~km}$ (direita) para as estações Santana (superior), MS-INMET (centro) e AF-IAG (inferior) na RMSP para o período de 12 a 15 de novembro de 2011.

Os testes estatísticos (ver tabela 8.14 no apêndice E) mostram que a grade de 3 $\mathrm{km}$ representou melhor a variabilidade do vento do que a configuração estabelecida para a grade de $1 \mathrm{~km}$, diferentemente do período anterior em que a grade de $1 \mathrm{~km}$ foi quem representou melhor esta variável. Os coeficientes de correlação linear e índices de 
concordância foram, em geral, menores que 0,5 , enquanto que os erros $R M S E$ médios foram de 1,91 e $2,81 \mathrm{~m} / \mathrm{s}$ para as grades de 3 e $1 \mathrm{~km}$, respectivamente.

No caso do ozônio, tal como era esperado devido às características sinóticas do período, as concentrações observadas foram menores (apenas três estações registraram ultrapassagem do $P Q A$ ) com padrões decrescentes e ciclos diários irregulares, principalmente nos dias 14 e 15 quando o sistema frontal atingiu a região metropolitana, resultando em um impacto maior da nebulosidade sobre a fotoquímica de formação do ozônio, mostrando que condições meteorológicas muito diferentes podem ter grandes repercussões no comportamento e caracterização química do ozônio. Tie et al., 2009a e Geng et al., 2007, estudando a variabilidade do ozônio para períodos caracterizados pela transição entre duas situações sinóticas diferentes, concluíram que as tendências observadas de diminuição e aumento do ozônio ao longo dos períodos analisados respondem diretamente as mudanças das condições meteorológicas. No estudo realizado por Tie et al., 2009a, por exemplo, observa-se um padrão de diminuição de ozônio parecido ao padrão das concentrações observadas neste período de estudo (ver figura 4.21), no entanto, preservando o ciclo diário já que a diminuição da concentração foi ocasionada por processos de transporte associados com a atuação de uma alta subtropical e não por efeitos de nebulosidade e/ou precipitação. A figura 4.21 mostra as séries temporais observadas (pontos pretos) e simuladas para resoluções de $3 \mathrm{~km}$ (pontos azuis) e $1 \mathrm{~km}$ (pontos vermelhos) em ' $\mu \mathrm{g} / \mathrm{m}^{3}$, para dez estações da rede de monitoramento da CETESB (ver tabela 8.4 no apêndice D). A linha verde representa o $P Q A$ para este poluente $\left(160 \mu \mathrm{g} / \mathrm{m}^{3}\right)$. Como no período anterior, também neste período foi a configuração com a grade de $3 \mathrm{~km}$ quem melhor representou a variabilidade do ozônio. Observa-se da figura 4.21 que o modelo consegue representar coerentemente os ciclos de formação do ozônio durante os dias 12 e 13 (situação pré-frontal com instabilidades), inclusive com representação razoavel dos picos máximos na grade de 3 km, no entanto, com grande deficiência para representar o padrão irregular observado durante os dias 14 e 15 (passagem da frente fria), calculando um padrão de concentração pouco variável dentre 30 e $50 \mu \mathrm{g} / \mathrm{m}^{3}$. Dada a caracteristica dos padrões de concentração de ozonio calculados, podemos associar as baixas concentrações calculadas na RMSP com a nebulosidade e precipitação (ver figura 4.23) e principalmente com o transporte do ozonio para o interior do continente (ver figuras 4.24 e 4.25), onde foram observados núcleos de alta concentração. 

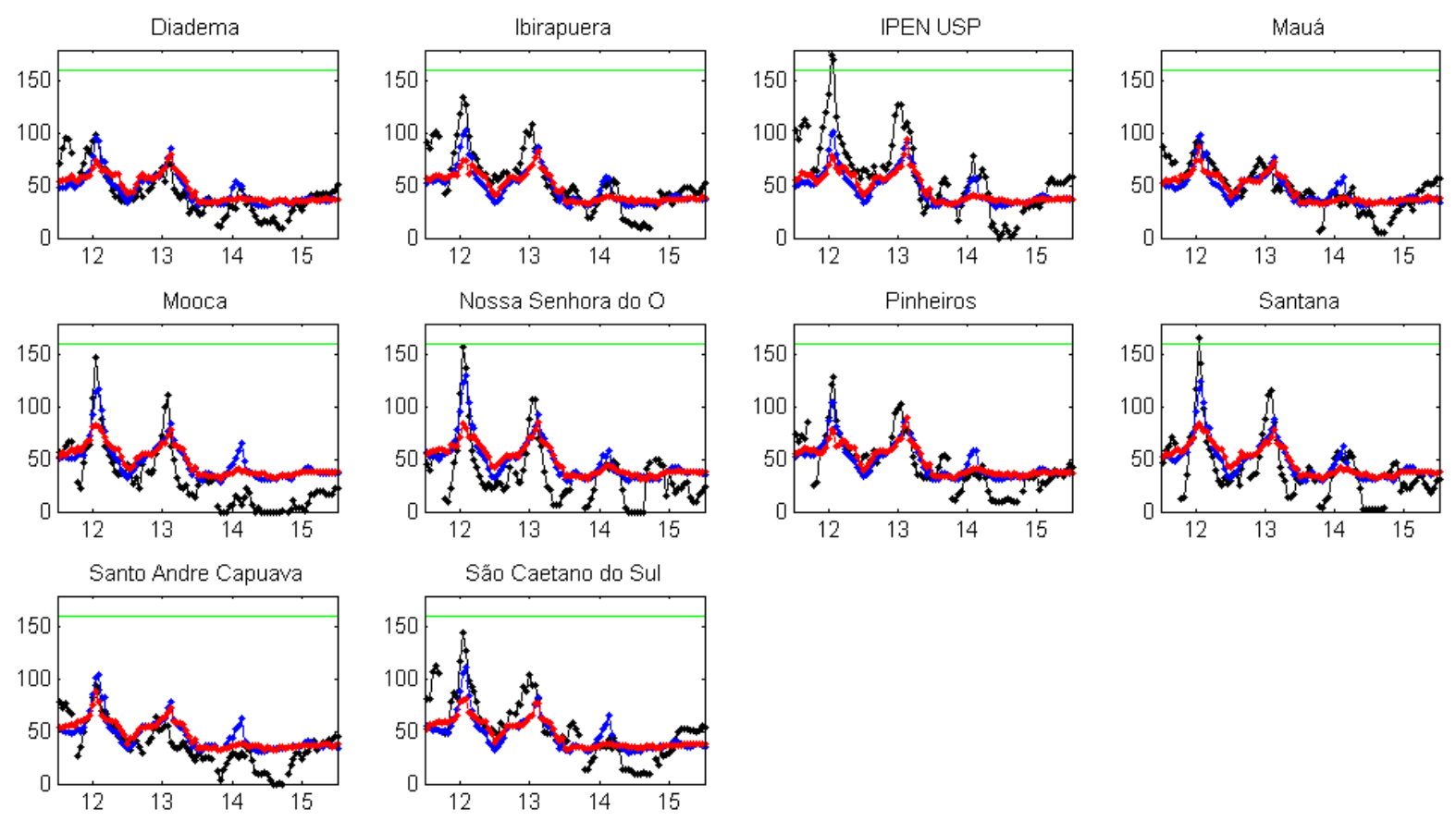

Figura 4.21. Concentração de ozônio observada (pontos pretos) e simulada a $3 \mathrm{~km}$ (pontos azuis) e $1 \mathrm{~km}$ (pontos vermelhos) em ' $\mu \mathrm{g} / \mathrm{m}^{3}$ ' para dez estações na $R M S P$ para o período de 12 a 15 de novembro de 2011.

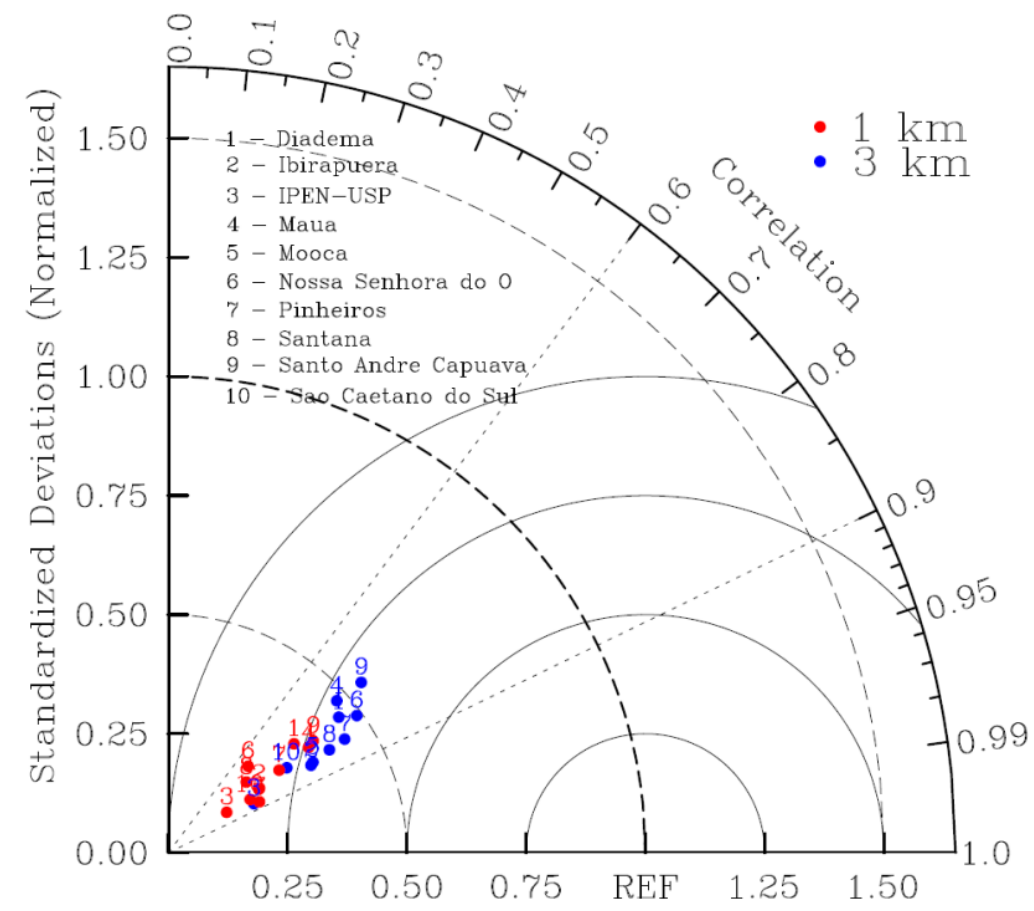

Figura 4.22. Diagrama de Taylor para a concentração do ozônio em onze estações na RMSP para o período de 12 a 15 de novembro de 2011. 
Os testes estatísticos (ver tabelas 8.15 e 8.16 no apêndice E) mostram, em geral, que a configuração estabelecida para a grade de $3 \mathrm{~km}$ foi quem melhor representou a evolução temporal do ozônio. Os coeficientes de correlação linear e índices de concordância foram, em geral, superiores a 0,7. Os erros RMSE médios foram de 18,9 e 20,4 $\mu \mathrm{g} / \mathrm{m}^{3}$ para as grades de 3 e $1 \mathrm{~km}$, respectivamente. O estatístico $\mathrm{PO}_{3}$ para representação da previsão média do pico de ozônio foi de -3.24 e $-21.15 \%$ para as grades de 3 e $1 \mathrm{~km}$, respectivamente, no caso pareado. A figura 4.22 mostra o Diagrama de Taylor para a concentração do ozônio em ambas as grades. Neste diagrama é possível observar, por exemplo, que a simulação com a grade de $3 \mathrm{~km}$ representou melhor a dispersão das concentrações observadas.

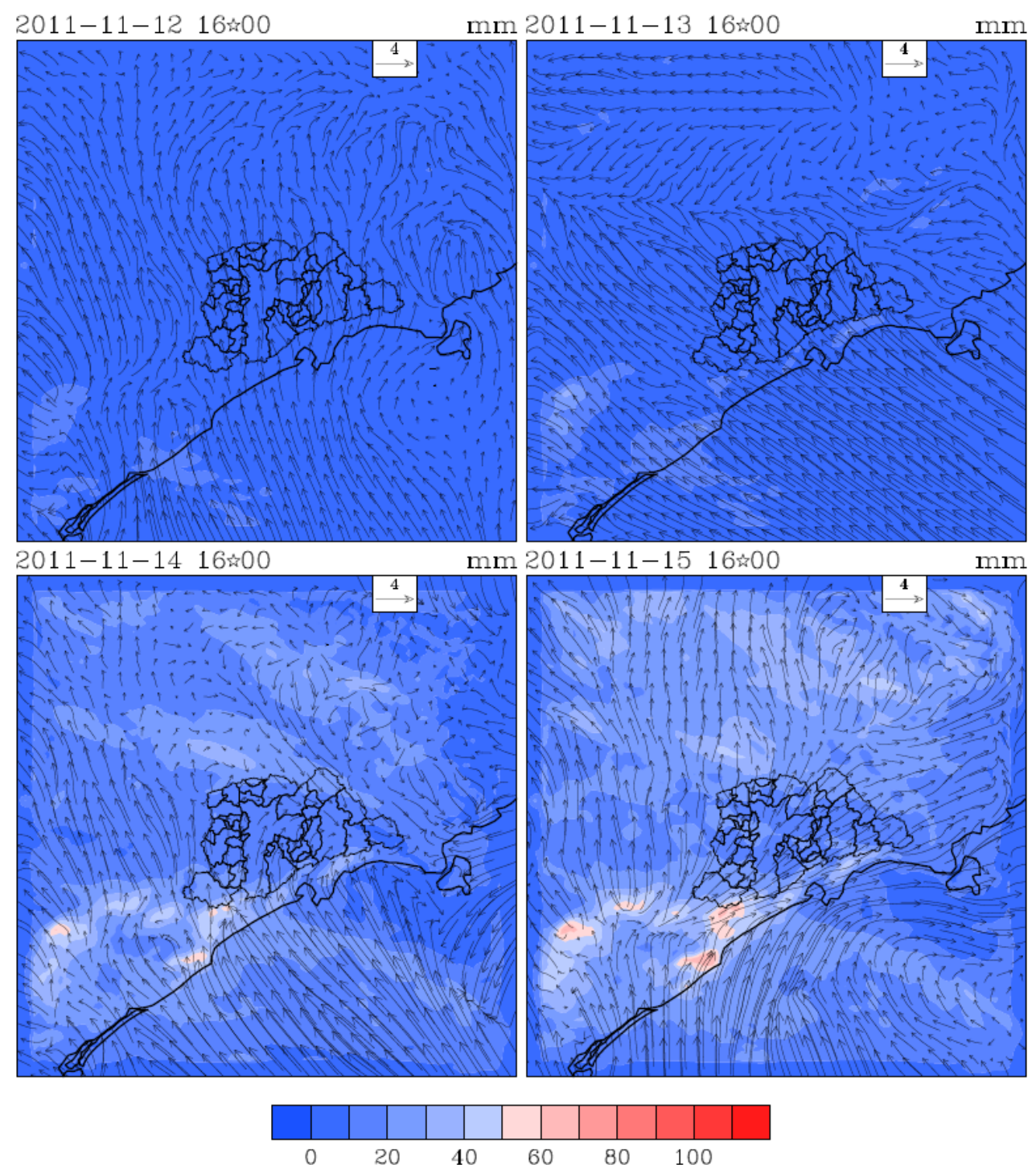

Figura 4.23. Cálculo superficial de precipitação acumulada horária em ' $m m$ ' às $14 \mathrm{~h}$, hora local, para a grade de $3 \mathrm{~km}$ para o período de 12 a 15 de novembro de 2011. 
As figuras 4.24 e 4.25 mostram o cálculo superficial da concentração do ozônio para as grades de 3 e $1 \mathrm{~km}$, respectivamente, às 14 horas, hora local. Destas figuras é possível observar que as concentrações calculadas sobre a $R M S P$ são, em geral, maiores na grade de $3 \mathrm{~km}$ do que na de $1 \mathrm{~km}$, produto de um transporte mais efetivo de ozônio para o interior do Estado, produzido pelo intenso campo de vento calculado nesta última grade (ver figuras $4.18 ; 4.19$ e 4.20 ).
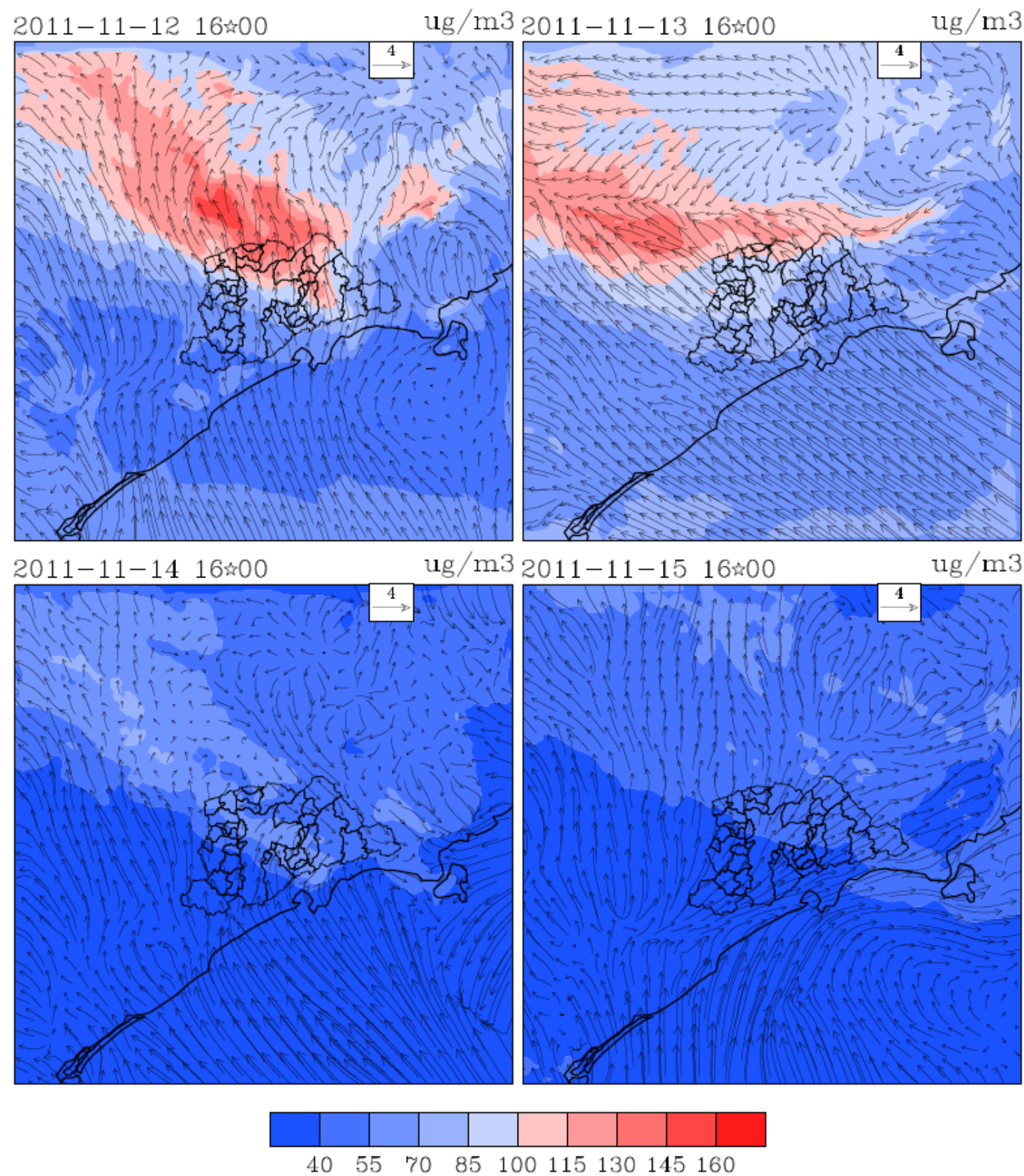

Figura 4.24. Cálculo superficial de ozônio às 14h, hora local, na grade de $3 \mathrm{~km}$ para o período de 12 a 15 de novembro de 2011. 

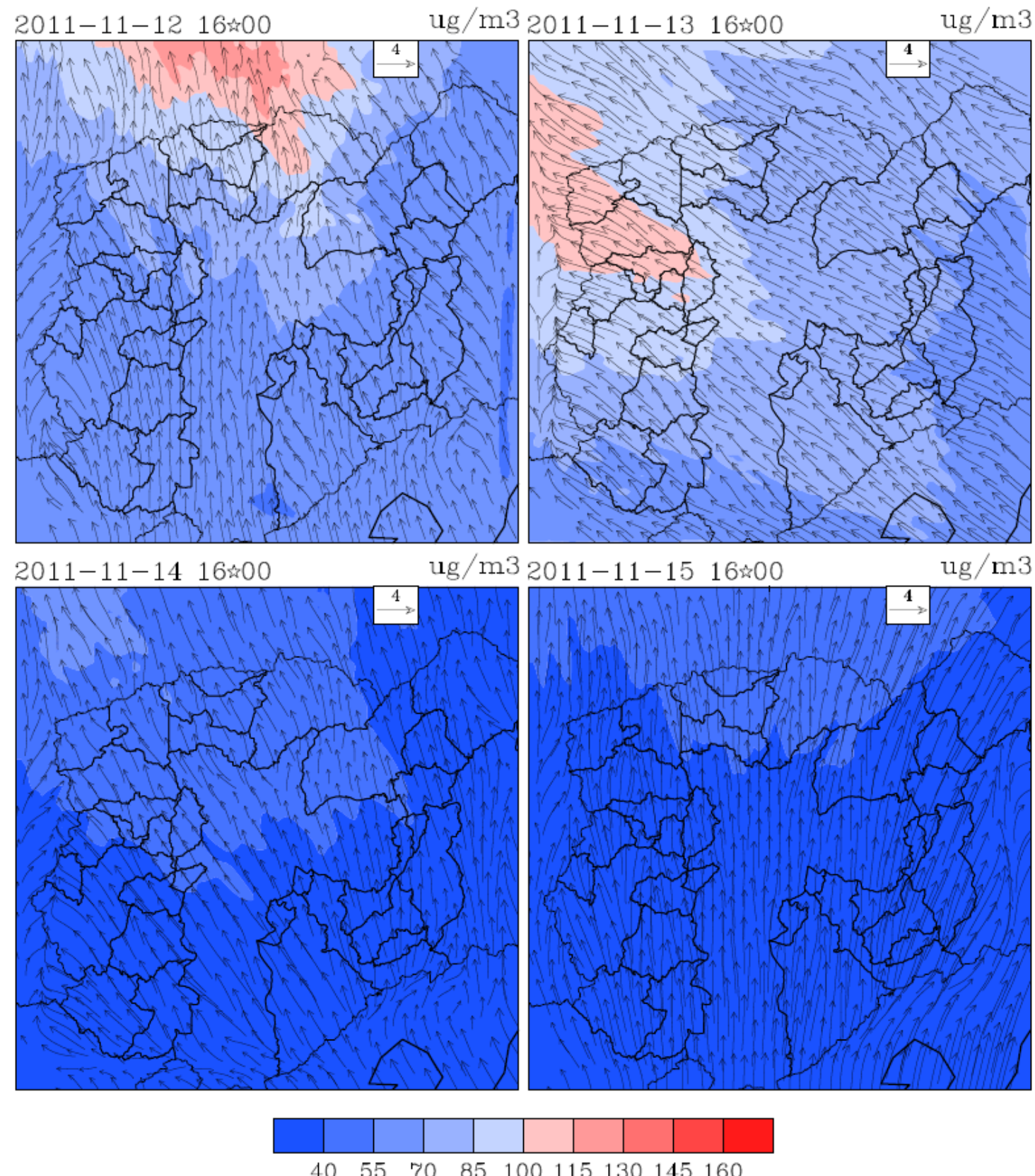

Figura 4.25. Cálculo superficial de ozônio às $14 \mathrm{~h}$, hora local, na grade de $1 \mathrm{~km}$ para o período de 12 a 15 de novembro de 2011.

Apesar da simulação considerando a grade de $1 \mathrm{~km}$ mostrar um transporte maior do ozônio para o interior do continente e não considerar o efeito do transporte remoto do ozônio e seus precursores provenientes de outras regiões metropolitanas como, por exemplo, a Baixada Santista, dada a direção predominante do vento (ver figuras 4.19 e 4.20); as diferenças entre as concentrações medidas e simuladas por ambas as grades resultaram menores quando comparadas com o período anterior, fato que poderia estar relacionado com o estabelecimento de uma razão COV/NOx média maior para esta grade (ver tabela 2.4). Aliás, a inclusão de condições iniciais e de fronteira químicas na 
grade de $27 \mathrm{~km}$, por exemplo, do modelo de transporte químico global Model for Ozone And Related chemical Tracers (MOZART) poderia levar para uma melhora na representação do ozônio, principalmente durante os dias com características meteorológicas mais favoráveis à sua formação. Chuang et al., 2011 e Ritter et al., 2012 obtiveram uma melhor representação do ozônio a partir de uma modificação adequada das condições de fronteira laterais. Outro aspecto importante não considerado no cálculo das emissões é o impacto produzido pelas diferenças nos padrões de tráfego veicular durante dias de semana e finais de semana sobre a concentração de ozônio. Silva Junior et al., 2009 indicam a ocorrência de concentrações de ozônio mais elevadas no fim de semana quando comparadas com os dias de semana devido ao fato das concentrações de seus precursores serem mais baixas nos finais de semana, em especial o NOx. A ausência de um perfil de emissão de final de semana pode ter influenciado na subestimativa do ozônio calculado, principalmente neste período, dado que os dias em que foram observadas altas concentrações de ozônio (12 e 13 de Novembro) foram sábado e domingo, respectivamente. Quanto às concentrações observadas dos precursores de ozônio: $C O$ e $N O x$, muitas das estações consideradas mostram novamente o que já foi discutido na seção anterior com relação as localizações das estações de qualidade do ar. As concentrações de $C O$ e $N O x$ nas estações Congonhas e Ibirapuera, por exemplo (ver figuras 4.24 e 4.25), voltam a mostrar quão importantes são as características dos locais de amostragem e seus entornos quanto à emissão, com propósito de avaliar corretamente o desempenho de um modelo fotoquímico como o WRF-Chem. As figuras 4.26 e 4.27 mostram as séries temporais observadas (pontos pretos) e simuladas a $3 \mathrm{~km}$ (pontos azuis) e $1 \mathrm{~km}$ (pontos vermelhos) do $C O \mathrm{em}$ ' $p p m v$ ' e $N O x$ em ' $p p b v$ ', respectivamente, nas estações de qualidade do ar consideradas nesta comparação (ver tabela 8.4 no apêndice D). Analisando as séries temporais observadas do $C O$ e $N O x$ na maioria das estações consideradas, observa-se, em geral, dois períodos bem diferenciados: o primeiro (12-13 Novembro) com baixas concentrações destes poluentes e o segundo (14-15 Novembro) apresentando altas concentrações quando comparadas com as concentrações do período anterior. Durante o primeiro período, aparentemente caracterizado por um cenário típico de tráfego veicular, as concentrações do $C O$ foram, em geral, subestimadas pelo WRF-Chem, fato muito provavelmente relacionado com uma subestimativa nas emissões deste poluente, no entanto, no caso do NOx, as concentrações observadas foram representadas coerentemente pelo modelo. 

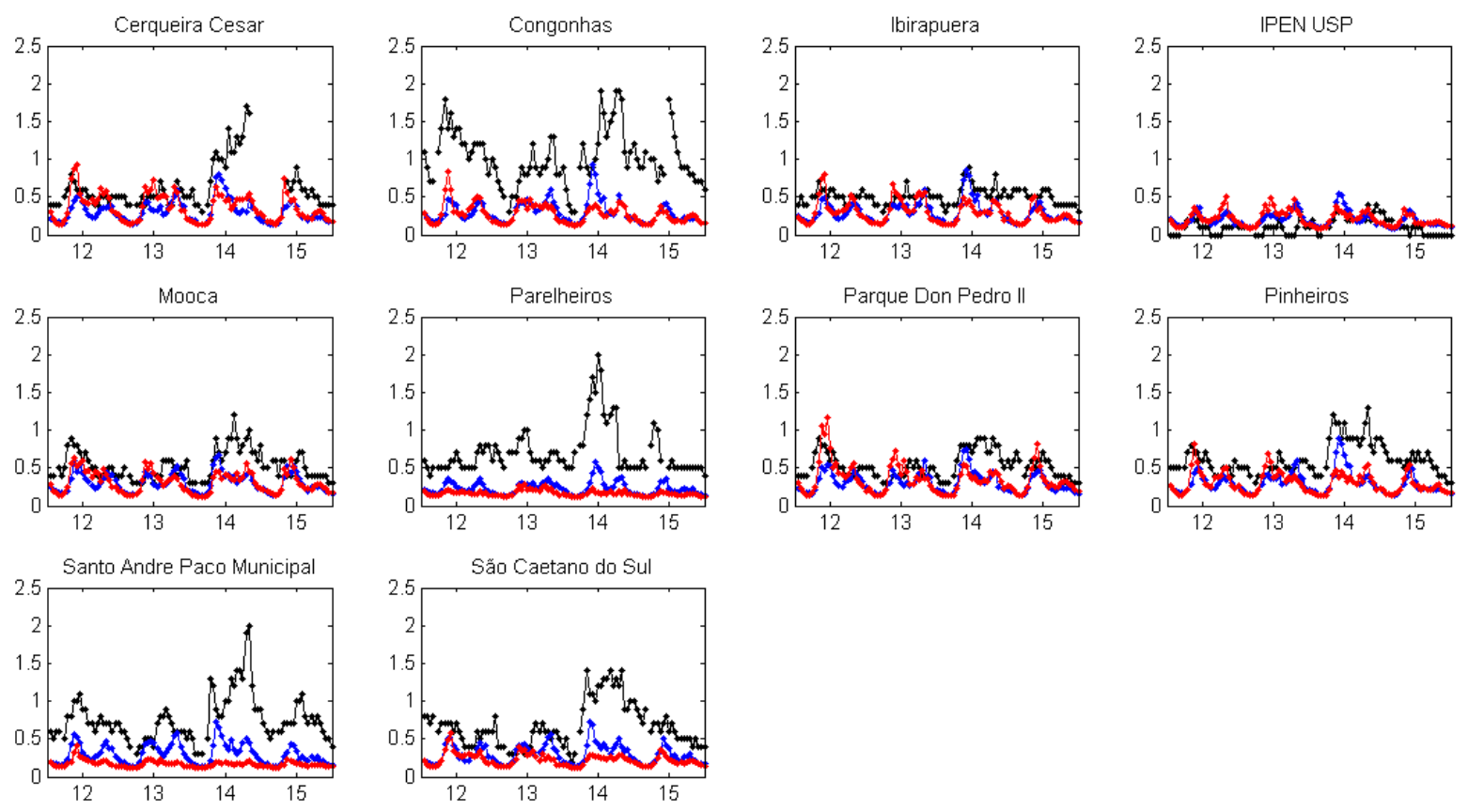

Figura 4.26. Concentração de $C O$ observada (pontos pretos) e simulada a $3 \mathrm{~km}$ (pontos azuis) e $1 \mathrm{~km}$ (pontos vermelhos) em ' $p p m v$ ' para dez estações na $R M S P$ para o período de 12 a 15 de novembro de 2011.
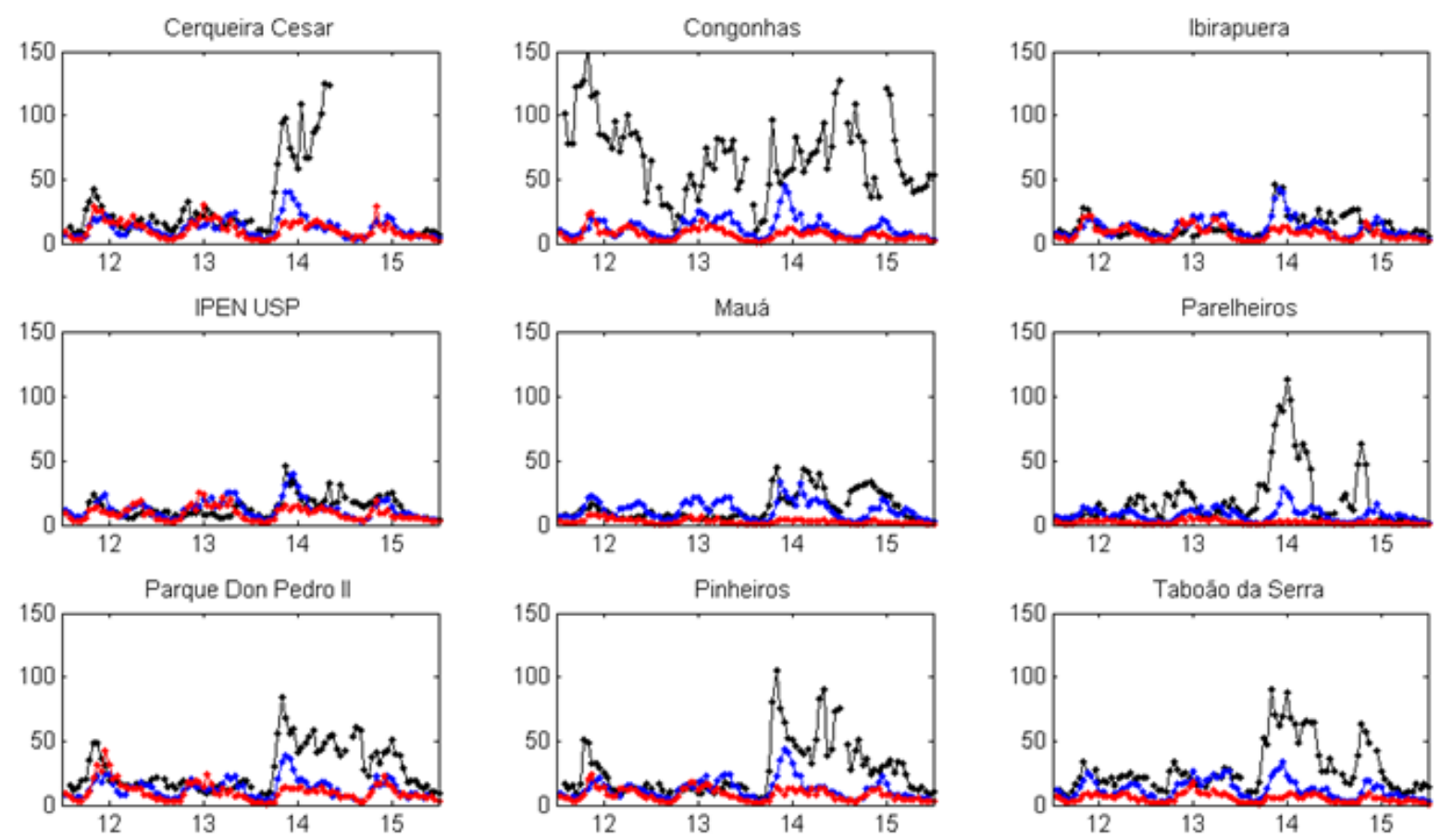

Figura 4.27. Concentração de $N O x$ observada (pontos pretos) e simulada a de $3 \mathrm{~km}$ (pontos azuis) e $1 \mathrm{~km}$ (pontos vermelhos) em ' $p p b v$ ' para nove estações na $R M S P$ para o período de 12 a 15 de novembro de 2011. 
Analisando as séries temporais observadas do $C O$ e $N O x$ na maioria das estações consideradas, observa-se, em geral, dois períodos bem diferenciados: o primeiro (12-13 Novembro) com baixas concentrações destes poluentes e o segundo (14-15 Novembro) apresentando altas concentrações quando comparadas com as concentrações do período anterior. Durante o primeiro período, aparentemente caracterizado por um cenário típico de tráfego veicular, as concentrações do $C O$ foram, em geral, subestimadas pelo WRFChem, fato muito provavelmente relacionado com uma subestimativa nas emissões deste poluente, no entanto, no caso do NOx, as concentrações observadas foram representadas coerentemente pelo modelo. Para ambos poluentes foi observado um rápido incremento das concentrações no começo do dia 14 por volta das $5 \mathrm{~h}$, característica razoavelmente representada pela configuração da grade de $3 \mathrm{~km}$ em algumas estações como Ibirapuera, IPEN USP (ver figuras 4.26 e 4.27). Dadas às condições meteorológicas observadas de nebulosidade e precipitação, podemos atribuir tais aumentos à ocorrência de um episodio de alta emissão, dificilmente representado pelo modelo na maioria das estações consideradas, devido às suas características inadequadas para a representação pontual de concentração.

Os testes estatísticos para as concentrações simuladas de $N O x$ (ver tabelas $8.17 \mathrm{e}$ 8.18 no apêndice E) e $C O$ (ver tabelas 8.19 e 8.20 no mesmo apêndice) mostram que a configuração da grade de $3 \mathrm{~km}$ representou melhor a variabilidade temporal desses poluentes. Os coeficientes de correlação linear e índices de concordância foram menores que 0,7 e 0,6, respectivamente para o caso do $C O$ e menores que 0,6 e 0,8, respectivamente, para o caso do NOx. Os erros RMSE médios foram de 0,40 e 0,43 ppmv para as grade de 3 e $1 \mathrm{~km}$, respectivamente, para o caso do $C O$, e 23,96 e 18,43 $p p b v$ para as grades de 3 e $1 \mathrm{~km}$, respectivamente, para o caso do $N O x$ e com melhor desempenho na representação da dispersão das concentrações observadas para a grade de $3 \mathrm{~km}$. A figura 4.28 mostra as séries temporais da razão CO/NOx observadas (pontos pretos) e simuladas com $3 \mathrm{~km}$ (pontos azuis) e $1 \mathrm{~km}$ (pontos vermelhos) de resolução em ' $p p m v / p p b v$ ' para sete estações na RMSP. Diferentemente do primeiro período de estudo (6-9 Setembro de 2004), neste é observada uma razão CO/NOx maior com a configuração da grade de $1 \mathrm{~km}$. Esta razão maior para a grade de $1 \mathrm{~km}$ está associada com uma subestimativa da concentração do $N O x$, fato que certamente tem influenciado em uma estimativa mais acurada do ozônio (menores diferenças entre as concentrações simuladas em ambas grades) quando comparado para o primeiro período de estudo (ver 
tabela 2.4), apesar da contribuição negativa produzida pelo intenso transporte do ozônio para o interior do Estado.
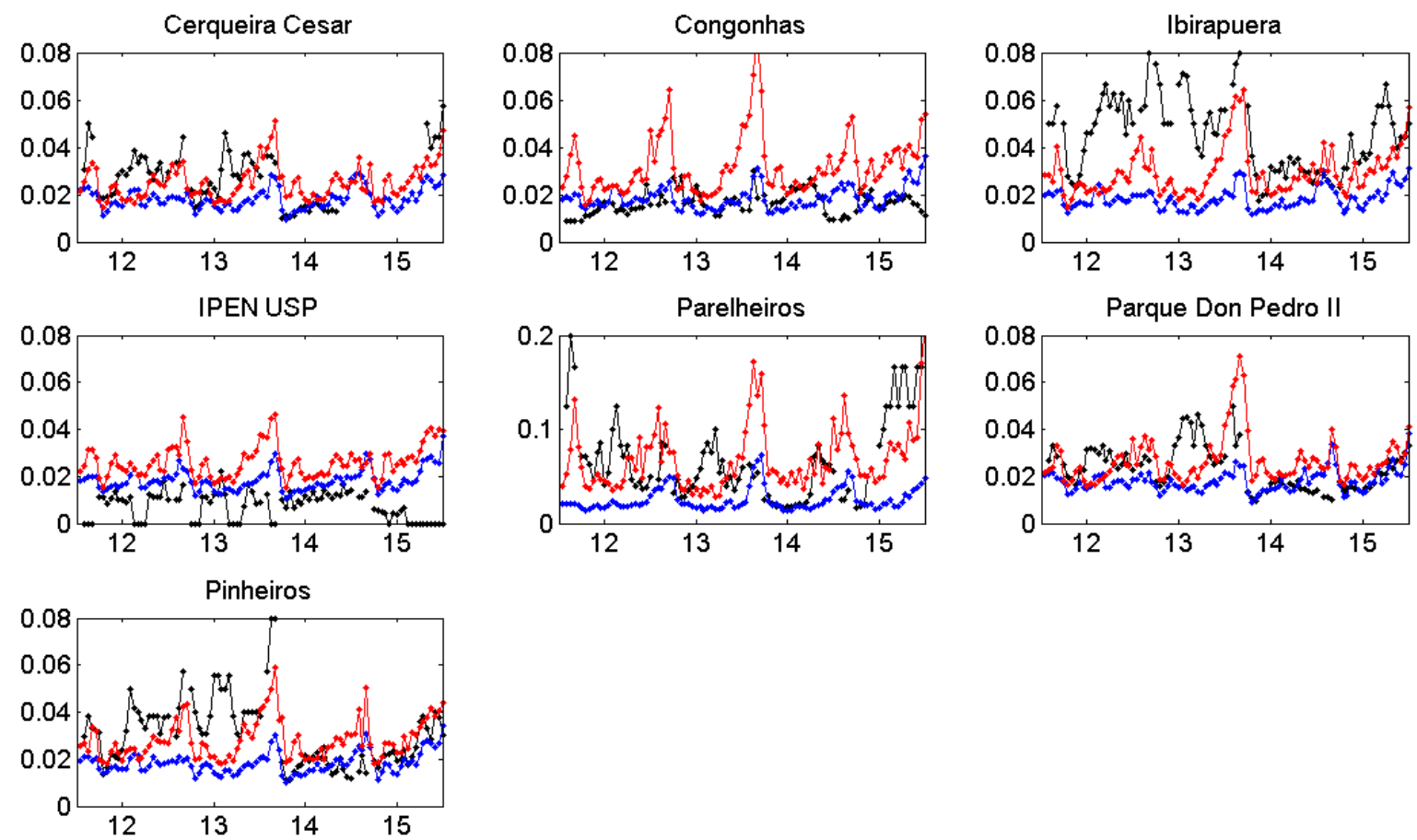

Figura 4.28. Razão CO/NOx observada (pontos pretos) e simulada para resolução de 3 km (pontos azuis) e $1 \mathrm{~km}$ (pontos vermelhos) em ' $p p m v / p p b v$ ' para sete estações na RMSP para o período de 12 a 15 de novembro de 2011.

Das figuras 4.26 e 4.27 e a tabela 2.4 podemos dizer que a estimativa ligeiramente maior das concentrações de $C O$ com a grade de $3 \mathrm{~km}$, apesar de apresentar uma emissão total menor quando comparada com a grade de $1 \mathrm{~km}$, deve-se aos campos de vento menos intensos, produzindo uma menor diluição das concentrações deste poluente na $R M S P$. No caso do NOx as menores concentrações simuladas com a configuração da grade de $1 \mathrm{~km}$ estariam relacionadas diretamente com a subestimativa da emissão total e maior diluição pelo transporte para áreas externas à região metropolitana. Finalmente, como no caso do período anterior, aplicando o critério sugerido por Sillman, 1995, concluímos que a $R M S P$ esta sobre um regime $\mathrm{COV}$-limitante, conforme apresentado na figura 4.29 . 


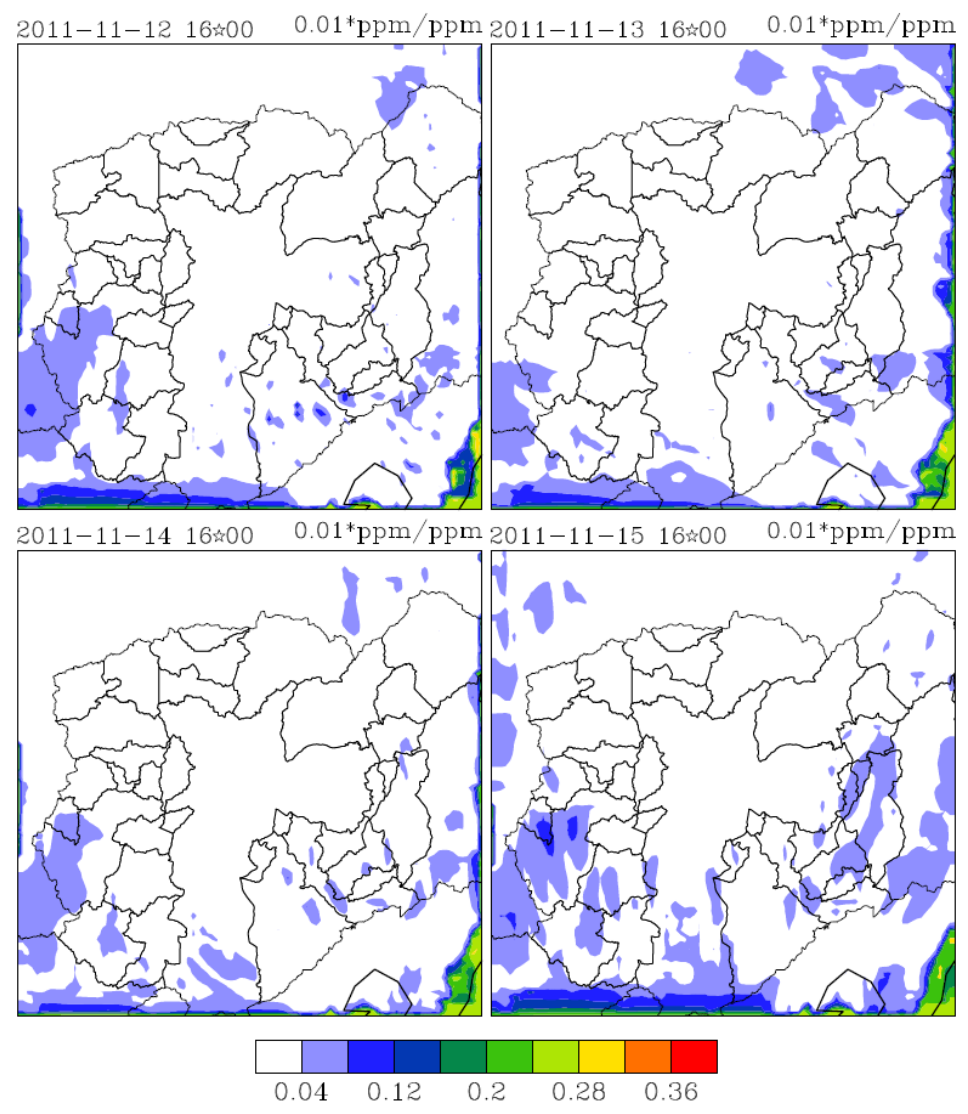

Figura 4.29. Cálculo da razão $\mathrm{CH}_{2} \mathrm{O} / \mathrm{NOy}$ para a grade de $1 \mathrm{~km}$ às $14 \mathrm{~h}$, hora local. 


\subsection{Cenário de emissão com os FE 2004 atuando no período estabelecido para 0 ano 2011}

Para avaliar o impacto da mudança dos fatores de emissão sobre a produção de ozônio, simularam-se cenários de emissão considerando os fatores de emissão de 2004 atuando em 2011. Para atender tal objetivo, foram realizadas duas simulações, uma para cada grade, com as forçantes químicas baseadas nos $F E$ do ano 2004. Posteriormente, aos resultados obtidos foram subtraídos os resultados obtidos das simulações do caso base de 2011 (seção 4.2).
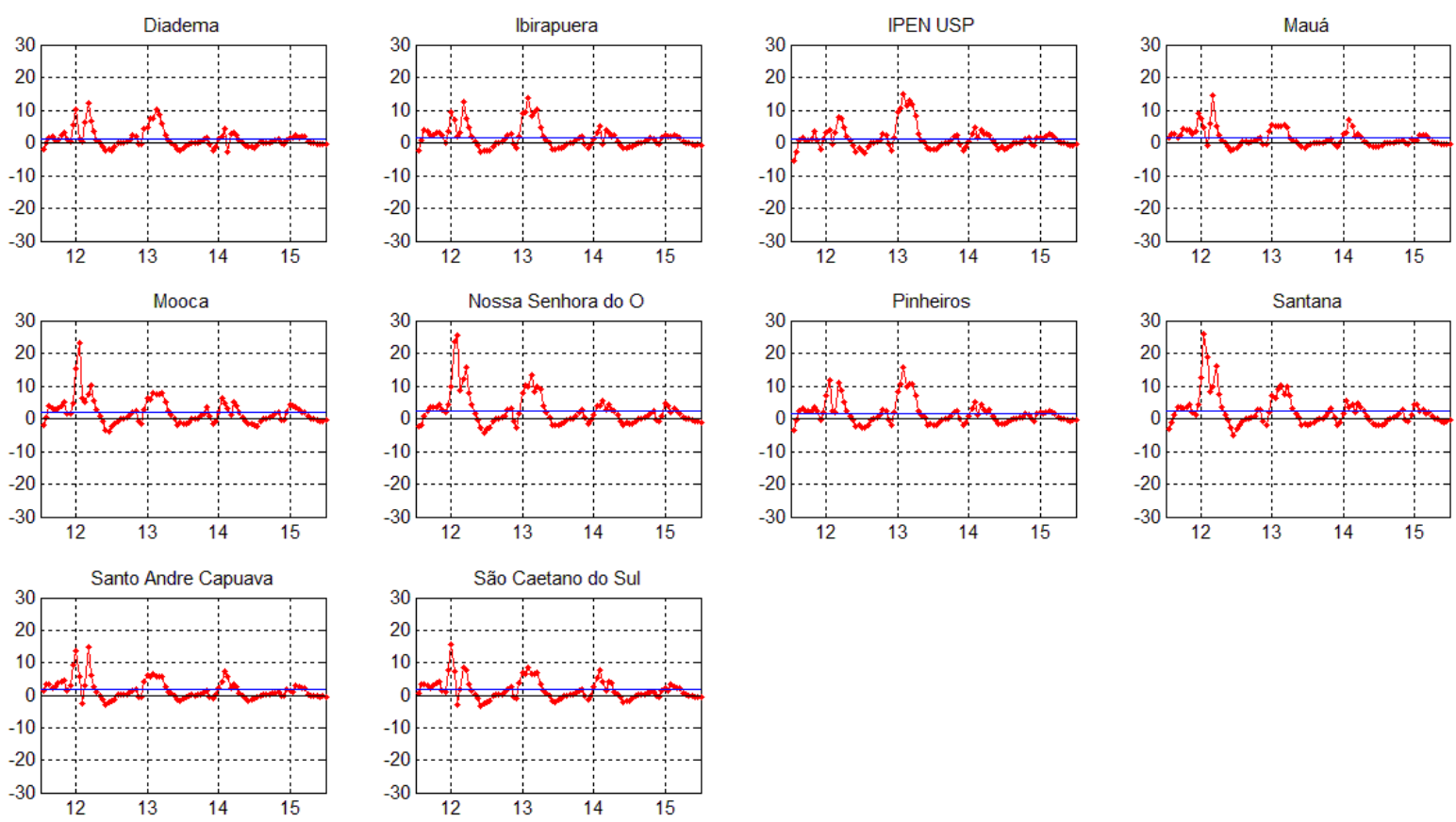

Figura 4.30. Diferença de concentração de ozônio, em ' $\mu \mathrm{g} / \mathrm{m}^{3}$ ', entre o cenário com os FE referentes ao ano de 2004 atuando em 2011, e a simulação correspondente para o período de 12 a 15 de novembro de 2011 para a grade de $3 \mathrm{~km}$. A linha azul representa o valor médio do período.

As figuras 4.30 e 4.31 mostram as diferenças de concentração para o ozônio e $N O x$, respectivamente, para a grade de $3 \mathrm{~km}$ em dez locais (estações consideradas para avaliação do ozônio no período de 12-15 de Novembro de 2011) na RMSP. Destas figuras observa-se uma diferença positiva de até $30 \mu \mathrm{g} / \mathrm{m}^{3}$ durante os horários de 
máxima concentração de ozônio, no entanto, negativas próximas de zero durante a noite para o caso do ozônio. No caso do NOx observa-se um comportamento similar com diferenças positivas durante a maior parte do dia, no entanto, com valores negativos durante as primeiras horas do dia com picos mínimos de até $-50 p p b v$ às $9 \mathrm{~h}$ aproximadamente. As diferenças positivas de ozônio indicam uma redução do ozônio e estão relacionadas com uma diminuição da emissão dos seus precursores em 2011 (ver tabela 2.4). Observar, no entanto, que as razões médias COV/NOx são muito parecidas (4,09 para o ano 2004 e 4,39 para o ano 2011).
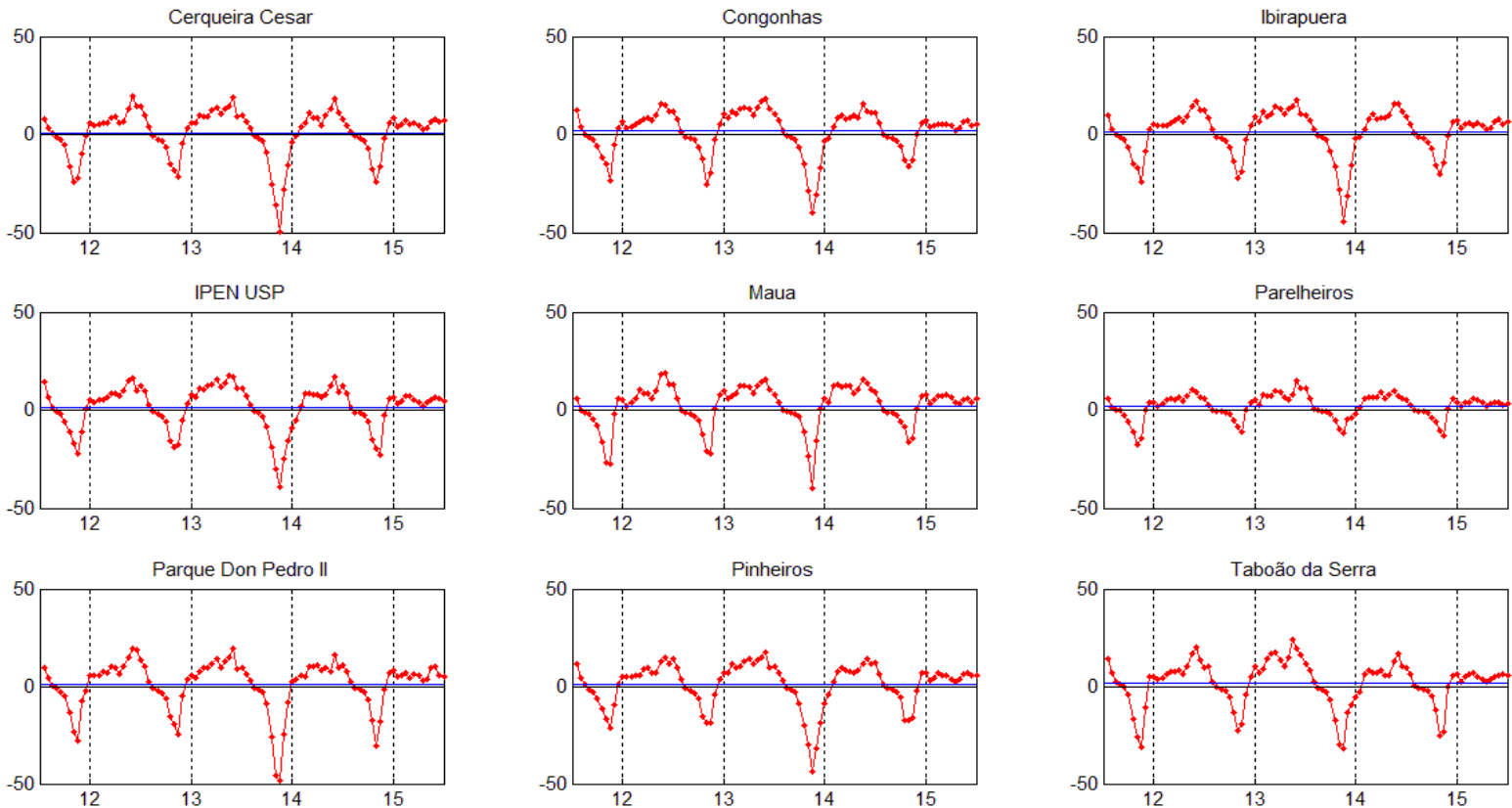

Figura 4.31. Diferença de concentração do $N O x$, em ' $p p b v$ ', entre o cenário com os $F E$ referentes ao ano de 2004 atuando em 2011, e a simulação correspondente para o período de 12 a 15 de novembro de 2011 para a grade de $3 \mathrm{~km}$. A linha azul representa o valor médio do período.

Apesar da pouca representatividade das simulações para este período, o resultado do cenário de emissão para a grade de $3 \mathrm{~km}$ indica que uma diminuição da emissão dos precursores do ozônio em proporções parecidas produz uma diminuição na eficiência de formação de ozônio. As figuras 4.32 e 4.33 mostram as diferenças mostradas nas figuras 4.30 e 4.31 para as concentrações de ozônio e $N O x$, respectivamente, na grade de $1 \mathrm{~km}$. Para esta resolução as diferenças entre as duas simulações foram menores quando 
comparadas com a grade de $3 \mathrm{~km}$ para o caso do ozônio, com valores de até $10 \mu \mathrm{g} / \mathrm{m}^{3}$ durante os horários de máxima formação de ozônio. Quanto ao $N O x$, as diferenças máximas encontradas foram maiores que as observadas com a grade de $3 \mathrm{~km}$, com valores de até 50 ppbv e estão relacionadas com uma subestimativa da emissão de $N O x$ maior na grade de $1 \mathrm{~km}$ para o ano de 2011. Os resultados indicam também que uma diminuição da emissão dos precursores de ozônio, principalmente do $N O x$ (razão média COV/NOx de 3,20 considerando os $F E$ do ano 2004 e 6,67 para o cenário natural em 2011, considerando a grade de $1 \mathrm{~km}$ ), levam para uma formação de ozônio mais eficiente quando comparada com as simulações com a grade de $3 \mathrm{~km}$. Uma perspectiva espaço-temporal das diferenças de concentração de ozônio troposférico é mostrada no apêndice F. Como observado nas figuras 4.30 e 4.32, as figuras no apêndice F mostram novamente as oscilações positivas durante o dia e negativas durante a noite, no entanto, com as máximas diferenças calculadas em regiões no interior do Estado externas à RMSP como resposta aos intensos campos de vento calculados em ambas as grades.
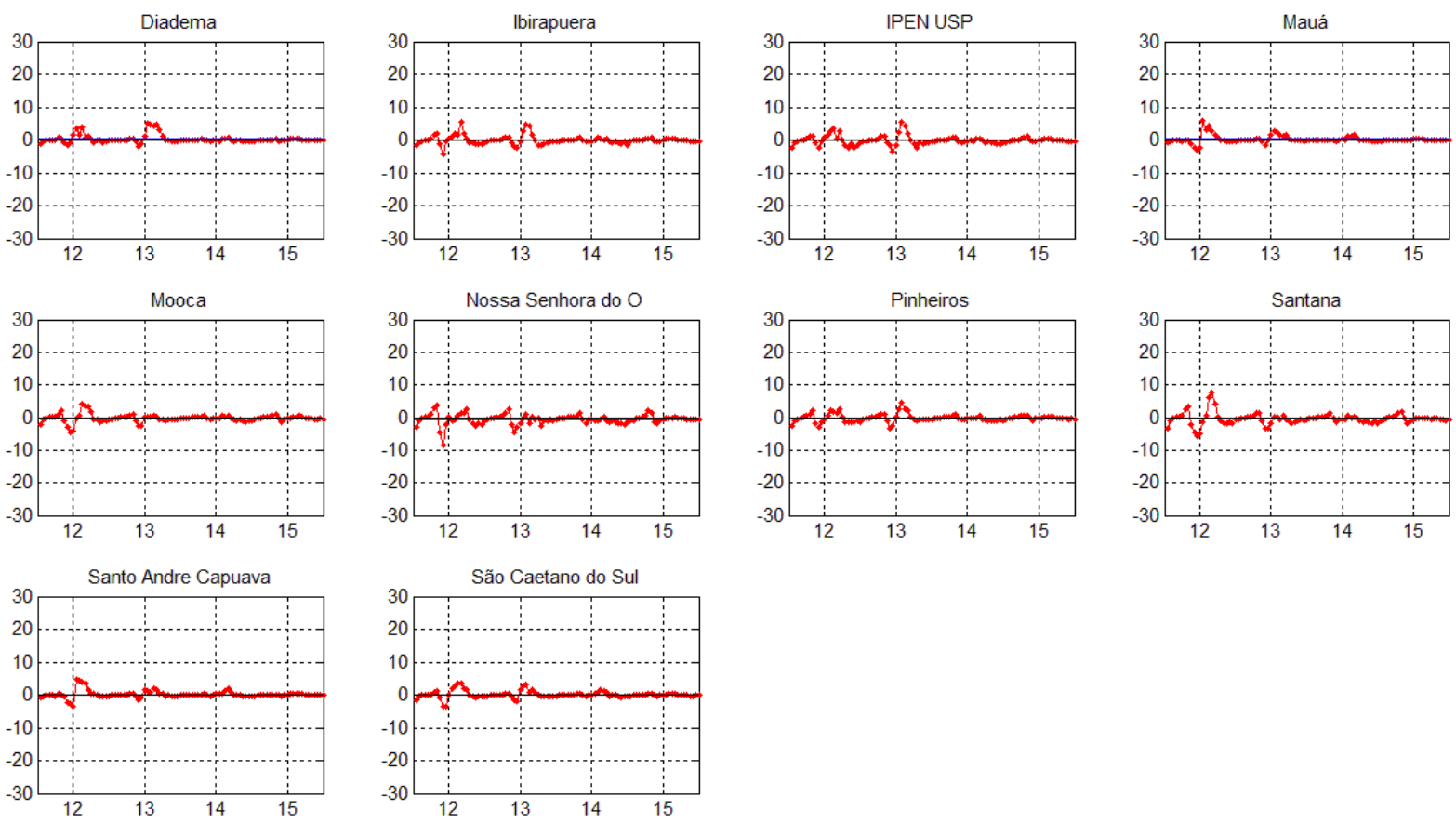

Figura 4.32. Diferença da concentração de ozônio, em ' $\mu \mathrm{g} / \mathrm{m}^{3}$ ', entre o cenário com os FE referentes ao ano de 2004 atuando em 2011, e a simulação correspondente para o período de 12 a 15 de novembro de 2011 para a grade de $1 \mathrm{~km}$. A linha azul representa o valor médio do período. 

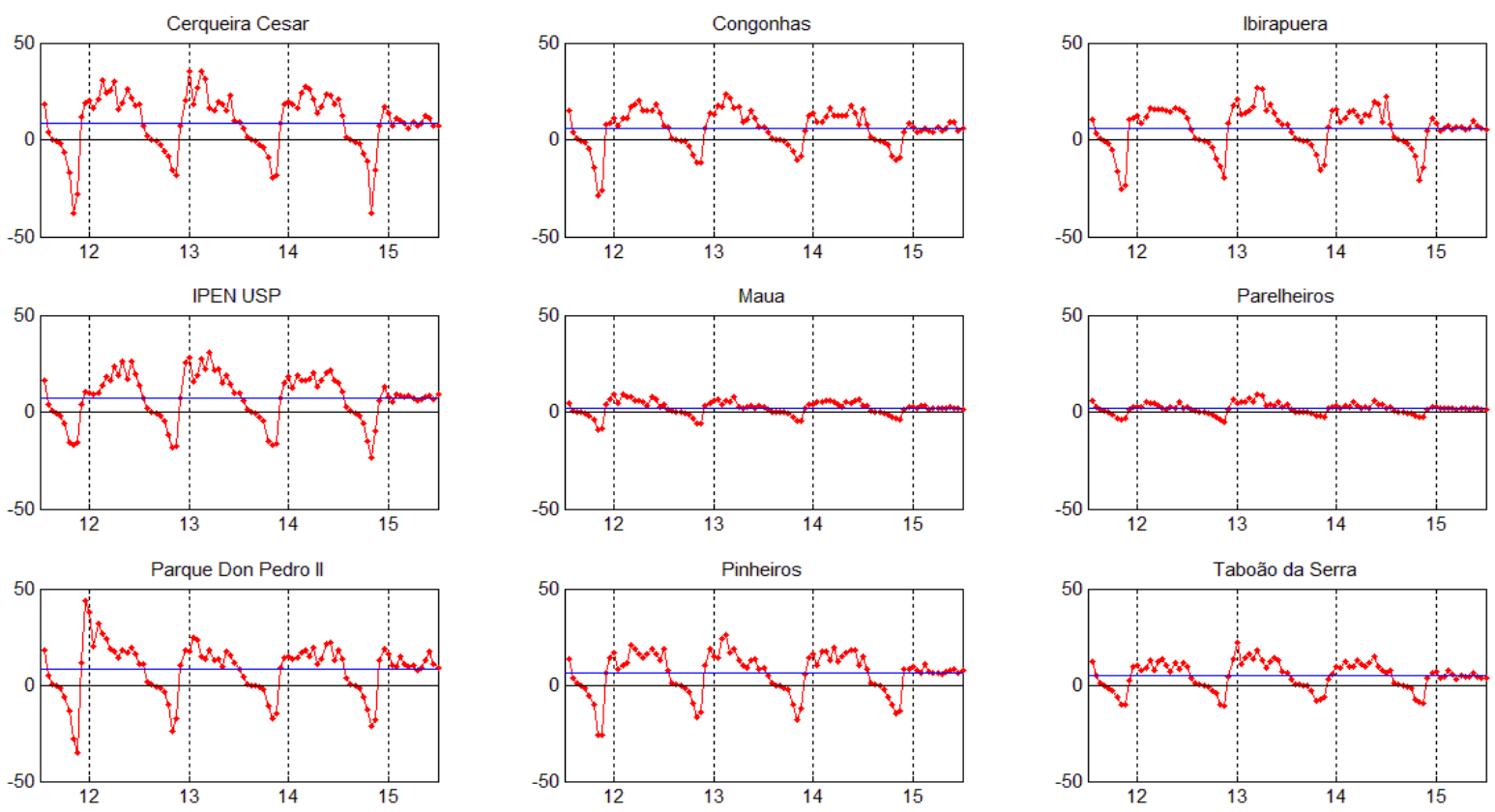

Figura 4.33. Diferença de concentração do $N O x$, em ' $p p b v$ ', entre o cenário com os $F E$ referentes ao ano de 2004 atuando em 2011, e a simulação correspondente para o período de 12 a 15 de novembro de 2011 para a grade de $1 \mathrm{~km}$. A linha azul representa o valor médio do período.

Em resumo pode-se afirmar que os maiores impactos na concentração simulada de ozônio estiveram associados com a representação da mudança das características de uso da frota, e consequentemente das emissões, nas grades de 3 e $1 \mathrm{~km}$. Zhang e Dubey, 2009 indicam que incertezas no cálculo das taxas de emissão dos COV poderiam ter uma grande contribuição na deficiência do modelo desde que as concentrações de ozônio na região estudada sejam altamente sensíveis às emissões de $C O V$. Em nosso caso, o efeito da mudança do fracionamento e número de veículos de 2004 para 2011, mantendo os FE referentes ao ano de 2004, permitiu na grade de $1 \mathrm{~km}$ o estabelecimento de uma razão média COV/NOx menos eficiente em termos de formação de ozônio $(3,20)$ quando comparada com a razão COV/NOx estimada para o ano de 2011 (6,70). O maior cálculo da razão COV/NOx em 2011 é resposta de uma maior diminuição do $F E$ do $N O x$ que dos $C O V$, uma contribuição mais significativa na emissão de $H C$ através dos processos de transferência de combustível e ao fato dos veículos leves ter aumentado em maior proporção que os veículos pesados, esta última característica não considerada na grade de $3 \mathrm{~km}$, dada que nesta, a frota permanece 
constante (utilizou-se a mesma imagem de satélite de ILN para estimar o número de veículos em ambos anos: 2004 e 2011), variando apenas o fracionamento por tipo de veículo. Do exposto anteriormente, podemos apontar que o esquema de emissão considerado para a grade de $1 \mathrm{~km}$ seria, em princípio, o mais adequado para avaliar a formação de ozônio troposférico por emissões veiculares dado que representa com melhor aproximação o impacto da mudança das características de uso veicular na $R M S P$; além de considerar uma distribuição espacial das emissões mais realista. Finalmente, os cenários de emissão considerando os $F E$ referentes ao ano de 2004 atuando em 2011 mostram, principalmente com a grade de $1 \mathrm{~km}$, como o estabelecimento de uma razão COV/NOx mais eficiente em termos de produção de ozônio, como consequência de uma mudança dos FE de 2004 para 2011, pode impactar negativamente na qualidade do ar com maiores concentrações de ozônio, apesar das emissões dos seus precursores tenham diminuído em relação a 2004. 


\section{CONSIDERAÇÕES FINAIS}

O presente estudo teve como objetivo avaliar o impacto da mudança dos fatores de emissão veicular na formação de ozônio troposférico sobre a RMSP. A avaliação foi realizada por meio de modelagem numérica com o modelo de qualidade do ar WRFChem, e consistiu na construção e simulação de duas forçantes químicas: uma para o ano 2004 e a outra para o ano 2011 (anos em que foram realizadas companhas experimentais no interior de túneis de tráfego para determinação de fatores de emissão veicular), considerando, finalmente, após a calibração de ambas forçantes, um cenário de emissão com os fatores de emissão veicular referentes ao ano de 2004 atuando no período estabelecido para o ano de 2011. Os experimentos de sensibilidade para avaliação dos inventários de emissão (simulações base) mostraram que o modelo $W R F$ Chem conseguiu representar com uma maior robustez o período selecionado para o ano de 2004 (06-09 setembro), caracterizado pela atuação de uma massa de ar seca com ausência de nuvens e intensa radiação solar (fatores que contribuíram diretamente para o estabelecimento de condições meteorológicas favoráveis à formação de ozônio) do que o período selecionado para o ano de 2011 (12-15 novembro), caracterizado pela passagem de uma frente fria, embora com chuvas abaixo da média climatológica.

As condições meteorológicas do primeiro período foram ligeiramente melhor representadas na simulação considerando a configuração da grade de $1 \mathrm{~km}$. As variáveis temperatura e umidade relativa apresentaram coeficientes de correlação linear superiores a 0,9 e 0,8 e erros $R M S E$ médios (em todas as estações) de $2,33{ }^{\circ} \mathrm{C}$ e 13,20 $\%$, respectivamente, para a grade de $1 \mathrm{~km}$. Com relação ao vento, os resultados mostraram, em geral, uma superestimativa em relação aos valores observados. Os coeficientes de correlação linear foram menores que 0,6, enquanto o erro RMSE médio foi de $1,10 \mathrm{~m} / \mathrm{s}$ para a grade de $1 \mathrm{~km}$. O melhor desempenho do modelo na representação das condições meteorológicas específicas deste período com a simulação considerando a configuração da grade de $1 \mathrm{~km}$ sugere uma melhoria da estimativa das variáveis meteorológicas na superfície a partir da implementação de dados geográficos de alta resolução. Apesar das variáveis meteorológicas terem sido melhor representadas com a grade de $1 \mathrm{~km}$, as concentrações de ozônio foram melhor representadas com a simulação considerando a configuração da grade de $3 \mathrm{~km}$. O índice estatístico para avaliação da previsão média do pico de ozônio foi de $-8,12$ e -17,13 \% para as grades de 
3 e $1 \mathrm{~km}$, respectivamente, no caso pareado. As menores concentrações de ozônio simuladas com a grade de $1 \mathrm{~km}$ responderam basicamente ao fato desta grade não ter considerado o efeito do transporte remoto de ozônio e seus precursores, provenientes de outras regiões metropolitanas como, por exemplo, a Baixada Santista; além de outras características como a menor alocação espacial dos veículos em termos de área urbana e maiores emissões estimadas para seus precursores $C O$ e $N O x$, levando para uma razão COV/NOx média ligeiramente menor nesta grade. Os coeficientes de correlação linear e índices de concordância foram, em geral, superiores a 0,8 , enquanto os erros $R M S E$ médios foram de 31,9 e $32,2 \mu \mathrm{g} / \mathrm{m}^{3}$ para as grades de 3 e $1 \mathrm{~km}$, respectivamente. Quanto aos precursores de ozônio $C O$ e $N O x$, os resultados mostraram como a inadequada localização de algumas estações da rede de monitoramento automático da CETESB como, por exemplo, Congonhas, localizada na intersecção de duas vias de tráfego veicular, podem não ser boas referências para avaliar resultados de simulações numéricas, no entanto, em estações como Ibirapuera, localizadas em áreas com menor influência de fontes veiculares, os processos de mistura são melhor representados. Os coeficientes de correlação linear e índices de concordância foram menores que 0,5 e 0,7, respectivamente, para o caso do $C O$ e menores que 0,6 e 0,7, respectivamente, para o caso do NOx. Os erros RMSE médios foram de 1,30 ppmv e 116,70 ppbv para o CO e NOx, respectivamente, na grade de $3 \mathrm{~km}$.

No caso do segundo período, as condições meteorológicas foram melhor representadas na simulação considerando a configuração da grade de $3 \mathrm{~km}$, embora com uma representatividade estatística menor quando comparada com o período anterior. A temperatura apresentou coeficientes de correlação linear, em geral, superiores a 0,7. O erro RMSE médio foi de $1,25{ }^{\circ} \mathrm{C}$ para a grade de $3 \mathrm{~km}$. Nos casos da umidade relativa e o vento os coeficientes de correlação linear foram menores que 0,8 e 0,5 com erros RMSE médios de 7,54\% e 1,91 m/s, respectivamente, para a grade de $3 \mathrm{~km}$. A intensidade do vento foi superestimada em ambas as grades, principalmente para a grade de $1 \mathrm{~km}$, característica que impactou no cálculo da distribuição espacial da concentração de ozônio sobre a RMSP. Quanto às concentrações do ozônio e seus precursores $C O$ e $N O x$, como no período anterior, estas foram melhor representadas na grade de $3 \mathrm{~km}$. No caso do ozônio, tal como era esperado devido às características sinóticas do período, as concentrações observadas foram menores quando comparadas com as concentrações observadas no primeiro período, com padrões decrescentes e 
ciclos diários irregulares, principalmente nos dias 14 e 15 quando um forte sistema frontal atingiu a região metropolitana. As simulações considerando as configurações de ambas as grades representaram coerentemente os ciclos de formação de ozônio durante os dias 12 e 13 (situação pré-frontal), inclusive com representação razoável dos picos máximos na grade de $3 \mathrm{~km}$, no entanto, com grande deficiência para representar o padrão irregular observado durante os dias 14 e 15 (passagem da frente fria). O índice estatístico para avaliação da previsão média do pico de ozônio foi de -3,24 e -21,15 \% para as grades de 3 e $1 \mathrm{~km}$, respectivamente. Dada as características dos padrões de concentração de ozônio superficial calculados, podemos associar as baixas concentrações calculadas na RMSP, principalmente nos dias 14 e 15, com a nebulosidade, precipitação e transporte para o interior do Estado (ver figuras 4.23, 4.24 e 4.25), onde núcleos de alta concentração foram observados. Os coeficientes de correlação linear e índices de concordância foram, em geral, superiores a 0,7. Os erros $R M S E$ médios foram de 18,9 e $20,4 \mu \mathrm{g} / \mathrm{m}^{3}$ para as grades de 3 e $1 \mathrm{~km}$, respectivamente. As séries temporais observadas de $C O$ e $N O x$ na maioria das estações consideradas mostraram dois períodos bem diferenciados: o primeiro (12-13 novembro) com baixas concentrações destes poluentes e o segundo (14-15 novembro) apresentando altas concentrações em relação às concentrações observadas no primeiro período. Durante o primeiro período, as concentrações de $C O$ foram, em geral, subestimadas pelo WRFChem, fato relacionado com uma subestimativa nas emissões deste poluente, no entanto, no caso do $N O x$, as concentrações observadas foram representadas razoavelmente pelo modelo. Para ambos poluentes foi observado um rápido aumento das concentrações no começo do dia 14 por volta das $5 \mathrm{~h}$, característica representada em algumas estações como Ibirapuera e IPEN USP, considerando a simulação com a grade de $3 \mathrm{~km}$, e atribuindo para tais aumentos a ocorrência de um episódio de altas emissões, dificilmente representado pelo modelo de emissão utilizado, dado que este considera um padrão de tráfego veicular homogêneo no espaço e no tempo. Os coeficientes de correlação linear e índices de concordância foram menores que 0,7 e 0,6 , respectivamente, para o caso do $C O$ e menores que 0,6 e 0,8 , respectivamente, para o caso do NOx. Os erros RMSE médios foram de 0,40 ppmv e 23,96 ppbv para o $C O$ e NOx, respectivamente, na grade de $3 \mathrm{~km}$. Independentemente da pouca representatividade das simulações para o período selecionado para o ano de 2011 (12-15 novembro), os resultados do cenário de emissão com os fatores de emissão referentes ao 
ano de 2004 atuando no período estabelecido para o ano de 2011 considerando a grade de $3 \mathrm{~km}$ indicaram que uma diminuição das emissões dos precursores do ozônio em proporções parecidas (razão média COV/NOx de 4,09 para o ano de 2004 e 4,39 para o ano de 2011) produz uma diferença na concentração de ozônio de até $30 \mu \mathrm{g} / \mathrm{m}^{3}$ menor durante os horários de máxima formação, enquanto os resultados do cenário de emissão para a grade de $1 \mathrm{~km}$ indicaram que uma diminuição das emissões dos precursores de ozônio, principalmente do $N O x$ (razão média COV/NOx de 3,20 considerando os fatores de emissão referentes ao ano de 2004 e 6,67 considerando os fatores de emissão correspondentes para o período de simulação em 2011), levam a uma formação de ozônio mais eficiente (diferenças menores que $10 \mu \mathrm{g} / \mathrm{m}^{3}$ ) quando comparada com a grade de $3 \mathrm{~km}$. Finalmente, podemos concluir que apesar da simplicidade dos modelos de emissão considerados neste estudo, as configurações físicas e químicas estabelecidas no WRF-Chem conseguiram representar de forma coerente a formação e transporte do ozônio troposférico em várias regiões da RMSP; e que as elevadas concentrações de ozônio observadas em 2011 (embora as emissões de seus precursores tenham diminuído) estiveram diretamente relacionadas ao fato da mudança das características de uso da frota ter estabelecido na atmosfera uma razão média COV/NOx mais eficiente em termos de produção de ozônio quando comparada com o ano 2004, considerando a grade de $1 \mathrm{~km}$, dado que esta representou melhor ditas mudanças; além de considerar uma distribuição espacial das emissões mais realista. 


\section{SUGESTÕES E PERSPECTIVAS}

\subsection{Sugestões para trabalhos futuros}

Em primeiro lugar se sugere realizar um estudo mais exaustivo sobre a sensibilidade dos valores preditos pelo modelo WRF-Chem a parâmetros físicos envolvidos na descrição da Camada Limite Planetária $(C L P)$, Superfície Terrestre e Camada Superficial (que são responsáveis pelo cálculo dos fluxos horizontais e verticais de calor e umidade) em função do espaçamento de grade. Em segundo lugar se sugere aprimorar o cálculo utilizado para distribuir as emissões veiculares tanto espacial quanto temporalmente. Considerar, por exemplo, duas forçantes: uma para dias de semana e a outra para finais de semana. Embora o mapa utilizado para distribuir as emissões na grade de $1 \mathrm{~km}$ (produto compilado pelo IED para o $C O$ na $R M S P$ ) seja mais representativo do que a distribuição de $I L N$ (que reflete, em geral, o grau de ocupação urbana) utilizado na grade de $3 \mathrm{~km}$, é preciso levar em consideração características como perfis de emissão e fluxo de veículos associados com os diferentes tipos de vias existentes na RMSP. Em terceiro lugar, sugere-se considerar na grade de $1 \mathrm{~km}$, a interação entre a $R M S P$ e as regiões metropolitanas contíguas, através do transporte remoto de ozônio e seus precursores como no caso da grade de $3 \mathrm{~km}$. Neste mesmo ponto podemos sugerir também a inclusão de condições iniciais e de fronteira químicas como, por exemplo, os cálculos feitos pelo modelo de transporte químico global MOZART (Model for Ozone And Related chemical Tracers) para representação das concentrações de fundo. Como quarto ponto, recomenda-se fazer um levantamento adequado das informações de tipo e uso do solo na RMSP para poder assimilá-las no pacote geográfico do WRF com propósitos de melhorar a sensibilidade do modelo no cálculo das variáveis de superfície. Finalmente, outras sugestões que poderiam melhorar as simulações seriam: usar campos meteorológicos de maior resolução horizontal como,

por exemplo, as reanálises CFSR (Climate Forecast System Reanalysis) de $0,5^{\circ}$ de resolução horizontal, com o objetivo de usar um número menor de aninhamentos; considerar grades com uma quantidade maior de pontos, principalmente na grade maior, de modo a resolver com uma melhor representação os processos físicos e evitar uma propagação maior de erros produzidos nas bordas para os centros das grades. 
Ainda propõe-se:

- Realizar testes de sensibilidade da formação do ozônio com a aplicação de outros módulos químicos como o Carbon Bond ( $C B M Z)$ chemical mechanism ou o Statewide Air Pollution Research Center (SAPRC), os quais incluem uma especiação de $C O V$ maior;

- Realizar um estudo do impacto das emissões veiculares no desenvolvimento vertical do ozônio troposférico. 


\section{REFERÊNCIAS}

Albuquerque, T. T. A., 2010. Formação e transporte das partículas finas inorgânicas em uma atmosfera urbana: o exemplo de São Paulo. Tese de Doutorado. Departamento de Ciências Atmosféricas do Instituto de Astronomia, Geofísica e Ciências Atmosféricas da Universidade de São Paulo.

Baertsch-Ritter, N., Keller, J., Dommen, J., Prevot, A. S. H., 2004. Effects of various meteorological conditions and spatial emission resolutions on the ozone concentration and ROG/NOx limitation in the Milan area (I). Atmos. Chem. Phys., 4, 423-438.

Carbone, S., 2008. Modelagem de ozônio troposférico em regiões urbanas Aperfeiçoamento do módulo químico no modelo CIT. Dissertação de mestrado. Departamento de Ciências Atmosféricas do Instituto de Astronomia, Geofísica e Ciências Atmosféricas da Universidade de São Paulo.

Carvalho, V. S. B., 2010. O impacto das megacidades sobre a qualidade do ar: os casos das regiões metropolitanas de São Paulo e do Rio de Janeiro. Tese de Doutorado. Departamento de Ciências Atmosféricas do Instituto de Astronomia, Geofísica e Ciências Atmosféricas da Universidade de São Paulo.

Cavalcanti, I. F. A., Ferreira, N. J., Justi da Silva., M. G. A., Silva Dias, M. A. F., 2009. Tempo e Clima no Brasil. Oficina de Texto, São Paulo. (ISBN 978-85-86238-92-5).

CETESB, 2012b. Emissões veiculares no Estado de São Paulo 2011. Série Relatórios/Secretaria do Estado do Meio Ambiente, São Paulo, 69p. (ISSN 0103-4103).

CETESB, 2012a. Relatório Anual de Qualidade do Ar no Estado de São Paulo 2011. Série Relatórios/Secretaria do Estado do Meio Ambiente, São Paulo, 120p. (ISSN 01034103).

CETESB, 2011. Relatório Anual de Qualidade do Ar no Estado de São Paulo 2010. Série Relatórios/Secretaria do Estado do Meio Ambiente, São Paulo, 234p. (ISSN 01034103).

CETESB, 2010. Relatório Anual de Qualidade do Ar no Estado de São Paulo 2009. Série Relatórios/Secretaria do Estado do Meio Ambiente, São Paulo, 290p. (ISSN 01034103).

CETESB, 2005. Relatório de qualidade do ar no Estado de São Paulo 2004. Série Relatórios/Secretaria do Estado do Meio Ambiente, São Paulo, 137p. (ISSN 01034103).

Chin, H-N. S., Leach, M. J., Sugiyama, G. A., Leone Jr, J, M., Walker, H., Nasstrom, J. S., Brown, M. J., 2005. Evaluation of an urban canopy parameterization in a mesoscale model using VTMX and URBAN 2000 data. Mon. Weather Rev., 133, 2043-2068. 
Chuang, M. T., Zhang, Y., Kang, D., 2011. Application of WRF/Chem-MADRID for real-time air quality forecasting over the Southeastern United States. Atmospheric Environment, 45, 6241-6250.

Climanálise 2004. Boletim de monitoramento e análise climática, v. 19, nro. 09.

Climanálise 2011. Boletim de monitoramento e análise climática, v. 26, nro. 11.

Finlayson-Pitts, B. J., Pitts Jr. J. N., Chemistry of the Upper and Lower Atmosphere: Theory, Experiments, and Applications. Academis Press, 2000.

Freitas, E. D., Rozoff, C., Cotton, W. R., Silva Dias, P. L., 2007. Interactions of an urban heat island and see breeze circulations during winter over the Metropolitan Area of São Paulo-Brazil. Boundary-Layer Meteorology, 122, 43-65.

Freitas, E. D., Martins, L. D., Silva, P. L., Andrade, M. F., 2005. A simple photochemical module implemented in RAMS for tropospheric ozone concentration forecast in the Metropolitan Area of São Paulo, Brazil: Coupling and validation. Atmospheric Environment, 39, 6352-6361.

Galichio, W., 2011. Aplicação do modelo WRF-Chem para modelagem de ozônio troposférico: estudo de caso de outubro de 2002. Dissertação de mestrado. Departamento de Ciências Atmosféricas do Instituto de Astronomia, Geofísica e Ciências Atmosféricas da Universidade de São Paulo.

Gallardo, L., Escribano, J., Dawidowski, N R., Andrade, M. F., Osses, M., 2012. Evaluation of vehicle emission inventories for carbon monoxide and nitrogen oxides for Bogotá, Buenos Aires, Santiago, and São Paulo. Atmospheric Environment, 47, 12-19.

Geng, F., Zhao, C., Tang, X., Lu, G., Tie, X., 2007. Analysis of ozone and VOCs measured in Shanghai: A case study. Atmospheric Environment, 41, 989-1001.

Grell, G. A. Peckham, S. E., Schmitz, R., McKeen, S. A., Wilczak, J., Eder, B., 2005. Fully coupled "online" chemistry within the WRF model. Atmos. Environ. 39, 69576975.

Gross, A., Stockwell, W. R., 2003. Comparison of the EMEP, RADM2 and RACM Mechanisms. Journal of Atmospheric Chemistry, 44, 151-170.

Guenther, A.B., Zimmerman, P.R., Harley, P.C., Monson, R.K., Fall, R., 1993. Isoprene and monoterpene emission rate variability: model evaluations and sensitivity analyses. Journal of Geophysical Research-Atmosphere 98D, 12609-12617.

Itimura, M. S., 2010. Condições atmosféricas associadas a concentrações máximas e mínimas de ozônio observadas na Região Metropolitana de São Paulo. Dissertação de mestrado. Departamento de Ciências Atmosféricas do Instituto de Astronomia, Geofísica e Ciências Atmosféricas da Universidade de São Paulo.

Kristensson, A., Johansson, C., Westerholm, R., Swietlicki, E., Gidhagen, L., Wideqvist, U., Vesely, V., 2004. Real-world traffic emission factors of gases and 
particles measured in a road tunnel in Stockholm, Sweden. Atmospheric Environment, 38, 657-673.

Landmann, M. C., 2004. Estimativa das emissões de poluentes de automóveis na RMSP considerando as rotas de tráfego. II Encontro da ANPPAS, São Paulo, Brasil.

Lents, J., Walsh, M., He, K., Davis, N., Osses, M., Tolvett, M., Liu, H., 2012. Handbook of air quality management. International Sustainable Systems Research Center. (http://www.aqbook.org/).

Lents, J., Osses, M., Nikkila, N., 2007. Vehicle activity ando n-road emissions data collection for the application of the International Vehicle Emissions Model (IVE) in the São Paulo Metropolitan Region. Reunião de Poluição Atmosferica IAG-USP, São Paulo.

Lents, J., Nikkila, N., Osses, M., 2004. São Paulo Vehicle Activity Study. Internacional Sustainable Systems Research Center.

Marr, L. C., Kirchstetter, T. W., Harley, R. A., 1999. Characterization of Polycyclic Aromatic Hydrocarbons in Motor Vehicle Fuels and Exhaust Emissions. Environmental Science \& Technology, 33, 3091-3099.

Martins, L. D., Andrade, M. F., 2008a. Ozone Formation Potentials of Volatile Organic Compounds and Ozone Sensitivity to Their Emission in the Megacity of Sao Paulo, Brazil. Water Air Pollut., DOI 10.1007/s11270-008-9740-x.

Martins, L. D., Andrade, M. F., 2008b. Emission Scenario Assessment of Gasohol Reformulation Proposals and Ethanol Use in the Metropolitan Area of Sao Paulo. The Open Atmospheric Science Journal, 2, 166-175.

Martins, J. A., Mazzoli, C. R., Oliveira, M. G. L., Ynoue, R. Y., Andrade, M. F., Freitas, E. D., Martins, L. D., 2010. Desenvolvimento de inventários de emissão de alta resolução: Intensidade de luzes noturnas e distribuição espacial de veículos. In: XVI Congresso Brasileiro de Meteorologia, Belém.

Martins, J. A.; Martins, L. D.; Freitas, E. D.; Mazzoli, C. R. R.; Hallak, R.; Andrade, M. F., 2008. Aplicação de imagens de satélite no desenvolvimento de inventários de emissão de alta resolução, In: XV Congresso Brasileiro de Meteorologia, São Paulo.

Martins, L. D., Andrade, M. F., Freitas, E. D., Pretto, A., Gatti, L. V., Albuquerque, E. L., Tomaz, E., Guardani, M. L., Martins, M. H. R. B., Junior, O. M. A., 2006. Emission factors for gás-powered vehicles traveling through Road tunnels in São Paulo City, Brasil. Environmental Science \& Technology, 40, 6722-6729.

Martins, L. D., 2006. Sensibilidade da formação do ozônio troposférico às emissões veiculares na Região Metropolitana de São Paulo. Tese de Doutorado. Departamento de Ciências Atmosféricas do Instituto de Astronomia, Geofísica e Ciências Atmosféricas da Universidade de São Paulo. 
Martins M.H.R.B, Anazia R., Guardani M.L.G., Lacava C.I.V., Romano J., Silva S.R., 2004. Evolution of air quality in the São Paulo Metropolitan Area and its relation with public policies. International Journal of Environment and Pollution, 22, 430-440.

Mayer, H., 1999. Air pollution in cities. Atmospheric Environment, 33, 4029-4037.

Misenis, C., Zhang, Y., 2010. An examination of sensitivity of WRF-Chem predictions to physical parameterizations, horizontal grid spacing, and nesting options. Atmospheric Research, 97, 315-334.

NEI, 2005. National Emissions Inventory Data \& Documentation, Environmental Protection Agency (EPA), U.S. (http://www.epa.gov/ttn/chief/net/2005inventory.html).

Nogueira, T., Pérez M. P. J., Gregorio, H. I., Yuri, Y. R., Fornaro, A., Andrade, M. F., 2013. Vehicular emission factor of gases measured in two road tunnels in Metropolitan Area of São Paulo, Brazil. Environmental Science \& Technology. (Submetido)

Orlando, J. P., Alvim, D. S., Yamazaki, A., Corrêa, S. M., Gatti, L. V., 2010. Ozone precursors for the São Paulo Metropolitan Area. Science of the Environment, 408, 16121620.

Oliveira, A. P., E. J. Escobedo, A. J. Machado, 2002. Diurnal evolution of solar radiation at the surface in the City of São Paulo: Seasonal variation and modeling. Theor. Appl. Climatol., 71, 231-249.

Pereira, F. A., Santos, P. M., Xavier, T. M. B. S., 2007. Evolução do Tempo e Clima na Região Metropolitana de São Paulo. Editora Linear B, São Paulo, 299p. (ISBN 978-8598232-32-4).

Pielke, R. A., Mesoscale Meteorological Modeling, Second Edition. International Geophysics Series, vol. 78. Academic Press. 2002, 676p.

Ritter, M., Muller, M. D., Jorba, O., Parlow, E., Liu, L. J. S., 2012. Impact of chemical and meteorological boundary and initial conditions on air quality modeling: WRFChem sensitivity evaluation for a European domain. Meteorol. Atmos. Phys., DOI 10.1007/s00703-012-0222-8.

Sánchez-Ccoyllo, O. R., Ynoue, R. Y., Martins, L. D., Astolfo, R., Miranda, R. M., Freitas, E. D., Borges, A. S., Fornaro, A., Freitas, H., Moreira, A., Andrade, M. F., 2009. Vehicular particulate matter emissions in road tunnels in São Paulo, Brazil. Environ. Monit. Assess., 149, 241-249.

Sánchez-Ccoyllo, O. R., Martins, L. D., Ynoue, R. Y., Andrade, M. F., 2007. The impacto on tropospheric ozone formation on the implementation of a program for mobile emissions control: a case study in São Paulo, Brazil. Environ. Fluid. Mech., 7, 95-119.

Sanchez-Ccoyllo, O. R., Silva Dias, P. L., Andrade, M. F., Freitas, S. R., 2006a. Determination of O3-, CO- and PM10- transport in the metropolitan área of São Paulo, 
Brazil through synoptic-scale analysis of back trajectories. Meteorol. Atmos. Phys., 92, 83-93.

Sánchez-Ccoyllo, O. R., Ynoue, R. Y., Martins, L. D., Andrade, M. F., 2006b. Impacts of ozone precursor limitation and meteorological variables on ozone concentration in São Paulo, Brazil. Atmospheric Environment, 40, 552-562.

Seinfeld, J. H.; Pandis, S. N., Atmospheric Chemistry and Physics: from air pollution to climate change, Second Edition. Jhon Wiley, New Jersey, 2006, 1203p.

Sillman, S., 1995. The use of NOy, $\mathrm{H}_{2} \mathrm{O}_{2}$ and $\mathrm{HNO}_{3}$ as indicators for ozone-NOxhydrocarbon sensitivity in urban locations. Journal of Geophysical Research, 100, 14175-14188.

Silva Junior, R. S., 2009. Sensibilidade na estimativa da concentração de poluentes fotoquímicos com aplicação de diferentes parametrizações de Camada Limite Planetária utilizando o modelo de Qualidade do Ar WRF-Chem. Tese de Doutorado. Departamento de Ciências Atmosféricas do Instituto de Astronomia, Geofísica e Ciências Atmosféricas da Universidade de São Paulo.

Silva Junior, R. S., Oliveira, M. G. L., Andrade, M. F., 2009. Weekend/Weekday Differences in Concentrations of Ozone, NOx and Non-Methane Hydrocarbon in the Metropolitan Area of São Paulo. Revista Brasileira de Meteorologia, 24, 100-110.

Simpson, D., Guenther, A., Hewitt, C.N., Steinbrecher, R., 1995. Biogenic emissions in Europe. 1. Estimates and uncertainties. Journal of Geophysical Research-Atmosphere $100 \mathrm{D}, 22875-22890$.

Skamarock, W. C., Klemp, J. B., Dudhia, J., Gill, D. O., Barker, D. M., Duda, M. G., Huang, X. Y., Wang, W., Powers, J. G., 2008. A Description of the Advanced Research WRF Version 3. NCAR Technical Note. NCAR/TN-475+STR.

Taylor, K. E. 2001. Summarizing multiple aspects of model performance in a single diagram. Journal Geophysical Research, 106, 7183-7192.

Tie, X., Brasseur, G., Ying, Z., 2010. Impact of model resolution on chemical ozone formation in Mexico City: application of the WRF-Chem model. Atmos. Chem. Phys., 10, 8983-8995.

Tie, X., Madronich, S., Li, G., Ying, Z., Weinheimer, A., Apel, E., Campos, T., 2009b. Simulation of Mexico City plumes during the MIRAGE-Mex field campaing using the WRF-Chem model. Atmos. Chem. Phys., 9, 4621-4638.

Tie, X., Geng, F. H., Peng, L., Gao, W., Zhao, C. S., 2009a. Measurement and modeling of $\mathrm{O}_{3}$ variability in Shanghai, China: Application of the WRF-Chem model. Atmos. Environ., 43, 4289-4302.

Tie, X., Madronich, S., Li, G. H., Ying, Z. M., Zhang, R., Garcia, A., Lee-Taylor, J., Liu, Y., 2007. Characterizations of chemical oxidants in Mexico City: a regional chemical/dynamical model (WRF-Chem) study. Atmos. Environ. 41, 1989-2008. 
Vemado, F., 2012. Analise da circulação de brisa marítima e seus impactos sobre a precipitação na Região Metropolitana de São Paulo por meio do modelo ARPS. Dissertação de Mestrado. Departamento de Ciências Atmosféricas do Instituto de Astronomia, Geofísica e Ciências Atmosféricas da Universidade de São Paulo.

Wang, X., Liang X. Z., Jiang, W., Tao, Z., Wang, J. X. L., Liu, H., Han, Z., Liu, S., Zhang, Y., Grell, G. A., Peckham, S. E., 2010. WRF-Chem simulation of East Asian air quality: Sensitivity to temporal and vertical emissions distributions. Atmospheric Environment, 44, 660-669.

Wang, W., Bruyère, C., Duda, M., Dudhia, J., Gill, D., Lin, H-C., Michalakes, J., Rizvi, S., Zhang, X. 2009. Advanced Research WRF (ARW) Version 3 Modeling User's Guide, Mesoscale \& Microscale Meteorology Division, National Center for Atmospheric Research (NCAR), USA.

Wilks, D. S., Statistical Methods in the Atmospheric Sciences, Second Edition. International Geophysics Series, vol. 91. Academic Press, 2006, 627p.

Willmott, C. J., 1981. On the validation of models. Physical Geography, 2, 184-194.

Ying, Z. M., Tie, X., Li, G. H., 2009. Sensitivity of ozone concentrations to diurnal variations of surface emissions in Mexico City: A WRF-Chem modeling study. Atmos. Environ., 43, 851-859.

Zhang, Y., Dubey, M. K., 2009. Comparisons of WRF-Chem simulations O3 concentrations in Mexico City with ground-based RAMA measurements during the MILAGRO period. Atmospheric Environment, 43, 4622-4631.

Zhang, Y., Pun, B., Vijayaraghavam, K., Wu, S. Y., Seigneur, C., Pandis, S., Jacobson, M., Nenes, A., Seinfeld, J. H., 2004. Development and application of the model of aerosol dynamics, reaction, ionization and dissolution (MADRID). Journal of Geophysical Research-Atmosphere, 109 (D01202), doi:10.1029/2007JD009226. 


\section{APÊNDICES}

\section{A. Padrões nacionais de qualidade do ar}

\begin{tabular}{|c|c|c|c|c|}
\hline Poluente & $\begin{array}{c}\text { Tempo de } \\
\text { Amostragem }\end{array}$ & $\begin{array}{l}\text { Padrão Primário } \\
\left(\mu \mathrm{g} / \mathrm{m}^{3}\right)\end{array}$ & $\begin{array}{l}\text { Padrão Secundário } \\
\left(\mu \mathrm{g} / \mathrm{m}^{3}\right)\end{array}$ & Método de Medição \\
\hline \multirow{2}{*}{$\begin{array}{l}\text { Partículas totais em } \\
\text { suspensão }\end{array}$} & 24 horas ${ }^{(1)}$ & 240 & 150 & \multirow{2}{*}{$\begin{array}{c}\text { Amostrador de grandes } \\
\text { volumes }\end{array}$} \\
\hline & MGA $^{(2)}$ & 80 & 60 & \\
\hline \multirow{2}{*}{ Partículas inaláveis } & 24 horas $^{(1)}$ & 150 & 150 & \multirow{2}{*}{$\begin{array}{c}\text { Separação } \\
\text { inercial/filtração }\end{array}$} \\
\hline & $\mathrm{MAA}^{(3)}$ & 50 & 50 & \\
\hline \multirow{2}{*}{ Fumaça } & 24 horas $^{(1)}$ & 150 & 100 & \multirow{2}{*}{ Refletância } \\
\hline & MAA $^{(2)}$ & 60 & 40 & \\
\hline \multirow{2}{*}{ Dióxido de enxofre } & 24 horas $^{(1)}$ & 365 & 100 & \multirow{2}{*}{ Pararosanilina } \\
\hline & $\mathrm{MAA}^{(2)}$ & 80 & 40 & \\
\hline \multirow{2}{*}{ Dióxido de nitrogênio } & 1 hora & 320 & 190 & \multirow{2}{*}{ Quimiluminescência } \\
\hline & $\mathrm{MAA}^{(3)}$ & 100 & 100 & \\
\hline \multirow{4}{*}{ Monóxido de carbono } & 1 hora $^{(1)}$ & 40.000 & 40.000 & \multirow{4}{*}{$\begin{array}{c}\text { Infravermelho não } \\
\text { dispersivo }\end{array}$} \\
\hline & & $35 \mathrm{ppm}$ & $35 \mathrm{ppm}$ & \\
\hline & \multirow{2}{*}{8 horas $^{(1)}$} & 10.000 & 10.000 & \\
\hline & & $9 \mathrm{ppm}$ & $9 \mathrm{ppm}$ & \\
\hline Ozônio & 1 hora $^{(1)}$ & 160 & 160 & Quimiluminescência \\
\hline
\end{tabular}

Tabela 8.1. Padrões nacionais de qualidade do ar (Resolução CONAMA $\mathrm{n}^{\circ}$ 03/90). ${ }^{(1)}$ Não deve ser excedido mais que uma vez ao ano, ${ }^{(2)}$ Média Geométrica Anual, ${ }^{(3)}$ Média Aritmética Anual (Fonte: CETESB, 2010). Em verde ressalta-se o padrão correspondente para o ozônio. 


\section{B. Agrupamento de espécies químicas no mecanismo químico RADM2}

\begin{tabular}{|c|c|c|c|c|c|c|c|c|c|c|}
\hline \multirow{2}{*}{ Espécie } & \multirow{2}{*}{$\begin{array}{c}\text { Nome no } \\
W R F-C h e m\end{array}$} & \multicolumn{3}{|c|}{ Gasolina (mol/100g COV emitido) } & \multicolumn{3}{|c|}{ Álcool (mol/100g COV emitido) } & \multicolumn{3}{|c|}{ Diesel (mol/100g COV emitido) } \\
\hline & & Vapor & Liquido & Exaustão & Vapor & Liquido & Exaustão & Vapor & Liquido & Exaustão \\
\hline 1. Acetaldeído e Aldeídos & e_ald & 0.00000 & 0.00000 & 0.08556 & 0.00000 & 0.00000 & 0.35053 & 0.00000 & 0.00000 & 0.10752 \\
\hline 2. Formaldeído & e_hcho & 0.00000 & 0.00000 & 0.07628 & 0.00000 & 0.00000 & 0.06170 & 0.00000 & 0.00000 & 0.29176 \\
\hline 3. Ácidos Orgânicos & e_ora2 & 0.00000 & 0.00000 & 0.00000 & 0.00000 & 0.00000 & 0.00000 & 0.00000 & 0.00000 & 0.00000 \\
\hline 4. Alcanos $500<\mathrm{kOH}<5000$ & e_hc3 & 0.22762 & 0.02132 & 0.36673 & 0.00000 & 0.00000 & 0.00000 & 0.00000 & 0.00000 & 0.14900 \\
\hline 5. Alcanos $5000<\mathrm{kOH}<10000$ & e_hc5 & 0.44454 & 0.14730 & 0.13002 & 0.00000 & 0.00000 & 0.00000 & 0.00000 & 0.00000 & 0.05774 \\
\hline 6. Alcanos kOH $>10000$ & e_hc8 & 0.00000 & 0.19263 & 0.06274 & 0.00000 & 0.00000 & 0.04904 & 0.00000 & 0.00000 & 0.12191 \\
\hline 7. Etano $\mathrm{kOH}<500$ & e_eth & 0.00000 & 0.00000 & 0.23166 & 0.00000 & 0.00000 & 0.00000 & 0.00000 & 0.00000 & 0.00000 \\
\hline 8. Etileno & e_ol2 & 0.00000 & 0.00000 & 0.28000 & 0.00000 & 0.00000 & 0.12602 & 0.00000 & 0.00000 & 0.15757 \\
\hline 9. Alcenos $\mathrm{kOH}<20000$ & e_olt & 0.16132 & 0.07205 & 0.11739 & 0.00000 & 0.00000 & 0.00179 & 0.00000 & 0.00000 & 0.38532 \\
\hline 10. Alcenos kOH>20000 & e_oli & 0.39558 & 0.16985 & 0.13230 & 0.00000 & 0.00000 & 0.00130 & 0.00000 & 0.00000 & 0.00000 \\
\hline 11. Aromáticos $\mathrm{kOH}<20000$ & e_tol & 0.01280 & 0.04835 & 0.11517 & 0.00000 & 0.00000 & 0.00569 & 0.00000 & 0.00000 & 0.23512 \\
\hline 12. Aromáticos kOH>20000 & e_xyl & 0.00000 & 0.09793 & 0.14906 & 0.00000 & 0.00000 & 0.01490 & 0.00000 & 0.00000 & 0.00836 \\
\hline 13. Acetona e Cetonas & e_ket & 0.32559 & 0.59508 & 0.30820 & 2.17061 & 2.17061 & 1.52262 & 0.00000 & 0.00000 & 0.01850 \\
\hline 14. Fenóis e Cresóis & e_csl & 0.00000 & 0.00000 & 0.00000 & 0.00000 & 0.00000 & 0.00000 & 0.00000 & 0.00000 & 0.00000 \\
\hline 15. Isopreno & e_iso & 0.00000 & 0.00115 & 0.00373 & 0.00000 & 0.00000 & 0.00000 & 0.00000 & 0.00000 & 0.00000 \\
\hline 16. Dióxido de enxofre & e_so2 & --- & --- & --- & --- & --- & --- & --- & --- & --- \\
\hline 17. Óxidos de nitrogênio & e_no & --- & --- & --- & --- & --- & --- & --- & --- & --- \\
\hline 18. Monóxido de carbono & e_co & --- & --- & --- & --- & --- & --- & --- & --- & --- \\
\hline 19. Amônia & e_nh3 & --- & --- & --- & --- & --- & --- & --- & --- & --- \\
\hline
\end{tabular}

Tabela 8.2. Espécies químicas consideradas no mecanismo químico RADM2. Esta tabela mostra a quantidade de massa emitida dos $C O V$ considerados no mecanismo químico RADM2 (espécies 1 a 15) por cada 100g de $C O V$ emitido por um veículo, considerando três tipos de combustíveis: Gasolina, Álcool e Diesel. 


\section{Descrição do cálculo das taxas de emissão de poluentes}

A emissão total diária de um certo poluente ' $P$ ' correspondente para um ponto de grade arbitrário $(i, j)$ foi estimada basicamente com informações estimadas de número de veículos, fatores de emissão e número médio de quilômetros percorridos por dia pelos diferentes tipos de veículos considerados segundo a equação (2.4) descrita na seção 2.2.1:

$$
\mathrm{E}_{\mathrm{P}}^{(\mathrm{i}, \mathrm{j})}=\sum_{\text {veic }=1}^{5} \mathrm{~N}_{\text {veic }}^{(i, j)} \times \mathrm{FE}_{\mathrm{P}, \mathrm{veic}}^{(\mathrm{i}, \mathrm{j})} \times \mathrm{I}_{\mathrm{veic}}^{(\mathrm{i}, \mathrm{j})}
$$

O número de veículos ' $N$ ' neste ponto de grade foi considerado como sendo proporcional à luminosidade noturna associada a esse ponto, considerando uma imagem de satélite de $I L N$ correspondente ao ano de 2009 (consultar Martins et al., 2008 para maior informação) para a grade de $3 \mathrm{~km}$, enquanto proporcional à emissão total diária de $C O$ estimada pelo IED também em 2009 para o ponto em questão (consultar Lents et al., 2012 para maior informação) no caso da grade de $1 \mathrm{~km}$. Neste último caso, o número de veículos foi normalizado pela emissão total de $C O$ com o objetivo de assimilar os dados oficiais de frota fornecidos pela DETRAN. Logo, após atribuir o número de veículos para cada um dos pontos de grade em ambas as grades (e que representa a base da distribuição espacial das emissões), este foi fracionado de acordo com os 5 tipos de veículos considerados (ver tabela 2.2). Uma vez determinada a quantidade e tipos de veículos em cada ponto de grade, multiplicaram-se essas quantidades diretamente pelos fatores de emissão $(\mathrm{g} / \mathrm{km})$ (ver tabela 2.3) e intensidades de uso (km/dia) consideradas (ver tabela 2.2) e obter assim um estimado das emissões totais diárias de $C O$ e $N O x$ em cada ponto de grade, por serem estes poluentes unicamente emitidos pelo escapamento dos veículos. No caso dos $C O V$, é sabido que existem mais duas fontes de emissão veicular relevantes além do escapamento: o cárter e evaporativa e as operações de transferência de combustível (ver tabela 2.3). Nesse sentido, devido à complexidade de representação daquelas fontes no espaço, dado que a emissão associada acontece, pelo geral, em postos de abastecimento; consideraram-se tais emissões, por simplicidade, como sendo emitidas pelo escapamento dos veículos 
(ver equação acima), porém, agrupando adequadamente as suas contribuições (cárter e evaporativa e as operações de transferência de combustível) com as contribuições do escapamento, considerando três tipos de combustível: Gasolina, Álcool e Diesel, com o objetivo de estimar a quantidade de $C O V$ correspondente para cada um dos 15 agrupamentos considerados no mecanismo químico RADM2 (ver apêndice B). Com o procedimento descrito até aqui, conseguiu-se distribuir a emissão total diária, em gramas por dia (g/dia), correspondente para as 19 espécies consideradas no mecanismo químico $R A D M 2$ para um ponto de grade qualquer. Como o objetivo é simular as emissões veiculares de hora em hora ao longo dos períodos de estudo escolhidos, foram considerados dois perfis de emissão: um para o $C O$ e os $C O V$ e o outro para o $N O x$ (ver figura 2.5); ambos obtidos de medidas experimentais de contagens de tráfego (tipos de veículos) no interior dos túneis Jânio Quadros e Rodoanel durante o ano de 2011. Finalmente, para que as emissões possam ser lidas corretamente pelo modelo é necessário acertar as unidades de ' $\mathrm{g} / \mathrm{h}$ ' para ' $\mathrm{mol} / \mathrm{km}^{2} / \mathrm{h}$ '. Para o cálculo e interpolação das taxas de emissão às coordenadas curvilíneas do $W R F$ foi construído um programa em NCL (NCAR Command Language) baseado na metodologia proposta pelo Observatorio Latinoamericano de Eventos Extraordinarios $\left(O L E^{2}\right)$ para assimilar emissões químicas locais no WRF-Chem. Para maior informação pode acessar o link abaixo:

http://www.cmc.org.ve/mediawiki/index.php?title=Calidad_de_Aire 


\section{Estações e variáveis consideradas}

\begin{tabular}{|c|c|c|c|c|c|c|c|c|}
\hline Nome & Latitude & Longitude & $\mathrm{T}\left({ }^{\circ} \mathrm{C}\right)$ & UR (\%) & $\mathrm{VV}(\mathrm{m} / \mathrm{s})$ & $\mathrm{CO}$ (ppmv) & NOx (ppbv) & $\mathrm{O}_{3}\left(\mu \mathrm{g} / \mathrm{m}^{3}\right)$ \\
\hline AF-IAG & $-23,6500$ & $-46,6167$ & X & X & X & & & \\
\hline Centro & $-23,5472$ & $-46,6422$ & & & & $X$ & & \\
\hline Cerqueira Cesar & $-23,5531$ & $-46,6723$ & & & & $X$ & $\mathrm{X}$ & \\
\hline Congonhas & $-23,6159$ & $-46,6630$ & & & & & $X$ & \\
\hline Diadema & $-23,6855$ & $-46,6113$ & & & & & & $\mathrm{X}$ \\
\hline Ibirapuera & $-23,5914$ & $-46,6602$ & $\mathrm{X}$ & $\mathrm{X}$ & & $\mathrm{X}$ & $\mathrm{X}$ & $\mathrm{X}$ \\
\hline Mauá & $-23,6685$ & $-46,4653$ & & & & & $\mathrm{X}$ & $\mathrm{X}$ \\
\hline Mooca & $-23,5497$ & $-46,5984$ & & & & & & $X$ \\
\hline Nossa Senhora do O & $-23,4796$ & $-46,6916$ & $X$ & $X$ & & & & $X$ \\
\hline Osasco & $-23,5263$ & $-46,7916$ & & & $X$ & & & \\
\hline Pinheiros & $-23,5610$ & $-46,7016$ & $X$ & $\mathrm{X}$ & & $X$ & $\mathrm{X}$ & $\mathrm{X}$ \\
\hline Santana & $-23,5055$ & $-46,6285$ & & & & & & $\mathrm{X}$ \\
\hline Santo Amaro & $-23,6545$ & $-46,7095$ & & & $\mathrm{X}$ & $\mathrm{X}$ & & $\mathrm{X}$ \\
\hline Santo Andre Capuava & $-23,6393$ & $-46,4911$ & & & $\mathrm{X}$ & & & $\mathrm{X}$ \\
\hline Santo Andre Centro & $-23,6566$ & $-46,5305$ & & & & $\mathrm{X}$ & & \\
\hline São Caetano do Sul & $-23,6184$ & $-46,5563$ & $X$ & $X$ & & $X$ & & $\mathrm{X}$ \\
\hline São Miguel Paulista & $-23,4980$ & $-46,4443$ & $X$ & $\mathrm{X}$ & & & & $\mathrm{X}$ \\
\hline Taboão da Serra & $-23,6088$ & $-46,7578$ & $X$ & $\mathrm{X}$ & & & $\mathrm{X}$ & \\
\hline
\end{tabular}

Tabela 8.3. Estações utilizadas para avaliação do primeiro período de estudo. 


\begin{tabular}{|c|c|c|c|c|c|c|c|c|}
\hline Nome & Latitude & Longitude & $\mathrm{T}\left({ }^{\circ} \mathrm{C}\right)$ & UR (\%) & $\mathrm{VV}(\mathrm{m} / \mathrm{s})$ & $\mathrm{CO}$ (ppmv) & NOx (ppbv) & $\mathrm{O} 3\left(\mu \mathrm{g} / \mathrm{m}^{3}\right)$ \\
\hline AF-IAG & $-23,6500$ & $-46,6167$ & $\mathrm{X}$ & $\mathrm{X}$ & $\mathrm{X}$ & & & \\
\hline Cerqueira Cesar & $-23,5531$ & $-46,6723$ & & & & $\mathrm{X}$ & $\mathrm{X}$ & \\
\hline Congonhas & $-23,6159$ & $-46,6630$ & & & & $\mathrm{X}$ & $\mathrm{X}$ & \\
\hline Diadema & $-23,6855$ & $-46,6113$ & & & & & & $\mathrm{X}$ \\
\hline Ibirapuera & $-23,5914$ & $-46,6602$ & & & $\mathrm{X}$ & $X$ & $X$ & $\mathrm{X}$ \\
\hline IPEN USP & $-23,5662$ & $-46,7374$ & & & & $\mathrm{X}$ & $\mathrm{X}$ & $\mathrm{X}$ \\
\hline Mauá & $-23,6685$ & $-46,4653$ & & & & & $\mathrm{X}$ & $\mathrm{X}$ \\
\hline Mooca & $-23,5497$ & $-46,5984$ & & & $\mathrm{X}$ & $\mathrm{X}$ & & $\mathrm{X}$ \\
\hline MS-INMET & $-23,4964$ & $-46,6200$ & $\mathrm{X}$ & $\mathrm{X}$ & $\mathrm{X}$ & & & \\
\hline Nossa Senhora do O & $-23,4796$ & $-46,6916$ & & & & & & $X$ \\
\hline Parelheiros & $-23,7762$ & $-46,6970$ & $\mathrm{X}$ & $\mathrm{X}$ & & $\mathrm{X}$ & $X$ & \\
\hline Parque Don Pedro II & $-23,5448$ & $-46,6276$ & & & & $\mathrm{X}$ & $\mathrm{X}$ & \\
\hline Pinheiros & $-23,5610$ & $-46,7016$ & $\mathrm{X}$ & & $\mathrm{X}$ & $\mathrm{X}$ & $\mathrm{X}$ & $\mathrm{X}$ \\
\hline Santana & $-23,5055$ & $-46,6285$ & & & $X$ & & & $\mathrm{X}$ \\
\hline Santo Andre Capuava & $-23,6393$ & $-46,4911$ & & & & & & $\mathrm{X}$ \\
\hline Santo Andre Paço M. & $-23,6570$ & $-46,5310$ & & & & $\mathrm{X}$ & & \\
\hline São Caetano do Sul & $-23,6184$ & $-46,5563$ & $\mathrm{X}$ & $X$ & & $\mathrm{X}$ & & $\mathrm{X}$ \\
\hline Taboão da Serra & $-23,6088$ & $-46,7578$ & $\mathrm{X}$ & $\mathrm{X}$ & & & $\mathrm{X}$ & \\
\hline
\end{tabular}

Tabela 8.4. Estações utilizadas para avaliação do segundo período de estudo. 


\section{E. Resumo dos testes estatísticos}

\begin{tabular}{|c|c|c|c|c|c|c|c|c|c|c|c|c|c|c|}
\hline & \multicolumn{2}{|c|}{ Ibirapuera } & \multicolumn{2}{|c|}{ Nossa Senhora do O } & \multicolumn{2}{|c|}{ Pinheiros } & \multicolumn{2}{|c|}{ São Caetano do Sul } & \multicolumn{2}{|c|}{ São Miguel Paulista } & \multicolumn{2}{|c|}{ Taboão da Serra } & \multicolumn{2}{|c|}{ AF-IAG } \\
\hline & $3 \mathrm{~km}$ & $1 \mathrm{~km}$ & $3 \mathrm{~km}$ & $1 \mathrm{~km}$ & $3 \mathrm{~km}$ & $1 \mathrm{~km}$ & $3 \mathrm{~km}$ & $1 \mathrm{~km}$ & $3 \mathrm{~km}$ & $1 \mathrm{~km}$ & $3 \mathrm{~km}$ & $1 \mathrm{~km}$ & $3 \mathrm{~km}$ & $1 \mathrm{~km}$ \\
\hline$\sigma_{\text {obs }}$ & 4,9 & 4,9 & 5,2 & 5,2 & 5,6 & 5,6 & 6,4 & 6,4 & 4,6 & 4,6 & 5,8 & 5,8 & 5,6 & 5,6 \\
\hline$\sigma_{\text {sim }}$ & 5,3 & 5,6 & 4,6 & 5,5 & 5,3 & 5,7 & 5,1 & 5,6 & 5,7 & 5,5 & 5,2 & 5,6 & 5,0 & 5,4 \\
\hline $\mathrm{R}$ & 0,94 & 0,93 & 0,96 & 0,95 & 0,96 & 0,94 & 0,97 & 0,96 & 0,97 & 0,91 & 0,94 & 0,93 & 0,92 & 0,90 \\
\hline RMSE & 2,3 & 2,2 & 2,8 & 2,3 & 1,7 & 2,1 & 2,3 & 2,7 & 1,9 & 2,4 & 1,9 & 2,2 & 2,6 & 2,5 \\
\hline $\mathrm{D}$ & 0,95 & 0,96 & 0,90 & 0,95 & 0,98 & 0,97 & 0,96 & 0,95 & 0,97 & 0,94 & 0,97 & 0,96 & 0,94 & 0,95 \\
\hline
\end{tabular}

Tabela 8.5. Testes estatísticos para a temperatura no primeiro período.

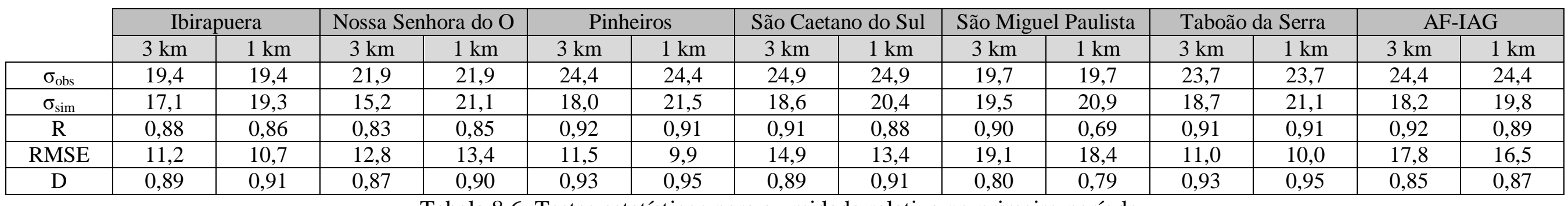

Tabela 8.6. Testes estatísticos para a umidade relativa no primeiro período. 


\begin{tabular}{|c|c|c|c|c|c|c|c|c|}
\cline { 2 - 9 } \multicolumn{1}{c|}{} & \multicolumn{2}{c|}{ Osasco } & \multicolumn{2}{c|}{ Santo Amaro } & \multicolumn{2}{c|}{ Santo Andre Capuava } & \multicolumn{2}{c|}{ AF-IAG } \\
\cline { 2 - 9 } \multicolumn{1}{c|}{} & $3 \mathrm{~km}$ & $1 \mathrm{~km}$ & $3 \mathrm{~km}$ & $1 \mathrm{~km}$ & $3 \mathrm{~km}$ & $1 \mathrm{~km}$ & $3 \mathrm{~km}$ & $1 \mathrm{~km}$ \\
\hline$\sigma_{\text {obs }}$ & 0,7 & 0,7 & 0,7 & 0,7 & 0,9 & 0,9 & 0,8 & 0,8 \\
\hline$\sigma_{\text {sim }}$ & 1,1 & 1,0 & 1,0 & 1,1 & 1,0 & 0,9 & 0,9 & 0,9 \\
\hline $\mathrm{r}$ & 0,34 & 0,38 & 0,39 & 0,57 & 0,31 & 0,41 & $-0,06$ & $-0,13$ \\
\hline $\mathrm{RMSE}$ & 1,2 & 1,0 & 1,6 & 1,0 & 1,3 & 1,0 & 1,9 & 1,5 \\
\hline $\mathrm{D}$ & 0,53 & 0,59 & 0,49 & 0,69 & 0,58 & 0,65 & 0,37 & 0,35 \\
\hline
\end{tabular}

Tabela 8.7. Testes estatísticos para a magnitude do vento no primeiro período.

\begin{tabular}{|c|c|c|c|c|c|c|c|c|c|c|c|c|c|c|}
\hline & \multicolumn{2}{|c|}{ Diadema } & \multicolumn{2}{|c|}{ Ibirapuera } & \multicolumn{2}{|c|}{ Mauá } & \multicolumn{2}{|c|}{ Mooca } & \multicolumn{2}{|c|}{ Nossa Senhora do O } & \multicolumn{2}{|c|}{ Pinheiros } & \multicolumn{2}{|c|}{ Santana } \\
\hline & $3 \mathrm{~km}$ & $1 \mathrm{~km}$ & $3 \mathrm{~km}$ & $1 \mathrm{~km}$ & $3 \mathrm{~km}$ & $1 \mathrm{~km}$ & $3 \mathrm{~km}$ & $1 \mathrm{~km}$ & $3 \mathrm{~km}$ & $1 \mathrm{~km}$ & $3 \mathrm{~km}$ & $1 \mathrm{~km}$ & $3 \mathrm{~km}$ & $1 \mathrm{~km}$ \\
\hline$\sigma_{\text {obs }}$ & 54,0 & 54,0 & 71,0 & 71,0 & 62,7 & 62,7 & 58,8 & 58,8 & 52,5 & 52,5 & 46,6 & 46,6 & 46,8 & 46,8 \\
\hline$\sigma_{\text {sim }}$ & 47,1 & 42,7 & 49,5 & 43,9 & 45,2 & 47,0 & 51,1 & 43,8 & 47,5 & 39,3 & 49,7 & 42,0 & 49,5 & 41,9 \\
\hline $\mathrm{R}$ & 0,92 & 0,91 & 0,90 & 0,88 & 0,91 & 0,87 & 0,90 & 0,84 & 0,87 & 0,86 & 0,88 & 0,87 & 0,86 & 0,79 \\
\hline RMSE & 26,3 & 25,2 & 35,2 & 38,8 & 32,6 & 34,3 & 29,5 & 33,7 & 41,1 & 34,2 & 42,1 & 35,6 & 33,6 & 32,0 \\
\hline $\mathrm{D}$ & 0,93 & 0,93 & 0,91 & 0,87 & 0,90 & 0,89 & 0,92 & 0,88 & 0,84 & 0,86 & 0,82 & 0,84 & 0,87 & 0,86 \\
\hline $\mathrm{PO}_{3}$ & $-6,54$ & $-12,75$ & $-24,34$ & $-27,24$ & $-13,93$ & $-16,61$ & $-11,06$ & $-19,82$ & 2,17 & $-17,10$ & 19,97 & 7,51 & $-4,36$ & $-17,62$ \\
\hline
\end{tabular}

Tabela 8.8. Testes estatísticos para o ozônio no primeiro período.

\begin{tabular}{|c|c|c|c|c|c|c|c|c|}
\cline { 2 - 9 } \multicolumn{1}{c|}{} & \multicolumn{2}{c|}{ Santo Amaro } & \multicolumn{2}{c|}{ Santo Andre Capuava } & \multicolumn{2}{c|}{ São Caetano do Sul } & \multicolumn{2}{c|}{ São Miguel Paulista } \\
\cline { 2 - 9 } \multicolumn{1}{c|}{} & $3 \mathrm{~km}$ & $1 \mathrm{~km}$ & $3 \mathrm{~km}$ & $1 \mathrm{~km}$ & $3 \mathrm{~km}$ & $1 \mathrm{~km}$ & $3 \mathrm{~km}$ & $1 \mathrm{~km}$ \\
\hline$\sigma_{\text {obs }}$ & 62,9 & 62,9 & 56,9 & 56,9 & 51,5 & 51,5 & 56,3 & 56,3 \\
\hline$\sigma_{\text {sim }}$ & 47,7 & 43,0 & 48,2 & 47,3 & 50,0 & 46,0 & 53,1 & 43,8 \\
\hline $\mathrm{r}$ & 0,92 & 0,93 & 0,84 & 0,79 & 0,91 & 0,86 & 0,91 & 0,90 \\
\hline $\mathrm{RMSE}$ & 28,3 & 31,3 & 31,2 & 34,7 & 26,7 & 29,2 & 24,5 & 25,4 \\
\hline $\mathrm{D}$ & 0,93 & 0,91 & 0,89 & 0,85 & 0,92 & 0,90 & 0,94 & 0,93 \\
\hline $\mathrm{PO}_{3}$ & $-24,07$ & $-27,64$ & $-14,02$ & $-18,75$ & $-7,12$ & $-15,69$ & $-6,45$ & $-22,72$ \\
\hline
\end{tabular}

Tabela 8.9. Continuação da tabela 8.8. 


\begin{tabular}{|c|c|c|c|c|c|c|c|c|c|c|c|c|}
\hline & \multicolumn{2}{|c|}{ Cerqueira Cesar } & \multicolumn{2}{|c|}{ Congonhas } & \multicolumn{2}{|c|}{ Ibirapuera } & \multicolumn{2}{|c|}{ Mauá } & \multicolumn{2}{|c|}{ Pinheiros } & \multicolumn{2}{|c|}{ Taboão da Serra } \\
\hline & $3 \mathrm{~km}$ & $1 \mathrm{~km}$ & $3 \mathrm{~km}$ & $1 \mathrm{~km}$ & $3 \mathrm{~km}$ & $1 \mathrm{~km}$ & $3 \mathrm{~km}$ & $1 \mathrm{~km}$ & $3 \mathrm{~km}$ & $1 \mathrm{~km}$ & $3 \mathrm{~km}$ & $1 \mathrm{~km}$ \\
\hline$\sigma_{\mathrm{obs}}$ & 68,4 & 68,4 & 131,5 & 131,5 & 47,9 & 47,9 & 21,8 & 21,8 & 157,2 & 157,2 & 95,0 & 95,0 \\
\hline$\sigma_{\text {sim }}$ & 20,1 & 56,7 & 20,3 & 46,2 & 20,1 & 46,5 & 15,2 & 12,8 & 20,0 & 42,9 & 21,9 & 40,6 \\
\hline $\mathrm{R}$ & 0,51 & 0,54 & 0,19 & $-0,11$ & 0,47 & 0,46 & 0,26 & 0,12 & 0,20 & 0,22 & 0,24 & 0,29 \\
\hline RMSE & 93,7 & 72,4 & 213,8 & 203,7 & 49,7 & 49,1 & 24,7 & 29,3 & 196,4 & 180,5 & 121,9 & 109,5 \\
\hline $\mathrm{D}$ & 0,48 & 0,66 & 0,45 & 0,42 & 0,52 & 0,66 & 0,50 & 0,42 & 0,43 & 0,43 & 0,42 & 0,48 \\
\hline
\end{tabular}

Tabela 8.10. Testes estatísticos para o NOx no primeiro período.

\begin{tabular}{|c|c|c|c|c|c|c|c|c|c|c|c|c|c|c|}
\hline & \multicolumn{2}{|c|}{ Centro } & \multicolumn{2}{|c|}{ Cerqueira Cesar } & \multicolumn{2}{|c|}{ Ibirapuera } & \multicolumn{2}{|c|}{ Pinheiros } & \multicolumn{2}{|c|}{ Santo Amaro } & \multicolumn{2}{|c|}{ Santo Andre Centro } & \multicolumn{2}{|c|}{ São Caetano do Sul } \\
\hline & $3 \mathrm{~km}$ & $1 \mathrm{~km}$ & $3 \mathrm{~km}$ & $1 \mathrm{~km}$ & $3 \mathrm{~km}$ & $1 \mathrm{~km}$ & $3 \mathrm{~km}$ & $1 \mathrm{~km}$ & $3 \mathrm{~km}$ & $1 \mathrm{~km}$ & $3 \mathrm{~km}$ & $1 \mathrm{~km}$ & $3 \mathrm{~km}$ & $1 \mathrm{~km}$ \\
\hline$\sigma_{\text {obs }}$ & 0,6 & 0,6 & 0,8 & 0,8 & 0,7 & 0,7 & 1,6 & 1,6 & 0,5 & 0,5 & 1,1 & 1,1 & 1,1 & 1,1 \\
\hline$\sigma_{\mathrm{sim}}$ & 0,4 & 0,9 & 0,4 & 0,8 & 0,4 & 0,7 & 0,4 & 0,6 & 0,4 & 0,4 & 0,3 & 0,3 & 0,3 & 0,4 \\
\hline $\mathrm{r}$ & 0,31 & 0,12 & 0,39 & 0,40 & 0,39 & 0,44 & 0,22 & 0,29 & 0,15 & 0,40 & 0,10 & $-0,07$ & 0,50 & 0,24 \\
\hline RMSE & 1,1 & 1,1 & 1,1 & 1,0 & 0,8 & 0,7 & 2,3 & 2,1 & 0,7 & 0,6 & 1,4 & 1,5 & 1,6 & 1.6 \\
\hline $\mathrm{D}$ & 0,47 & 0,43 & 0,50 & 0,60 & 0,54 & 0,66 & 0,44 & 0,47 & 0,48 & 0,60 & 0,35 & 0,32 & 0,47 & 0,44 \\
\hline
\end{tabular}

Tabela 8.11. Testes estatísticos para o $C O$ no primeiro período.

\begin{tabular}{|c|c|c|c|c|c|c|c|c|c|c|c|c|}
\hline & \multicolumn{2}{|c|}{ Parelheiros } & \multicolumn{2}{|c|}{ Pinheiros } & \multicolumn{2}{|c|}{ São Caetano do Sul } & \multicolumn{2}{|c|}{ Taboão da Serra } & \multicolumn{2}{|c|}{ MS-INMET } & \multicolumn{2}{|c|}{ AF-IAG } \\
\hline & $3 \mathrm{~km}$ & $1 \mathrm{~km}$ & $3 \mathrm{~km}$ & $1 \mathrm{~km}$ & $3 \mathrm{~km}$ & $1 \mathrm{~km}$ & $3 \mathrm{~km}$ & $1 \mathrm{~km}$ & $3 \mathrm{~km}$ & $1 \mathrm{~km}$ & $3 \mathrm{~km}$ & $1 \mathrm{~km}$ \\
\hline$\sigma_{\text {obs }}$ & 1,8 & 1,8 & 2,1 & 2,1 & 2,3 & 2,3 & 2,1 & 2,1 & 1,9 & 1,9 & 1,7 & 1,7 \\
\hline$\sigma_{\text {sim }}$ & 1,6 & 1,3 & 1,9 & 1,3 & 1,8 & 1,5 & 1,9 & 1,3 & 1,4 & 1,5 & 1,7 & 1,4 \\
\hline $\mathrm{r}$ & 0,66 & 0,72 & 0,85 & 0,77 & 0,85 & 0,77 & 0,83 & 0,81 & 0,75 & 0,35 & 0,84 & 0,77 \\
\hline RMSE & 1,5 & 1,4 & 1,1 & 1,4 & 1,3 & 1,5 & 1,3 & 1,4 & 1,3 & 2,1 & 1,0 & 1,2 \\
\hline $\mathrm{D}$ & 0,79 & 0,78 & 0,92 & 0,81 & 0,90 & 0,82 & 0,89 & 0,83 & 0,83 & 0,62 & 0,91 & 0,84 \\
\hline
\end{tabular}

Tabela 8.12. Testes estatísticos para a temperatura no segundo período. 


\begin{tabular}{|c|c|c|c|c|c|c|c|c|c|c|}
\cline { 2 - 11 } \multicolumn{1}{c|}{} & \multicolumn{2}{c|}{ Parelheiros } & \multicolumn{2}{c|}{ São Caetano do Sul } & \multicolumn{2}{c|}{ Taboão da Serra } & \multicolumn{2}{c|}{ MS-INMET } & \multicolumn{2}{c|}{ AF-IAG } \\
\cline { 2 - 12 } \multicolumn{1}{c|}{} & $3 \mathrm{~km}$ & $1 \mathrm{~km}$ & $3 \mathrm{~km}$ & $1 \mathrm{~km}$ & $3 \mathrm{~km}$ & $1 \mathrm{~km}$ & $3 \mathrm{~km}$ & $1 \mathrm{~km}$ & $3 \mathrm{~km}$ & $1 \mathrm{~km}$ \\
\hline$\sigma_{\text {obs }}$ & 4,5 & 4,5 & 9,8 & 9,8 & 11,8 & 11,8 & 12,0 & 12,0 & 7,4 & 7,4 \\
\hline$\sigma_{\text {sim }}$ & 3,3 & 1,3 & 5,5 & 4,3 & 8,3 & 6,5 & 9,8 & 7,2 & 6,7 & 4,6 \\
\hline $\mathrm{R}$ & 0,35 & 0,18 & 0,27 & $-0,19$ & 0,70 & 0,69 & 0,74 & 0,59 & 0,62 & 0,34 \\
\hline RMSE & 4,6 & 4,6 & 9,8 & 11,4 & 8,3 & 8,6 & 8,7 & 10,1 & 6,2 & 7,3 \\
\hline $\mathrm{D}$ & 0,56 & 0,28 & 0,53 & 0,14 & 0,81 & 0,76 & 0,83 & 0,70 & 0,78 & 0,57 \\
\hline
\end{tabular}

Tabela 8.13. Testes estatísticos para a umidade relativa no segundo período.

\begin{tabular}{|c|c|c|c|c|c|c|c|c|c|c|c|c|}
\hline & \multicolumn{2}{|c|}{ Ibirapuera } & \multicolumn{2}{|c|}{ Mooca } & \multicolumn{2}{|c|}{ Pinheiros } & \multicolumn{2}{|c|}{ Santana } & \multicolumn{2}{|c|}{ MS-INMET } & \multicolumn{2}{|c|}{ AF-IAG } \\
\hline & $3 \mathrm{~km}$ & $1 \mathrm{~km}$ & $3 \mathrm{~km}$ & $1 \mathrm{~km}$ & $3 \mathrm{~km}$ & $1 \mathrm{~km}$ & $3 \mathrm{~km}$ & $1 \mathrm{~km}$ & $3 \mathrm{~km}$ & $1 \mathrm{~km}$ & $3 \mathrm{~km}$ & $1 \mathrm{~km}$ \\
\hline$\sigma_{\text {obs }}$ & 0,9 & 0,9 & 1,0 & 1,0 & 0,6 & 0,6 & 0,8 & 0,8 & 1,1 & 1,1 & 0,7 & 0,7 \\
\hline$\sigma_{\text {sim }}$ & 1,2 & 1,4 & 1,3 & 1,4 & 1,2 & 1,2 & 1,2 & 1,4 & 1,2 & 1,4 & 1,2 & 1,5 \\
\hline $\mathrm{r}$ & 0,40 & 0,13 & 0,31 & 0,06 & 0,38 & 0,11 & 0,40 & 0,24 & 0,21 & 0,19 & 0,30 & 0,31 \\
\hline RMSE & 2,0 & 3,1 & 2,2 & 3,2 & 1,7 & 2,6 & 1,9 & 2,8 & 1,6 & 2,2 & 2,0 & 3,0 \\
\hline $\mathrm{D}$ & 0,45 & 0,28 & 0,45 & 0,33 & 0,39 & 0,24 & 0,43 & 0,30 & 0,50 & 0,44 & 0,37 & 0,28 \\
\hline
\end{tabular}

Tabela 8.14. Testes estatísticos para a magnitude do vento no segundo período.

\begin{tabular}{|c|c|c|c|c|c|c|c|c|c|c|c|c|c|c|}
\hline & \multicolumn{2}{|c|}{ Diadema } & \multicolumn{2}{|c|}{ Ibirapuera } & \multicolumn{2}{|c|}{ IPEN-USP } & \multicolumn{2}{|c|}{ Mauá } & \multicolumn{2}{|c|}{ Mooca } & \multicolumn{2}{|c|}{ Nossa Senhora do O } & \multicolumn{2}{|c|}{ Pinheiros } \\
\hline & $3 \mathrm{~km}$ & $1 \mathrm{~km}$ & $3 \mathrm{~km}$ & $1 \mathrm{~km}$ & $3 \mathrm{~km}$ & $1 \mathrm{~km}$ & $3 \mathrm{~km}$ & $1 \mathrm{~km}$ & $3 \mathrm{~km}$ & $1 \mathrm{~km}$ & $3 \mathrm{~km}$ & $1 \mathrm{~km}$ & $3 \mathrm{~km}$ & $1 \mathrm{~km}$ \\
\hline$\sigma_{\mathrm{obs}}$ & 21,8 & 21,8 & 27,6 & 27,6 & 36,5 & 36,5 & 21,2 & 21,2 & 30,0 & 30,0 & 28,9 & 28,9 & 25,6 & 25,6 \\
\hline$\sigma_{\mathrm{sim}}$ & 14,7 & 12,9 & 16,3 & 13,3 & 16,6 & 14,1 & 14,6 & 12,8 & 18,0 & 14,0 & 20,2 & 14,4 & 17,0 & 13,8 \\
\hline RMSE & 14,1 & 15,2 & 17,4 & 19,5 & 26,9 & 29,1 & 14,2 & 13,3 & 24,3 & 25,1 & 21,9 & 25,2 & 14,8 & 16,8 \\
\hline $\mathrm{D}$ & 0,83 & 0,78 & 0,83 & 0,75 & 0,74 & 0,66 & 0,82 & 0,83 & 0,77 & 0,72 & 0,80 & 0,67 & 0,87 & 0,80 \\
\hline $\mathrm{PO}_{3}$ & $-0,55$ & $-16,54$ & $-16,07$ & $-31,01$ & $-31,91$ & $-40,73$ & $-1,29$ & $-16,56$ & 32,73 & 4,25 & $-6,07$ & $-24,30$ & $-8,40$ & $-22,73$ \\
\hline
\end{tabular}

Tabela 8.15. Testes estatísticos para o ozônio no segundo período. 


\begin{tabular}{|c|c|c|c|c|c|c|}
\cline { 2 - 7 } \multicolumn{1}{c|}{} & \multicolumn{2}{c|}{ Santana } & \multicolumn{2}{c|}{ Santo Andre Capuava } & \multicolumn{2}{c|}{ São Caetano do Sul } \\
\cline { 2 - 7 } \multicolumn{1}{c|}{} & $3 \mathrm{~km}$ & $1 \mathrm{~km}$ & $3 \mathrm{~km}$ & $1 \mathrm{~km}$ & $3 \mathrm{~km}$ & $1 \mathrm{~km}$ \\
\hline$\sigma_{\text {obs }}$ & 30,4 & 30,4 & 21,0 & 21,0 & 29,7 & 29,7 \\
\hline$\sigma_{\text {sim }}$ & 19,3 & 14,3 & 15,4 & 13,0 & 16,4 & 13,5 \\
\hline $\mathrm{R}$ & 0,84 & 0,74 & 0,75 & 0,79 & 0,81 & 0,84 \\
\hline $\mathrm{RMSE}$ & 19,3 & 23,1 & 16,7 & 16,1 & 20,0 & 20,8 \\
\hline $\mathrm{D}$ & 0,84 & 0,72 & 0,78 & 0,77 & 0,79 & 0,74 \\
\hline $\mathrm{PO}_{3}$ & $-11,88$ & $-31,21$ & 24,93 & 0,56 & $-13,95$ & $-33,23$ \\
\hline
\end{tabular}

Tabela 8.16. Continuação da tabela 8.15.

\begin{tabular}{|c|c|c|c|c|c|c|c|c|c|c|c|c|}
\hline & \multicolumn{2}{|c|}{ Cerqueira Cesar } & \multicolumn{2}{|c|}{ Congonhas } & \multicolumn{2}{|c|}{ Ibirapuera } & \multicolumn{2}{|c|}{ IPEN-USP } & \multicolumn{2}{|c|}{ Mauá } & \multicolumn{2}{|c|}{ Parelheiros } \\
\hline & $3 \mathrm{~km}$ & $1 \mathrm{~km}$ & $3 \mathrm{~km}$ & $1 \mathrm{~km}$ & $3 \mathrm{~km}$ & $1 \mathrm{~km}$ & $3 \mathrm{~km}$ & $1 \mathrm{~km}$ & $3 \mathrm{~km}$ & $1 \mathrm{~km}$ & $3 \mathrm{~km}$ & $1 \mathrm{~km}$ \\
\hline$\sigma_{\mathrm{obs}}$ & 30,7 & 30,7 & 30,1 & 30,1 & 8,2 & 8,2 & 7,8 & 7,8 & 10,8 & 10,8 & 23,5 & 23,5 \\
\hline$\sigma_{\text {sim }}$ & 8,1 & 7,0 & 8,0 & 4,6 & 7,7 & 5,0 & 7,6 & 5,2 & 7,0 & 1,9 & 5,0 & 1,3 \\
\hline $\mathrm{r}$ & 0,53 & 0,30 & 0,05 & 0,34 & 0,58 & 0,28 & 0,52 & 0,22 & 0,26 & 0,05 & 0,50 & 0,12 \\
\hline RMSE & 32,5 & 35,1 & 63,1 & 67,0 & 7,3 & 9,9 & 7,5 & 9,1 & 11,4 & 15,4 & 24,7 & 29,5 \\
\hline $\mathrm{D}$ & 0,32 & 0,25 & 0,38 & 0,37 & 0,76 & 0,48 & 0,72 & 0,46 & 0,51 & 0,43 & 0,41 & 0,37 \\
\hline
\end{tabular}

Tabela 8.17. Testes estatísticos para o NOx no segundo período.

\begin{tabular}{|c|c|c|c|c|c|c|}
\cline { 2 - 7 } \multicolumn{1}{c|}{} & \multicolumn{2}{c|}{ Parque Don Pedro II } & \multicolumn{2}{c|}{ Pinheiros } & \multicolumn{2}{c|}{ Taboão da Serra } \\
\cline { 2 - 7 } \multicolumn{1}{c|}{} & $3 \mathrm{~km}$ & $1 \mathrm{~km}$ & $3 \mathrm{~km}$ & $1 \mathrm{~km}$ & $3 \mathrm{~km}$ & $1 \mathrm{~km}$ \\
\hline$\sigma_{\text {obs }}$ & 17,4 & 17,4 & 21,5 & 21,5 & 19,2 & 19,2 \\
\hline$\sigma_{\text {sim }}$ & 7,4 & 7,3 & 8,0 & 4,8 & 7,4 & 3,2 \\
\hline $\mathrm{R}$ & 0,48 & 0,19 & 0,38 & 0,21 & 0,46 & 0,28 \\
\hline $\mathrm{RMSE}$ & 21,2 & 24,5 & 24,5 & 28,0 & 23,4 & 29,3 \\
\hline $\mathrm{D}$ & 0,54 & 0,47 & 0,49 & 0,43 & 0,49 & 0,42 \\
\hline
\end{tabular}

Tabela 8.18. Continuação da tabela 8.17. 


\begin{tabular}{|c|c|c|c|c|c|c|c|c|c|c|c|c|c|c|}
\hline & \multicolumn{2}{|c|}{ Cerqueira Cesar } & \multicolumn{2}{|c|}{ Congonhas } & \multicolumn{2}{|c|}{ Ibirapuera } & \multicolumn{2}{|c|}{ IPEN-USP } & \multicolumn{2}{|c|}{ Mooca } & \multicolumn{2}{|c|}{ Parelheiros } & \multicolumn{2}{|c|}{ Parque Don Pedro II } \\
\hline & $3 \mathrm{~km}$ & $1 \mathrm{~km}$ & $3 \mathrm{~km}$ & $1 \mathrm{~km}$ & $3 \mathrm{~km}$ & $1 \mathrm{~km}$ & $3 \mathrm{~km}$ & $1 \mathrm{~km}$ & $3 \mathrm{~km}$ & $1 \mathrm{~km}$ & $3 \mathrm{~km}$ & $1 \mathrm{~km}$ & $3 \mathrm{~km}$ & $1 \mathrm{~km}$ \\
\hline$\sigma_{\text {obs }}$ & 0,3 & 0,3 & 0,4 & 0,4 & 0,1 & 0,1 & 0,1 & 0,1 & 0,2 & 0,2 & 0,3 & 0,3 & 0,2 & 0,2 \\
\hline$\sigma_{\mathrm{sim}}$ & 0,1 & 0,2 & 0,1 & 0,1 & 0,1 & 0,1 & 0,1 & 0,1 & 0,1 & 0,1 & 0,1 & 0,03 & 0,1 & 0,2 \\
\hline $\mathrm{r}$ & 0,50 & 0,35 & 0,31 & 0,42 & 0,62 & 0,32 & 0,36 & 0,18 & 0,45 & 0,43 & 0,55 & 0,20 & 0,52 & 0,38 \\
\hline RMSE & 0,4 & 0,4 & 0,8 & 0,8 & 0,2 & 0,3 & 0,1 & 0,2 & 0,3 & 0,3 & 0,6 & 0,6 & 0,3 & 0,3 \\
\hline $\mathrm{D}$ & 0,43 & 0,40 & 0,38 & 0,38 & 0,49 & 0,39 & 0,52 & 0,41 & 0,51 & 0,50 & 0,39 & 0,35 & 0,53 & 0,54 \\
\hline
\end{tabular}

Tabela 8.19. Testes estatísticos para o $C O$ no segundo período.

\begin{tabular}{|c|c|c|c|c|c|c|}
\cline { 2 - 7 } \multicolumn{1}{c|}{} & \multicolumn{2}{c|}{ Pinheiros } & \multicolumn{2}{c|}{ Santo Andre Paço M. } & \multicolumn{2}{c|}{ São Caetano do Sul } \\
\cline { 2 - 7 } \multicolumn{1}{c|}{} & $3 \mathrm{~km}$ & $1 \mathrm{~km}$ & $3 \mathrm{~km}$ & $1 \mathrm{~km}$ & $3 \mathrm{~km}$ & $1 \mathrm{~km}$ \\
\hline$\sigma_{\text {obs }}$ & 0,2 & 0,2 & 0,3 & 0,3 & 0,3 & 0,3 \\
\hline$\sigma_{\text {sim }}$ & 0,1 & 0,1 & 0,1 & 0,04 & 0,1 & 0,1 \\
\hline R & 0,50 & 0,29 & 0,43 & 0,33 & 0,39 & 0,14 \\
\hline RMSE & 0,36 & 0,37 & 0,53 & 0,65 & 0,45 & 0,53 \\
\hline $\mathrm{D}$ & 0,48 & 0,42 & 0,43 & 0,36 & 0,46 & 0,40 \\
\hline
\end{tabular}

Tabela 8.20. Continuação da tabela 8.19. 
F. Diferença espaço-temporal de ozônio no período de 12-15 novembro de 2011 com as emissões estimadas para os anos 2004 e 2011


Figura 8.1. Diferença de ozônio no período de 12 a 15 de novembro de $2011 \mathrm{com}$ as emissões estimadas para os anos 2004 e 2011 na grade de $3 \mathrm{~km}$. 



Figura 8.2. Continuação da figura 8.1. 

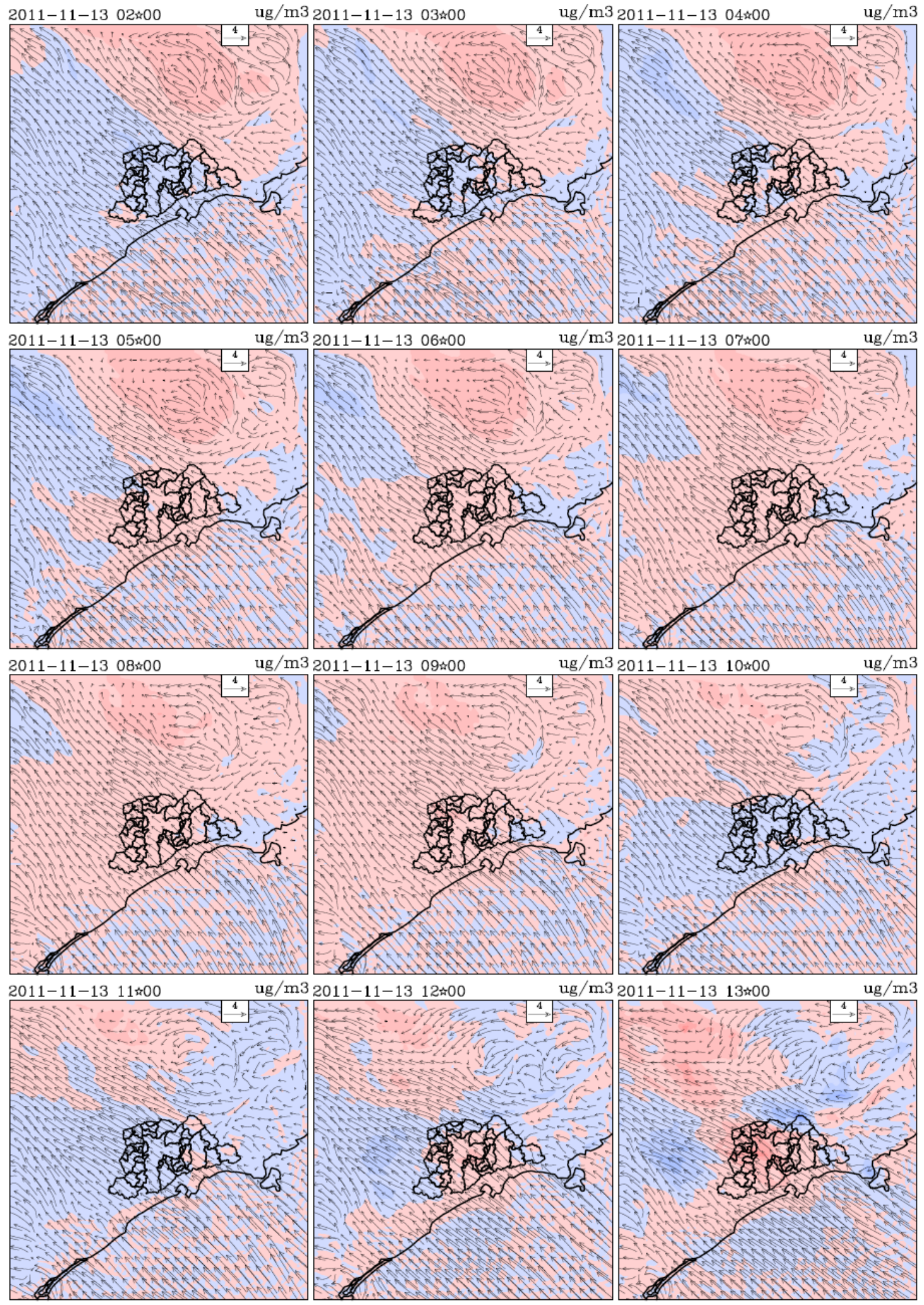

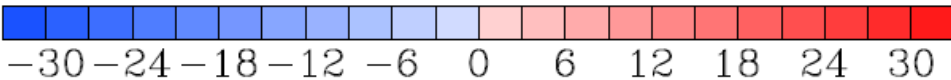

Figura 8.3. Continuação da figura 8.2. 

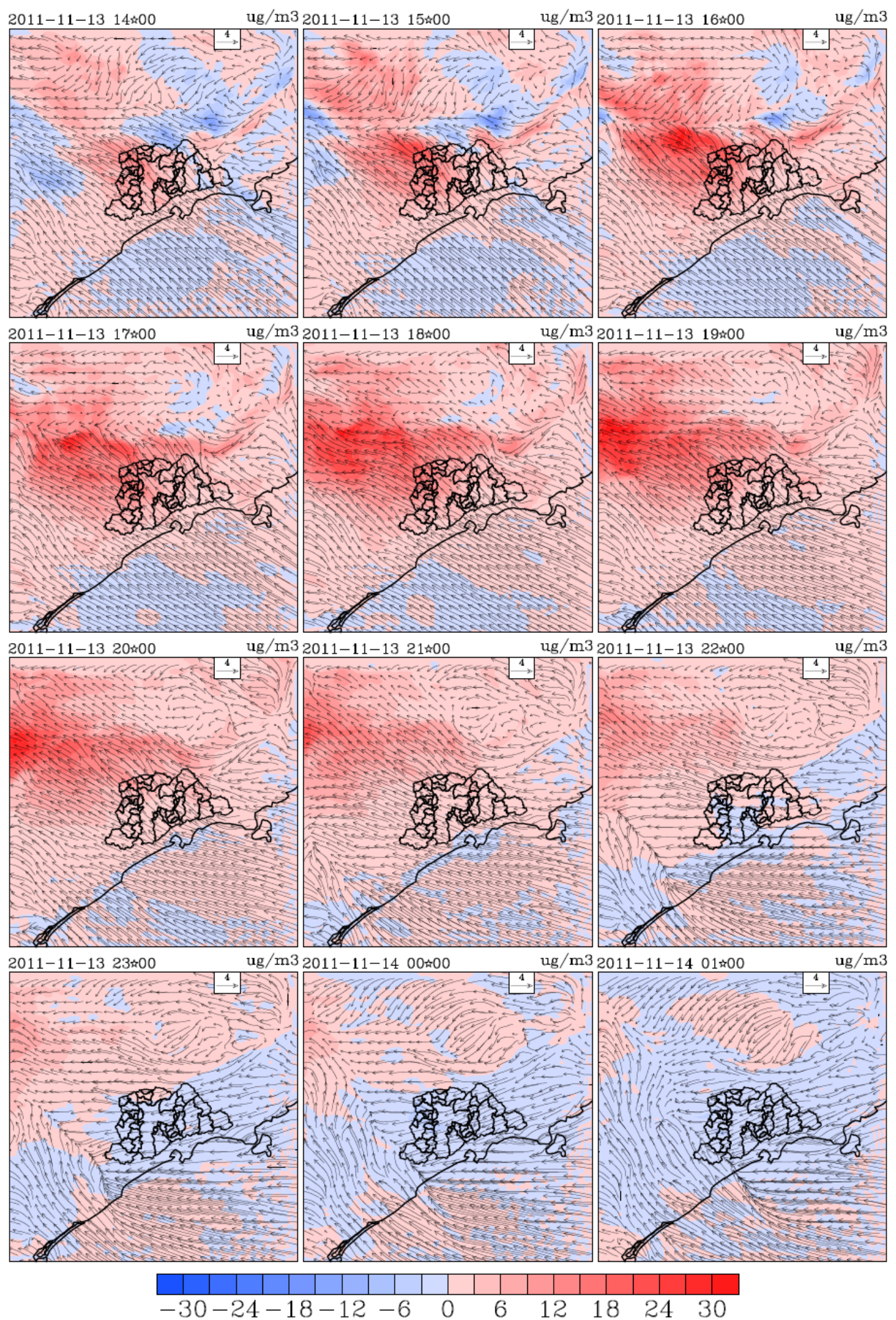

Figura 8.4. Continuação da figura 8.3. 

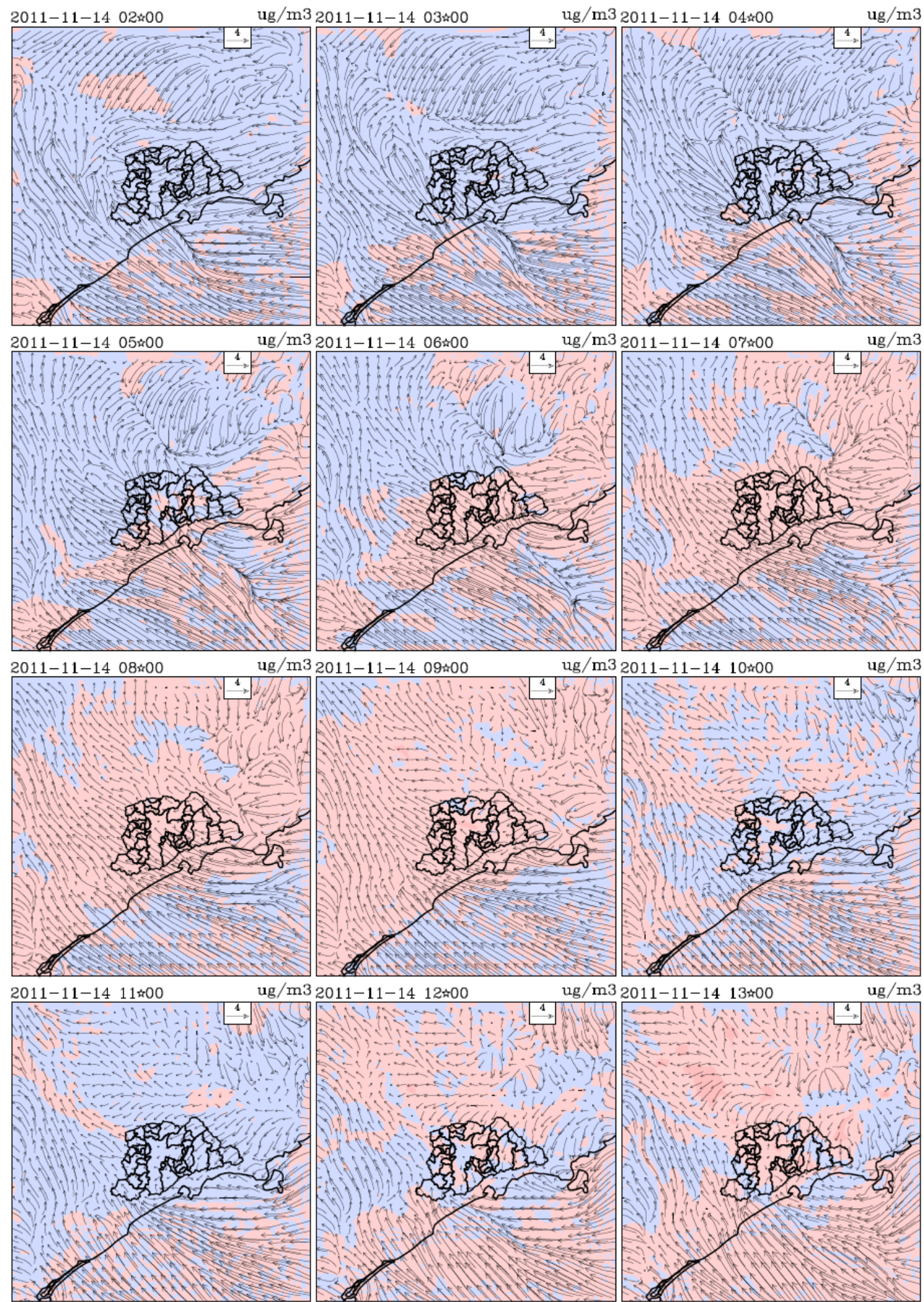

$$
\begin{array}{llllllll}
-30-24-18-12 & -6 & 0 & 6 & 12 & 18 & 24 & 30
\end{array}
$$

Figura 8.5. Continuação da figura 8.4. 

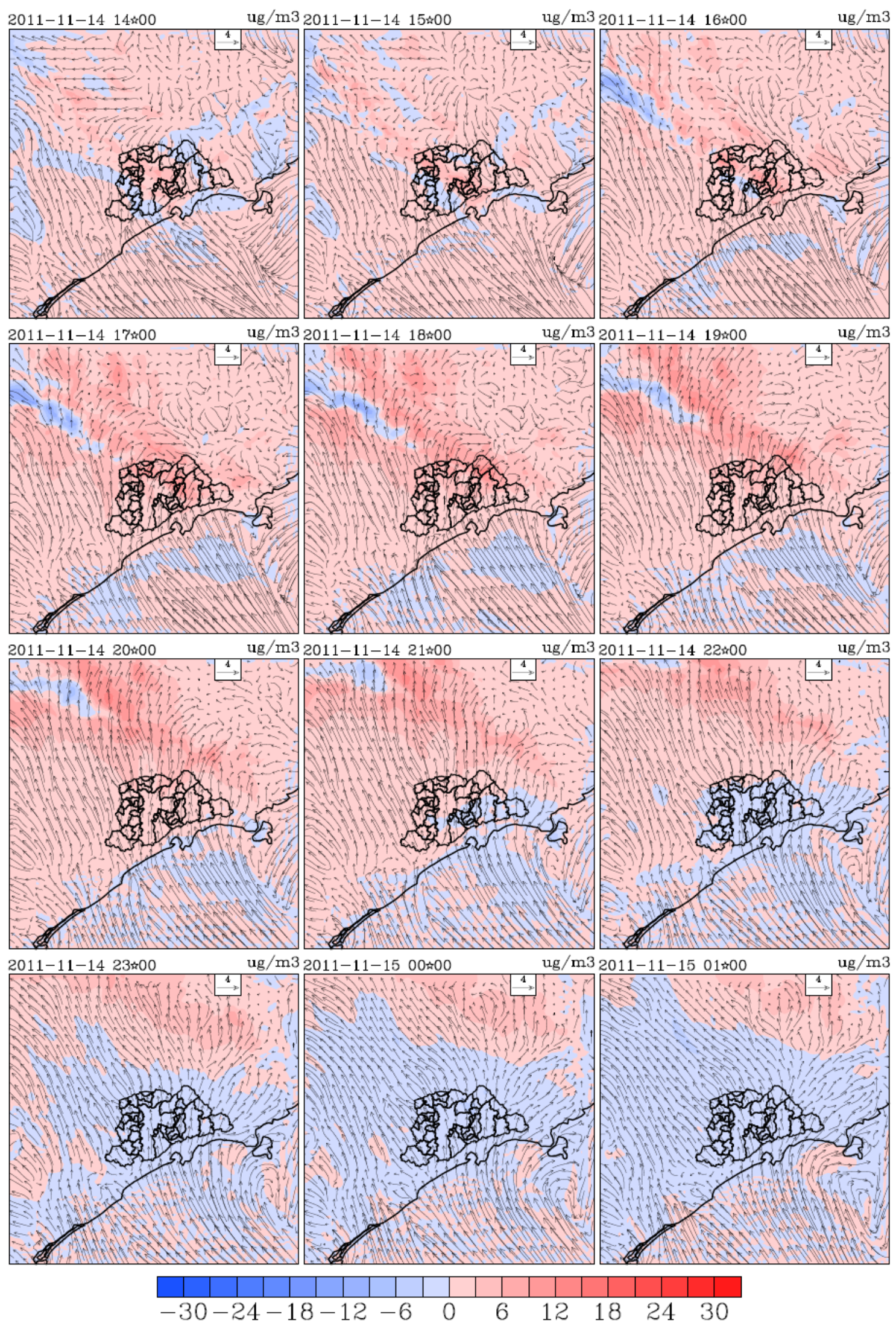

Figura 8.6. Continuação da figura 8.5. 

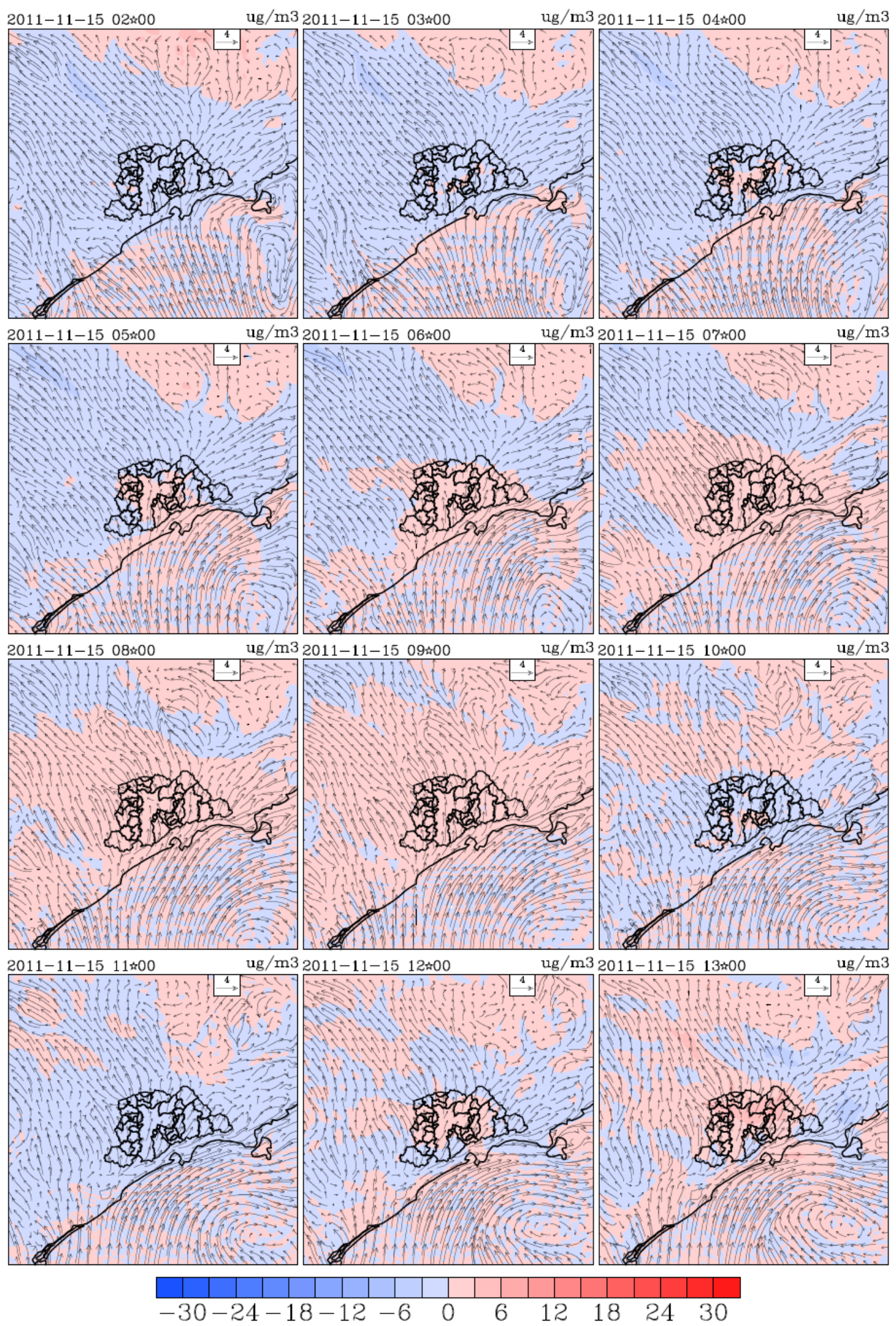

Figura 8.7. Continuação da figura 8.6. 

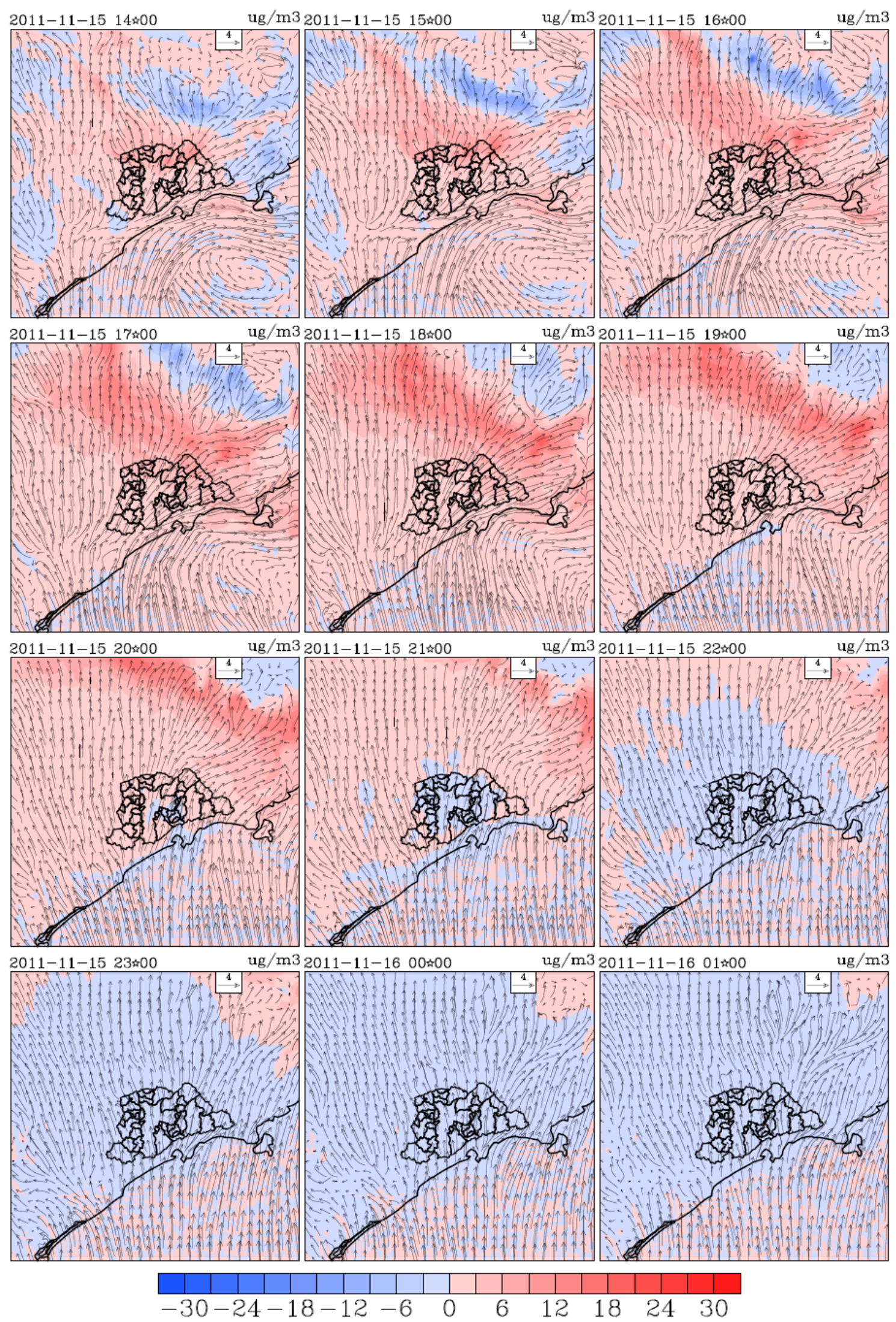

Figura 8.8. Continuação da figura 8.7. 


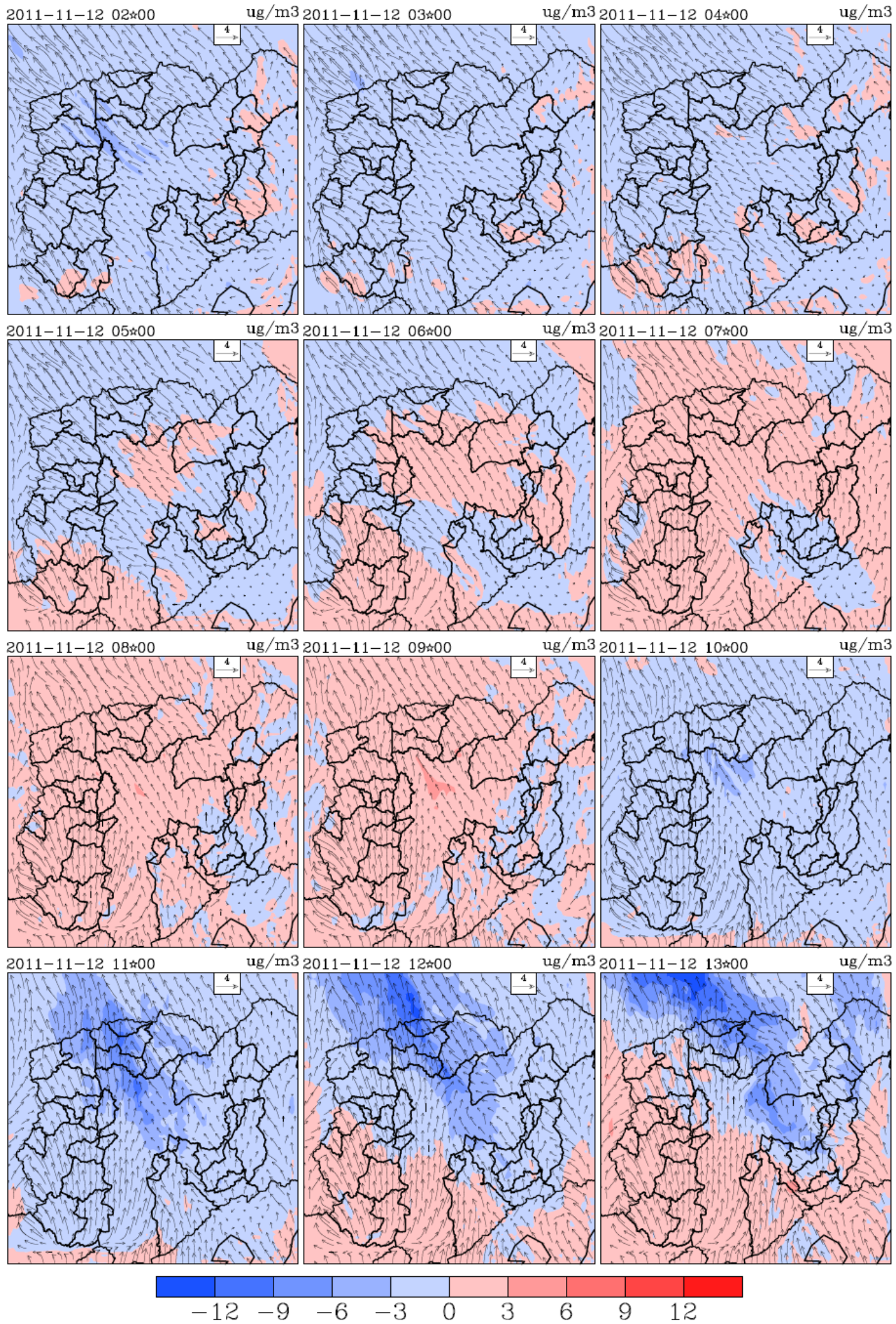

Figura 8.9. Diferença de ozônio no período de 12 a 15 de novembro de 2011 com as emissões estimadas para os anos 2004 e 2011 na grade de $1 \mathrm{~km}$. 


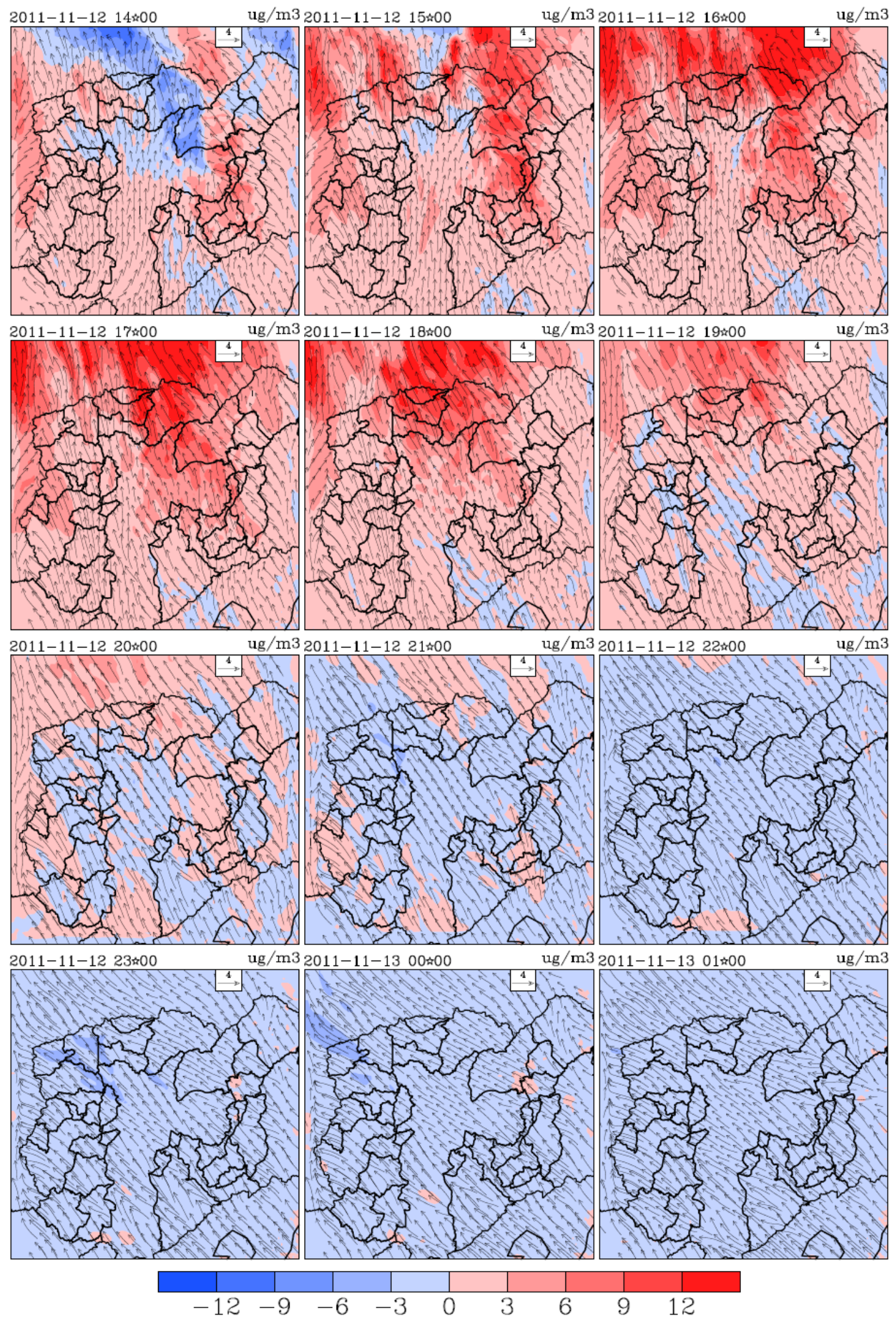

Figura 8.10. Continuação da figura 8.9. 




Figura 8.11. Continuação da figura 8.10. 


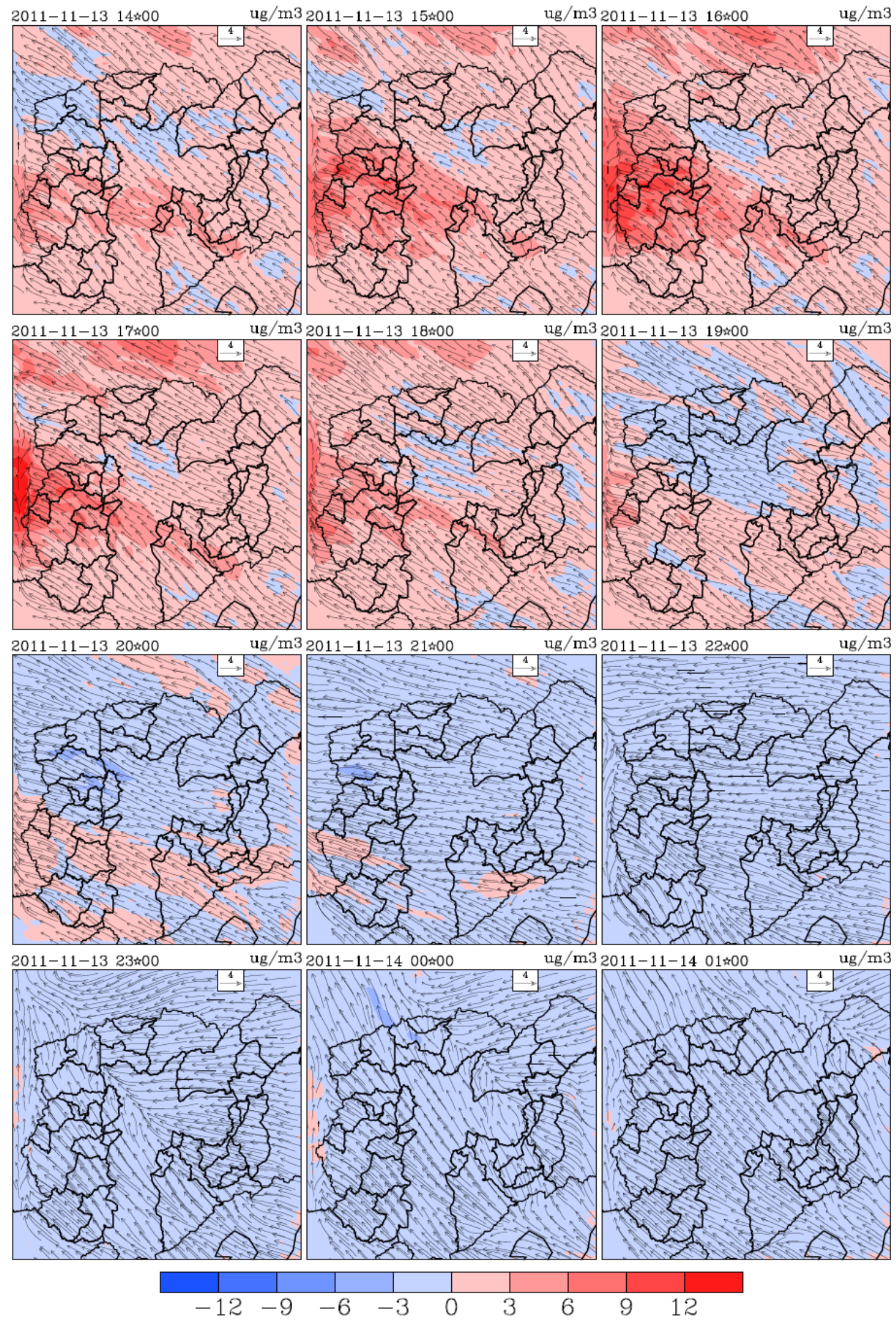

Figura 8.12. Continuação da figura 8.11. 


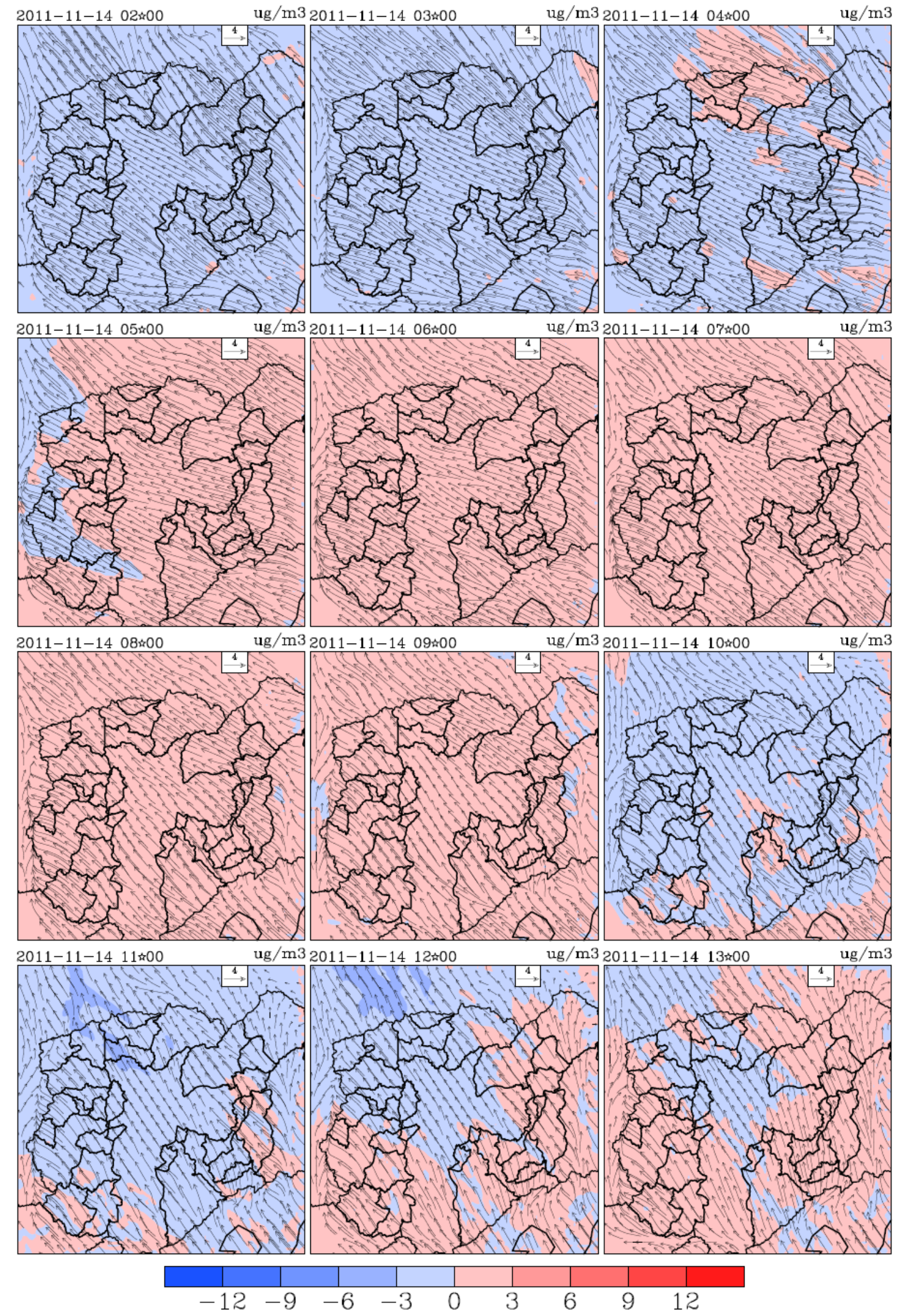

Figura 8.13. Continuação da figura 8.12. 


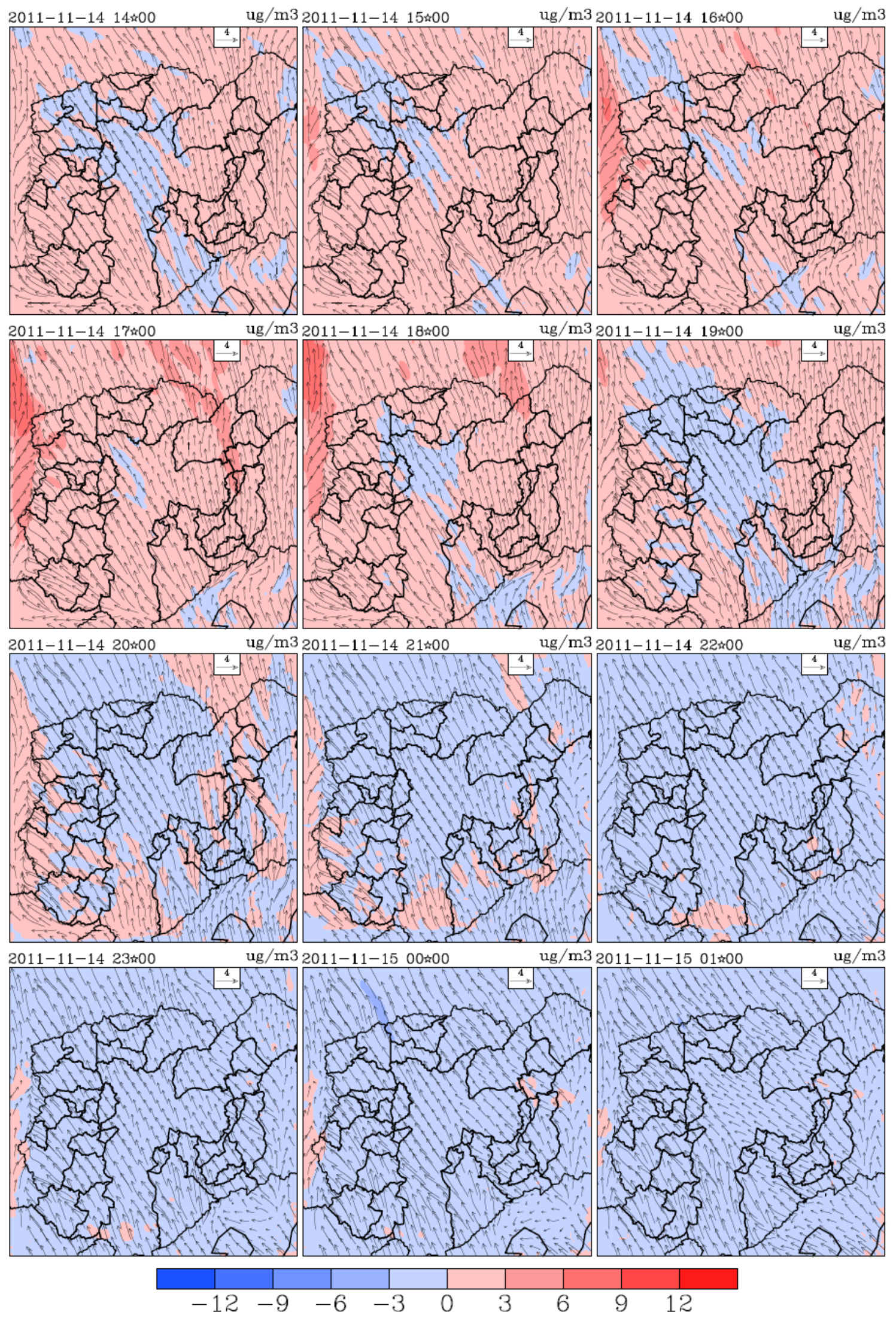

Figura 8.14. Continuação da figura 8.13. 


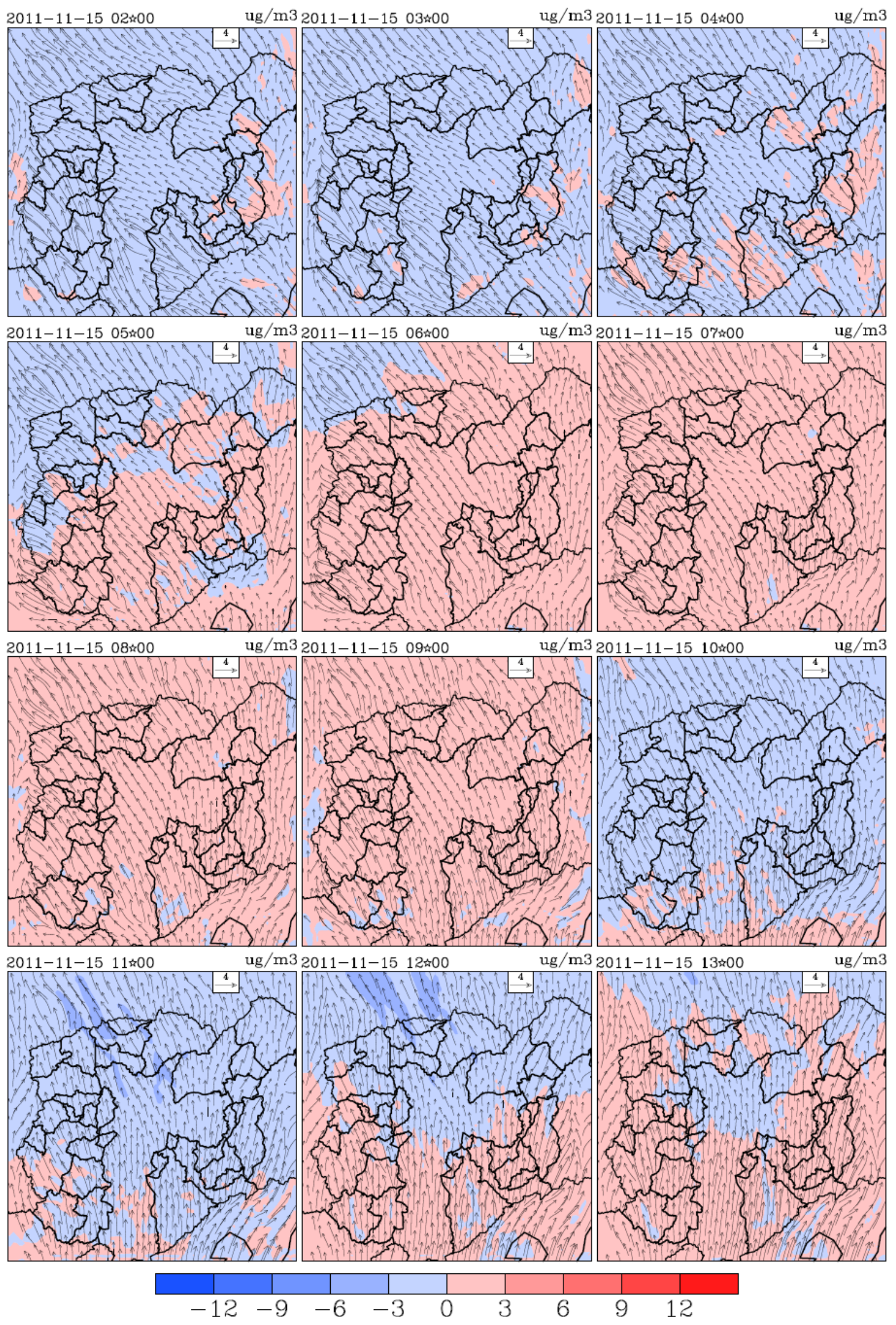

Figura 8.15. Continuação da figura 8.14. 


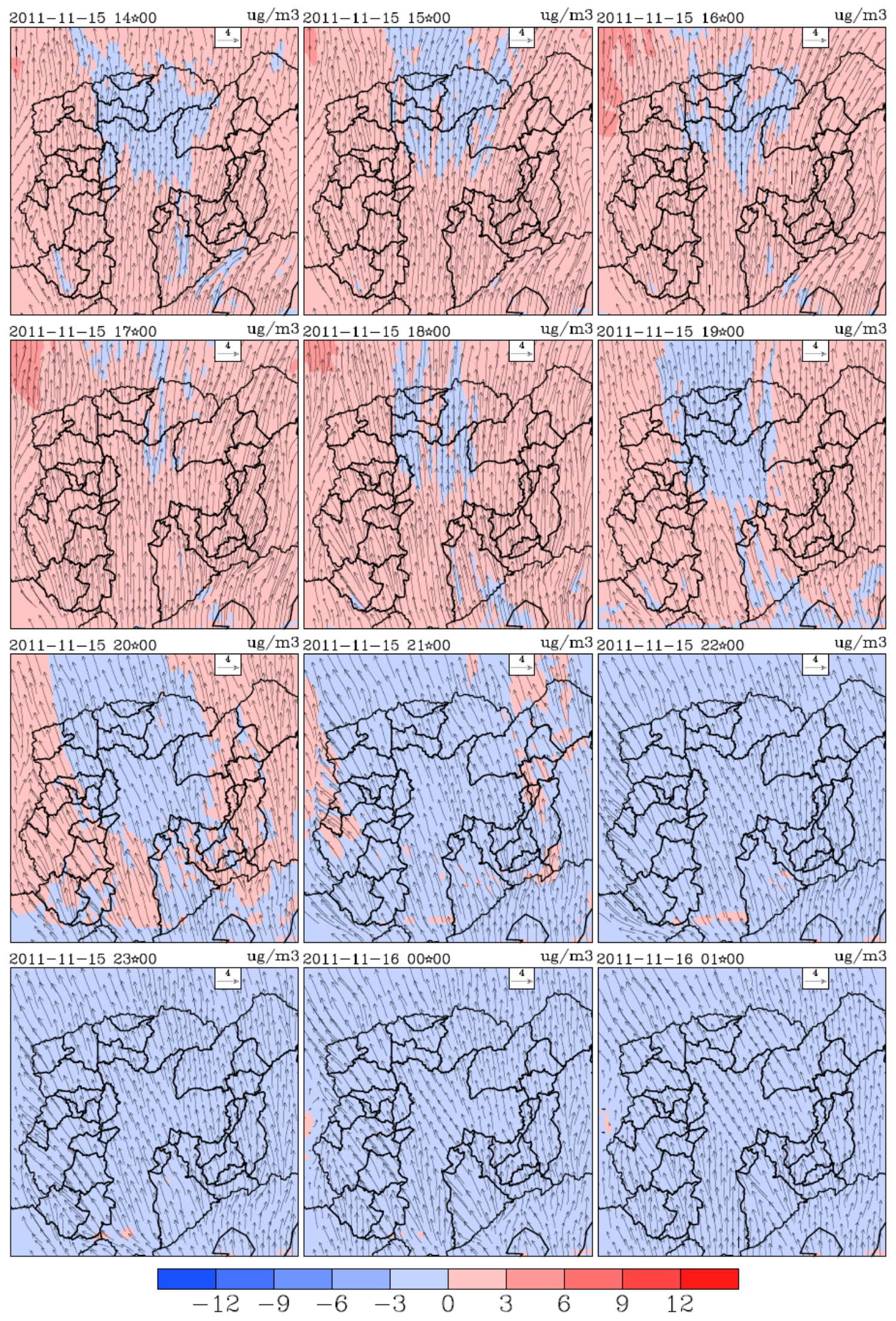

Figura 8.16. Continuação da figura 8.15. 